
ชิ 





\title{
GARDENING FOR THE SOUTH;
}

ов тив

\section{KITCHEN AND FRUIT GARDEN:}

\author{
WITH THE
}

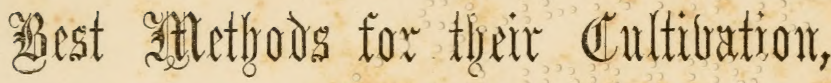
TOCETHER WITH $3, ;$;

HINTS UPON LANDSCAFE AND FLOWEP GAREENIYG.

CONTAINING

MODES OF CULTURE, AND DESCRIPTIONS OF THE SPECIES AND VARIETIES OF THE CULINARY VEGETABLES ; FRUIT TREES AND FRUITS; AND A SELECT LIST OF ORNAMENTAL TREES AND PLANTS, FOUND BY TRIAL ADAPTED TO THE STATES OF THE UNION SOUTH OF PENNSYLVANIA; WITH GARDENING CALENDARS FOR THE SAME.

BY WILLIAM N. WHITE. OF ATHENS, GA.

"In the home around which we see a well-kep garden, internal order almost always prevails ; and when there is a flower-stand outside, there is almost always a book-shelf within."-Schouw's Earth, Plants, and Man.

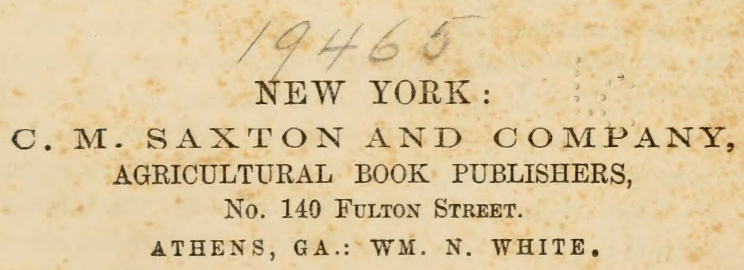

1856. 

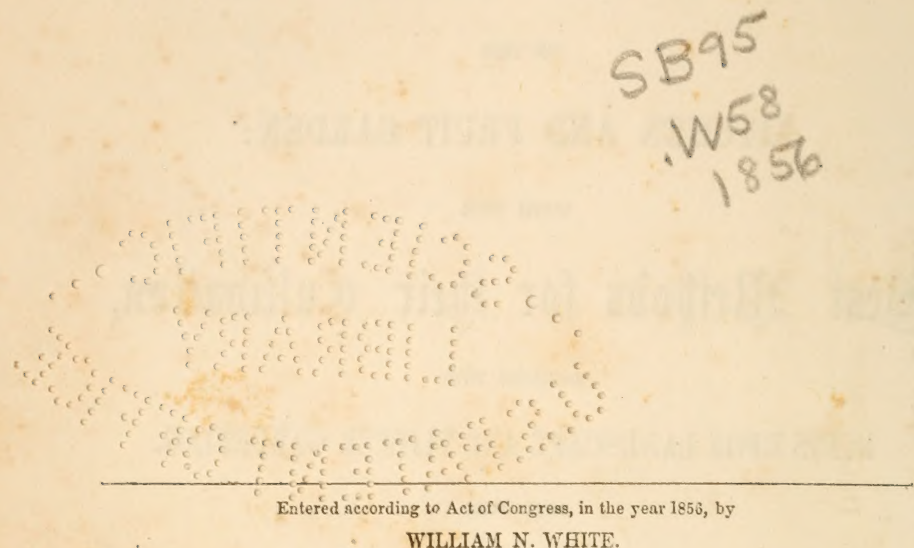

WILIIAM N. WHITE.

In the Clerk's Ofince of the District Court of the United States, for the Nurthern District of Georgia.

\section{sy transter troes \\ Pat. Oraoe Lith \\ and 1026.}

EDWARD O. JENKINS,

PRINTER AND STEREOTYPER,

26 Frankfort Strees, N. X.

$$
\because \because
$$




\section{P R E F A E.}

I HAve thought that, upon a subject so accordant with my tastes as is Horticulture, I might prepare a work adapted to our climate and useful to the public. The repeated inquiries made of me, as a Bookseller, for a practical treatise on the subject, and these inquiries growing more frequent with the manifest growth of the gardening spirit among us, led to the undertaking. Yet, written, as it has been, in the intervals of trade and subjected to its constant interruptions-now advancing but a line at once, again a page or an article-suspended totally for nearly two years, then hastily finished, looked over, and printed under circumstances that rendered the author's revision of the proof impossible-many defects of style, and errers of the press, are manifest. These, if the work contain the information sought, practical men will readily excuse in a first edition.

To claim much originality in a modern work on Gardening, would display in its author great ignorance or great presumption. If it did not contain much that is found in other horticultural works, it would be very defective. Gardening is as old as Adam, and what we know to-day of its principles and operations has been accumulated, little by little-the result of thousands of experiments and centuries of observation and practice. Hence, from the gardening literature of our language, has been selected, for this work, those modes of culture which considerable experience and 
observation has proved adapted to our climate. The species and varieties of plants found here most desirable for use or ornament, have been selected and described. This mass of material has been modified and increased by pretty copious garden-notes of my own. Still, it has been my object to make a useful and reliable, rather than an original work.

Where an author's language suited my purpose, it was at once incorporated into the text. If the expression is sometimes changed, it is generally to make it more concise. To save repeated acknowledgments and quotation-marks in the text, a list is appended of the authors which occur to me from whom assistance has been derived. The names of those to whom I am most indebted have a star prefixed.

It was first intended merely to modify an English work-G. W. Johnson's "Kitchen Gardening"-and adapt it to our own climate. Hence, his arrangement of articles in the alphabetical order of their genera is adhered to. Plants similar in nature are thus grouped together, and some repetition is avoided. But that work not proving so available as expected, and botanical names being still in a state of change,* not many articles were prepared before I regretted not having followed the common method, which is eertainly more convenient for reference to all except botanists. But as the index renders it easy to find any plant by its common name, the arrangement of the articles was of too little importance to be changed at that period.

The necessity of a Southern work on Gardening is felt by every Horticulturist in our midst. Our seasons differ from those of the Northern States, in heat and dryness, as much as the latter do from those of England. Treatises perfectly adapted to their climate we are obliged to follow very cautiously. English works require the exercise of a still greater degree of judgment in the reader, the climate of England being still more cool and humid. Again, our mild winters admit of garden-work nearly every day of the year. All the heavy operations of trenching, manuring, laying out, pruning, and planting trees, shrubs, and hardy ornamental plants, are at that season most conveniently performed.

* Chervil, for instance, is now Chærophylum sativum. 
In this particular aspect, our climate is much like that of the south of England. Hence, while the calendars of operations, in works prepared for the Northern States, seldom agree with our practice, those in English works are often found to coincide with it. But even where the time of performing certain operations is the same in both countries, the long, dry summers, and still milder winters, of this climate, often render necessary a peculiar mode of performing the same.

We need, then, works upon Gardening specially adapted to our latitude and wants. But, with the exception of the valuable matter scattered through our Agricultural and Horticultural periodicals, Holmes' "Southern Farmer and Market Gardener," written some years since, and briefly treating of the kitchen garden depart'ment merely, is the only work containing anything reliable on the subject.

The chief original features, then, of this work, are, that it endeavors to give more or less information upon the whole subject of Gardening; and information, too, that is practically adapted to our climate, habits and requirements. In the fruit-garden department, especially, a good deal of new matter is to be found. Throughout the entire work, processes are frequently described, and methods of culture gives, which are suited only to climates and seasons like our own. Those varieties of plants and trees are pointed out which experience has proved are least adapted to our orchards and gardens. Analyses of the most important vegetables and fruit-trees are supplied, both to gratify a rational curiosity and to assist those who wish to experiment in special manures-which should be very cautionsly rentured upon in the present state of our knowledge. Cnusual prominence is also giren to the general subject of manures, as they are the foundation, not only of successful gardening, but of profitable husbandry. The hints on Landscape-gardening have been gathered, with great care, from the works of Downing, Louden, Smith and others, and modified to suit our climate. In the Flower-garden department, few rarieties of plants are noticed that have not grown under my own eye, and none that I do not know are really fine. Besides the various works consulted, the experience of horticultural friends has been freely communicated. Valuable hints have been derived from Rer. Mr. Johnson and Mr. 
Thourmond, of Atlanta, Prof. J. P. Waddel, Dr. M. A. Ward and Dr. James Camak, of Athens, Rt. Rev. Bishop Elliott, of Savannah, Dr. J. C. Jenkyns and Mr. Affleck, of Mississippi; and especially from J. Van Buren, Esq., of Clarksville, Geo., whose successful efforts to make known and diffuse native southern varieties of the apple rendered him a public benefactor. It is hoped we shall yet see a work upon fruit-trees from his pen.

If this treatise, with all its imperfections, shall in any degree increase the love of Gardening among us; if it shall cause orchards to flourish, shade-trees to emborrer, and flowers to spring up around any Southern home, the author's purpose is accomplished.

* By an oversight, my own descriptions of the Batchelor, Marerick's Sweet, Nickajack, Berry, Disharoon, Catooga, Comack's Sweet and Neverfail Apples, for which Mr. Van Buren furnished the specimens of fruit, are placed among the varieties described by him. 


\section{CONTENTS.}

PAGE

Introduction

\section{FORMATION AND MANAGEMENT OF GARDENS IN GENERAL.}

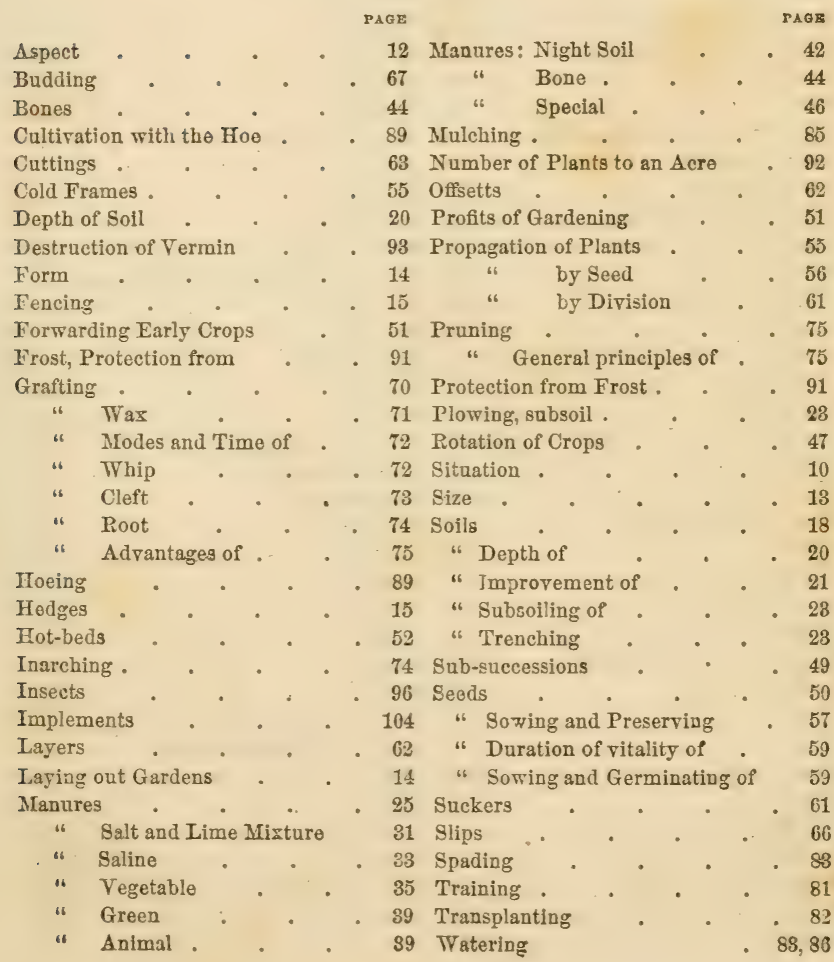




\section{THE KITCHEN GARDEN.}

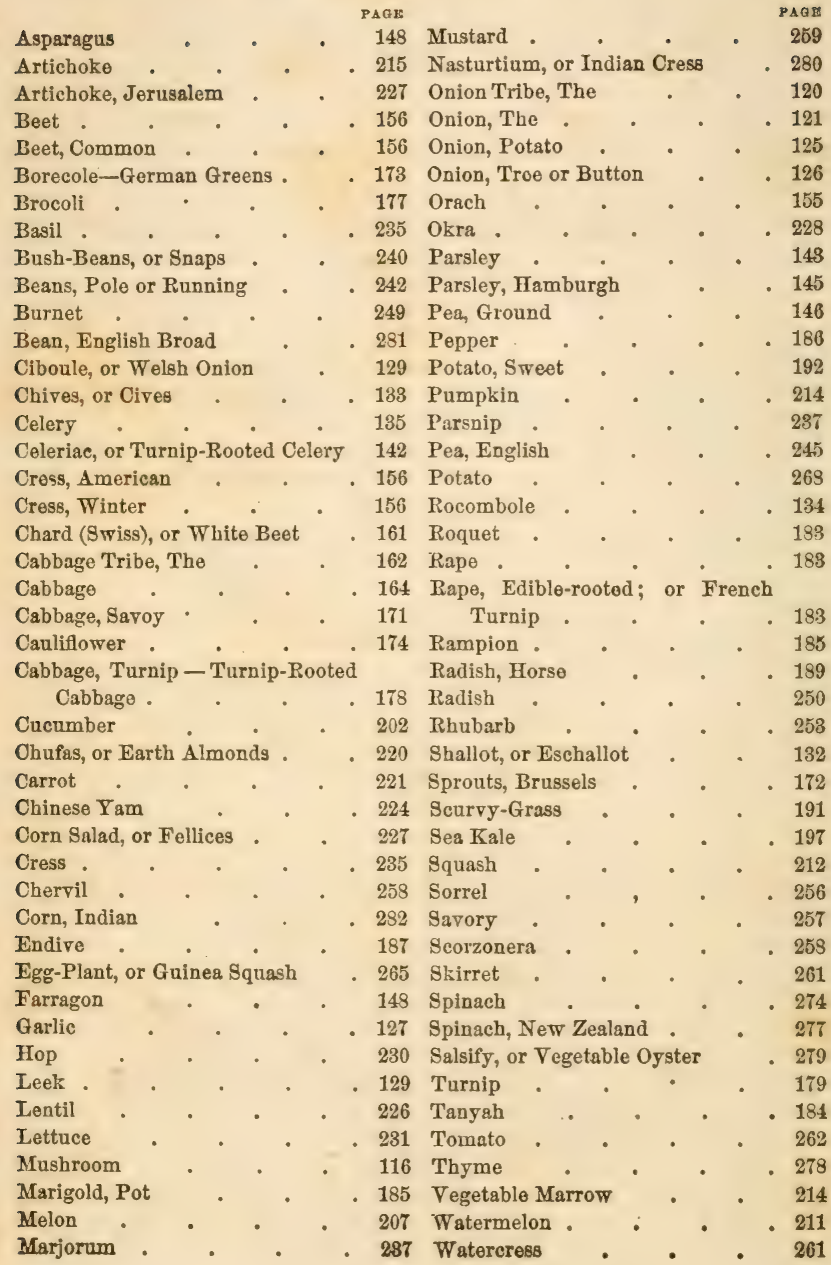




\section{MEDICINAL HERBS.}

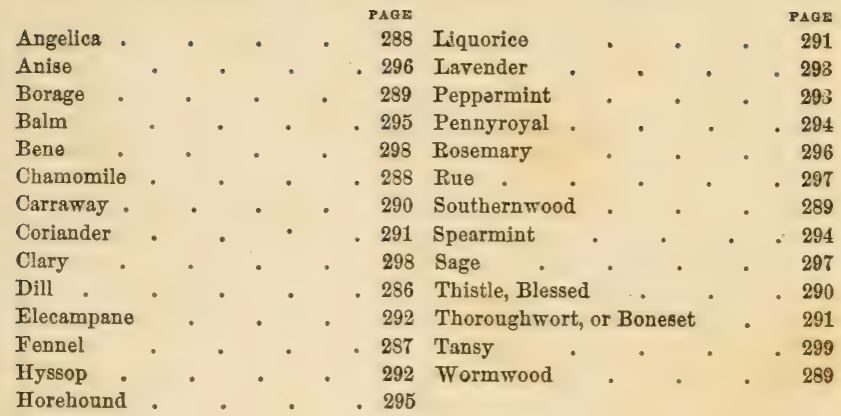

\section{THE FRUIT GARDEN.}

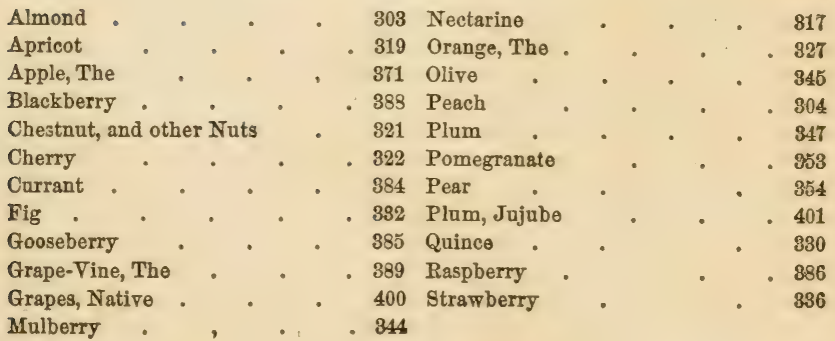





\section{LIST OF BOOKS AID AUTHORS}

FROM WHOM MATERIAL HAS BEEN DERIVED FOR THIS WORK.

Afrleck, Thos., . . . Southern Rural Almanac

Allen, A. B., . . . American Agriculturist.

*BarRY, P., . . . . Fruit Garden.

"6 6 . Horticulturist.

Boussingault, J. B., . . Rural Economy.

BURgess, H., . . . Amateur Gardener's Calendar.

BRECK, J., - . . Book of Flowers.

Bridgeman, T., . . Young Gardener's Assistant.

*Browne, D. Jay . Field Book of Manures.

" " . . . Patent Office Report, 1854

BON JARDINIER.

*Burst, R., . . . . Family Kitchen Gardener.

" " . . . . Rose Manual.

" " . . . American Flower Gardener's Director.

Cовет, W., . . . American Gardener.

*Cole, S. W., . . . American Fruit Book.

Country Gentleman, . . L. Tucker \& Son, Albany, N. Y.

Cultrvator,

"Soutrers, - Augusta, Geo., D. Lee and D. Redmond, Editors.

Data, S. L., . . . Muck Manual.

*Downing, A. J., . . . Fruits and Fruit Trees of America.

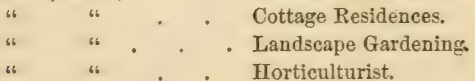

Downivg, Charles, - . Articles in Horticulturist and Correspondence.

*Elliorr, F. R., . . American Fruit Grower's Guide.

Florist, - . - . H. C. Hanson, Philadelphia.

Gardener's Chronicle, . Prof. J. Lindsey, London, Eng.

Genessee Farmer, . . J. Vick, Rochester, N. Y.

Griffith, R. E., . . Medical Botany.

Holmes, F. S., . . . Farmer and Market Gardener.

HARRIS, T. W., . . . On Insects injurious to Vegetation.

Hoare, Clemext, . On the Grape-Vine.

*Horticulturist, . . J. J. Smith, Philadelphia.

Hover, C. M., Magazine of Horticulture, Boston, Mass.

JoHsston, J. F. W., . . Agricultural Chemistry.

Johsson, C. W., . . Treatise on Manures.

* " G. W., . . Kitchen Garden.

KesP, E., - . . . How to lay out a small Garden.

KeNRICK, W., . . . New American Orchardist.

Kern, G. M., . . Practical Landscape Gardener.

LeE, Prof, D., . . Genesee Farmer, Southern Cultirator, and Patent

Office Reports. 


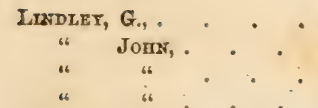

Liebig, J., . . . . Agricultural Chemistry.

* " \& Kopr, . . . Progress of Chemistry.

"Louder, J. C., . . . Encyclopxdia of Gardening.

$\begin{array}{ccc}\text { " } & \text { " } \\ \text { " } & \text { " } \\ \text { " } & \text { Mrs. J., . }\end{array}$

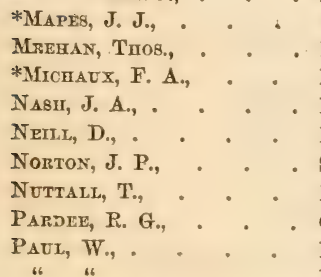

Parsong, S. B., . " "Plants.

- Suburban Gardener snd Villa Companion.

Magazine.

Ladies' Companion to the Flower Garden.

Working Farmer, Now York City.

Hand-Book of Ornamental Trees.

North American Sylva.

Progressive Farmer.

Fruit, Flower, and Kitchen Garden.

Scientific Agriculture.

North American Sylva continued.

On the Strawberry.

Hand-Book of Villa Gardening.

Rose Garden and Supplement.

*Pearodr, C. A., . . On the Soil of the South.

Rrverg, Thomas, . . Rose Amateur's Guide.

" 16

Stockнаврt's, J. A., - . Chemieal Field Leetures.

Sмrтн, C. H. J., .. . Landscape Gardening.

Sorl of tha Souti, . . Columbus, Ga., J. M. Chambers and C. A. Peabody.

*Sodthern Agriculterist, Laurensville, S. Carolina, A. G. \& Wm. 8ummer.

Thomas, J. J., - . - American Fruit Culturist.

Thoupsov, W., . . . Gardener's Book of Annuals.

WARING, G. E., - . Elements of Agriculture.

WARDER, Dr. J. A., . . Western Horticultural Reviem.

\section{A D V ERTISEMENT.}

It has been found impossible to complete the entire treatise in time for the work of the present season. Hence, it is thought best not to delay the publication of what is already prepared, as some persons may desire to purchase the Kitchen and Fruit Garden only. Little new work can be laid out in the Flower Garden until autumn, by which time will be issued, separately, the remainder of the work, containing the hints on Landscape and Flower Gardening, with the Calendars, and perbaps brief notes on a few of tho most promising Fruits that come into bearing with us this summer, thus considerably increasing the usefulness of the entire work, and enabling those who wish to procure either part by itself.

MАRОก. 1856. 


\section{INTRODUC'TION.}

GARDExing was man's first occupation. It has numbered among its votaries the wisest and best of our race, and has been deemed in all ages a delightful employment. But to yield pleasure or profit it must be prosecuted understandingly. He who desires in full the enjoyments and advantages of a garden, must be qualified to take charge of it himself; must thoroughly understand the principles and manipulations of horticulture; must know the qualities and requirements of his soil, and what may be most satisfactorily produced from it in his peculiar climate; in short, he should in all cases be capable of superintending and directing advisedly its operations, really knowing when they are well or ill done.

It is difficult to acquire this knowledge by reading or simply looking on. It is easiest and most pleasantly gained with implement in hand and a note-book in the pocket. The readier way of understanding the directions of the looks, is to put them in practice. He who thus heartily enters into the performance of horticultural operations, will be fully rewarcled by our good old mother earth in health, profit, and pleasure In health, for not only does the garden yield a choice and wholesome variety of fruits and vegetables, most salutary for daily food, but the ex- 
ercise afforded in moving the fresh soil, and the interest excited by the diversified operations of the garden, are still more salutary. In profit-but of that hereafter. In pleasure-for what is more delightful than to watch the daily developments of that which our own hands have planted, cultivated, and sheltered-or to witness, as the skillful gardener will do, the constantly improving condi tion of his soil, or to partake of the daily succession of choice vegetables and luscious fruits brought to perfection by his skill and care, or to enjoy the more spiritual and refined pleasures of landscape and flower-gardening where the eye is charmed with the greenness and breadth of lawns grouped with all rare and magnificent trees, or with parterres gay with brilliant colors and profuse with beautiful and perfect forms. But those who possess a taste for gardening need no display of inducements to attract them to their favorite haunts.

'They will not seek in these pages for arguments in favor of gardening, but for suggestions and instructions as to the best methods of performing its operations. 


\section{earadening for the Soutly.}

\section{FORMATION AND MANAGEMENT OF GARDENS IN GENERAL.}

Situation.-With us, gardening in all its departments is generally deemed the peculiar province of the ladies, and we cannot regret that it has fallen into their hands. Had Mr. Downing lived at the South, he would never have asked "What is the reason American ladies do not love to work in their gardens?" Hence the usual direction that the gardens should be formed near the house. becomes with us doubly important. The situation of the flower-garden and lawn should be immediately adjacent to the dwelling, in order to yield the highest degree of pleasure. The most satisfactory arrangement is to form the lawn directly in front, and the flower-garden on the side, sufficiently near to be overlooked by the drawingroom windows, while the sides of the dwelling, in part, and its entire rear, including the kitchen and servants' yard, are sheltered and concealed by trees. A dwelling thus embayed in well-grown trees is always regarded with pleasure. As neither the fruit or kitchen garden, especially the latter, can be considered ornamental, they should not, though near the dwelling, be placed obtrusively in view. Near they should be, as if either is distant, time is 
lost in watching its progress; it is in danger of being neglected; and even if this is not the case, its choicest products may gratify the palate of any one besides its owner. A good arrangement is to place them in immediate connection with the pleasure-ground, proceeding froin the shrubbery to the fruit department, and thence to the kitchen-garden. 'The latter should be near the stables, in order that it may be copiously replenished with manure without too great expenditure of labor.

Much, howerer, depends upon the soil. The best at command, in the vicinity of the dwelling, should be chosen. Proximity to water is also highly important, especially if it can be readily employed for irrigation. Low situations are more endangered by late and early frosts, but their abundant moisture renders them desirable for summer crops. A diversity of soils and exposures in the same inclosure is desirable.

Care should be taken that the productiveness of the garden be not diminished by the proximity of large trees, which are injurious by their drip to all plants beneath them, and by their shade and extended roots to those more remote. The small fibrous roots of trees extend far beyond their branches, and one is not safe from these devourers much short of the length of the stem which they nourish. If trees exist too valuable to be removed, dig a deep trench near them, and cut off all roots that extend into it. This will probably relieve the adjacent crops from their injurious effects.

Aspect and Inclination:-A slight exposure to the south and east is generally recommended. All good gardeners take pride in having early crops, and this compensates in some measure for their short duration in such an exposure. A north-eastern aspect is to be aroided, as 
our worst storms are from that direction. A north-western exposure, though cold and late, is less liable to injury from late and early frosts, as vegetation in such situations is sheltered somewhat from the rising sun, and does not suffer so much if it becomes slightly frozen. It is not the frost that injures plants so much as the direct heat of the sun falling upon the frozen leaves and blossoms.

Cabbage, cauliflower, strawberries, spinach, lettuce, and vther salads, are much more easily brought to perfection in a northern aspect. Many of these ran up to seed immediately if exposed to the full sun. The soil, too, is usually richer, and will retain its fertility longer, other things being equal, in a northern exposure. It is a great advantage, if the garden slope at all, to have it slope in more than one direction, giving a choice of exposure, and generally also of soil, as it is thus adapted to both late ind early crops. But when the drainage is good, a level is to be preferred, as by the aid of the fences any desired exposure can be oltained for particular plants. Indeed in this climate nothing is more to be regarded than the inelination of the soil. Whatever be the situation or aspect, a garden must be as level as possible. Any considerable inclination in this latitude subjects the richest portion of the soil to the danger of being washed away by our violent storms. In the rich mellow soil of a garden cultivated as it should be, if there be any perceptible slope, a single storm will cause a loss of manure and labor that will require considerable expense to repair. If the ground is not level at first, it will be economy to throw it at once into terraces of convenient breadth. The steeps of these can be clothed with blue grass or strawberry plants, to prevent them from washing.

Sizf.-A garden should be proportioned to the size of 
the family, and their partiality for its different products. A small garden with a suitable rotation of crops, and well manured and cultivated, will yield more pleasure and profit than an ordinary one of three times its size. An active industrious hand can take care of an acre, well provided with hot-beds, cold frames, \&c., keeping it in perfect neatness and condition; or if the plough and cultivator be brought into requisition, as they should be in large gardens, four times that amount can be under his care.

If but little room can be allowed near the house, cabbages, earrots, turnips, potatoes, and the common crops can be grown in the field, if well enriched and cultivated solely with the plough. The fruit garden should be in a separate compartment, as the shade of the trees is very injurious, and the exhaustion of the soil by their roots still more so. Dwarf pears upon the quince stock are the least injurious, and may be admitted into the vegetable department.

Form.-The form will often depend upon the situation of the garden or inclination of the ground. When a matter of choice, a square or parallelogram is most convenient for laying out the walks and beds. A parallelo gram extending from east to west gives a long south wall for shading plants in summer, and a long sheltered border for forwarding early crops. In plantation gardening an oblong shape has the further advantage of giving longer rows for the plough.

LAYING our.-In laying out, a hroad walk wide enough to admit a cart for manuring the plants, should run through the centre from end to end, until you nearly reach the border. Here may be a turning-place around an arbor or tool-house. A border, eight to twelve feet wide, should 
extend all around, next the boundary, and next this should be a walk, also entirely around, three or four feet wide. If cultivated with the plough, this division into the borders, and two large plats, will be sufficient, but the borders should then be, at least twelve feet wide, to give room enough for those regetables that will not admit cultivation with this implement.

The other regetables may be successfully cultivated in these two plats, in long rows. Where the spade and hoe are used, these oblong plats may be subdivided for convenience into smaller plats, by walks three feet wide, extending from the borders to the main walk, and a portion of these should be laid out each year by very narrow alleys into beds, four feet wide, for onions, beets, carrots, \&c. The earth should be dug out of the main walks, four inches deep, and spread evenly on each side over the adjacent ground. 'The walks may be filled with gravel, so as to be dry and comfortable, or fresh tan, if accessible, will answer very well, and will keep out the weeds for two years, when it should be used as a dressing for the strawberry beds, and its place filled with a fresh supply. No more walks or alleys should be made than are required for convenience in gardening operations, and where it is not desirable to admit a cart, the main walk need not be over five or six feet wide.

Fencixg.- The objects of fencing are to procure shelter for delicate plants from cold winds, also shade for those that require it, and, above all, to keep out of the garden intruders of all kinds, that the owner may enjoy its fruits without molestation. A high close board fence, or a stone or brick wall, answers a tolerable purpose; but the only thing to be relied on is a living hedge. The Osage Orange, Pyacanth, Cherokee, and single White 
Macartney roses are all good for this purpose. Osage Orange plants may be raised from seed, or bought at the nurseries for five or six dollars per thousand. 'The Pyracanth, or evergreen thorn, we have Mr. Affleck's authority for stating, will make a hedge as effectual as the Osage Orange, and, as it is an evergreen, is much the most desirable. The blossoms in Spring are very showy, and it is covered in Winter with bright scarlet berries, and hence it is often called the burning bush. It grows freely from cuttings in sandy soil, but these cuttings should remain in the nursery-bed a year to become well rooted before use. Mr. Nelson gires the following directions for planting and trimming a hedge, which apply equally well to Osage Orange and Pyracanth:

"Planting.-First dig a trench where the hedge is intended to be grown, two spades deep, throwing the surface to one, and the subsoil to another side; then throw the surface soil down on the bottom of the trench, and if it is very poor, add a little manure, or good surface earth, or even dry oak leaves. Autumn is by far the best time for transplanting, and can safely be dowe as soon as the leaves are dropped. Cut down the plants to within four inches above the roots before planting. Several authors recommend planting in double rows, but according to my experience in the management of hedges, (and I have had a good deal in my life), I decidedly prefer single rows. Assort the plants in two parcels, those of large and those of small size, and lay the smaller ones aside for the richest ground. Stretch the line firmly, and place the plants in as straight a line as possible, one foot apart ; fill up the trench with earth, leaving about two inches above ground; press the earth not too firmly, but water plentifully, and after that, level the whole nicely." 
"Trimming.-It is perfectly useless to plant a hedge and leave it to be killed by weeds, or grow without trimming. A young hedge will require the same amount of labor as a row of Indian corn. The plants having been cut so much down, will, of course, start vigorously the ensuing Spring. A good hedge ought never to be trimmed in any other than in a conical shape. When trimmed in a conical shape, every shoot will enjoy the full benefit of air, light, and moisture, and by this simple and natural method, a hedge can be shorn into a strong wall of rerdure, so green and close from bottom to top, that exen a sparrow cannot, without difficulty, pass through it. In order to make a hedge so thick and impervious as above meutioned, it is necessary to go to work eren in the first summer, with a pair of hedge shears, pruning the young growth, when about three months old, at the same time laying down some of the most rigorous shoots to fill up some racant places near the ground; these shoots may be fastened to the ground with some hooked pegs; they may be considered as layers, will soon send up a number of sprouts, and make the hedge impenetrable for pigs, and nearly for rabbits. The young twigs may be trimmed in a wedge shape, not more than one foot high, and at the base, six inches broad. The next season the hedge may be allowed to grow one foot higher, and three or four inches wider at the base. Thus the management must be continued until the hedge has attained the intended hight. allowing an addition of four inches broader at the bottom, for every foot more in hight. A hedge, regularly trimmed twice a year, will, with the exception of the first years, when it requires a little more care than afterward, continue impenetrable for fifty or eren one hundred years."

The Cherokee rose, by planting the enttings by the 
side of a plank or wire fence, two feet apart, will grow up and cover it in a short time, and effectually repel man and beast; but it requires constant shortening in, or it is apt to die out at the bottom, and become unsightly, and is in all respects much inferior to the single white Macartney.

'This is also an evergreen, and very easily grown from cuttings. It is very thorny, and of beautiful foliage. It never dies out at the bottom, whether pruned or not, and is very hardy, and of luxuriant growth. The most satisfactory fence can be made with this, by setting good chestnut or cedar posts, eight feet apart, with their small ends charred, and planted about two and a half or three feet in the ground. Upon this, form the usual paling fence, or nail a gond widle bottom board, and finish the fence with stout wire, strained through holes in the posts. The wire fence may be four feet high. The roses should be rooted cuttings, and may be planted at first, even eight feet apart, and by layering and training the bottom shoots, if the ground is kept in good order, in three years it will repel every intruder. It is better where plants are abundant, to set them out four feet apart. This hedge requires less pruning than any other to keep it impenetrable. The holly would also make an efficient and beautiful hedge, were it not so difficult to transplant. My own hedge of Macartney rose, where three years old, trained on a common fence of rails and paling, forms a barrier perfectly secure, and very ornamental.

Soll.-In our fine climate, the character of the soil is of much more inportance than situation or aspect. The mechanical texture is especially to be regarded, as on this depends the proper retention of manure and moisture. There are two grand divisions of soils, heavy and light, which pass into each other by imperceptible gradations. 
Heavy soils are those in which clay predominates. They are difficult to work, and in dry weather often bake like a brick, and are not permeable to dews or light rains, but after heary rains, become so saturated that they are a long time unfit to work, and the plants often die from excess of moisture. The crops, too, are full ten days later in coming to perfection than in a good sandy loam. Light soils include those in which sands or gravel are the chief ingredients. The water that falls upon these soils passes instantly through them, so that the crops suffer quickly from drought. In these, vegetation is earlier, but they do not readily combine with manures, the soluble parts of which are leached through into the subsoil, or are washed out by the rains, so that if manure be constantly applied, they will yield but a moderate crop. Gravels are, in this respect, from the coarseness of the particles, generally worse than sands. Sandy soils are better adapted to tap rooted plants and bulbs, and for striking cuttings of all kinds, while clays are better fitted for plants with fibrous roots.

In a garden designed for the cultivation of a variety of plants, both a light sand and stiff clay are desirable. But the best soil for general purposes, is a loam of medium texture, arising from a suitable admixture of the two, as they reciprocally correct the defects of each other, and with the addition of organic matter, form a soil suited to the cultivation of nearly all garden productions. Any soil with judicious culture, draining, and manures, can be converted into such a loam.

If either of the above soils contain in its composition a large quantity of lime, it is called a calcareous soil, and is admirably fitted for the culture of fruit trees and wheat.

An alluvial soil is that formed by the overflow of streams, 
or the deposition of various matters washed down from the hills, and has generally a large proportion of regetable matter. It is exceedingly well suited for the kitchen garden, requiring little manuring, and not suffering from drought, but is not so well suited for fruit trees, with the exception of the apple.

A peaty soil consists generally of vegetable mould, in a state of very slow decomposition, and possesses generally too much acidity for profitable cultivation, but when dried and combined with the lime and salt mixture described hereafter, and composted with animal matter, is a most valuable addition to all soils.

The depth of a soil is quite as important as its texture. If not naturally deep, it must be made so by trenching. Deep soils retain a constant supply of moisture in dry weather, so that the plants do not suffer; and they do not become too wet in rainy seasons, as the earth drinks in and retains the rain below the surface; besicle, they are not so liable to wash away. If equally rich, ther furmish plants with a more abundant pasturage and supply of food than shallow soils. Especially for all tap-rooted plants, a deep soil is indispensable. In the preparation of your garden, see that the ground is dry, deep, and rich. Good vegetables will not grow in a wet soil. A shallow soil will not furnish them with a regular supply of moisture, and the crops growing upon a poor soil never pay for the labor bestowed upon it.

A good garden soil must be not only of the proper depth and texture, but, that vegetation may be healthy, must contain not only alumina and silex, or, in other words, clay and sand, in proper proportions, but also the other inorganic or earthy matters found in plants. These are carbonate and sulphate of lime, potash, soda, magnesia, sulphur, phosphorus, oxide of iron, manganese, and chlo- 
rine, all which, except alumina, exist in plants, and sometimes form ten per cent. of their weight.

If any of these constituents are wanting, the soil is defective, but it will not be fertile if all of them are present, unless there is organic matter in the soil to afford an abundant supply of ammonia and carbonic acid to the growing crop.

IMPRovement of the Soll. - A soil may be improved in texture by the addition of any necessary constituents for the growth of plants which may be wanting.

The texture of a clayey soil can be rendered more pervious by thorough draining, deep trenching, and by the application of sand, ashes, lime, and unfermented manure. So much sand is required to produce any perceptible effect in improving a heavy clay, that it is the most expensive mode of improvement. Ashes and lime both have the property of rendering heavy soils lighter and light soils more tenacious, and both more productive, especially for potatoes, turnips, beets, and peas, which delight in calcareous soils. In cold climates, ploughing clay lands deeply in the fall, and exposing them to the action of the Winter's frost, is very beneficial, but in sections where there is little frost and abundant and heavy rains, it is worse than useless. Turning under coarse vegetable or carbonaceous matter, as straw, leaves, pine brush, cornstalks, a crop of cow peas, or any other green crop, bog or leaf mould, decomposed peat, and even tanbark itself, so deeply beneath the surface as not to interfere with cultivation, will by the slow decomposition of these materials much increase the fertility of a clay soil by improving its texture.

The frequent working of the soil with the hoe and spade, admitting the ammonia and fertilizing gases of the 
atmosphere is itself very beneficial to clay soils, if done when the earth is dry. A clay soil is exceedingly injured if worked wet. A clay soil is so difficult to work, and so liable to bake into a hard crust after every rain, that it will well repay where materials for the purpose are at all convenient to lay out a good deal of time and labor in improving its mechanical texture.

The texture of a sandy soil is much more easily improved than a clay, as the per centage of clay required to convert any sand into a loam is not very large and can easily be added. Fortunately too in sandy soils, clay is generally near at hand, often lying but a few inches beneath the surface. A few loads of stiff clay, scattered thinly over the surface in Autumn, are worth more applied to such a soil than any manure, for the clay will render manures permanent in their effect, which else would leach through without benefit to the erops; the effect of the clay itself is lasting. Lime, as before observed, stiffens the texture of a sandy soil, and gympsum has the same effect. Ashes are also an excellent and pro. fitable dressing to such a soil, leached or unleached, but the best of all applications is a good clay marl. Peat, vegetable manure, and carbonaceous matters of all kinds, as refuse charcoal, are good applications to sandy soils, as they enable them better to retain the fertilizing properties of the manure applied, if they do not much affect the texture of the soil. Sandy soils very often rest upon a clay bottom, so that the thorough trenching a garden should receive, will often greatly improve its texture. Working such a soil while wet, and the continual use of the roller will also render it more tenacious. But clay is the great improver, and it is astonishing how small a quantity of fine clay will cement a loose sand into a good loam. 
To conclude, in regard to the texture of soils, choose or make for your garden a loam of medium texture a little inclined to sand, and the finer its particles the better. Clays and sands both become objectionable, as they depart from this friable loamy texture, and the first step in their improvement is to bring them to this condition. A medium consistency best agrees with regetation.

The depth of soil in the garden is as likely to need improvement as its texture. A deep soil is necessary that the roots may penetrate it freely in search of food, and be able to endure our summer droughts. The roots of a strawberry have been traced five feet down in a deep rich soil. The difference in freshness and growth of plants raised upon trenched soils, and those growing upon soils prepared in the common manner is remarkable. In lawns, the color of the grass will indicate very exactly the greater or less depth of the soil. 'The depth of soils may be increased by subsoil ploughing, or trenching.

Subsoil ploughing is much cheaper and answers a very good purpose when the spot to be prepared is large. A common turning plough goes first, and ploughs as deep a furrow as practicable. It is followed by the subsoil plough in the same furrow, which loosens the soil without turning it up to the depth of eighteen or twenty inches, unless it is a stiff clay or gravel.

Tienoling is the mode of improving the depth of the soil in smaller gardens, and is performed in this manner: At one end of the plot to be trenched, you dig with the spade a trench three feet wide, and two feet deep; you throw the earth out on the side away from the plot to be trenched. Shovel the bottom clean, and make the sides perpendicular, leaving a clear open trench the width of the plot. Open another trench the same width, and put the surface spadeful of that into the bottom of the former 
treuch, and the next spadeful upon that, until opened to the same depth as the first one. When the plot is entirely trenched in this way, the last trench will remain open, which must be filled with the earth thrown out from the first one, which finishes the work. If the subsoil is poor and gravelly, it is better to take off the top spadeful, and loosen up the bottom to the required depth, with a pick, without bringing it to the surface. If the soil requires it, as it generally will, layers of manure may be added to those of earth, alternately. If the soil is too sandy, clay and other amendments must be added; while if too heavy, woods-earth, leaves, muck, straw, tan-bark, or any other vegetable refuse can be alternated, putting the coarsest materials at the bottom. Tan-bark, particularly, should be buried at least six inches below the surface, unless the ground is to be cropped with strawberries or Irish potatoes, to which it is advantageous.

Trenching is an expensive operation, costing some thirty or forty dollars per acre, but "nothing," says Mr. Barry, " is so expensive and troublesome, as an ill-prepared soil." This process is found to be of great advantage in England, where there is no lack of moisture, and still more so by the market gardeners of the Northern States, while in our own dry, warm climate, it is, as I know by trial, absolutely indispensable. Ground thus prepared is not so liable to wash away, as it will readily soak up the heaviest rain, if properly terraced. There is no point of greater importance than this. Poor ground deeply moved, is better than rich with shallow tillage, and when the ground has been prepared once in this manner, it will feel the benefit forever after. Increasing the depth of the soil in this mode, is to all intents and purposes increasing the size of your garden; for one-fourth of an acre thus prepared, will yield in a dry season, as much as an acre will, with shallow tillage; and the growth 
of the plants in a good season, will be fully doubled. Trees especially feel the benefit of this preparation, and all fruit gardens should be thus prepared. No matter how deep you may work the soil for trees or plants, their fibres will penetrate it, and feel the good effect.

Trenching should be performed in the fall - the coarse manure dug in at that time. At the top it should be well manured with well rotted dung, charcoal dust, ashes, or other good manure, dug in shallowly, taking care to level the ground while trenching, so as to prevent washing. Another good coat of compost should be added just before planting in the spring.

Manures.-Soils are also improved by supplying any necessary constituents of plants in which they are partly or wholly deficient; in other words, by the application of manures. -Anything which being added to the soil directly or indirectly, promotes the growth of plants, is a manure. They are of two classes. Organic and inorganic. The first embracing animal and regetable, and the second mineral manure. Manures directly assist regetable growth either by entering into the composition of plants, by absorbing and retaining moisture from the atmosphere, or by absorbing from it nutritive gases.

Manures indirectly assist the growth of plants either by destroying vermin or weeds by decomposing in the soil, and rendering available any stubborn organic remains, by protecting plants from sudden changes of temperature, or by improving the texture of the soil.

All the above properties probably never are combined in any one manure, each being characterized by superiority in some one of the above qualities.

The manures most generally applicable, are those composed of substances which directly enter into and are essen- 
tial to the grouth of plants. What are these substances? If you burn dried vegetables, a few ashes only remain; less than one-tenth of their substance. This is all the plant got necessarily from the soil. Over ninety per cent. has escaped into the air, from which the plant derived it immediately or remotely. The composition of their ashes, varies in different species of plants, and slightly in the same species, when grown in different soils ; but they are always a valuable manure for that species, and when slowly dissolved in the soil, furnish the roots with just the salts required to nourish the growing plant.

But over nine pounds in erery ten, have disappeared under the action of fire. The substances expelled are carbon, hydrogen, oxygen and nitrogen; all essential to growth, and which must be furnished to the plant, or it will perish. Carbon, nearly pure, occurs in charcoal in a solid form, composing all of this substance but the ash. Carbon uniting with the oxygen of the air, forms the carbonic acid gas, so destructive to animal life when charcoal is burned in a close room. The carbon of plants is derived partly by the absorbtion of carbonic acid gas from the air by their leaves; but the roots, also, extract a portion of the same gas from the soil. We can increase the supply of this by vegetable manure, such as decayed leaves and other carbonaceous matters, which, slowly decomposing, supply the roots with abundant food. The others occur only as gases or in combination with other substances. Oxygen forms nearly half the substance of the globe. It unites with hydrogen, forming eight-ninths of the water we drink; and with nitrogen forming one-fifth of the air we breathe. With carbon it forms the carbonic acid described above. The oxygen of plants is derived from all of the above sources, being placed abundantly within the reach of every living thing. Hydrogen, in combination with oxygen, forms one-ninth 
of the weight of water; with carbon, it composes carburetted hydrogen, and with nitrogen, ammonia. The main supply of hydrogen is derived from water, a portion, however, is obtained from the ammoniacal and other gases which pass from decomposing organic substances, and from the absorption of soluble organic matters in the soil.

Of all the substances that minister directly to the growth of plants, by entering into their composition, nitrogen is perhaps the most necessary to supply. Though it forms four-fifths of the atmosphere, yet in this state plants cannot appropriate it. It unites with hydrogen forming ammonia, and with oxygen forming nitric and nitrous acids, from which compounds plants derive the small proportions they appropriate. Though the proportion of nitrogen existing in plants is small, yet it is not the less essential; but in fact, is that which is most needful to place within their reach. Ammonia is the substance from which plants derive most of their nitrogen. Ammonia or hartshorn is the gas giren ont by the common smelling salts. It is that which gives to animal manures their peculiar value.

This gas enters immediately into the circulation of plants. We all know how luxuriantly plants grow in putrid animal manure.

This is owing to the ammonia given off by the manure, and appropriated directly by the plants, supplying them with both its constituents nitrogen and hydrogen. Indeed the value of manure is measured by the amount of ammonia it contains, not because ammonia is more essential than some of the other constituents of plants, but because more difficult to obtain in sufficient quantity. Manures that are rich in nitrogen, readily pass into a state of fermentation, and the abundant ammonia given off will often burn the plants with which it comes in contact; hence they are called hot manures, as guano, horse and pig 
manure. These are most valuable for clays, which retain the fertilizing gases and store them up for use.

Manures deficient in nitrogen, like those of all ruminating animals and all kinds of vegetable manures are called cold, and are best fitted for sandy soils, to which they give tenacity and the power of retaining moisture and ammonia.

The decayed parts rendered soluble of any plant as well as its ashes are among the best manures for plants of its own species. Vineyards have been kept fertile by digging into the soil the fresh prunings of the vines, and indeed, increase in richness from the slight manuring their own leaves afford. So forests are enriched by falling leaves.

After the oxygen, carbon, hydrogen, and nitrogen, are driven off by combustion, the small per centage of ashes remaining is made up of the following substances, viz. chlorine, sulphur, phosphorous, silica or sand, potash, soda lime, magnesia, and oxide of iron, all which in greater or less proportions enter into the composition of our garden crops, and must be supplied if wanting in the soil. Of these, less general, or as they are called special manures, lime and sulphur are most cheaply supplied by sulphate of lime or gypsum, that being composed of sulphur, oxygen and lime. It is a component of turnips, peas, and beans, and if not already in the soil is a useful application to these crops.

Phosphorous and lime can be supplied by crushed bones, a most valuable manure, composed of phosphate of lime and from thirty-four to fifty per cent. of gelatine, which latter substance rapidly putrifies and becomes available in supplying ammonia. The phosphate of lime is found in wheat, peas, beans, cucumbers, potatoes, garlic, \&c., \&c. Wood ashes afford the cheapest mode of sup- 
plying potash. Chlorine and soda are found in many plants, and are best supplied from refuse common salt, which not only enters into the composition of plants, but is otherwise beneficial as shown hereafter. Phosphate of lime and potash are the additions most frequently needed by soils.

Let us now examine the constituents of common stable manure, and note its value as a direct food for plants. It contains,

$\left.\begin{array}{l}\text { Carbon, } \\ \text { Hydrogen, } \\ \text { Oxygen, } \\ \text { Nitrogen. }\end{array}\right\}$ Found in all plants.

$\left.\begin{array}{c}\text { Carbonate of lime, } \\ \text { do. of soda. }\end{array}\right\}$ In most.

Mruriate of potash, in cucumbers, garlic, \&c. Sulphate of soda,

do. of potash, in cucumbers, garlic, \&c. Magnesia in grains of all kinds.

Phosphate of lime, $\left\{\begin{array}{l}\text { Potatoes, vines, onions, } \\ \text { peas, beans, grain. }\end{array}\right.$

Oxide of Iron,

Alumina,
Silica. In most plants.

Thus, the value of stable manure is readily seen, every part of it has been formed of vegetable products, and is ready when rendered soluble to enter into and minister again to their growth. So of every other manure composed of animal and regetable remains, bones included. It is not enough, however, that a substance contain the essential components of the plant to which it is to be applied. It must be in such a state, that the plants may 
appropriate them, hence, animal matters which are easily rendered soluble, have a much greater effect when first applied, than vegetable manures, but the latter are more permanent as their constituents gradually become soluble. It is by putrefaction that all animal and vegetable remains are rendered available to plants, but if they are allowed to putrefy without eare, the loss is immense- the soluble parts are washed away, the gases pass off into the air, and at least 50 per cent. of the manure is dissipated.

Some manures ameliorate the soil by absorbing and retaining moisture from the atmosphere. This property is as beneficial to a clay as to a sandy soil during drought, as at such times clays are often baked so as to be impervious to the dew, and suffer nearly or quite as much as more sandy soils. The best absorbents of moisture are stable manure, thoroughly decomposed tanbark, and the manure of the cow and pig, in the order named. After these come sheep and fowl manure, salt, soot, and even burnt clay is not without its virtue. All these absorbents are much more effectual when finely divided, and the soil itself is a good absorbent in proportion to its richness, and the friability produced by frequent culture. In the power of retaining moisture absorded, pig manure stands preeminent, next that of the horse, then common salt and soot.

Some manures are beneficial in absorbing not only moisture, but nutritious gases from the atmosphere which they yield to the roots in a concentrated form. All animal and vegetable manures have the power of attracting oxygen from the air during decomposition.

Charcoal and all carbonaceous matters have the power of absorbing carbonic acid gas in large quantities, supplying constantly to the roots of plants an atmosphere of carbonic acid, which is renewed as quickly as it is ab- 
stracted. The same substances are especially valuable for their power of absorbing ammonia. Charcoal will absorb ninety times its volume of ammoniacal gas which can be separated by simply moistening it with water.

Decayed wood absorbs seventy times its volume, while leaf mould, perfectly rotted tanbark, and in fact all vegetable manures are exceedingly valuable in this respect.

Manures indirectly assist the growth of plants by destroying weeds and predatory vermin. This is not a property of animal and regetable manures, (except that guano repels most insects,) they fuster these enemies of the crop, but salt, lime and ashes applied to the surface of the soil are very destructive to nearly all insects, while the roots of weeds and grasses if composted with the salt and lime mixture are completely destroyed, and converted into an excellent manure.

Anotber indirect action of manure in assisting the growth of plants, is in decomposing and rendering available any stubborn organic substances in the soil. Stable manure and all decomposing animal and regetable substances have a tendency to promote the decay of any organic remains in the soil. All putrescent substances hasten the process of putrefaction in other organic bodies with which they come in contact. Even peat and tanbark mingled with stable dung, and liept moist are converted into good manure; common salt in small proportions has a similar septic property, and the eficacy of lime in this respect is well known.

But the most valuable agent in decomposing organic substances is the salt and lime mixture made as follows:

Take three bushels of unslacked lime, dissolve a bushel of salt in as little water as possible, and slake the lime therewith-if the lime will not take up all the brine at 
once, which it will, if good and fresh burned, turn it over and let it lie a day and add a little more of the brine, daily turning and adding until all is taken up.

This salt and lime mixture is exceedingly valuable. It destroys the odor of putrefying animal matters, while it retains the ammonia. Of itself it supplies plants with chlorine, lime and soda, all of which are requisite. Any vegetable refuse whatever, leaf mould, turf, straw, chips, and even tanbark, if kept moist and sprinkled throughout with this mixture, become thoroughly decomposed in a very short time, and if used for the bottom of pig-pens, stables and yards where they can absorb the urine, they become the very best of manures.

Another indirect agency of manures, is in protecting plants from sudden changes of temperature. There is no doubt, that rich soils and those abounding in animal and vegetable remains are less liable to change their temperature with the incumbent atmosphere, than those of poorer constituents, for the decomposition of manures gives warmth to the soil. Corn can be grown in high latitudes upon rich land only, upon a poor soil it would perish. Some manures as salt, it is asserted, protect plants from suffering by sudden reduction of temperature by entering into their systems-stimulating and rendering them more vigorous impregnating their sap and rendering it less likely to be congealed. This is doubtful.

The last indirect effect of manures upon plants is by improving the texture of the soils in which they grow. Decomposing in the ground they leave interstices as they become less in bulk, making it more light and porous. The effect of manure in rendering a stiff soil light and porous is very well known. It is equally true that vegetable manures give to sandy soils greater tenacity, enabling them better to retain moisture and ammonia. 
Having considered the modes in which manures act upon the growth of plants, a still more important inquiry remains, viz.: What manures can we obtain and render available. The scarcity of manures at the South is a great difficulty in gardening. But a small amount of live stock is kept by our planters in proportion to the number of acres in cultivation. What is thus obtainable is not well husbanded, and is needed on the plantation for corn and cotton. Still, on most country places, enough is wasted to supply not only the garden, but to leave a surplus for the plantation. In town, wherever a horse and cow can be kept, enough can be made for a large garden, while even a pig if kept at work in his pen with the aid of soap-suds from the house, will convert some fifteen loads of weeds, yard sweepings, chips, tanbark, and leaves, into a valuable manure.

Of Saline Manures, the most available are ashes leached and unleached, which should be most carefully saved, as potash is one of the elements most speedily exhausted from the soil. They contain besides potash, phosphoric and sulphuric acids, manganese, chlorine, soda, magnesia, carbonate of lime, and soluble silica. They may be applied directly to any crops and especially to fruit trees. Composted with swamp, earth, and other vegetable matter, they correct its acidity, and form an excellent manure for all crops, and in connection with lime form the best compost for orchard purposes.

Lime may be applied in this compost for trees, but for all garden crops, the lime and salt mixture affords a sufficiency for the growing crops. Shell lime is the best to employ, as it contains some phospate of lime which is still more valuable. If lime is used alone, mix it intimately with the surface soil, but do not plough or spade it in. Its effect in improving the texture of soils, we have already considered. 
All the constituents of the lime and salt mixture are available to plants, the caustic lime decomposes the salt forming chloride of calcium, while the soda set free, draws carbonic acid from the atmosphere and becomes a carbonate. Lime decomposes all organic matters, but it drives off the ammonia, and hence, should not be used in connection with animal manure. The mixture is still better than lime for decomposing organic inatters, and besides does not drive off the ammonia therein.

Lime rubbish from old brick walls, and the plastering of old houses, absorb nitrogen from the air, forming nitrate of lime. This salt furnishes nitrogen abumdantly to plants. This rubbish also contains a portion of hair and silicate of lime, and is a very powerful manure. One ton is sufficient for an acre.

Common salt on lands so distant from the sea, that the spray does not reach them, is a very beneficial manure. The refuse salt which has been used for bacon is the most valuable, as it contains in addition the blood and juices of the meat which greatly increase its value. It may be directly applied to asparagus without injury, and at the rate of six or eight bushels per acre applied in autumn, it benefits all garden crops, keeping the soil moist and free from insects and worms. Gypsum enters into the composition of many crops, but a very small quantity will suffice. One bushel per acre yearly is all that is needed. In absorbing ammonia from the manure heap, charcoal dust and leaf mould are much cheaper.

Marl where it can be obtained may be applied with advantage especially to sandy soils. It is generally beneficial in proportion to the quantity of lime it contains.

Soot is rich in ammonia ; very little of this can be procured, but it should be carefully preserved and applied in small quantities to cabbage and other plants infested with 
insects. It drives these off and its ammonia also promotes the growth of the plants.

Among the vegetable matters which may add to the stock of manures for the garden, the rery best is cotton seed where it can be obtained. If the husk were remored and the remainder reduced to an equally dried state, it would scarcely be inferior in strength to guano itself. It may be applied with advantage to any crop.

Charcoal renders the soil light and friable, gives it a dark color and additional warmth for early crops. The bed whereon charcoal has been burnt is always marked by a more vigorous growth of plants when it becomes sufficiently mixed with earth. It contains also small quantities of silicate of potash and other fertilizing salts.

It absorbs both carbonic acid and ammonia from the air, and yields them to the roots of plants. It is most marked in its effects on plants which require abundant nitrogen. As it is indestructible, its beneficial efiects last as long as it remains in the soil, supplying the spongioles or rootlets of plants with an atmosphere of carbonic acid which is renewed as fast as abstracted. Its good effects begin to be scen when the dust is applied at the rate of furty bushels per acre. Charcoal is invaluable for destroying the odor of decaying animal matter, retaining all the gases in its own substance ready to yield them up for the use of plants. Hence, the best application of this substance is not directly to the soil, but to compost it with putrescent animal matters, urine or night soil, of which it will absorb all the odor and fertilizing gases given off during their decomposition. Composted with the last named substance, it becomes poudrette, and is second only to guano as a fertilizer.

In striking cuttings or potting plants, charcoal is a valuable substitute for sand, plants rooting in with greater 
certainty. Fine charcoal can be obtained in considerable quantities from the old hearths where it has been buried, also the refuse of smith's shops, founderies, and machine shops. All the refuse of the garden that will not decay, pea-brush, trimmings of trees, cabbage and corn stalks, together with tanbark, saw-dust, fresh shavings may be collected, the coarser materials placed at the bottom and set on fire when the heap is building, then covered with the finer, beating all well tngether, cover it well with short moist, rubbish weeds and clods. Bermu grass turf is the best material for this purpose if you are troubled with it. Thrust a stake in different places that the fire may run through the entire heap, and if it breaks out in any of these, stop them with rubbish or earth and make holes in a new place. When finished and the fire put out, store it up for use. The roasted turf as well as the charcoal is a most valuable manure, especially for roses.

Beside charcoal, there are many other vegetable substances of great value, as absorbents of the fertilizing salts and gases that would otherwise escape from animal manures. Carbonaceous matter of every sort should be prorided for this purpose. Gather the leaves of trees of all kinds including pine straw. They contain all the substances necessary for the growth of the plants from which they fall, and in the proportion needed for new growth. Throw them into the stables and yards, moisten them and sprinkle them with the lime and salt mixture, and if kept in a damp state and turned over once or twice, they form the best manure known for all kinds of trees and shrubs, and indeed afford all the necessary constituents organic and inorganic of all cultivated plants.

Another valuable absorbent is swamp muck. Gather the black carth of swamps, place in piles and let it dry out the superflunus moisture, haul it to the compost heap 
or yard, and mix with every load a bushel and a half of the lime and salt mixture intimately while it is in a moderately moist state, and in thirty days it will be decomposed. Upon a layer of this earth six inches thick, spread a coat of fresh stable manure, each day covering it with ten times its quantity of prepared muck which will absorb all the gases and salts. Let the pile accumulate until four feet high, and then turn it all over, mix it intimately, and cover the whole with a thick coat of prepared muck. If too dry to ferment, add water, and in three weeks it will be fit for use, and will be found equal to common stable manure, and is entirely free from insects of all kinds. In reducing composts of all kinds, the heap must be kept moist or no fermentation will be produced, keeping it "always moist but never leached" is the way to produce a strong compost.

A thick layer of the muck should be kept also in the hog-pens and stables to absorb the urine, removing the solid manure from the latter daily, and the muck at the end of each week. Upon this muck also the house slops of all kinds should be poured and where charcoal is not employed, a bushel every three days should be thrown into the privy to destroy the offensive gases produced.

Swamp muck may also be reduced with ashes or lime, either of which will destroy all acid properties. The salt and lime mixture is the best and usually the cheapest, but leached ashes mixed with carbonaceous matter have an additional part of their potash, rendered soluble and available for plants, and should be used thus where obtainable.

Of still more value is leaf mould or the black surface soil of the woods. This is free from the acid properties of swamp muck, and may be applied directly to most plants in the flower garden, many of which will not flourish un- 
less this material is present in the soil. It is of still more importance for potting plants in the greenhouse. For the kitchen and fruit garden it is best composted like swamp muck with fresh animal manure.

Another material abounding in carbon which may, to some extent, be used as an absorbent of animal manure is tanbark. It may be beneficially applied directly to strawberries, to which it answers the double purpose of mulching and manure. But the crowns of the plants must not be covered; for all purposes it should be obtained as much decomposed as possible.

Tan may be applied directly to Irish potatoes when ready to cover in the furrow. After they are dropped fill the furrow even with the surface with tan, and finish by covering this with earth. A little of the lime and salt mixture is applied with the tan to great advantage. It improves the yield materially and the quality also, as all carbonaceous matters do. Where swamp muck or leaf mould can be obtained, it is hardly worth while to use $\tan$ as an absorbent of animal manures. It is very difficult to reduce, but if kept moist the lime and salt mixture will do it. It may be strewed in the stock yard six or eight inches thick, and sprinkled pretty thickly with the mixture. The treading of the stock will mix it. Let the whole be turned over in a moist state once or twice, and in the course of the winter it will become a valuable application to the plants that do well with fresh manure. There are abundant elements of fertility in tan but it is more difficult to render them available than with any other vegetable substance; perhaps the readiest and most profitable method is to char it. Decayed chips, sawdust, shavings, \&c., are best applied to Irish potatoes, as directed in the case of tanbark. They should be covered with soil to promote a more speedy decay. 
Green Manures.-There are various crops raised to turn into the ground in a fresh state for fertilizing it. For this purpose all the weeds of the garden should be em ployed while green unless they are thrown to the pig. Over any racant spots in the garden not wished to be used in autumn, rye or barley can be sown which will keep the soil from washing, and when large enough may be either cut for the cow or turned into the soil as the plots are wanted for use.

Spinach should be sown in considerable quantities as it grows all winter and spaded into the soil in the spring adds a good deal to its fertility-the seed in any quantity can be saved with little trouble. The most important class of manures is that derived from animals. All animal manures when compared with the preceding class are rich in nitrogen, easily decomposed and rendered soluble, but though the effect of this class of substances is much more obvious it is not so lasting.

The greatest attention should be paid to collecting, preserving, and economizing animal manure. Its great value consists in certain volatile and soluble substances which in the common mode of preserving manure are dissipated in the air or washed away by heavy rains. In this climate to shelter it from the sun and rain is very necessary. All animal matter is either directly or indirectly derived from vegetable substances, hence, every portion of the same that can be rendered soluble is a valuable food for plants. Among the most important animal substances employed as manures are urine and dung of all kinds. The first of these is almost invariably wasted, though in the case of the cor, it is of more value than the solid excrements. It should be carefully saved by bedding the yard and stables with swamp muck or some other absorbent. Urine is particularly rich in ammonia. This may 
be absorbed by the muck or its strength may be retained by sprinkling the floor of stables and the manure heap frequently with fine charcoal or plaster of Paris. Gypsum sprinkled upon the floors of stables forms a compound like the urate of commerce, so powerful that 500 pounds will amply manure an acre. If you can obtain no other absorbent, even tanner's bark is not without its value, but the weeds, sweepings of walks, and other refuse of the garden are to be preferred. Urine may also be diluted with three times its weight of water and permitted to grow stale and be applied at night or in moist weather directly to the growing erops. The principal animal manures are those of the horse, the hog, the cow, and the sheep. Of these horse manure is most valuable in its fresh state. That of the hog comes next, then that of the ox, while the cow is at the bottom of the list because most of the enriching substances in her food go to the formation of milk, leaving the manure comparatively weakened. The manures of animals is far rieher than their food, because it contrins more nitrogen, the carbon and oxygen of the food being taken up by the lungs and blood to sustain the animal heat. The richer the food given to animals the more powerful is the manure. If animal manures are employed in a fresh state they should be mixed intimately with the soil and given to such coarse feeding crops as corn and the garden pea. But nearly all plants do better if the manure is composted and fully fermented before use. Pig manure used alone is pernicions to the growth of the cabbage and turnip tribe, and gives an unpleasant taste to many other regetables, but composted with muck or mould it is much more beneficial as well as more durable.

In managing animal manures, decomposition must be promoted to convert the nitrogen into ammonia-the volatile parts must be preserved from dissipation in the air, 
and the soluble portions from being washed out by rains. 'That it may ferment, it must be kejt in a body that heat may be generated and its natural moisture retained, while beneath it a layer of some absorbent substance should be placed to receive and retain its soluble parts, and as fast as it is thrown. from the stables it should be covered with layers of muck to retain the ammonia. Horse manure, especially, should not be exposed at all, it begins to heat and lose nitrogen almost immediately as may be perceived by the smell. Mix it with other manures and cover it with absorbents as soon as possible.

The manure of birds is richer than that of any other animals; as the solid and liquid excrements are mixed together, it is particularly rich in nitrogen and the phosphates. Three or four hundred weight of the manure of fowls, turkeys, \&c., is of equal value with from fourteen to eighteen loads of animal manure. Guano is a manure of this class. It is the manure of sea-birds which has accumulated in tropical latitudes where it seldom or never rains. These birds feed upon fish entirely, hence, the manure is remarkably rich in nitrogen. Guano is this substance with the water evaporated. The Peruvian and Bolivian are the best varieties, and when these ean be bought pure, delivered at not over three dollars to three dollars and a half per hundred weight, it is generally the cheapest manure to be obtained as it is so easily applied-the labor of applying other manures often approaching the price of guano. It is well to apply about two hundred weight per acre with one half the usual quantity of other manure. Guano should never in a fresh state come in contact with seeds or the roots of plants as it is sure to destroy their vitality. In setting out fruit trees and shrmbs of all kin.ds guano is the cheapest and most convenient manure to apply. After the holes are dug, sprinkle the bottom 
thinly with a handful of guano. Cover this at least three inches deep. On this you may plant your trees with safety, and after the roots are covered a little more may be sprinkled and the whole covered with soil. But the great value of guano is in forming liquid manure, one pound of guano to five gallons of water applied once a week will add wonderfully to the growth of any plants watered with this mixture. For very delicate plants twice the above quantity of water should be given. If guano is not to be had, the manure of fowls is a good substiture. 'This liquid is especially valuable in the flower garden. It must be poured upon the roots and not upon the leaves or collars of the plants. On lawns, a pound sprinkled upon each square rod will restore their verdure. A great advantage of applying guano is that no seeds of weeds are scattered in the soil.

Night soil and chamber slops should be composted as before directed with charcoal or the black mould from the woods.

Gypsum may be added to the mixture, all smell is thus destroyed and an offensive nuisance is converted into a valuable application to any crop. Where charcoal is fireely used this substance becomes perfectly inodorous. Guano and poudrette are the best possible manures for the cabbage tribe and other plants that need phosphates and nitrogen. Both these manures are exceedingly powerful but their effects do not last beyond one season. The fertilizing properties exist in the right proportions to be taken up at once by the plants, and nearly all their nutritive properties are exhausted the season they are applied.

The following table from Boussingault gives a comprehensive view of the proportion of azote or nitrogen contained in the most common manures, and of their quality 
and equivalents, referred to farm yard dung as the standard. Thus ten lbs. of fresh cotton-seed oil cake is equal in value to one hundred fresh or wet farm yard dung as far as the nitrogen in each is concerned. To form a perfect table of equivalents the phosphates, potash, \&c., must be also taken into consideration.

\begin{tabular}{|c|c|c|c|c|c|c|c|}
\hline & \multirow{2}{*}{ 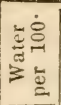 } & \multicolumn{2}{|c|}{ Azote in 100} & \multicolumn{2}{|c|}{$\begin{array}{l}\text { Quality } \\
\text { according to } \\
\text { state. }\end{array}$} & \multicolumn{2}{|c|}{$\begin{array}{c}\text { Equivalent } \\
\text { according } \\
\text { to state. } \\
\end{array}$} \\
\hline & & Dry. & Wet & Dry & Wet. & Dry. & Wet \\
\hline Farm yard dung, & 79.3 & 1.95 & $\overline{0.41}$ & 100 & 100 & 100 & $\overline{100}$ \\
\hline from an Inn yard, & 60.6 & 208 & 0.79 & $10 \bar{t}$ & 107 & 94 & 51 \\
\hline water, & 99.6 & 1.54 & 0.06 & 78 & 21 & 127 & 68 \\
\hline Withered leares o & 70.9 & 2.94 & 0.85 & 150 & 212.5 & 66 & 47 \\
\hline do. of $o$ & 25.0 & 1.57 & 1.18 & 80 & 2931 & 125 & 34 \\
\hline hells, • & 17.9 & 0.40 & 0.32 & 20 & 80 & 488 & 125 \\
\hline 0 & 26.0 & 0.72 & 0.54 & 36 & 135 & 256 & 74 \\
\hline f cotton sced, & 11.0 & 4.52 & 4.02 & 231 & 1000 & 32 & 10 \\
\hline dung, . & 859 & 2.30 & 0.32 & 117 & 80 & 84 & 125 \\
\hline ne of cows, . & 88.3 & 3.80 & 0.44 & 194 & 110 & 51 & 91 \\
\hline dung, & & 2.5 & 0.41 & 132 & 102.5 & 75 & 98 \\
\hline $\begin{array}{l}\text { horse dung, } \\
\text { urine.. }\end{array}$ & & $\begin{array}{r}2.21 \\
12.50\end{array}$ & $\begin{array}{l}0.55 \\
2.61\end{array}$ & $\begin{array}{l}113 \\
641\end{array}$ & $\begin{array}{l}137.5 \\
652.5\end{array}$ & $\begin{array}{l}88 \\
15 \frac{1}{2}\end{array}$ & 13 \\
\hline Nixed (horse dung, & & 3.02 & 2.74 & 154 & 185 & 66 & 54 \\
\hline - & 81.4 & 3.37 & 0.63 & 172 & 157.5 & 58 & 63 \\
\hline & 63.0 & 2.99 & 1.11 & 153 & 277 & 65 & 36 \\
\hline of Belloni, & 12.5 & 4.40 & 3.8 .5 & 225 & 962 & 44 & $10 \frac{1}{3}$ \\
\hline ung & 9.6 & 9.02 & 8.30 & 462 & 2075 & 21 & 5 \\
\hline England & 19.6 & $\begin{array}{l}6.20 \\
7.05\end{array}$ & $\begin{array}{l}5.00 \\
5.40\end{array}$ & 328 & $\begin{array}{l}1247 \\
1349\end{array}$ & $\begin{array}{l}31 \frac{1}{2} \\
28\end{array}$ & 74 \\
\hline do, 1 & & 15.73 & 13.95 & 80 & 348 & $12 \frac{1}{2}$ & $28 \frac{1}{2}$ \\
\hline Dried muscular flesh, . & 8.5 & 14.251 & 13.04 & 730 & 3260 & $13 \frac{1}{2}$ & 3 \\
\hline Liquid blood, & 81.0 & & 2.95 & 795 & 3045 & 12 & 34 \\
\hline Feathers, . & $\begin{array}{l}30.0 \\
12.9\end{array} \mid$ & 1 & $\begin{array}{r}5.31 \\
15.34\end{array}$ & & $\begin{array}{l}1326 \\
3835\end{array}$ & 11 & $2 \frac{1}{2}$ \\
\hline Cow hair flock, & 8.9 & 15.121 & 13.7 & 77 & 34 & 13 & 3 \\
\hline $\mathrm{s}$, . & 11.3 & 20.261 & & 103 & 44 & 9 & $2 \frac{1}{4}$ \\
\hline Horn shavings, & 9.0 & $15.78 \mid 1$ & 14.36 & 809 & 3590 & $12 \frac{1}{2}$ & 3 \\
\hline & 5.6 & 1.31 & 1.15 & 67 & $287 \cdot 51$ & 149 & 35 \\
\hline . & & 1.0 & & שo & & 159 & 33 \\
\hline
\end{tabular}

There are several other substances which, when they can be obtained, should be carefully applied. Among 
these, the most available are the offal of slaughtered animals and their carcasses, hair, bristles, leather, refuse from the tamners and shoemakers, woollen rags, and bones. All these contain the elements required by growing plants in a very concentrated state. 'The hair, bristles, \&c., may be applied directly to any crop. These matters are very powerful, and a small quantity will suffice. Slaughterhouse offal, and the carcasses of any animals that may have died, should be buried deeply in a pit, with absorbents beneath, and covered with muck or loam. In a year it will become a most valuable manure.

Boves are an especially useful application to almost any garden crop. Bones contain sixty-six parts of earthy matter, mostly phosphate of lime, and thirty-four parts of gelatine. Phosphate of lime, next to ammonia, is the most necessary application to a soil, because the first element exhausted. Gelatine is rich in nitrogen, so that in bones are united the most desirable organic and inorganic manures. Applied whole, bones decompose too slowly to be of much value, and would be greatly in the way of tillage. They may be broken small with a sledge-hammer or crowbar, in a large wooden mortar, lined at the bottom with a thick iron plate. When beaten small, the fine dust can be sifted out, and the remainder moistened and thrown up in heaps, to ferment a few months. Bones can be dissolved by boiling them in strong lye, and dried, by mixing with ashes or sand, can be applied broadeast or in the drills. The best way to treat bones is to dissolve them in sulphuric acid, forming superphosphate of lime. A carboy of sulphuric acid, costing about four dollars, at wholesale, in the cities, and containing one hundred and sixty pounds, will dissolve about three hundred pounds of bones. 'The bones should be put in a tub. A portion of the acid 
equal to one-third should be diluted by pouring it into three times its bulk of water, and then should be poured upon the bones. After standing a day or two, pour on another portion of diluted acid, and if not already dissolved, in a day or two after the remainder should be added. The mass must be often stirred. The bones will dissolve into a kind of paste, which may be mixed with thirty times its bulk of water, and used as a liquid manure, but it is more convenient in practice to mix it with ashes, sawdust, or fine charcoal. 'Three bushels of these dissolved bones are sufficient for an acre. The acid has converted the bones into a superphosphate of lime, which is very soluble, and is readily taken up by the plant. This is the most valuable of all manures for the turnip, and the quantity needed for the acre is so little that the expense is less than almost any other application.

Composts.-The composting of manure should take place, as a general thing, as fast as it is made. Still, in the garden, out of sight, there should be a compost heap for receiving all kinds of rubbish that can have the least value as fertilizers. Make a shallow excavation of a square or oblong form, with the bottom sloping to one end. Into this collect the litter and sweepings of the yards, decayed regetables of all kinds, brine, soapsuds, and slops from the house, woollen rags, leares, green weeds, and garden refuse. After it has accumulated a little, turn it over, adding a little of the salt and lime mixture, and keep the whole inodorous, by covering it with rich mould or black earth from the woods. If the heap is formed entirely of vegetable materials, ashes and lime should be added; but if it contain animal matter, they would do harm by letting free the ammonia. The heap should not be deep, but, like all other manure heaps, should be kept 
"always moist, but never leached," by the addition of liquids from the house and kitchen. If this compost be for a sandy soil, the addition of clay would be very beneficial.

Spectal Manures.-The subject of special manures, though still in its infancy having attracted great attention, we have given under the head of all the most important vegetables, their analyses and sometimes with hints for special manuring the same.

We know each species of animals requires peculiar kinds of food in order fully to develop its powers, and that food specially adapted to one species will not nourish and will be refused by another. The dog or cat would starve on food which would fatten the horse. So each species of regetable is equally select in its requirements for food. Some plants will perish in soil specially adapted for the growth of a different species. Every plant will not come to perfection in a rich soil. More or less lime is necessary for instance to most cultivated plants, yet the pine sorrel and kalmia will not grow where much lime is present.

Besides organic substances as already stated, all cultivated plants contain several or all of the following constituents : potash, soda, lime, magnesia, chlorine, sulphuric and phosphoric acids, silex, \&c., and for successful culture all the inorganic materials of a plant must be found in the soil. The amount of these substances found in the soil can be pretty exactly determined by analysis, but sufficiently so for all practical purposes by noticing its geological formation and the plants growing spontaneonsly upon it. Soil analyses should be obtained only of the most accurate chemists as there are many sources of error and the proportion of some one or two materials required by plants in the soil is so small that they may possibly exist in sufficient quantity and yet escape detection. The amount of 
these substances taken up by each plant is determined by analyzing its ashes. The amount of each of these materials in healthy plants of the same species at the same stage of growth is pretty constant.

In some species no soda at all is found, in others no magnesia, in others very little lime, and the proportion of acids as well as alkalies, varies in different plants. The object of special manures is to supply those substances which are most likely not to exist in the soil in sufficient quantity for the wants of the plant under cultivation. The salts most important to the growth of plants in which soils are most apt to be deficient are lime, phosphate of lime, and potash. An application of the two latter is almost invariably beneficial. Other substances also when taken up in large quantities will require to be supplied, such as soda, sulphuric acid, and chlorine. The analysis of a plant however does not always indicate truly what the plant most needs in the soil. Many plants have more of the phosphate in their composition than the turnip but no one is so much benefited by the application of phosphate and superphosphate of lime.

Rotation of Crops.-As different plants appropriate different substances, the rotation of crops has considerable influence in retaining the fertility of a soil. If the same kind of plants are continued upon the same soil, only a portion of the properties of the manure applied is used, while by a judicious rotation everything in the soil or in the manure suitable for regetable food is taken up and appropriated by the crop. Some regetables as onions and carrots are very exhausting to the soil while lettuce is very slightly prejudicial. Hence, howerer plentiful manure may be, a succession of exhausting crops should not be grown upon the same bed, not only because abundance is no excuse for 
want of economy, but because mantre freshly applied is not so immediately beneficial as those remains of organized matter which by long continuance in the soil have become impalpably divided and diffused through its texture of which each succeeding crop consumes a portion. Those plants generally are least exhausting which have the largest surface of leaves, not only because they are made up of a greater proportion of aqueous matter but also because they are enabled to obtain more in proportion of their food from the atmosphere. A rotation was formerly thought necessary from an idea that each plant throws off from its roots into the soil certain matters which are iujurious to others of the same species afterward grown upon the soil, but this view can hardly be sustained. Another reason for rotation of crops is that some crops are so favorable to weeds that if continued long upon the same bed the labor of cultivating them is much increased, while if raised but once in a place and followed by a cleaning crop, the weeds are easily kept under.

Besides many crops planted continually in the same soil are more liable to be attacked by the insects which are the peculiar enemies of those plants. Again different plants derive their principal nourishment from different depths of soil. Hence deep-rooted plants should be succeeded by those whose roots extend but little below the surface. Perennial plants by annuals, crops left for seed or that are of a dry solid texture, by those which are succulent and juicy.

In short, the same species of plants should never be grown in successive crops upon the same ground. The most beneficial plan is where exhansting and non-exhausting crops alternate with each other, as after manure, viz.

Onions, Lettuce, Cabbage, Carrots, Manure ; or, Turnips, Celery, Peas, Potatocs, Manure. 
The following is also a very good rotation:

1. The cabbage tribe to be followed by

2. Alliaceous plants, as onions, leeks, \&c., to be followed by legumes, as beans or peas. Peas may be followed the same year with celery.

3. Tap-rooted plants, as carrots, beets, parsnips

4. Surface roots, as onions, potatoes, turnips.

5. Celery, endive, lettuce, spinach, \&c.

Celery is excellent to precede asparagus, onions, cauliflowers, or turnips; old asparagus beds for carrots, potatoes, \&c.; strawberries, and raspberries for the cabbage tribe; cabbage for the tap-rooted plants; potatoes for the cabbage tribe.

In these rotations it is not necessary to apply manure to every crop. For the bulbous roots as the onion, plants cultivated for their leaves as spinach and asparagus, the ground can scarcely be too rich, and the bulk of the manures may be applied to them and the cabbage and turnip crops, while for plants raised for seed it is best that the foliage should not be stimulated into too great luxuriance.

Sub-Succession.-To get the highest possible results from a garden, there must be not only a general rotation of crops year by year, but a number of sub-successions each year, as fast as the crops are removed. One-fourth of an acre thoroughly manured and kept perfectly free from weeds, and as fast as one crop is removed another placed upon the ground, will yield more than an acre managed in the common way.

For instance, late in the fall a portion of the garden may be occupied with spinach; this should be heavily manured, and may keep the ground until time to plant melons and other vines, when just enough of the ground 
may be deeply dug to form the melon hills, and the crop will be ready to remove before the melons begin to run. The melon crop may be followed by one of turnips. All such plants as radish, lettuce, and other small salads need take up no room: they can, any of them, be raised between the potatoe drills, or between melon hills, rows of corn, \&e. and will come to perfection before the potatoe or other crops require the ground. Radishes can be raised in the beds of all kinds of plants that are slow in coming up, as carrots, parsnips, \&c., and will be ready to remove by the time the others come up. Three or four weeks before Irish potatoes are ripe, a plant of winter cabbage can be placed in the trench caused by earthing up the potatoes, where it will find shade and moisture until well established, and digging the potatoes will cultivate the cabbage. Between the rows of early potatoes is also a good situation for raising celery for linme use.

Any racant spot that occurs early in summer should be oceupied with plantings of extra early or sweet com, potatoes, kidney beans, for preserving for winter use, and cucumbers for pickling. Those coming later in the season, may be occupied by sweet potatoe until July, then corn, cow peas, or Ruta Baga tumips. Where the early onions grow, both in the alleys and in the centre of the bed, before much of the crop is removed, may be planted with late cabbages or Silerian kale. Cabbage will head out planted 1st August if in moist ground and well cultirated, and swcet corn may be planted at the same time. Still later, every unoceupied corner should he corered with turnips and winter radishes, which may cover nearly the whole garden, being sown in drills between the rows of plants not yet quite ready to be remored. After the frost has come, any racant spaces should be immediately sown with spinach, onions, and other crops for early spring 
use, or with barley or rye for the cow. The secret of successful cultiration, says Downing, is an abundant supply of manure. A small extent of ground well manured and trenched deeply, by these sub-successions, will produce an enormous amount of regetables, while only the same surface needs to be hoed, manured, and kept free from weeds as if it produced but one crop. To be sure, more manure and more labor are needed, but nothing like the amount which would be required to produce the same crops without these sub-successions. Many other sub-successions will occur to a thoughtful gardener, but to clerive the full benefit of them the grounds should be trenched at least thirty inches deep when the garden is formed.

Profits of Gardenixg.-The results of the above mode of procedure, in the case of the garden of the Retreat for the Insane at Utica, New Tork, were published by Dr. Brigham. The land was good and yearly manured. The product was as follows on one and one-fourth acres of land :-1100 heads lettuce, large ; 1400 heads cabbage, large ; 700 bunches radishes; 250 bunches asparagus; 300 bunches rhubarb; 14 bushels pods, marrowfat peas; 40 bushels beans; sweet corn, 3 plantings, 419 dozen; summer squash, 715 dozen; squash peppers, 45 dozen; cucumbers, 756 dozen; cucumber pickles, 7 barrels; beets, 147 bushels; carrots, 29 bushels; parsnips, 26 bushels; onions, 120 bushels; turnips, S0 bushels; early potatoes, 35 bushels; tomatoes, 40 bushels; winter squash, 7 wagon loads; celery, 500 hcads—all wortl 621 dollars in Utica market, but supplied one hundred and thirty persons with all they could consume. Only one man was required to do all the necessary labor.

Forwarding Early Crops.-Early crops in the open air should be planted in a sheltered situation, on a dark- 
colored, silicious soil. It may be brought to a proper state by the admixture of sand and charcoal. Crops may be retarded by planting in a border sheltered from the sun, and of a lighter color and more aluminous. There are many plants which do much better if sown in the fall. Rhubarb, parsley, stc., come up more freely if suffered to be in the ground all winter. Potatoes, too, may be early planted, and if they come up, should be sheltered by a covering of straw or litter, added from time to time to keep them from frost. Cabbage, cauliflower, brocoli, \&c., may be kept out all winter in boxes made by nailing four pieces of boards together, eight inches wide. Cut the pieces 12 inches wide at the bottom, and 10 at the top, nail them together at the corners. After the frosts begin to be severe, throw in a handful of loose straw, which will prevent the sudden freezing and thawing of the plants. Great care should be taken to produce early crops, as they are less liable to be injured by insects or weeds, and very much increase the satisfaction of gardening. Early plants may be obtained by sowing them in a box set by a window, or raised in autumn and protected in winter in a cold frame or pit, or raised any time during winter in a hot bed for those more delicate, or in a cold frame under glass for the hardier kinds. Radishes sown under glass without heat early in January are generally fit for use early in March. Such plants, when set out in the spring, require shading a few days until established.

Frames or Hot Beds are most usually employed for forwarding plants. The frame for general use has from three to five sashes, (see plate), and is made for convenience about four and a half or five feet wide, and the length depends on the number of sashes, which are usually about forty inches wide. Use the smallest glass you can obtain, certainly not over seren by nine. A 
smaller size is preferable, as it is not so liable to be broken, and can be more readily repaired. These sashes are made without cross-bars, the glass over-lapping like

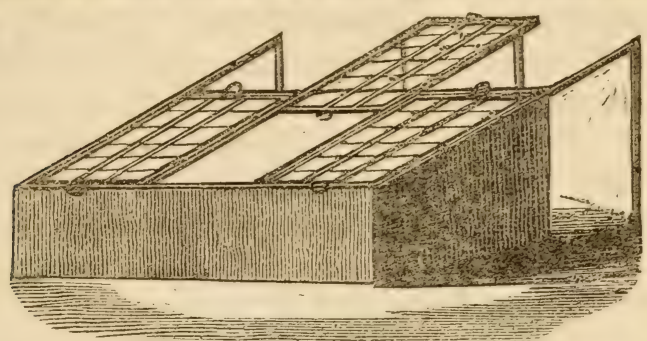

the shingles of a house, and resting on bars extending lengthwise of the sash. The lap of each pane of glass need not be over half an inch, and if the glass is set in the sash when freshly painted with two coats of good paint, no puttying is necessary. The bars which sustain the glass may be two inches wide, which will make the sash stronger. The frame is a box of boards, three feet high in front, and three feet ten inches in the back. The front, of course, is towards the south, Let the corners of the frame be nailed to small pieces of scantling, which may rest upon bricks or blocks. At the corner, also, of each sash let another piece of scantling be placed, and on the top of these, narrow strips twice the length of the sash are to be nailed, extending back for the sash to slide upon. The ends projecting should also be supported by pieces of timber. Between the sashes, nail an inch strip a little thicker than the sash to the narrow plank on which they slide, and put on the sash; and upon this strip nail another narrow strip, projecting over the sash a little, to hold them in their place, but not so tightly but what they will readily slide in this groove. They can be taken out at either end. Tack on a piece of leather at the upper 
end of each sash, to draw it up more readily. All cracks should be closed by fitting in pieces of boards over them.

Fill up the box thus constructed with good stable manure, in which there is plenty of litter. If this is not in the mass in sufficient quantity, add oak-leaves or tanbark. There should be at least one-third litter in the heap. Shake it up and mix it well together, adding water if at all dry, and throw it into a compact heap to ferment. In a week, turn it over, and if dry and musty in any part, water the same. Let it be two or three days longer, and then work it over thoroughly, as before, and water if necessary. Then put it into the frame and press it down closely, and equally filling it within twelve inches of the top all around, a little higher in the centre than at the sides. It is well to excavate about ten inches below the frame, to admit a larger body of manure. Put on the sash and keep them close until the heat rises and a steam appears upon the glass. As soon as the heat rises, give air at noon each day, but keep closed in the evening and at night, unless the heat is very violent, when a little air should be giren. In three days, if the manure was sufficiently moist, the bed will be ready for use. If it has settled unequally, level the surface and add eight inches of fine, dark-colored, sandy garden-soil, spread it evenly, and put on the sash. When warmed through, sow in pots plunged in the mould, or in small drills from one-eighth of an inch to an inch deep, varying in depth with the size of the seeds, and cover by sifting fine earth on the surface. Water gently by sprinkling through the fine rose of a watering pot, until the seeds appear, when they should have air every day frecly (unless absolutely freezing) which will bring them up strong, and prevent their dropping off by excess of confined moisture. There are very few days which will not permit opening the bed at 
noon. During warm, gentle rains, the sash should be opened, but closed very carefully during cold or heavy washing storms. About $60^{\circ}$ is the proper temperature. Such a bed as this is invaluable for striking cutting of all kinds, in which case there should be an inch of clear river sand or charcoal spread over the surface. Annuals of all kinds for the flower garden, radish, tomatoes, peppers, cabbage and lettuce plants, \&c., will be ready, if the bed is made in January, for transplanting quite as soon as they can be removed with safety.

Cold Frames are made just like the above, only the box need not be over 15 inches high at the back, and are excellent for wintering half hardy plants of all kinds, and also for forwarding the more hardy plants, as cabbage, lettuce, \&c. Indeed, they are quite as indispensable as the hot bed, and less expensive. In very severe weather, the heat may be kept in by earthing up the sides and corering the sash with niats iuring the night. Air should always be given when the weather will admit, or the plants will grow up yellow and spindling. In managing. frames, the secret of success is to give plenty of air. Plants raised in cold frames are generally more hardy and desirable than those from a hot bed.

Propagation of Plants.-There are only two general modes of propagating plants, viz., by seed and by division. Species are propagated by seed, but rarieties, generally by division as they do not always continue true from seed. There are also two modes of propagating by division; in the one, the plants root in the ground as suekers, layers and cuttings, and in the other they root in another plant, as in budding, grafting, and inarching. While all plants are naturally multiplied by seed, most kinds also allow of propagation by division, as by taking offsets, parting their 
roots, suckers, cuttings, rumners, layers, \&c. Propagation by seed often produces new varieties which are only to be perpetuated by division of their roots, cuttings, layers, or budding and grafting upon stocks.

Propagation by Seed.-The most healthy and vigorous plants are generally produced by seed, and this is the only method of obtaining new varieties. Great care should be used in the selection of seed, as on their perfection the growth of the young plant very much depends. They should be sound and well ripened that they may germinate freely. Some seeds lose their vitality very soon after being gathered, others retain it but one or two seasons, and are better if sown as fresh as possible, while molon seed grows better by kreping. The soundness of seed may be tested by putting them into warm water; nearly all sound seeds will sink in this fluid in a short time. They can also be proved by planting a few in a pot and keeping it in a warm room, or plunged in a hot bed, and a few days will test the somdness of the seed. The causes of unsoundness in seed are blight, unripeness, mouldiness and age.

Seed should not only be sound but of the right kind as it is very rexations to sow early Yorks when you think your are sowing drumheads and rice versa. The way to avoid such mistakes is either to raise your own seed, or to know of whom you buy. Your own eye in the case of many seeds will not assist you at all in discriminating.

Seed must not only be of the right sort, but true to that sort. Early York cabbage seed may be sown, or Scarlet radish seed, yet from having been planted near to some other varieties, the seed is crossed with them and the most valuable qualities of the variety lost. The cabbage may be late or long-legged and not head at all, or the radish 
tough and misshapen. The seed may come up well but when fullgrown not be at all the thing you wish. Truth in seed is in insured by raising them yourself and at so great a distance from any other plants of the same species that intermixture is impossible. If you buy, purchase only of a trusty seedsmen, and as these cannot raise all the varieties, even they may be deceived. If you get hold of seeds that are very true, it is best to buy enough to last as long as those seeds will keep. Among the minst reliable wholesale scedsmen, I will mention the following houses (without disparaging others), whose seeds I hare used and find them reliable. Buist \& Landreth, of Priladelphia; Horey \& Co., of Boston; and Thorburn, of New York. In many cases it would be better to remit to these gentlemen direct, through a merchant and obtain the desired kinds, than to plant the miserable seeds often sent out to our stores, even if the latter were gratis. There is no reason in the world why the South should not raise its own seeds.

Saving and Preservixg Seeds.-Directions are given under each plant, but we will add the following general rules :-

The very finest plants should be chosen for this purpose, that is, those most true to their kind and most perfect in shape and quality. In the cabbage, a small short stem, well formed head with few loose leaves; in the turnip large bulb, small neck, few short and slender stalked leaves, and solid flesh. In the radish, high color (unless white), small neck, few and short leaves, and in the case of flowers, seed should be saved only from those most perfectly developed.

Great care should be taken to preserve the varieties unmixed, as if varieties of the same species, or very similar 
species are planted near each other they will cross and produce untrue seed. In this way, it is true, valuable varieties often originate, but the chances preponderate that the produce will be worthless. There can be no cross between a cabbage and a carrot, because they are of totally different races, and there is no similarity; but all the varieties of cabbage will cross with each other, with Brussels sprouts, turnips, and in short with all the others described uncier the genus Brassica. So of corn; in a few years the early varieties from the North become so intermingled with our own as not to be distinguished. Often three or four rarieties of as many colors may be found on one ear when sereral sorts grow near together. The pollen of one variety is conveyed to the pistil of the other and the result is a hylurid partaking more or less of the character of both parents. The difficulty of keeping seeds pure renders it advisable not to save seeds of two varieties of any species the same year.

Seeds should stand until perfectly ripe, and should be cut or pulled in dry weather, and dried thoroughly before being threshed. If any moisture then appears, dry them further and store in paper bags, keeping free from vermin and damp. Insects can be kept from most seeds by sprinkling the paper with spirits of turpentine. Peas and beans when thoroughly dried should be kept in well stopped bottles in which a few drops of spirits of turpentine have been placed. This will destroy the bugs as they hatch.

The following list of the time seeds keep is from Cobbett, but with a few exceptions mentioned hereafter, it is always best to sow new seed: 
Years.

Years.

Years.

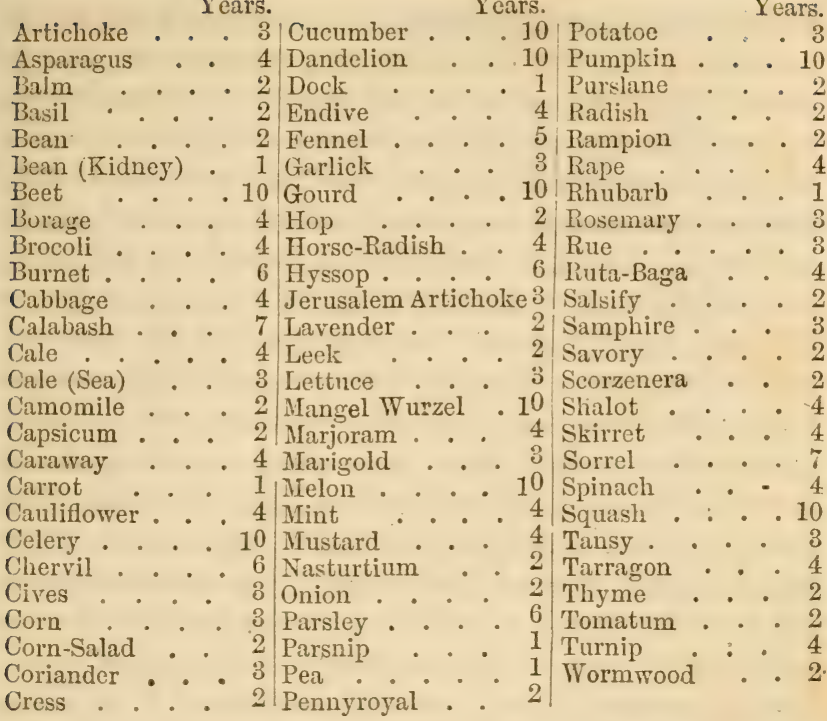

Sowing and Gerinnation of Seed.-The seedsman is often blamed for selling bad seed, when the fault is with the planter. That seed may germinate moisture, air, and a certain degree of warmth, varying with each variety, are necessary. Light must also be excluded until the root can derive nourishment from the soil. The first effect of air, heat, and moisture upon the seed, is to change its starchy matter into a sugary pulp, the proper food of the embryo. If at this time the seed be withered by exposure to heat without sufficient covering, it will perish. It often happens that seeds are planted in a freshdug soil, and the above change in the properties of the seed takes place, but the earth not being pressed upon it the seed dries up and the embryo perishes. Others again are buried too deeply, and though the seed swells, yet 
sufficient air and warmth are not obtained to give the embryo life. The seed should be just so far covered as to exclude light, and afford barely moisture sufficient for its wants. The first thing in sowing is a suitable preparation of the soil, so that the young roots thrown out may easily penetrate it. It must be made more or less fine for different seeds. Peas and beans do not require the soil to be as fincly pulverized as small seeds. The seeds must also be firmly fixed in the soil, and pressed by the earth in every part in order to retain moisture sufficient to encourage regetation, but they should not be so deeply buried ns to be deprived of air, or have their ascending shoots impeded by too much soil abore. In all cases, seeds should be sown in fresh dug soil, that they may have the benefit of the moisture therein, but they should never be put in when the soil is really wet, as the ground will bake and the seed perish. Moist weather in summer is excellent for putting in seeds, provided the ground is still friable. Just before a light rain is the best possible time for sowing turnips and other summer sown crops.

Sceds of all kinds should be sown in drills or rows. In these they can be planted at any required depth, while if broad cast, some will be uncorered, and others too deeply buried in the earth. In drills you can know also where to look for the young plants; they can have the soil dug around them, they will thus grow much faster, and are much more easily thinned and cultivated. When 1lie seeds are planted, the earth should generally be pressed upon them with a roller or by treading with the fect in the case of large seeds, or by smoothing the surface with the back of the spade or by walking over them on a board for the smaller kinds. Pressing the earth upon tirem will retain the moisture about them, and hasten their vegetation. When they come up keep them free 
from weeds, and thin them as directed under the name of each plant.

Propagation by Division.-Propagation by division, in the case of bulbs or tuthers, is analogous to sowing seeds. A bulb requires the same influences to make it regetate, and its manner of growth is much the same, but for all bulbs the soil should be deeply pulverized, and most bulbs and tonbers require to be planted more decply than seeds.

Suckers.-Sending up suckers, forming ofisets and throwing out rumners, are all natural ways of propagation, and if all plants produced them, nothing more would be required than to divide the offspring from the parent, and replant in any suitable soil. But, in general, those only produce suckers that send ont stray horizontal roots, as the sucker is in fact a bud from one of these roots which has pushed its way through the soil and become a stem As this stem generally forms fibrous roots of its own above the point of junction with the parent root, it may be slip. ped off and planted like a rooted cutting. Its supply of nourishment will be diminished when separated from the parent stem, and its head, therefore, should be cut in to diminish evaporation. It is well, when the parent plant is strong, to take up a part of the horizontal root and plant with the sucker attached.

Suckers of another kind spring from the collar of the old plant, and are slipped off with any fibrous roots they may have attached. The great objection to planting out suckers is, that plants grown from them have a much greater tendency to throw out suckers, and thereby become exceeàingly annoying in gardens, by encroaching on other plants, than if propagated by other methods. Raspberries, 
lilacs, roses, snowballs, and many other plants and shrubs are readily propagated by suckers. Suckers should never be used of plants that may be propagated by other modes.

Offsets are formed on bulbs only, being young bulbs attached to the sides of the old ones, and merely require breaking off and planting in a light, rich soil. Runners are thrown out by the strawberry, \&c. They spring from the crown or collar of the plant, and throw out roots at their joints, which may be cut off from the parent plant and set out in good soil, to make new plants.

Layers are branches bent into the earth, and half cut through near the bend, the free portion of the wound be-

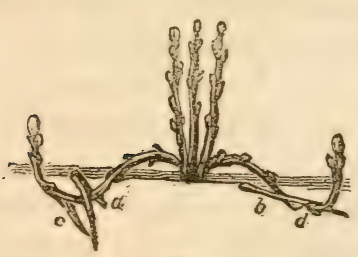

I.AYERQ. ing called a tongue $(a)$. This is kept open by a bit of twig, or piece of crock. 'They are in fact cuttings only partially separated from parent plants. The incision is made through the bark at the base of a bud. The object of the gardener is to incuce the layer to emit roots into the earth at the tongue.* With this view, he twists the shoot half round, so as to injure the wood ressels; he heads it back so that only a bud or two appear above ground, and when much watering is required, he places a handful of silver sand around the tongued part, then pressing the earth down with his foot, so as to secure the layer, he leaves it without further care. The intention of both tongueing and twisting is to prerent the return of the sap from the layer into the main stern, while a small portion is allowed to rise out of the latter into the former. The effect of this opera- 
tion is to compel the returning sap to organize itself externally as roots, instead of passing downwards below the bark as wood; the bending back is to assist this object, by preventing the expenditure of sap in the completion of leaves. The bud left on the tongue farors the emission of roots, as a tendency in nearly all plants exists to throw out roots at the joints, and the silver sand secures the drainage so necessary to cuttings. When the roots are thrown out naturally wherever a joint touches the earth, as in the verbena, they only require pegging down to make them form new plants. To make them emit roots, the returning sap may be arrested by taking off a ring of bark, or a wire twisted tightly around it pinching the bark, or any other operation that impedes the return of the sap beyond the parts where roots are desired. The best season for layering is before the sap begins to rise in the spring, or from the last of June, during summer on wood of the same season's growth. A good time for roses is after the first bloom is orer. Layered at this time, they wili generally be fit to take up the ensuing winter, but most plants require twelve months, and some two years, before they will root. In nurseries the ground is prepared around each stool by digging and manuring, and the branches laid down neatly, so as to form a radiated circle round the stool, with the ends rising all around the circle about the same height. Where it is difficult to get the shoot to be layered down to the soil, a portion of the soil may be raised to the plant as the Chinese gardeners practice in a pot, the earth in which should be kept steadily moist.

Cultings.-A cutting is a part of a plant capalle of emitting roots, and becoming an individual similar to its parent. To effect this, a suitable temperature and degree of moisture are required. Cuttings in general may be taken from stem, branch, or root. Cuttings of the stems 
and branches differ from layers, in being removed without root, and they generally require shading, which layers do not, and occasionally bottom heat, to make them throw out roots. The branches most suitable for cuttings are those which grow nearest to the ground, especially those which recline upon it, as they have a greater tendency to throw out roots. The time for making cuttings of hardy plants is in the autumn, and through the early winter months, as the frost seldom throws them out with us. Rose cuttings put out the last of October will be ready,
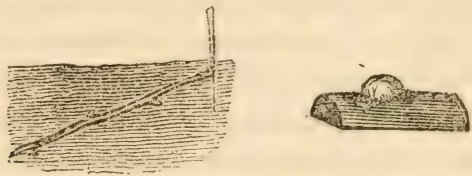

COTTING.

with a little care, to be put out in place early in spring, having rooted perfectly during the winter. If put in a hot bed, the plants will have increased in size materially, growing all winter. A good time for roses is also directly after they have made their spring flowering, and are beginning to grow. At this time some roses will be upon the parent plants, and you are sure of getting the desired rarieties. With shading: they grow nearly as well as those put out in winter. It is from the joints only that roots can be expected to grow; hence, in making cuttings, the shoot is divided just below a joint, and it is considered best to choose a joint between the young wood and that of the previous season. The cut should be quite smooth, for if the shoot be bruised, the returning sap will not bo able to reach the joint in sufficient quantity to effect the desired end. Some plants, like the willow, currant, and vines, are very easy to strike from cuttings, and will throw out roots not only from the joints, but from every part of the stem, and it is not so needful to cut these off 
at a joint, but they succeed best when properly prepared.

The cutting being taken off just below the joint perfectly smooth, most of the leares should be cut off close to the stem with a sharp knife, and a hole being made in the soil the cutting should be put in and the earth closely pressed to its extremity or it will never strike root. The part which is to send out roots must be firmly fixed in the soil in the case of seeds, transplanted trees, and layers, and this necessity exists with equal or greater force in regard to cuttings. When cuttings are struck in a pot they will more readily strike if they rest against the side or bottom of the pot. Cuttings may be short, containing only one bud, when desired to be extremely multiplied, in which case they should be planted horizontally in moist sand near the surface and watered frequently and kept under glass. This is also a good way to plant euttings of greater length. They may be planted obliquely with but a bud or two above the surface, as is usual with grapes or inserted perpendicularly as already directed. A new mode is to insert both ends of the cutting in the soil, bending the cutting like a bow so that the bud in the centre of the shoot may just appear above the soil. Cuttings of plants that strike very readily may be struck in the open soil without any covering. When struck in pots, it is customary to fill the pots half full with silver sand or fine charcoal, to prevent the stalk of the cutting from having too much moisture around it at the surface. Some plants liable to be injured by moisture are struck entirely in sand, as heaths, \&ce, but most euttings do best with the lower end in earth and with sand only one or two inches deep at the top of the pot to keep the stem dry and prerent it from rotting. The cutting when prepared should be buried to the second or third joint, and two or three 
joints with a few leaves should be left above the soil. A few leaves to elaborate the sap are an adrantage, but only one or two, or the evaporation will be too great. Cuttings of delicate plants require eovering with a bell glass pressed closely to the earth to prevent evaporation and keep a regular degree of moisture about the plants, but some cuttings thus treated damp off and require the glass to be taken off and wiped daily. They should of course, be planted in a shady situation and as long as they look fresh they are doing well. Cuttings are often set in the soil of a hot bed or in pots sunk therein, to induce them to take root. Cuttings of succulent plants, as the cacti require to be dried for some time after they are made. The principal points in making cuttings to be attended to, are to cut off the shoot at a joint without harming the stem; to select shoots with well matured buds; to fix the end which is to send out roots firmly in the soil; to keep up an equable degree of heat and moisture; to cut off part of the leaves and shade the whole to prevent evaporation without excluding light, of which a portion is needed to stimulate the cutting into growth; to keep the soil moist but not too damp; and it is well to transplant them into small pots, supplied with water regularly and moderately as soon as they begin to grow. Cuttings of slow-growing plants are those most liable to fail.

Sllips are cuttings made from the shoots which spring from the root and collar of the plant or little branches slipped off with a portion of the root and stem attached, and need no preparation except cutting of the portion of bark smooth and close to the shoot. They are treated like cuttings. Nearly all our fruit trees in this climate suceed extremely well, propagated from cuttings. They strike as readily as roses. 'The most successful place for striking cuttings is in the sandy bottom soil by the side of our 
small streams. The soil is often just what is required by cuttings, and the supply of moisture rery equal, so that camellias, cape jasmines and many plants rather difficult to strike, take very readily in such a situation.

Budding is the art of making a bud unite to the stem or branch of another tree independently of its parent. It is a cutting with a single eye inserted in another tree called a stock, instead of in the ground. Budding may take place at any time after the buds of the new wood are sufficiently matured. These must be perfectly developed, which is seldom the case, until the shoot has temporarily ceased to lengthen which is indicated by the perfect formation of the terminal bud. If the buds are desired very early their maturity may be hastened by pinching the tops of the shoots. Buds in this climate are inserted at any time when the bark will rise from June to October. Those put in early will make a fine growth before autumn in favorable seasons. A very necessary condition to successful budding is that the bark rise freely from the stock and this "must be in a thrifty, growing state, as when pushing into new growth a day or two after a fine rain. If the weather is too cold or the soil too dry, the bark will not rise. Such trees as makes their growth mostly early in the season, must be budded before they cease to grow. The young shoots when in a proper state, are cut below the lowest plump bud. If to be budded immediately, all the leaf is cut off, except a very small portion where it joins the stem which with the leaf stem is left for conrenience of inserting, and in order to attract the sap into the buds. If the buds are to be preserved any time, the whole leaf with half of the leaf stem is remored to prevent eraporation. If this is done as soon as they are cut, they may be preserved several days in a tin box, close covered and kept cool, if the buds are wrapped in a cloth slightly 
dampened, when put in the box. In general the buds take much more kindly when a bit of the leaf is left on at the insertion.

The strings used for tying are taken from bass-mats, which should be wet until perfectly pliable, before use. Better strings are made of white woollen yarn, as they are more elastic, and the color reflects the heat. The pruning and budding knives are the only implements required for the operation. 'The condition of the buddingknife is of importance to success. It should be made thin, and the edge kept perfectly smooth and keen. A figure of it is given in the list of instruments.

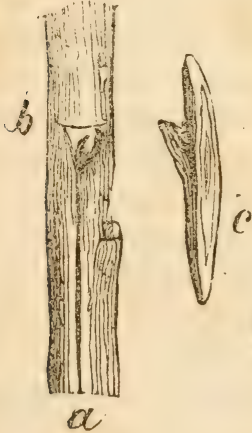

a Longitudinal incision.

$b$ Transverse incision.

c Prepared bud.

a Bud inserted and bred.

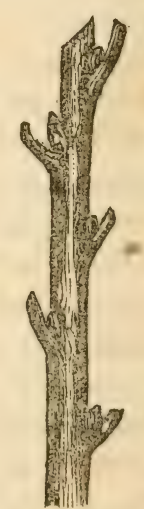

Srick of BUDs.

Having the implements, stocks, and buds in the proper condition, take the shoot in the left hand, and the buddingknife in the right. Insert the edge of the knife in the shoot, half an inch above the bud to be taken off. The bud is taken off with a drawing cut, parallel with the shoot, 
removing the bark and the bud attached, with a slight portion of the wood beneath the bud, half an inch above, and three-fourths of an inch below. The English remove this slight portion of the wood, taking care not to injure the root of the bud; but it does not succeed so well in this climate as if a small portion of wood be left directly under the bud. Sclect, then, a small portion of the stock free from branches, and make two cuts through the bark, one across the end of the other, in the shape of a $T$, as in the figure. Then raise the bark on the two edges of the perpendicular eut with the smooth ivory haft of the buddingknife; insert the bud gently beneath the parts raised; cut off the top of the bark attached to the bud square, that it may fit the cut across the stock; then wind the bass pretty tightly about the stock; cover every part of the incision, except the bud and leaf-stalk attached, which should remain uncovered. Do not tie it so tightly as to cut into the bark, but so as to exert upon it a moderate pressure. The bud should always be put in the north side of the stock, when practicable, and when not, a little paper cap may be tied to the stock projecting over the bud, so as to admit the light, but exclude the direct rays of the sun. The success of the operation depends on its being performed rapidly, and with fresh, healthy buds; clean, smooth cuts; the bark rising cleanly and freely from the wood; the exact fit of the bud to the incision, and close, secure tying, to exclude the air and water. If the operation is performed in moist weather, and the bark of the bud be joined closely to the wood of the stock, success is almost certain. If the stocks are in a proper state, the upper edges only of the slit need be raised with the haft, and the bud being gently pushed to its place, will raise the bark smoothly before it, and be more firm than if the bark had been entirely raised with the haft. 
This is an opcration requiring much exactness, and the point where a beginner will most likely fail, is in the proper removal of the bud. As soon as the bud begins to grow, the ligature may be loosened, and should be entirely removed when it begins to cut into the bark. 'Two or three days after budding, the stock may be shortened to within ten or twelve inches of the bud, and all shoots must be rubbed off as they appear, except the inserted bud. When this has grown three or four inches, the stock is cut off again near the budded shoot. In September budding, this is delayed until spring. Budding is the easiest method of propagating apples, pears, and most other fruit-trees. In the case of peaches it is almost universally applied, and also with those roses that will not succeed readily from cuttings. Budding and grafting can be performed only upon plants of the same, or nearly related species. Thus a peach can be budded on a plum, as they are both stone fruits, and belong to the same natural group of plants, but no art could make the peach flourish on the apple or pear, as a stock.

Grafting.-This differs from budding in its being the transfer of a shnot, with several buds upon it, from one tree to another, instead of merely employing a single bud. It is performed by bringing portions of two growing shoots together, so that the liber ur soft wood of the two may unite together. The shoot to be transferred is called the scion, and the tree which is to receive it is called the stock. The stocks are of all ages and sizes, but they must be sound and healthy. The scions employed are generally shoots of the preceding year's growth, which may be cut at any time after the leaves fall, and may be buried in a dry soil, with the upper extremities slightly projecting on the north of a wall. Those of healthy, well-ripened, 
close-jointed wood, should always be cnosen. Where scions are to be sent to a distance, those of rather large size and close joints should be selected, enveloped in a little thin paper slightly dampened, and the whole covered tightly with oiled silk. In this way, they will go a thousand miles in perfect safety. The but and extremities of scions should both be rejected. The tools required are, a grafting-knife, saw, and chisel ; but, for whip-grafting, the knife only is employed. Two kinds should be used, one to prune and pare the stock, and the other to prepare the graft.

Grafting Wrax.-A composition of very good quality is made of four parts rosin, two of beeswax, and one of tallow. Melt it all together, turn it into cold water, and work and pull it thoroughly until it turns whitish; just as children do in making molasses candy. The stiffness of the wax is increased or diminished by employing less or more of tallow. In cold weather keep the composition in warm water, and in warm, in cold water; and, in putting it on, the hands must be slightly greased, to keep it from sticking to them. In applying it, be careful to cover the scion on the sides and cleft in the stock, forming a cap orer the top, and pressed closely and tightly around the graft, so as to cover every crack, and carefully to exclude the air and water. Cloth, saturated in a composition made a little softer by a greater addition of tallow and beeswax, is more convenient than the wax itself. Take any thin, half-worn calico or muslin, tear it into narrow strips, roll them loosely into small balls, and soak them in the hot composition until every pore is flled. When wished for use, it is unwound from the balls, and torn into smaller strips, of the proper length and breadth required by the size of the stock, and winding it two or three times around the 
stock and graft, secures it perfectly. This is the most convenient way of applying wax.

Modes and Time of Grafting.-The modes of grafting most usually practised are whip and cleft grafting, and they are practised on the stem and branches, or the roots of trees. Root-grafting can be performed at any time in this climate, from December to March inclusive, or from the fall of the leaf until the buds begin to open. Stoncfruits of all kinds must be grafted earlier than apples, pears, \&c., as the sap, in the case of stone-fruits, seems to lose all agglutinating properties after its first flow. But the best time for grafting, except in the root, where the scion will be protected by the earth covering it, is while the buds are swelling in the spring. If put in before that time, the alternate freezing and thawing to which they are exposed often destroys the vitality of the graft. February is an excellent time for all stone-fruits; while apples, pears, \&c., may be grafted until they blossom, if the scions are kept perfectly fresh, without growth. Grafting the pear succeeds perfectly well just before the second growth, early in August, if the sap is thrown into the graft, by rubbing off the other shoots as they appear.

Whip, or Splice Grafting-(see figure).-This mode is applicable to all small stocks, and succeeds best where the scion and stock are exactly the same size. Both stock and scion are cut off with a sloping cut about an inch and a half long on each, so as to match precisely, if of the same size; or, if not, at least on one side. $\Lambda$ tongue is then made by slitting the scion upward, and the stock downward, which is raised on each WUIP GRAFT ING.

and fitted into the slit of the other-holding the scion 
firmly in its place, bind it closely with the cloth covered with the composition. It is the neatest, most exexpeditious, and most successful mode of grafting, where the stocks are of the proper size. Stocks, three-fourths of an inch in diameter, or even an inch, may be grafted in this way, but for inch stocks cleft grafting is preferable.

Cleft Grafting is the more common mode. It may be practised on large or small stocks, but for the latter whip-grafting only should be employed. The top of the stock is cut off carefully with a fine saw, and pared smoothly with a sharp knife. The stock is then split with the grafting-knife, and held open with the chisel of the same. A common knife will answer for splitting, and the split may be kept open for insertion with a woodCluert graft.

IxG. en wedge or a large nail of which the point has been ground down to a wedge shape. Sharpen the scion one and a-half inches long, more or less, according to its size and that of the split in the stock, cutting the lower part into a smooth wedge. The exterior side of the scion when sharpened should be slightly thicker than the other, that it may be sure to make a close fit there. Let the scion have two or more buds, of which one should be on the werlge and inserted just below the top of the stock. This often grows when the others fail. The main point is that the inside bark of the scion and that of the stock should exactly correspond at least in one place. To effect this, it is usual to set the scion so that its extremity falls a little without the line made by the continuation of the stock on the side in which it is inserted. One or two scions are set in the stock according to its size; the wedge is then withdrawn, and the whole carefully 
covered with the composition so as to exclude all air and moisture.

Root Grafiing.-Both these modes are successfully applied in root grafting. The best stocks for the purpose are seedling's which are cut off at the collar and grafts inserted in one or the other of these modes, according to the size of the stock. If such stocks cannot be got, roots of thrifty trees may be employed, but are more apt to produce diseased trees. This can be performed at any leisure time during the winter, and they should be set out at once and covered about an inch above the point of junction with soil. Many do not apply any composition in root grafting, and just cover the wound with soil ; but the loss is more than enough to render the use of the wax advisable. Clay instead of wax is used in all kinds of grafting, but the wax is much the best.

In grafting, as in budding, always have sharp instruments; make the cuts clean and smooth; bring the inner bark of stock and scion in close contact, by a permanent pressure of the stock upon its scion; the top of the scion should be cut off next to a bud, and have a bud just beneath the shoulder where it unites with the stock; every portion of the wound should be perfectly covered with the composition, and the stock and scion must correspond, not only in their nature, but in their habits of growth.

In-arching or Grafting by approach.-This mode is practised with Camellias and Magnolias. A branch is bent and partly cut through, and the heel, thus formed is slipped into a slit made downward in the stock to receive it; the parts are then made to meet as exactly as possible, and are bound with bass strings, and covered with grafting clay, or with the composition. In five or six months the union is complete, and the in-arched plant may be separated from its parent, which is done with a sharp knife so as to 
leave a clean cut. The head of the stock, if not removed before, is then cut awar, and the plant is ready for removal.

The advantages of grafing and budding are the rapidity with which a valuable kind which will not grow from cuttings may be propagated: trees of worthless fruit may be changed into more valuable varieties, seedlings can be brought into early bearing, foreign tender fruits may be rendered hardier on hardy native stocks, a kind of fruit may be grown in a soil not congenial to it, as the pear by grafting on the quince. Sereral varieties of fruit may be grown upon the same tree; and, finally, by grafting on dwarf-growing stocks the trees may be so dwarfed as to afford many varieties ripening in succession within the limits of a small garden.

Pruning.-This important operation is generally performed more at random than any other in gardening. Not even a twig should be removed from a tree without some definite object This is a work above all others requiring care, knowledge, and judgment, and should never be left to ignorant operators. Either prune your trees and plants yourself, or stand by and direct the manner in which it is to be done. "The time to prune," says an experienced cultivator, "is when your knife is sharp." Pruning may take place at any time, but is most conveniently performed while the leaves are off. Our frosts are not so severe as to often injure the terminal bud. A good time for the peach is when the buds begin to swell. Grapes may be pruned any time during the winter months. If delayed later they are apt to bleed excessively. Besides the general winter pruning, shoots may be removed at any time, if the tree seem to be throwing its strength in a wrong direction. This is better accomplished by disbudding, that is, removing those buds which would produce unnecessary 
shoots, or pinching the extremities of those shoots which are making too much wood.

The implements required in pruning are the common pruning knife, a small saw with very fine teeth, and a pair of pruning-shears with a sliding joint to make a draw cut, in order to divide the branch with a clean, smooth cut, and not to bruise it on the side next the plant.

When a branch is pruned it should be generally cut as near a bud as may be without injury to the bud, or to speak more definitely, not more in length than the branch is thick should be left beyond the bud. The cut should slope downward from the bud, to prevent the water from lodging in the angle, and that the sun and air may excite the bark to cover the wound.

If a long piece of branch or snag be left beyond the bud, it withers and decays, seriously injuring, not only the branch to which it is attached, but the general health of the tree.

The great art is to make a clean smooth cut, so as to leave the bark in a healthy state to cover the wound, and to prune so near a bud as to leave no dead wood. Hence, if the branch be removed with the saw, the cut must be smoothed over with the knife. In cutting off large branches the wound should be covered with grafting wax, or brushed over with Mr. Downing's preparation of shellac dissolved in alcohol, in order to exclude the air. Pruning is most commonly intended either to improve the form of the tree by directing the growth from one part to another, to renew the growth of stunted trees, to induce or diminish fruitfulness, to remove diseased or decaying branches, and in cases of transplanting to proportion the head to the roots.

In pruning to improve the furm of the tree, as in pleasure grounds, the object is to preserve its natural shape, so that it may be an agreeable object on the lawn, or when com- 
bined with others in a group. Lawn trees should never have the stems trimmed up to bare poles, but the branches should proceed from near the ground, so that when covered. with foliage they will nearly sweep the ground, and be one mass of green from the base to the top. So in all kinds of fruit-trees the branches should be allowed to proceed from the trunk within a foot of the ground. Such trunks are screened from our burning sun, and are much more healthy and fruitful than those with naked stems five or six feet high. Every tree growing naturally has its trunk sheltered from the sun. If it grow in the open ground, this is accomplished by its own branches, while in the forest all the trunks are sheltered by the canopy of foliage above. If one part of the tree is disposed to outgrow another, and thus destroy the balance, it may be shortened in winter, and the shoots pinched off the next summer, until the sap is thrown in the right direction into weaker branches that were left entire, and the balance is restored. When it is desired that new shoots of a branch should take an upright direction, prune to an inside bud. If you wish an open spreading top, prune to an outside bud of the branch. To make a stem grow straighter in cutting back young trees, choose the leader on opposite sides each year, and it will keep a straight line.

When a tree has stopped growing, remaining stationary, it often happens that if the tree is cut back in winter to a few buds, the whole force of the sap being made to act on these few buds, vigorous young shoots will be produced, and these sending down new woody matter to the stem, new roots are formed, and the whole tree is renewed.

Pruning to reduce or diminish fruitfulness.-Everything that is favorable to rapid, vigorous growth is generally unfavorable to the immediate production of fruit. Hence, pruning to induce fruitfulness is performed after 
vegetation has commenced. If a tree be severely pruned immediately after its leaves have put forth, it is so checked as to be unable to make a vigorous growth the same season, and the circulation of the sap is impeded, and the young shoots that would have made wood branches, had the growth been unchecked, will become fruit spurs. Pinching the extremities is however the usual mode of pruning, to induce fruitfulness. The same result is produced by pruning the roots, which also lessens the dimension of the trees.

Pruning at transplanting.-At this time all bruised and broken roots and branches should be removed. When trees are taken from the ground, a greater or less portion of the roots are destroyed or injured, and the natural balance between the root and top is destroyed, and the tree in this condition will either die or make a slow growth. In England, the climate is so moist, that trees may be removed and leave nearly all the branches as they were; but under the hot suns and strong winds of this climate a vigorous shortening in is requisite. Trees must be pruned much more closely here at the period of transplanting than even at the north. It matters very little how closely you prume the top of the trees; only have good roots and a single season's growth will restore the balance. Just after transplanting some of my own trees, which I had pruned sufficiently, as I thought, a cow got in while the fence was repairing, and browsed ofi sereral, eating all the young shoots. The wounds were carefully cut over immediately down to a bud, and the loosened roots fixed firmly in the soil. The trees, the ensuing summer made a better average growth than those which were not so closely shortened. Do not leave more than one or two buds to a branch of the previous year's growth if the tree is of much size at the time of transplanting. 
The general principles of pruning are consisely expressed by M. Dubreuil, as follows:

1. The vigor of a tree subjected to pruning, depends in a great measure on the equal distribution of sap in all its branches. That this equal distribution may take place-

Prune the branches of the most vigorous parts very short, and those of the weak parts long. The feeble parts being pruned long, present a great number of buds and a large surface of leaves, which attract the sap, and produce vigorous growth; while the rigorous parts being pruned short and the surface of leaves diminished, growth in those parts is also diminished.

Leave a large quantity of fruit on the strong part and remore the whole or the greater part from the feeble. All the sap which arrires in the strong part will be appropriated by the fruit, and the wood there will make little growth, while the feeble parts being deprived of fruit, the sap will be appropriated by the growing parts and they will increase in size and strength.

Bend the strong parls and lieep the weak erect. The more erect the branches are the greater will be the flow of sap and consequent growth; lience, the balance may be restored by bending down those disposed to make too much growth.

Remove from the rigorous parts the superfluous shoots as early in the season as possible, and from the feeble parts as late as possible. The fewer the young shoots are in number the fewer the leaves, and the less the sap is attracted there; but leaving these standing on the feeble parts, these leaves attract the sap and induce vigorous growth. Pinch early the soft extremities of the shoots on the rigorous parts, and as late as possible on the feeble parts, excepting always any shoots which may be too vigorous for their position. By this practice the flow of sap to that 
point is checked and turned to the growing points that have not been pinched.

In training, lay in the strong shoots on the trellis early and leave the feeble parts loose as long as possible. Laying in the strong shoots obstructs in them the circulation and favors the weak parts which are at liberty. Giving also the feeble parts.the benefit of the light in training, and confining the strong parts more in the shade, restores a balance.

2. The sap acts with greater force and produces more vigorous growth on a brinch short pruned than on one long pruned. The whole sap of the branch acting on two buds must produce greater development of wood on them than if divided among fifteen or twenty. Hence, to produce wood branches, we prune short, or if fruit branches we prune long, because slender and feeble shoots are more disposed to fruit. Hence, also trees that are enfeebled by over-bearing should for a year or two be pruned short.

The sap tending always to the extremities of the shools causes the terminal bud to push with greater vigor than the laterals. -When we wish a prolongation of a stem, we should prune to a vigorous wood bud, and leave no production that can interfere with the action of the sap on it.

4. The more the sap is obstructed in its circulation, the more likely it will be to produce fruit buds. Sap circulating slowly is subjected to a more complete elaboration in the tissues of the tree, and becomes better adapted to form fruit buds. If we wish a branch to bear fruit, we can obstruct the circulation of the sap by bending or making incisions around the branch, or if wished to change a fruit into a wood-branch, raise it into a vertical position and prune it to two or three buds on which we concentrate the action of the sap and induce them to grow vigorously. 
5. The leares serve to prepare the sap absorbed by the roots for the nourishment of the tree und aid in the formation of buds on the shoots. All trees therefore deprived of their leaves, are liable to perish. Hence, the leaves should never be removed from a tree under the pretext of aiding the growth, or ripening the fruit, as deprived of leaves trees cannot grow, neither can their fruit mature.

6. When the buds of any shoot or branch do not derelop before the age of two years, they can be forced into activity only by a very close pruning and in some cases, as the peach, even this will fail. Hence the main branches should be trimmed so as to secure a development of their successive sections, and so shortened in as not to allow the production of long naked stems, leaving the interior of the tree bare of shoots, and consequently unproductive. In order to induce trees to grow in any particular form it is not so much labor as continued attention that is required. A thorough pruning once a year will not produce the desired effect, but a little attention two or three times a week during the growing season, will be sufficient to examine every shoot in an acre of garden trees, and the eye is very soon trained so as to detect at a glance tne shoots that require attention.

For fuller information on this subject, and indeed upon every one connected with the management of trees, the very best manual is Barry's Fruit Garden, from which a portion of the above is condensed.

Training.-The principal objects of training are to render plants more productive of fruits and flowers than if left to grow voluntary, also to form screens of various running plants to keep any unsightly object from view. The points to be attended. to, are to entirely cover the 
wall or trellis, bending the branches backwards and forwards so as to form numerous deposits of returning sap, and the full exposure of the fruit-bearing branches to the sun and air. The long shoots are shortened to make them throw out side branches, with which the trellis is covered, without permitting them to cross each other. Training flowers should be regulated by a knowledge of their habits of growth. It consists principally in checking overluxuriance of growth and tying them to stakes or frames. Special directions for training the grape and pear, \&c., will be given hereafter.

Transplantrac.-In transplanting the main points to be regarded are, care in taking up the plant so as to avoid injuring, the spongeoles of the roots; planting firmly, so as to enable the plant to take a secure hold of the soil; reducing the top in order to prevent evaporation, and to restore the balance between it and the root; shading to prevent the evaporation from the leaves being greater than the plant can support, and watering that it may be abundantly supplied with food in its new abode, and last by performing the operation in moist weather, and with as little delay as possible.

The first thing is to avoid injury to the roots; a little care here will often save a year's growth in a tree. The roots are of two kinds, the main roots which support the plant in the soil, and the small fibrous roots that supply it with nourishment. The fibres terminate in small pores of great delicacy which act as little sponges in imbibing moisture for the use of the plant. These spongeoles supply the plant with food, and if injured or broken off the plant must supply itself with others, or perish for want of nourishment. These fibrous roots are the ones most likely to be destroyed or injured by transplanting, and 
if so, the power of expansion and contraction possessed by the fibres is either entirely lost or the circulation is weakly and imperfectly carried on through a diseased organ. When a plant therefore is transplanted, the roots must be carefully examined and all the injured roots should be cut off before it is re-set, in order to force the plant to throw out new fibres.

With deciduous plants, especially trees and shrubs, it is best to transplant when the leaves have fallen, that they may not suffer from the effects of evaporation. November and December are the best times for transplanting all hardy plants, as even evergreens at that period require less moisture and the branches are torpid, while the roots continue active, and fresh ones are formed during the winter to take the place of those injured by transplanting. Half-hardy and tender plants should not be taken up until the danger of heavy frost has passed, for when just removed they are much more susceptible to injury during severe weather.

Shading is necessary in summer transplanting, if the plant retains its leaves, unless in damp weather. This is to diminish the evaporation, and the removal of a large portion of its leaves is also advisable for the same purpose.

Watering is quite as obviously necessary in order to supply the spongeoles with an 'abundance of food, that the increased quantity imbibed by each may, in some degree, supply their diminished number. A single copious watering is better than more.

As a general rule in transplanting, neverbury the collar of the root. Some exceptions exist, as cabbages, balsams, and some other annuals, which will throw out roots above the collar, and in pears on the quince, which must be set above the place where grafted. In transplanting trees, 
the hole should be made large enough to receive the roots at full length. If a ball of earth ean be retained so much the better, as it will both protect the roots and steady the tree. The roots should be as little exposed as possible; they should rest upon a bed of fine soil, and be covered with the same material. Two persons are needed in this operation, one to hold the tree, very gently shaking it while the other is sprinkling with his spade the fine earth about the roots. Care should be taken to have the roots set firmly in the ground, and to let the earth penetrate and fill all their insterstices. When it is to be fixed with water, after a little earth is thrown over the roots, water is applied by pouring it from the open spout of a watering pot, held as high as a man can reach; more earth is then thrown in and the water again applied. This sets the tree firm without staking or treading the earth, as usually done. Others spread the roots carefully and fill in as above, but make the earth firm by treading the soil closely about the roots as soon as they are sufficiently covered. If the roots are made firm either with water or treading, and a proper proportion of the top taken off, the tree will hardly require staking. Formerly in transplanting trees, they were frequently reduced to bare poles, but now the tendency is to leave on too much top, especially with those who derive their ideas from standard English authors. In their moist climate, but very little of the top requires removal, but with us the evaporation is so great that a pretty severe pruning is required to insure success. Besides, if the tree is thus pruned, you have its subsequent growth under control, and can train it in any shape you like. Where trees have been long out of the ground, it is well to cover them entirely with earth a few days before replanting. This will often restore freshness after they begin to shrivel. Prune them very closely, taking off all 
dead roots, and then re-set them, and they will often succeed when apparently almost hopelessly dead.

In transplanting herbaceous plants, as annuals, an evening, or a damp cloudy day, or just before a shower, is the proper time for the operation. The earth should be first well dug to afford a moist situation in which the delicate fibres may quickly establish themselves. Do not transplant immediately after a heavy rain, as the soil, if moved while wet, will form a crust about the plant. This operation should always be performed in the case of choice young plants with the trowel, removing with them a little ball of earth, and the plant will hardly show its change of situation by any check in its growth. Larger plants may be removed in the same way with the spade.

Plants that are not removed with a ball, are benefited by grouting. Mix up a quantity of rich loam in water to a semi-fluid state, in which insert the roots. Plants which are readily transplanted, as the cabbage, tomato, \&c., may have a hole made with a dibble, and the plant inserted, when the dibble is again inserted near the stem, and the earth pushed up close to the root. Tap-rooted plants are transplanted with great difficulty, and as they cannot be taken up with a ball, should always be grouted before they are replanted. Sweet potato slips, cabbage plants, \&c., may be set out even in dry weather, in freshly moved soil, by making a hole in the earth, setting the plants erect therein, and washing in the earth with water (from the spout of a water-pot) about the roots, and covering them at the surface with dry soil to retain the moisture and keep the soil from baking. This should be done in the evening.

Mulching.-Mulching is placing mulch or moist litter, of various kinds, upon the surface of the soil over the 
roots of newly-planted trees and shrubs. A little earth should be thrown on the mulch, to keep it in its place, and is more neat than exposing it on the surface. Mulching prevents moisture from evaporating, and it also prevents frost from penetrating to the roots. Mulching should also be applied to those herbaceous plants that are impatient of heat about the roots. Strawberries thinly mulched, the crown being uncovered, are much more productive, and continue longer in bearing. Irish potatoes produce more abundantly, and are of better quality. English peas are thus kept much longer in bearing, and rhubarb and other plants, requiring a cool soil, cau be more readily raised. Fruit trees, by having their roots mulched, are kept in better health and vigor. Mulching not only wards off drought, but, in this way, by keeping the ground moist, and by the decay of the mulching substance, a good deal of food is conveyed to the plants. Some authors, indeed, think also that ground will become continually richer by being shaded. A supply of small, fibrous roots are thrown out at the surface by mulched plants, and thus is prevented the formation of tap-roots, which are inimical to the production of blossom-buds. But the great benefit of mulching is that a steady permanency of moisture is retained, in spite of adverse circumstances, and without stagnation. In general, the coat of litter for mulching must be thin, that the rain may not be prevented from reaching the roots of plants.

WATERING.-Watering is a very essential branch of culture. Seed cannot regetate, and plants cannot grow, without water. All the sulsstances which the plant derives from the soil, as food, enter into its circulation dissolved in water; and even the spongeoles themselves, unless kept moist, lose their power of absorption. 
J. J. Thomas remarks: "From repeated experiments, we are induced to draw the conclusion that, next to manure, nothing is more important in regetable growth, in many cases, than irrigation. Practical gardeners, in countries more moist than our own, regard it as indispensable, and a large share of their success depends upon copious watering."

Some interesting cases which have recently occurred may be worth stating. Two rows of raspberries stand on ground in every respect alike; but one receives the drip of the wood-house, and the other does not. The watered row is fully four times as large as the other. Again, the berries on the bushes of the Fastolf and Franconia raspberries were at least twice as large when the soil was kept well moistened as afterward, when allowed to become dry. A repetition of watering again doubled the size. Again, a near neighbor, who cultivates strawberries for market, and who uses a water-cart for irrigating the rows, raised at the rate of 120 bushels per acre of good fruit on common soil by this means, and he noticed, where the cart was left standing orer night, so that the water dripped gradually from it for some hours upon a portion of the plants, the fruit had grown to double the size the rest in twenty-four hours. In watering, several points are to be attended to. One is (except while or after transplanting), nerer saturate the soil. Frequent sprinklings are more beneficial. The water should be of the temperature of the atmosphere, or it will chill the ground and the plants. Water that has stood in the sun all day is best for watering plants in the open air, and in a green-house it should be kept standing until the chill is remored. Do not pour water down close to the stem and collar of the plant, as it will be likely to injure and rot that vital part; apply it 
rather to the extremities of the roots, more or less near to the stem, according to the size and nature of the plant.

The quantily of water depends upon the nature of the plant and its stage of growth. In spring, while in a growing state, or while the plant is in flower, or the fruit is swelling, the plant requires an abundance of water. But when the fruit is ripening, and in winter, when the plant is at rest, very little is required, and much is injurious. Water is necessary to make seeds germinate; but much is very injurious to plants just coming up, as it unsettles their roots, and even washes them away. After the second pair of leaves have opened, water may be given sparingly. As it begins to grow more vigorously, more will be required. Plants with large, broad leaves, like tobacco, require more water than those with small pinnate leaves like the acacia. Plants, also, in a strong light, more than those growing in the shade.

The best time for watering plants, generally, is the evening. This gives them all night to refresh themselves.

It does no good to water in the heat of the day, as the heated atmosphere drinks up the moisture before the plant can imbibe it; but, if plants are watered in the evening, they can drink their fill in the cool of the night. When small seeds are sown, they should be sprinkled, in dry weather, with water from a fine rosed water-pot; and, if in small patches, may be shaded by a mat until they come up.

If the ground has become very dry and hard, it should be loosened before the water is applied, or it will not penetrate, to be of any service to the plant. Water, early in spring and in autumn, may be given in the morning, or it might chill the plants, if the night should be cold; so in the green-house, during winter, water should be given in the morning. Watering the leaves when the sun shines 
will make them blister and become covered with brown spots, wherever the water touches. If watering a plant has been once commenced, keep on until the necessity ceases, or more injury than good will result. The use of the hoe should always follow the water-pot, as soon as the ground gets dry.

The best water to use in the garden is rain-water caught in open cisterns. It abounds in ammonia and fertilizing gases. If spring or well-water must be used, a very little guano, say one pound (or two pounds of fowl-manure) to twenty gallons of water, will give it proper fertilizing properties. Let it remain covered in the sun one or two days before use.

Cultivation with the Hoe.-If the ground be not often moved, it becomes so hard that the roots cannot penetrat it to get their proper food. The rains flow off the surface, without sinking into and moistening the soil, and the beneficial influence of the atmosphere is excluded. A soil well hoed has a new surface continually ready to absorb the fertilizing gases of the atmosphere, and the manures applied are more thoroughly intermingled.

"If I had to preach a sermon on horticulture," says Downing, "I should take this for my text: Stir the soil." The surface of the soil cannot be too frequently stirred. As soon as the plants are well above ground, they should be thinned out so as not to interfere with each other's growth; say to an inch in the drills. At the same time, the soil may be loosened a little about them, so as to break any crust that may have formed, withont injury to the young plants, and the weeds may be removed.

A little later, stir the soil more deeply with a narrow hoe, taking care not to cover the young plants. Every weed should be cut down or pulled up, no matter how 
small. As the plants grow larger, the hoe may be used more fearlessly, and thinning should also take place, from time to time, as the danger diminishes of their being destroyed by insects. It is not enough to keep the weeds down; digging deeply among the plants admits the atmosphere, with it fertilizing gases, and actually manures the young plants. Many persons do not like to use the hoe in dry weather, for fear the plants will suffer for want of moisture. But if the earth be kept loose, and in fine tilth, the air that enters into its pores will leave a precious deposit of moisture in the soil. Notice a plat of fresh dug ground, some dewy morning during a drought, how moist is the surface, and see how hard and dry is the unstirred plot near by! The air has watered the fresh dug soil more effectually than you could do; and moisture, too, comes up by capillary attraction from the subsoil, and abundantly, too, if the ground was deeply trenched. "A man will raise more moisture," says Cobbett, "with the hoe and spade in a day, than he can pour on the earth out of a watering-pot in a month." The deposit of moisture on the outside of a pitcher of cold water every one has noticed. As the air in contact with the cold surface of the pitcher is robbed of its moisture, which is condensed upon the surface of the pitcher, so the fresh stirred earth condenses upon its surface the moisture of the air, and conveys it to the roots of the thirsty plants. If the ground be suffered to become close and compact, the cool surface exposed to the air for the reception of moisture is smaller, and what is deposited does not enter into the earth far enough to be appropriated; but if the soil be loose and porous, the air enters more deeply, and deposits its moisture beneath the surface. Almost any soil in which a seed may be made to germinate will, by continual hoeing, pro- 
duce a crop. Do not be afraid of cutting off the roots of your plants and killing them by digging. In very dry weather you need hoe but one side of your plants the same day. For every fibre you cut off, two fresh ones will start, and the next day or two after you may hoe the other side of the row with safety.

The ground should be hoed deeply; corn, unless it is ploughed between, will produce hardly anything, and the great secret of raising good cabbage is deep digging between them, while the dew is on. "The best protection," says Cobbett, "against frequent droughts is frequent digring:" Above all, cut up every weed that appears. "One year's seeding makes seven years' weeding." The only use of weeds is to make a necessity of tilling the ground more frequently. Weeds will come up in spite of all our care, but much can be done to prevent them. Their seeds are brought in with the manure. On this account guano is preferable to any other application, as it is perfectly clear of them. They are brought in also by the wind, and they are dug up from beneath and start into vegetation at once, though they have been torpid for years. As soon as one appears above the ground, dig it up at once. If they have already gone to seed, mix the salt and lime mixture with them, and their regetating power will be destroyed, and these robbers of the soil converted into valuable fertilizers.

Protection from Frost.-Camellias and many halfhardy plants may be protected by laying straw and litter about the roots, as the sererest frost will penetrate but a few inches. Very few half-hardy plants will be seriously injured if their roots are covered a few inches deep with straw or leaves. Garden pots, empty boxes, barrels, \&c., 
are all useful. If any of these are used, holes should be left in the top that the dampness may not accumulate underneath, which might be more injurious than the frost. Common tumblers are used in protecting small plants, to be raised whenever much moisture accumulates.

Wooden frames covered with oiled paper are very useful in protecting low plants. Vine-shields are also employed for this purpose during the winter months. A very slight covering over the top will protect from frost, even though the sides are exposed, but the top should never be left exposed to perpendicular frost. All tender plants will survive the winter better in a northern exposure, where the changes of atmosphere are more gradual, than if subjected to alternate freezings and thawings suddenly, as they are in warm exposures.

Fruit trees while in blossom or with the young fruit just formed are most easily protected from frost by having a quantity of chips, dried tan, or trash of any description, at hand. If the prospect of frost is pretty certain, small fires are built in various parts of the garden on the windward side, and when burning well are covered with damp trash of various kinds to create a great smoke, these are kept up all night, and the protection from the clouds of warm smoke rising from the garden is quite sufficient to ward off all danger of frost. A large fruit garden may be thus protected at an expense of less than a dollar for fuel and one hand to watch the fires and keep them up all night, and the pleasure and profit of a fine crop of fruit when it is generally cut off is a great remuneration for the small expense incurred.

Number of Plants required to an Acre.-The following table, showing the number of plants required for an acre, is often of great convenience in planting gardens and orchards : 


$\begin{array}{lccc}\begin{array}{c}\text { Distance } \\ \text { apart. }\end{array} & \begin{array}{c}\text { No. of } \\ \text { Plants. }\end{array} & \begin{array}{c}\text { Distance. } \\ \text { apart. }\end{array} & \begin{array}{c}\text { No. of } \\ \text { Plants. }\end{array} \\ 1 \text { foot } & 43,560 & 10 \text { feet } & 435 \\ 1 \frac{1}{2} \text { " } & 19,360 & 11 \text { "6 } & 360 \\ 2 \text { feet } & 10,890 & 12 \text { " } & 302 \\ 2 \frac{1}{2} \text { " } & 6,969 & 13 \text { " } & 257 \\ 3 \text { " } & 4,840 & 14 \text { " } & 222 \\ 3 \frac{1}{2} \text { " } & 3,556 & 15 \text { " } & 193 \\ 4 \text { " } & 2,722 & 16 \text { "6 } & 170 \\ 4 \frac{1}{2} \text { " } & 2,232 & 17 \text { " } & 150 \\ 5 \text { " } & 1,742 & 18 \text { "6 } & 134 \\ 6 \text { " } & 1,210 & 19 \text { "6 } & 122 \\ 7 \text { " } & 889 & 20 \text { "6 } & 108 \\ 8 \text { " } & 680 & 25 \text { "6 } & 69 \\ 9 \text { " } & 537 & 30 \text { "6 } & 49\end{array}$

Destruction of Vermin.-Insects are much more destructive to the vegetable kingdom in warm climates. These minute destroyers attack almost every cultivated plant, of which no portion escapes their ravages. One devours its tender leaf as it issues from the ground, another preys upon the root and the plant perishes; another burrows into the stem, boring it in every direction until it is broken off by the wind. The caterpillar preys upon the leaves when it gets more mature, while the black grub cuts off the young plant just as it is shooting into growth. Some feed upon the flowers, while others devour the matured fruit or seed. But though we cannot entirely check, we can materially diminish their ravages.

During autumn, let the garden be sown with salt at the rate of six or eight bushels per acre and many insects will disappear. Even arsenic has been proposed to be mingled with the manure and incorporated with it in the soil at the rate of some fifty pounds to an ordinary garden, but this is a substance too dangerous. "In the cold freezing weather of winter let the soil be frequently turned over and exposed to frost, the oftener the better. 
"Erect a post in the centre of the garden, on which nail a platform of planks some thirty inehes square, which cover with sand; on this build nightly a fire of fat lightwood for some weeks, from the time that moths, millers, and butterflies begin to infest the garden. Large numbers will fly into the fire and be consumed."*

Hang ip common porter bottles, though wide-mouthed bottles are preferable, during the same season, with a few spoonfuls of sweetened water or molasses and rinegar in them to be renewed every second evening, and hundreds of moths that would have been the parents of a new race of destroyers will be caught. This is the most promising mode of waging war also upon the melon-worm as well as the corn and boll-worm, and many other insects. For filling the bottles, a better preparation still is a pint of water to half a pint of molasses, the water having as much cobalt dissolved in it as it will take up before mixing with the molasses. Put a wineglassful to each bottle and empty once or twice a week.

Mr. Downing mentions an acquaintance who, using the molasses and water only one season, caught and exterminated three bushels of insects in this manner, and preserved his garden almost free from them. Mr. Robinson, of New Haven, caught over a peck in one night. Keep the ground rich and sow healthy seed; cultivate thoroughly, and the crop will soon be beyond their rarages. After the crops are so far advanced that fowls will not do much injury by scratching, keep them in the garden during the summer, and the cabbage caterpillars and many other worms will be exterminated. Birds are valuable assistants in the work of destruction. Toads live almost entirely upon insects, and do no injury to vegetables. Bonfires of brush

* R. B. Southern Cultivator, Nov. 1855. 
just after dark (where light wood is not convenient) will attract and destroy immense numbers of moths and beetles. Rolling the surface smooth when planted, destroys the hiding places of many insects, and renders them less destructive. Crush the beetle, the grub, or the leaf roller under your foot, and you destroy a thousand enemies at once, by preventing reproduction.

When the plants are attacked, various remedies are required.

Try the camphor preparation of R. B. in the Southern Cultivator. Put into a barrel of water a quarter of a pound of camphor, in pieces the size of a hickory nut, fill with water and let it stand a day, and with this water your plants, and fill the barrel for the next watering. The camphor is slowly absorbed, and will last a long time. If the camphor water is too weak, add to a barrel of water a cupful or more of strong lye, and more will dissolve. Add also a pound of cheap cape aloes to a gallon of lye (or water in which a pound of saleratus or potash has been dissolved); add a pint of this to a barrel of water, and use as the camphor water. Camphor and aloes (especially the former) are offensive to most insects.

- Try also sprinkling the plants with ashes, air-slaked lime, charcoal dust impregnated with the odor of oil turpentine, soot, sulphur, or better still, Scotch snuff sifted on the plants, by placing it in a tin cup, with the mouth covered with gauze, and shaking it when inverted over the plants. Try also to drive away the insects.

Watering them and the plants with an infusion of tobacco, or China berries, soapsuds, solutions of guano, or whale oil soap, when the latter can be obtained. Fumigating with sulphur and tobacco is very efficient. But tobacco water is the great remedy. Watering with guano water 
is very satisfactory, as it is repulsive to most insects, and hastens the growth of the plants.

The following are some of the most troublesome of these pests :

Aphides, or plant lice, some species of which peculiar to itself are found on almost every plant. They multiply with astonishing rapidity. They are best destroyed by tobacco juice. Steep the leaves until the solution is of a dark brown color, and mix with an equal quantity of strong soapsuds; dip the affected branch in the liquid, or sprinkle it liberally over the affected parts. Repeat as often as one makes its appearance. The green aphis, which is very injurious to rose bushes and other plants, may be thus destroyed.

The Woolly Aphis is found mostly upon the apple trec. It is a small dark-colored insect, covered with a white woolly substance that conceals its body. Destroy the first one that makes it appearance. Scrape the lark smooth if rough, wash the tree, and fill every crevice with Harris's Composition: Two parts soft-soap and eight of water, thickened with lime to the consistency of thick whitewash, or wash with a solution of two pounds potash to seven quarts of water. If the roots are affected, they must also be washed, and fresh earth put about them. The best application to the roots is strong tobacco-water poured about them after removing the surface soil.

The Scaly Aplis, a bark louse, infests the bark of the apple tree. They are of a dark brown color like the bark. Tobacco-water and soapsuds applied to them the last of May, while they are young, will destroy them.

Ants may be killed by pouring boiling water into their hillocks; or may be caught in the wide-mouthed bottles containing sweetened water, which are general exterminators of moths, insects, and beetles of all kinds. 
The Apple Moth deposits its eggs in the eye of the young fruit into which the gru, when hatched eats its way, causing the fruit to drop prematurely. A similar insect attacks the peach. The only remedy is to allow swine to pick up the fallen fruit, or do it by hand as soon as they fall, and destroy them. Their thin paper-like cocoons may be found in the crevices of the trees in February and March, and should be destroyed.

The Apple-tree Borer is a grub produced by a beetle which deposits its eggs in the bark of the apple and quince near the ground. 'The egg becomes a whitish grub which eats into the tree in all directions, often completely girdling it. Insert a wire into the holes and kill them. A mound of ashes or lime rubbish raised about the base of the trunk in the spring will prevent the beetles from depositing their eggs in the soft bark. 'This should be remored late in summer when the danger is orer and spread for manure. Hot water might be as effectual as in the case of the Peach borer, but it may be injurious to the tree.

The Peach-tree Borer deposits its eggs at the base of the trunk on the soft bark; when hatched they bore their way under the bark, sometimes proceeding upwards along the trunk, at other times downward into the root. Its presence is made known by the effusiou of gum; as it does not penetrate the wood, it is easily traced by its holes under the bark. Haul away the earth from the roots; clean away the gum; cut out and destroy the grub with a knife, or pour sealding water into his haunts from the spout of a tea-kettle, which will kill the grub without injury to the tree. Put a small mound of ashes or slacked lime around the base of the trunk, to be scattered over the ground in the fall, as they are an excellent dressing for the trees. Peach trees should be carefully examined erery autumn and spring. The hot water application is desirable as it 
promotes the health of the tree, almost always throwing the most feeble into vigorous growth.

The Grape-vine Borer attacks grape-vines, except the Scuppernong, in the same way as the peach-tree borer injures peach trees, and the remedies are the same. Both these insects are of the genus Egreria.

The Melcn Worm is noticed under the article, Melon. The most hopeful remedy is to destroy the moths before laying their eggs by the light wood fires, or by catching them in the bottles; and whether this will prove successful or not is to be ascertained.

Caterpillars.-There are many varieties destructive to the foliage of fruit and ornamental trees. One most loathsome of these has caused the beautiful Catalpa to be banished from our pleasure-grounds. The one on the apple tree is the tent caterpillar, of which the moth lays its eggs in large rings on the branches of trees which are hatched the ensuing spring. If any of these clusters of eggs are found at pruning time, cut them off and burn them. If any caterpillars appear in the spring, they may be removed by a round bush fastened to a pole, which is put into the nest, and with a few tums web and all is removed to be crushed by the foot. Some kinds do not seem put to any inconvenience by the application of strong soapsuds, and on these the tobaceo and soap preparation may be applied. They may be brushed off into this liquid. If nothing else will do, hand picking and scalding water must be resorted to.

The Cherry and Pear Slugs are small slimy dark-brown slugs that appear in summer devouring the leaves of the pear and cherry. A sprinkling with the soap and tobacco preparation weakened, applied two or three times, or throwing slacked lime or ashes over them will destroy them. The slugs that are injurious to garden regetables 
are caught by placing pieces of cabbage and turnip leaves in their way, on which they will be found collected, and may be thrown into the fire.

Cut-worm, or black grub. There are several varieties of these, differing somewhat in color-the progeny of different beetles. The common variety is ash-colored with a dark stripe on the back. When full-grown they are an inch and a-half long and the size of a large quill. They hide in the ground in hot sumny days, but come out at night to eat of the tender stems of young plants. They are much more destructive in warm, wet seasons. The only remedy when they once appear is to examine the beds every morning, when by digging near the plants cut off you will generally find the destroyer. Choice plants may be transplanted in trenches, as directed under the article Cabbage, or protected by wrapping their stems in paper when transplanted. Salt or lime will not kill them in the spring, but if salt be applied in the fall broadcast they do not appear the ensuing summer.

I have found it so one year at least in adjacent gardens; the one salted was free from the grub, while in the other. it was very destructive.

Cucumber and Squast Bugs resemble each other except in color. If very troublesome, the plants may be sown under boxes covered with millinet which will prevent access to the plants.

The Curculio.-This is a small brownish beetle about a quarter of an inch long, and deposits its egg in a semi-circular incision that it makes in stone fruit, which hatches and eats its way into the young fruit, causing it to fall prematurely. It attacks all stone fruits, but especially apricots, nectarines and plums. It is not so destructive in clayey or hard soils. The remedies that have hitherto proved successful, are to pare the ground so that the grub 
cannot enter it to complete his transformation ; besides this, picking up the fruit as fast as it drops before the worm can enter the earth has been found beneficial; likewise jarring the tree (by striking sharply with a mallet on the stump of a limb removed for the purpose) as soon as the fruit is the size of a pea, and collecting the insects on a white sheet as they fall, and destroying them; as the insects are torpid in the morning, that is the best time for the operation, which should be kept up until the fruit begins to ripen. Trees planted near piles of fiesh horse manure are said to be free from the insects, they being repelled by the ammoniacal gas. But the best of all methods is to plant all stone fruits in an enclosure by themselves in which pigs and poultry are admitted; these will collect the fruit as fast as it falls, and tread the ground firmly together, so that it is not easy for the insects to enter it. None of these methods will be fully effectual if there are neglected trees near by from which the curculin may emigrate. The most reliable of them is jarring the trees, and destroying the insects daily; the next is giving access to a large flock of chickens which destroying the perfect insect are a much more efficient remedy than the pigs alone.

The Corn Horm (Heliothes) comes from the egg of a yellowish moth deposited in June, and after in the silk or apex of the ears of Indian Corn while in the milk. 'The caterpillar, at first scarcely visible, increases rapidly, and, sheltered by the husk, feeds roraciously upon the tender grains at the end of the cob. It is thought to be identical with the boll-worm of the cotton plant. Injury may probably be warded off by catching the first brood of moths in the wide-mouth bottles before mentioned, or by Col. Sorsbey's plan with the moth of the boll-worm. He mixed four parts vinegar to one of molasses and put 
a gill of the mixture upon a common dinner plate which was set on a board six inches square fastened to a stake in height a little above the plants. The next morning from eighteen to thirty-five of the insects were found in each plate. Following it up a few days, the crop ceased to be infested. A very few plates would be sufficient, as the odor of the mixture attracts the insects from a great distance and alighting on it in their eagemess to feed its adhesive natuie prevents escape. The light wood fires would also probably serve the same purpose.

Where the worm has eaten the ear a secure retreat is afforded to many other insects, and as the dampness from the exuded sap farors the growth of mould, the remainder of the ear is thus destroyed.-(Pat. Off. Rep., 1854.)

Procris Americana.-The caterpillars of the American Procris are very destructive to the foliage of grape-vines, late in the season, injuring it as if scorched by fire. The larvæ are found in companies of several together underneath the leaves, feeding side by side upon the substance, learing only the stalk and large ribs untouched. The eggs are deposited in clusters, and the caterpillars are from five to six tenths of an inch in length, covered with short hairs, which are longer on the second and last segments; they are of a yellow color, spotted with distinct black spots, and attain their growth in twelve or fourteen days. There are several broods in a season. The cocoons are whitish, oblong, oval and flattened, with a chestnut brown chrysalis. The moths measure nearly an inch across the expanded wings, and are of a blue black color except the collar, which is orange. Destroy the caterpillars, by syringing the infested leaves with whale oil soap in solution, and crush by trampling those that fall to the ground; or by picking off the infested leaves by hand, and 
burning them when not too numerous. (Pat. Off. Report, 1854.)

Desmia Maculalis.-This insect first appeared on my own vines last summer, 1855 , and is very destructive to the foliage. The caterpillar is nearly an inch long, of a green color, with a black semi-circle on the first, and two more black spots on the second segment of the body, It is very lively, and when disturbed, backs out of its shelter (made first by rolling a leaf and then fastening the outer edge with silk) and suspends itself from the leaf. The moth measures about an inch across the wings; the female, which it is most important to recognize, has two distinct white spots on a black ground on each upper and under wing, two white bands around the abdomen, and a white border around each wing, with a line of black through the centre. Those moths are very troublesome the latter part of summer, and should be destroyed by plucking and trampling on each infected leaf, which may be easily. recognized by its rolled-up appearance. (See Pat. Off. Report, 1854.)

The Vine-hopper is a small insect, very destructive to the foliage of the grape vine. The insect in its first stage is unprovided with wings, and sucks the sap or juice of the leaves with its beak, causing them to turn yellow, assuming a blotched or scorched appearance. The outer skin is cast several times before the insect attains its full size, which it does about the end of July; meanwhile it has been constantly feeding upon and draining the sap from the leaves of the plant. When fully grown, it is provided with four wings, and jumps with great activity if disturbed, or takes to flight in such multitudes as to amnoy people passing. It has been asserted that these insects pass the winter under leaves, roots, and tufts of grass, and in the spring 
crawl out to deposit their eggrs upon the vines, and then die. Fumigation with tabacco under a movable tent is the only known remedy, but in vineyards this is hardly practicable. (Pat. Off. Report.)

Rose Bugs are troublesome to rose bushes and fruit trees in sandy soils. They lay their eggs in the earth, which hatch about the time roses bloom. They are sluggish things and the best way is to strike them off the bushes upon cloths and empty them into hot water.

The Turnip Fly is a general name for several insects which attack the turnip, cabbage, \&c., devouring the seed leaves. These are not troublesome in ground manured by yarding cattle and sheep upon them. The best preventive is to use guano or any other manure so abounding in phosphates that the turnips are soon out of reachdusting the plants with lime, soot ashes, \&c., or keeping broods of chickens in the turnip patch will be found beneficial.

Mice may be caught in traps, or poisoned with arsenic; but the latter is dangerous if fowls or children have access to the garden.

Moles are often very troublesome in undermining beds of cuttings or young plants in search of worms and insects. They may be caught in various traps sold for the purpose, but by putting tarred sticks in their burrows they will be driven from them. Salting the soil is fatal to many insects that are the food of the mole.

Hares and Rabbits are very destructive to trees and garden vegetables in all country places, and even in towns we do not escape, but can be repelled by a tight board fence, or a close hedge of the Macartney rose. Choice trees can be bound up in broom straw during the winter. 


\section{GARDEN IMPLEMENTS.}

The principal implements employed in gardening are the following:

\section{Implements for Preparing and Opfrating upon} THE SOIL.

Subsoil Plough.-This is of great service in large gardens, answering as a tolerable substitute for the spade in trenching for orchards and market gardens, doing the work more cheaply and expeditiously, but not so well. It requires a powerful team to manage it.

The one-horse Turning Plough is very efficient in deeply stirring the soil among plantations of trees and the larger garden crops. The whiffletrees should be short that the trees and plants may not be injured. A strong animal is required, and the plough must not come too near the trees and plants.

The Cultivator supersedes in a great degree in market gardens the necessity of hand-hoeing among the main crops. By passing it over once a week between the rows, all the hoeing required is a narrow strip of a few inches in the row.

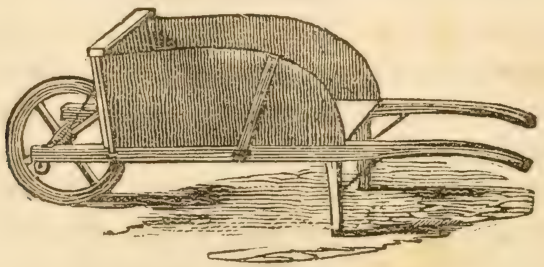

THE WHEELBARROW.

The Wheelbarrow.-This is indispensable in the smallest garden. In carrying manures, applying composts, moving 
soils, and gathering crops, it is of constant service. The handles and frame should be of tough wood, but the sides and bottom may be of poplar or any light material.

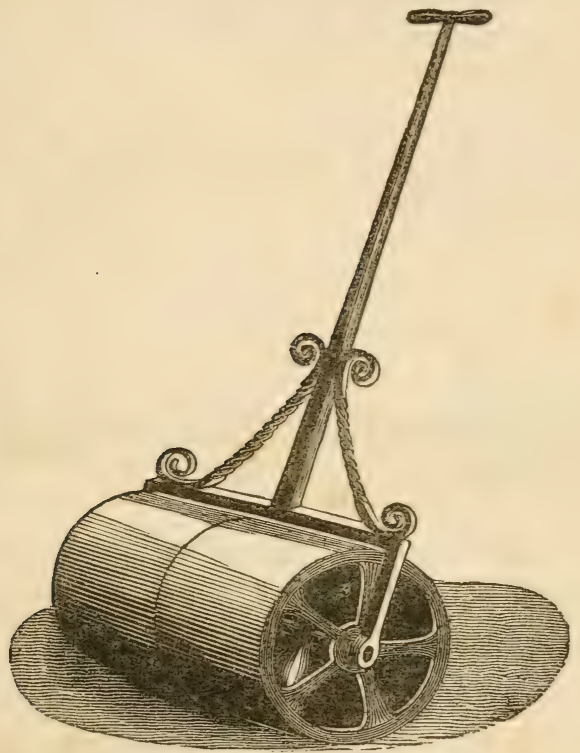

GARDEY ROLIER.

The Garden Roller.-This consists of two cast iron sections one foot in width and twenty inches in diameter, with an iron handle. Weights can be attached to the inside to make it heavier if desired. Being made in two sections the earth is not scraped up while turning around. It is very useful in keeping grass lawns smooth and relrety, and is valuable to follow the putting in of all seeds in sandy soils. Lawns should be rolled when the ground is moderately soft with rain, after each mowing. A tolerable substitute, for a small plot of grass, is a piece of plank 
two inches thick, eighteen inches long and ten wide, with a handle inserted perpendicularly in the centre. With this the lawn should be beat when the turf is set to a perfect level. This is quite as effectual a mode of smoothing a lawn, but much more time and labor are required than by the use of the roller

The Pick.-This is indispensable in trenching hard clay subsoils in which the spade cannot penetrate. It consists of a wooden handle inserted in a head composed of two iron levers both pointed with steel, one of which should come to a point and the other made about two inches wide for entting roots or any obstructions.

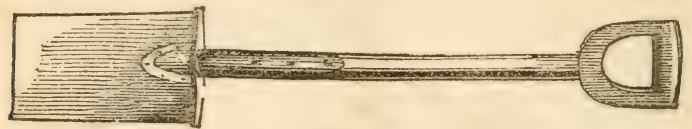

EPADE.

The Spade.-The best are Ames', cast steel. A large one is required for lifting trees, trenching, \&c., but a lighter one is convenient for common purposes.
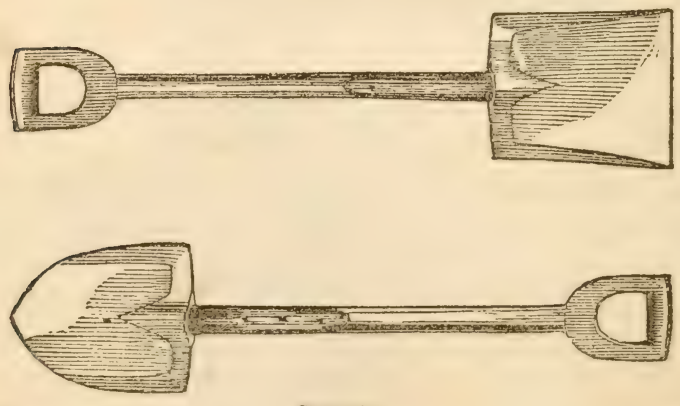

SHOVRLS.

Shovels are necessary for loading and spreading composts 
and manures. The round pointed one is most convenient for garden purposes.
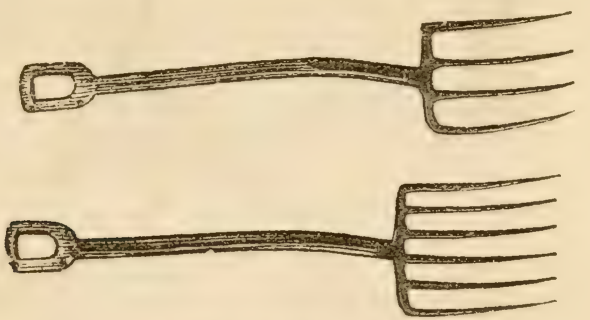

MAZURE FORKS.

Manure Forks are made with from four to eight tines. The four-tined ones cut out of a solid plate are the best. They are indispensable for moving fresh long manures with celerity and ease. A three-tined fork made like the above with stout tines an inch wide is called a forked spade. It is used like the spade for trenching heary soils, to loosen the earth and digging in manure in asparagus beds or about trees without injury to or cutting the roots, and is an exceedingly convenient implement.

The Crowlar is used in the garien, mostly for setting poles for climbers, pea brush or other fixtures for training plants and for removing rocks and other obstructions.

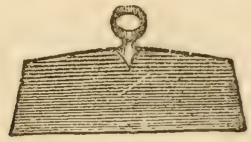

HOF.

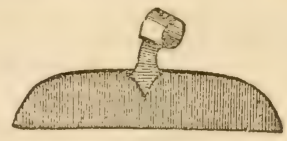

HOI.

Hocs.-These are of constant use in gardening. They are of two kinds; the draw-hoe and thrust-hoe, but the draw-hoe is the most convenient. The most useful are the square draw-hoes made of a cast steel plate six inches long and four wide, 

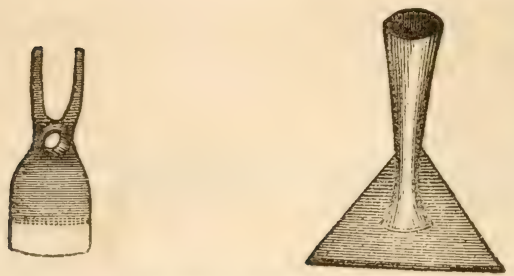

TRIANGULAR DRAT-HOE.

The Triangular Draw-Hoe for digging furrows, for sowing seeds, and the narrow semi-circular or narrow square turnip hoes with sharp edges for scraping the surface and killing weeds. For digging deeply, a four pronged hoe, sold at the North as a potato digger, is unequalled in the facility with which the earth may be easily and thoroughly worked. The tines should be stout and made of the best cast-steel. The handles of all hoes should be smooth and light, and there should be no extra weight about the implement.

The Garden Rake is indispensable for levelling and finely pulverizing the ground preparatory to sowing small seeds after it has been spaded or hoed. The best are those hammered out of a solid bar of steel as they never lose their teeth or get out of order.

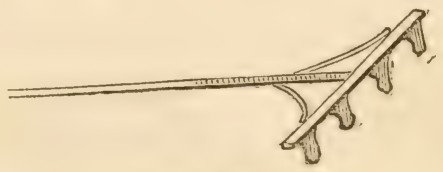

DRILL RAKE,

Drill Ralies are made of wood, and the teeth placed at a greater or less distance for sowing different seeds. In using, the first drill is guided by stretching a line, and afterwards the first tooth is kept in the drill last made to 
guide, and thus all the rows in a long bed can be made perfectly parallel. Several different sizes are required.

The Dibble is very convenient in transplanting cabbages and all those plants that readily succeed when moved.

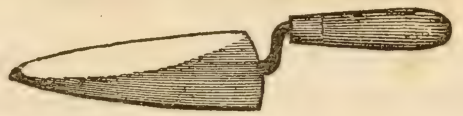

THE TROWEr.

The Trowel is a much better implement for removing flowers and other tender plants, as they can be taken up with a ball of earth attached without injury to the plants.

Screens for sifting earth, for filling flower-pots or covering small seeds, are best made with rather stout wires and the meshes $\frac{1}{4}$ of an inch in diameter.

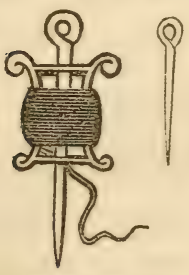

GARDEN REEL AND LNE.

The Garden Reel and Line.-The line should be a good hemp cord $\frac{1}{4}$ of an inch in diameter. The axis of the reel is fastened in the earth. This is indispensable where neatness and regularity are desired in the rows and plats. It can be easily and quickly wound up when not in use.

2. Cutting Implenents, for Operating on Plants.

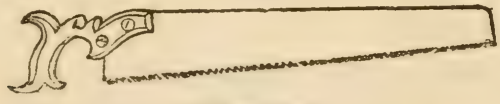

PRUNTNG SAW.

The Pruning-Saw is made with fine teeth, from fourteen to eighteen inches long, and a hooked handle, for hanging upon a limb, while in the tree. It is also used in cutting off large stocks for grafting. 


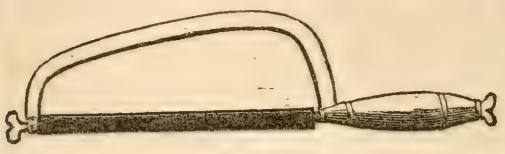

BOW SAW.

The Bow-Saw, which has a very narrow blade, stiffened with an arched back, the blade of which can be mado more or less stiff, by tightening the screw on which the back turns, is the best for gardening purposes, and indispensable for sawing off stocks horizontally, near the ground. A small tenon saw is very convenient for grafting purposes.

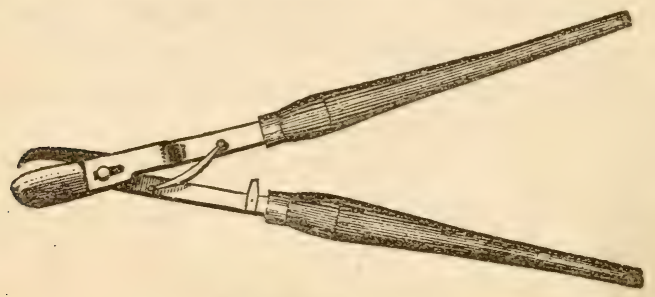

HAND PRENING-SHEARS.

Hand Pruning-Shears.-Those with a sliding centre are most desirable, as with them a draw-cut can be made as smooth as with a knife. Small sizes are made for ladies, and very highly finished. They are useful in clipping hedges, shortening in peach trees, and cutting out small dead branches. One man, with them, can do as much as four with a pruning-knife.

Pole Pruning-Shears are fastened to a long handle, and worked with a cord passing over a pulley. They are used for removing dead branches, or those infested with insects, from high trees. Branches an inch in diameter can be cut off with this instrument. 'They are best with a sliding centre.

Nots. Many of these implements are from the well known manufacturcr, Mr. R. L. Allen, 189 Water street, New York. 


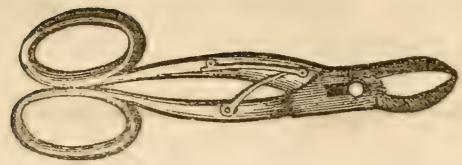

PRENING-SCISSORS.

Pruning-Scissors are also made with a sliding centre and spring. They cut as smoothly as a pruning-knife, and are very convenient for ladies' use in pruning rosebushes.

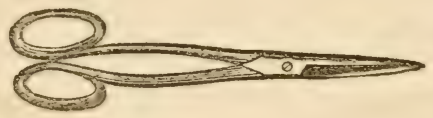

FINESCISSORS.

Vine-Scissors are used in thinning grapes, when they are too crowded in the bunches.

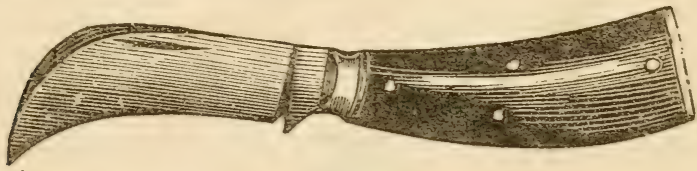

PROATIG-KNIFF.

Pruning-Knife-Those of English make are the best. One of moderate size, about four inches long, is most conrenient for the pocket. Another, of larger size, for heavy work, is desirable.

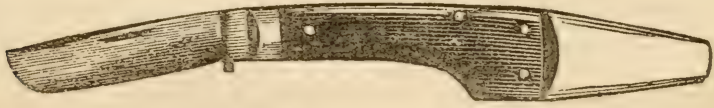

BUDDING-KNIFE .

The Budding-Knife has a broad, flat blade, the edge of which is rounded outwards, to make the incision in tho 
bark more readily. It has an ivory haft, thin and smooth at the end, for raising the bark.

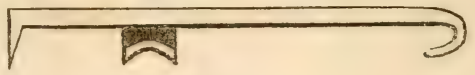

GRAFTING-TOOL.

The Grafting-Tool is employed in cleft-grafting large stocks. It is used for splitting the stock, and has a sharp edge, curved inwards, to cut the bark in splitting. The wedge part is used to keep the stock open while the scions are inserted.

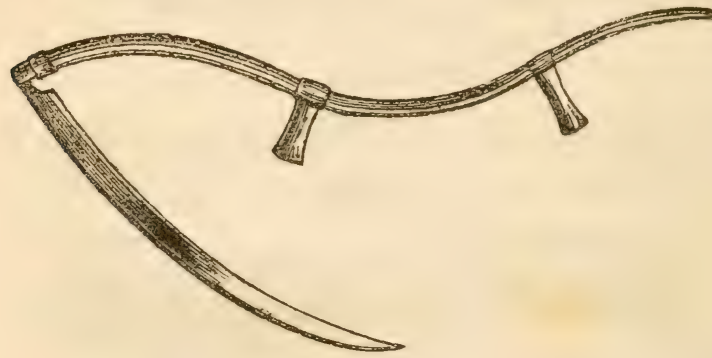

LAWN-SCTTHE.

The Lawn-Scythe, with snath, is very necessary to keep the grass smooth shaven, and of that soft green, velvety appearance, so desirable. Those made of a thin plate of steel, welded to an iron back, are light and durable, and may be whet until the blade is within half an inch of the back, without grinding.

3.-Instruments of Designating, Watering, \&c.

Tallies.-Those for common use, to last a single season, are most readily prepared from the white pine of which most dry-goods boxes are made. The wood is very soft. 
For marking trees or grafts, a small tally, three-quarters of an inch wide by three inches long, notched at one end for attaching the wire, is commonly used. The name of the variety should be marked on it with a lead pencil, immediately afler the tally has been brushed over with a thin coat of white lead. If marked while the paint is wet, it can be read as long as the tally lasts; otherwise it will soon be effaced.

Another kind is made, about six or eight inches long by an inch wide, of the same material, and marked in the same manner, to be stuck in the beds of flowers and vegetables, to mark the different varieties. Zinc labels will last for ever. They may be cut in any desired shape out of sheet zinc. Write on it with an ink made of two parts fine verdigris, two sal ammoniac, one lampblack. After this is made fine in a mortar, add twenty parts water; bottle and shake it occasionally some days before using. It will keep for years, if the bottle is kept cork downward, to prevent the ammonia from escaping. The labels should be fastened to the limbs with a stout wire.
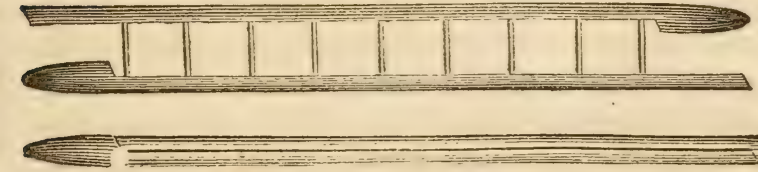

FOLDING-LADDERS.

Folding-Ladders are very convenient in gathering fruit. The rounds are fastened by pivots at the ends on which they turn, and when the ladder is folded up, they lie in grooves made in the side-pieces. 
The Standing-Ladder is also indispensable in the fruit

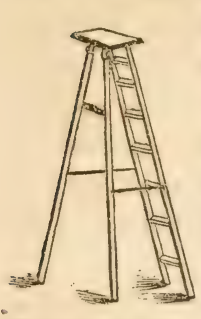

STANDING LADDER. garden. It should be made light, with flat steps. The supports are two sticks of light timber fixed to the top, with hooks and straps, to be expanded or contracted at pleasure. They should be six or eight feet high.

The Orchardist's Hook is a light rod with a hook at the end, with a movable piece of wood which slides upon the rod. The branches to be gathered from are brought near by the hooked end, and returned in place by hooking the slidingpiece into another branch.

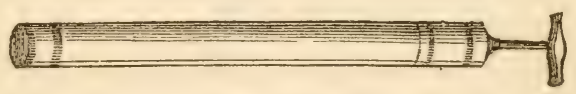

BAND STRINGK.

Hand Syringes are useful in watering plants in gardens or in pots. They will also be found of use, occasionally, in washing the foliage of plants. 'They should be made of copper, with several caps of greater or less fineness. There should also be an inverted or gooseneck cap, not shown in the cut, for washing the under-side of leaves. Insects may be expelled from plants by using an infusion of tobacco or sulphur water for sprinkling them. They are made of any desired size, up to a gallon.

Watering-Pots are well known implements, very necessary in a garden. The best are of copper. There should be two or three roses of different fineness. Hang them so the water can run out, when not in use. Tin ones should be painted occasionally, to prevent rusting.

Vine-Shields are excellent for protecting young plants 
from the cucumber and squash bugs. The top may be covered with millinet. They should be about eight or ten inches high, and made bevelled, so that one can be set within the other when

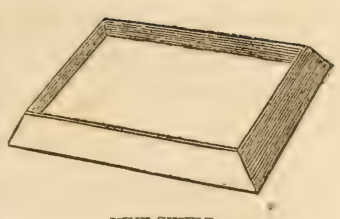

VINE-SHIELD. put away. They are made with or without a pane of glass in the top. Put around any half-hardy plant, with a lock of hay in them, they afford a very good protection during winter. With a movable top, containing a pane or two of glass, they are a tolerable substitute for the next described.

The Hand-Glass.-The frame is made either of hard wood or cast iron. It is made in two parts, to give air readily to the plants. Its mode of construction is readily seen

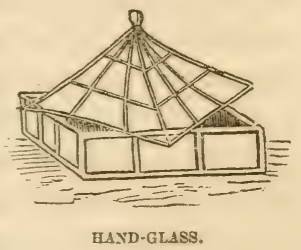
in the figure. 


\section{THE KITCHEN GARDEN.}

\section{Agaricus Campestris-Mushroom.}

"THE mushroom," says Loudon, "is a well-known native vegetable, springing up in open pastures in August and September. It is most readily distinguished when of middle size, by its fine pink or flesh-colored gills and pleasant smell. In a more advanced stage the gills become of a chocolate color, and it is then more apt to be confounded with other kinds of dubious quality; but the species which most nearly resembles it is slimy to the touch, having a rather disagreeable smell-further, the noxious kind grows in woods, or in the margin of woods, while the true mushroom springs up chiefly in open pastures, and should be gathered only in such places."

Some of the species of this genus are very poisonous. The mushroom is remarkable for its close assimilation in taste to animal matter. It is beginning to be extensively cultivated in this country near our large cities.

Cullure.-Beds may be readily constructed at any time of the year, except between April and September, when the temperature is rather too high for successful culture, unless in the cool cellar of some outhouse. But November and December are the best months for the purpose. Mushrooms are propagated by spawn, which may be obtained for commencing from the seedsmen of our large cities. After a little spawn is obtained, it can be increased as follows:-Take a quantity of fresh manure from high-fed horses, mixed with short litter-add one-third cow's dung, 
and a good portion of loamy mould. Incorporate them thoroughly, mixing them with the drainings of a dungheap, and beat them until the whole becomes of the consistency of a thick mortar. Spread the mixture on the level floor of an open shed, and beat it flat with a spade. When it becomes dried to the proper consistency, cut it into bricks about eight inches square; set them on edge, and turn frequently until half dry, then dibble two holes about half through each brick, and when perfectly dry, insert in each hole a piece of good spawn. Then somewhere under cover place a bottom of dry horse dung six inches thick, and place the bricks spawn side up, one upon another. The pile may be made three feet high ; cover it with warm horse-dung sufficient to diffuse a gentle glow of heat through the whole. The heat should not be over $70^{\circ}$, and the pile should be examined the second day to see that it does not orerheat. When the spawn is diffused entirely through the bricks the process is finished. The bricks should then be laid separately in a dry place, and if kept perfectly dry, retain their vegetative power for many years. One bushel of spawn will plant a bed four feet by twelve.

Beds for mushrooms may be made anywhere in a dry situation under cover. Make them four feet wide, and from ten to fifteen feet long, according to the wants of the family. A small shed might be erected for the purpose, but the back of a greenhouse is a rery good situation, as they do not need much light. Space must be left for an alley, and if the shed be ten feet wide, it will admit of a bed on each side.

A sufficient quantity of the droppings of hard-fed horses, pretty free from litter, must be obtained, which, while collecting, must be kept dry, and spread out thinly and turned frequently to prevent riolent heating. When 
the rank steam has escaped the bed may be built. The site should be dry. Dig out the earth six inches deep, the size of the bed, and if good lay it aside for use. Fill this trench with good fresh dung for the bottom, and lay on this the prepared dung, until the whole is six inches thick above the surface; beat it down firmly with the back of the fork, and build up the sides with a slight but regular slope. Let the bed slope downwards towards the walk, lay over it three inches of good clayey loam ; place another layer ten or twelve inches thick of prepared dung, and in the same manner continue until the bed is two and a half or three feet thick. Cover the bed with clean litter to prevent drying and the escape of the gases, and let it remain ten days, or until the temperature becomes mild and regular; about $60^{\circ}$, and certainly not less than $50^{\circ}$, is the proper degree of warmth. Here skili and practice are most required, for on the treatment at this precise point, the success of the bed depends. If the manure has a brown color, and is so loose and mellow that when pressed it will yield no water, but has a fat unctious feel without any smell of fresh dung, the bed is in a right state. If it is dry, and hard, or sloppy and liquid, it is not in the proper condition. In the first case moderate watering may restore it, but in the latter the superabundance of water will probably spoil it, and it is better to commence anew. When the bed is ready, break the bricks of spawn into lumps the size of a walnut, which plant regularly six inches apart over the surface of the bed, including its sides and ends, just beneath the surface of the manure. Level the surface by gently smoothing with the back of the spade. Fine rich loam, rather light than otherwise, is then put on two inches thick. Lastly, a covering of straw from six to twelve inches, according to the temperature. If the bed gets too hot, take off most of the covering. When 
the bed appears too dry, sprinkle it gently with soft tepid water in the morning. The water should be poured through the rose of a watering-pot upon a thin layer of straw, laid on for the purpose, and when the earth becomes a little moistened, the straw should be removed, and the dry covering replaced. In warm weather it will need frequent sprinkling, but in winter very little.

In four or five weeks after spawning, the bed should begin to produce, and if kept dry and warm will last several months. A gathering may take place two or three times a week according to the productiveness. If it should not come on in two or three months, a little more warmth or a sprinkling of water will generally bring it into plentiful bearing, unless the spawn has been destroyed by over-heating or too much moisture. In gathering, detach them with a gentle twist and fill the cavity with mould; do not use a knife, as the stumps left in the ground become the nurseries of maggots which are liable to infest the succeeding crop. Gather before they become flat-when half an inch or more in diameter, while compact and firm.

Use.-This "voluptuous poison" has been cultivated and in high esteem among epicures since the time of the Romans. They are employed in catsups, pickles, and rich gravies and considered by those accustomed to them very delicious. Dried and powdered they are preserred in closely stopped bottles for times when they are not to be procured fresh.

To Stew.-Cut off the part of the stem that grows in the earth; wash carefully, and take off the skin from the top; place in a stew-pan with salt, without water; stew slowly, shaking the pan occasionally until tender; then 
thicken with a spoonful of browned flour and one of butter; add spices and wine, if to your taste.

To broil.-Prepare as above, and lay on a small gridiron over bright coals, stalk upmost; broil quickly and serve with butter, salt and pepper.

Mushroom Catsup.-Take the flaps of two gallons of fresh mushrooms and put in an earthen dish ; sprinkle upon them three-fourths of a pound of salt; crush them fine; boil sometime and strain; put them upon the fire again, and add a few cloves of garlic, one-half ounce of black pepper, and one-half ounce of ground cloves; boil until reduced to one-half the original quantity; bottle, cork tight, and keep in a cool place.

\section{Allium-The Onion Tribe.}

This genus contains several of the most useful plants which demand the gardener's care. They all require a rich, friable soil and a situation enjoying the full influence of the sun, and free from the shade and drip of trees. If the soil be poor or exhausted, abundance of manure should be applied some time before planting and thoroughly incorporated with it; for rank, unreduced dung is injurious, engendering decay. If applied at the time of planting, the manure must be thoroughly putrescent, and turned in only to a moderate depth. If the ground be tenacious, sand, or better still, charcoal dust is advantageous; ashes and soot are particularly beneficial. Common salt, at the rate of six to eight bushels per acre, is an excellent application to this family of plants. In digging the ground, small spadefuls should be turned over at a time, that the texture may be well broken and pulverized.

Light, sandy soils, if rich, are very well suited to the growth of these regetables. 


\section{Allium Cepa-The Onion.}

This plant, which is probably a native of Asia and Egypt, has been cultivated from the most remote antiquity, and is one of the most useful of our garden crops.

Analysis by Richardson:

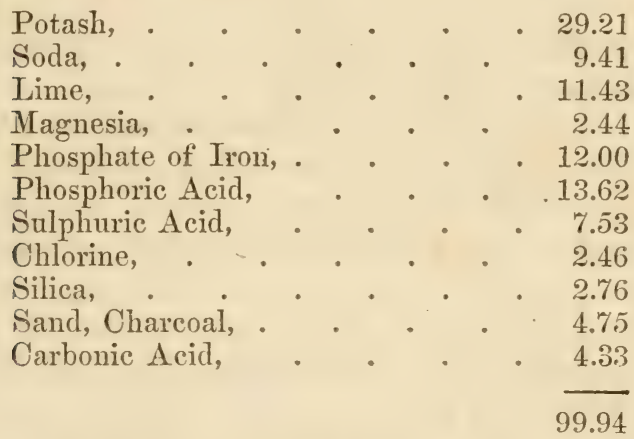

It will be seen from the above analysis that to raise good onions, soda, lime, potash, phosphoric and sulphuric acid, and silica must be found in the soil abundantly. Ashes, bone dust, gypsum, and the salt and lime mixture will supply nearly all the inorganic constituents of this crop; and where they do not already exist in sufficient quantities in the soil they may be supplied in addition to animal manure. Professor Mapes directs that when sufficient manure cannot be obtained, four hundred pounds of Peruvian guano composted with five bushels of bone dust, dissolved in sulphuric acid and enough charcoal dust to divide the mass, will be found to produce a maximum crop. Guano water and spent lye well diluted are excellent liquid manures.

VARIETIES.-There is a great number of varieties of onions, among which are

Large Red, a hardy variety raised abundantly in the 
Northern States for export. It is deep red, medium size, rather flat, and keeps well.

Yellow Strasburg.-Large yellow, oval, a little flattened, very hardy; keeps exceedingly well, but is a little too strong in flavor for most tastes. Best for winter use at the South.

Silcer-stizned.-Of smaller size but finer flavor, silvery white, flat, and very much used for pickling.

These three are the best among some fourteen varieties to raise for family use; and the Yellow and Red for general culture, as the white is apt to decay. Besides these varieties the Top and Potato onion will be hereafter noticed.

Cultur-Onions are raised from seed or sets which may be planted from October to April, but February is the best month for the purpose. Onions require a very rich, light soil and a free, open exposure; they will not do anything under the shade of trees. If the soil is not rich, a plenty of well rotted manure should be applied some time before planting and well dug in. A moderate quantity of leached ashes and soap suds will not come amiss, whether before or after planting. They do not require a change of soil, being an exception to the general rule that plants like a rotation, as they have been grown in Scotland a century in the same spot without any diminution of the crop. The root throws off no excrementitious matter.

The onion can be grown in great perfection at the South. In the hot climates of Spain, Portugal, and especially Egypt, the finest onions in the world are produced, the roots being milder and of greater size than in most countries.

It is a good plan to make the beds just wide enough for three rows, say thirty inches wide, with a narrow alley between, which may be filled with sweet corn or cabbages, after the crop is laid by. The soil of the heds must be 
finely dug, the surface rolled smooth and all the clods beat fine that may have escaped the spade. The rows may be laid off from twelve to fourteen inches apart. The drills should be drawn very shallow, as the best onions grow upon the surface of the ground. For this reason, it is well to roll the bed, or beat it smooth with the back of the spade, before making the drills. Some soak the seed twenty-four hours before planting, but to little advantage. Do not sow very thick-only one or two seeds in a place. A seed every two inches is quite thick enough, as thinning out, when too thick, is apt to injure the remainder. Corer the seeds about half an inch, and press down the earth upon them by a roller, or by walking over them on a board. When they come up, thin them out gradually in the drills, to 6 inches apart. Keep the bed clean and free fiom weeds; and stir it frequently, but not deeply, with a hoe. Do not hill the earth up against the onions; but draw it away from them with the fingers, as they do better to grow entirely above the ground. There is no crop more easily raised or preserved, if the ground is rich enough, and the bulbs made to grow upon the surface. After the young onions have got a good start, it is best to drop the hoe entirely and resort to hand-weeding. In dry weather, a thorough drenching in weak liquid manure, or soapsuds, is excellent. For pickling, the white onion should be sown much more thickly, and thinned out until about one or two inches apart in the row, which will cause them to ripen early, before they have made too large a growth.

If onions grow thick-necked, and do not bulb properly, bend down the stems about two inches above the neck, to the ground, without disturbing the roots. This is needful only in very wet seasons.

When rery large bulbs are desired, the seed may be 
sown quite thick, in pretty good soil, and not thinned out at all. Little bulbs or sets will form about the size of the button onion, which may be taken up when the tops die, and preserved in a dry loft until time for preparing the bed, and then may be planted, instead of the seed, eight inches apart, in the drills. If they throw up a seed stalk, it must be promptly broken off, or they will form no bottoms. These sets, planted out early in the year, will form fine large bulbs in May or June; while those raised from the seed, do not ripen until July. Hence the latter are better keepers. Besides, they are better flavored, and more solid.

When the crop is reakly for harvesting, it is known by the drying up and change of color of the stems.

To preserve them.-Pull them on a dry day, dry them thoroughly in the shade, and stow them in a loft where they can have plenty of air. When thoroughly dry, they can be strung in ropes. From two to five hundred bushels per acre is the usual crop.

For seed.-Select the lingest and finest bulbs and plant out in the fall, about twelve inches apart, in beds of common garden soil, not too rich. Keep them free from weeds; and when they throw up seed-stalks, support them by poles laid horizontally on stakes, six or eight inches above the surface of the beds. Home grown s ed from good bulbs is as good as the best imported. It will keep three years.

Use--Onions are among the most useful products of the garden. They possess valuable medicinal properties, and are used in colds and coughs as an expectorant. Rubbed on the skin, they are a good application for the sting of a bee. But they are mostly used in cooking, and especially as a flavoring ingredient and seasoning for soups, meats and sauces; for which purpose they have been employed from time immemorial. They contain considerable 
nutriment, and are tolerably wholesome, especially if boiled. Raw, they are not very digestible, and they are the same if fried or roasted. Eating a few leaves of parsley will destroy in a measure the unpleasant smell they impart to the breath.

To boil.-Boil them twenty minutes in water with a little salt; then pour off the water entirely. Then put in equal parts of hot water and milk, or skimmed milk alone, and boil them twenty minutes more. When they are done through, take them up carefully with a skimmer; let them drain a little, and lay them into the dish. Put on butter, pepper, and salt. Onions, like all other vegetables, need to be slightly salted while cooking or their sweetness will be mostly lost.

To pickle.-Select small silver-skins of equal size, peel off their outer skin, and scald them three times with boiling salt and water, allowing them to cool after each scalding; then put the onions into a pot, pour boiling vinegar upon them, cover them closely, and place them aside for use. 'They ought to be good pickles in two weeks. -Mrs. Bliss.

To malie Onion Sauce.-Peel and cut into slices two onions, put them into a stewpan with two tablespoonfuls of butter; set the pan on a slow fire, and let it stew until the onions are reduced to a pulp, then stir in one tablespoonful of flour and let it brown; then add half a tumbler of water, pouring it in a little at a time, and stirring continually. If the sauce is now too thick, add a little more water, and salt it to your taste.-Mirs. Bliss.

\section{Allium Tuberosum-Pотато Onion.}

I cannot learn the origin of this species-it derives its name from producing a cluster of bulbs or offsets beneath the surface of the soil. There are two species, 
one producing bulbs on the stem like the tree onion, and the other never throwing up flower-stems at all. The latter produces much larger bulbs than the other variety. Culture.-It is propagated by offsets of the roots which may be planted at any time from October to March. Prepare the soil as for the black seed variety, but not so rich, and insert the off'sets in drills twelve inches from each other, and ten inches apart in the drills, with the tops just level with the surface. Beds four fect wide are found the most convenient in practice. Keep the ground loose and free from weeds, but do not hoe deep nor earth them up, if you would have them ripen perfectly. Take them up when their leares turn yellow and treat them as the last variety described, if you wish to preserve for winter. They will be found earlier and milder in flavor than those raised from seed but not as profitable, as the bulbs are rather small. Used in the same way as the other varieties.

Allium Proliferum.-Tree or Button Onion.

Also called the Canada onion. A very hardy and perennial species, it is very much cultivated, and a great favorite in countries either too cold or too warm for the other varieties to flourish. It produces little bulbs at the top of its seed stems. Hence the name tree or top onion. This is the easiest cultivated of any of the onions, properly so called, and will always be a farorite as the crop is quite abundant and little care is required.

Culture.-Plant at any time from the first of October to A pril, the little buttons produced at the top of the stalk. The ground should be prepared and manured as directed for the common onion, and laid off in drills one foot apart, and the buttons set six inches distant in the drill. Beds four feet wide are most convenient for culture and weeding. Plant the button with its apex just even with the surface of the 
ground; every little button will produce one, and often two or three good sized onions. If you wish large bulbs, the seed-stem should be broken down. 'The old bulbs, if any remain over, may be planted and will yield an abundant crop of buttons and off-sets; keep the ground free of weeds and cultivate as directed for the other onions, They will be fit for use if well treated, in May, long before the other kinds. Gather and cure as directed for the common onion. The small bulbs are the finest of this tribe for pickling, being considered much superior in flavor.

\section{Allium Sativum-GarLIC.}

This is a hardy perennial plant, a native of Sicily and the south of France; it has been cultivated at least three hundred years. There are two sorts, one with large and the other with small bulbs; each bulb consisting of a half dozen or more small bulbs or cloves. 'The ashes of the garlic bulbs have been analysed by Herapath, and the constituents are given below. We have not been able to find an analysis of the leaves.

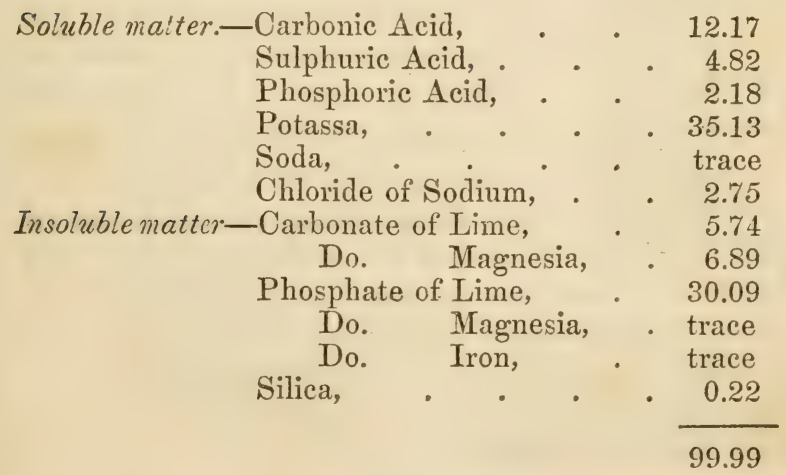


The above analysis indicates for Garlic a soil abounding in potash and phosphate of lime, which may be supplied if necessary by a compost of ashes and bone-dust.

Culture.--Garlic likes a dry light rich soil, but not freshly manured; the manure should be put on the preceding crop. Prepare the ground as directed for the rest of the onion tribe, and mark it off into drills eight inches apart. Plant the cloves four inches distant in the drills, and two inches deep, and see that they are put in right side up. Keep the ground free from weeds, and light by frequent hoeing; plant from October to March.

A few roots may be taken up the latter part of May for use as required, but do not lift the crop until the leaves are withered. Break down the seed stalk if it rises, to prevent from running to seed, which would lessen the size of the bulbs.

When the leaves turn yellow, take them up and dry them thoroughly in the shade, tie them together by the tops, and lay them up for winter in a dry loft as you would onions. If the ground is not needed for another crop, they may remain to be drawn as wanted.

Use.-This plant has a well known strong penetrating odor which is most powerful at mid-day. In medicine it is an excellent diaphoretic and expectorant; a diuretic when taken internally. If garlic be steeped in brandy, the tincture it forms is an excellent medicine for children. A teaspoonful should be given every morning in spring to every child on the premises, black or white, that is subject to worms, as it acts as an excellent tonic and anthelmintic. Some nations use it very extensively for seasoning soups and stews, and indeed it enters into almost every dish; but in this country it is not very much liked. Still a very slight, scarcely perceptible flavor, or as the French have it-a soupson of garlic is not repugnant, but 
rather agreeable to most tastes. The juice is a good cement for broken china.

\section{Allium Fistolosum-Crioule, or Welsh Onion.}

This is a perennial with large succulent fistular leaves, never forming bulbs, but cultivated for a spring salad. Sow the seed the last of September. It will continue growing all winter, withstanding the severest frosts. Sow thickly, and thin out when wanted for use. It may be sown at any time during the winter, but it is better when sown as directed above. Once introduced into the garden it will last many years, but it is hardly worth cultivating as, on account of its strong taste, it is much inferior to the common onion.

\section{Allium Porrum-LEek.}

The leek is a hardy biennial, found wild in Switzerland, but has been cultivated in gardens from the earliest times. It is mentionel in the Scriptures with the onion, as one of the vegetalles of the Egyptians; and at the present day is often assoriated with the name of St. David, the patron saint of the $W^{\mathrm{e}} \mathrm{el}$. This plant endures the extremes of heat and cold withort injury. The following analysis of the ashes of the roots and leaves of the leek is by Richardson :

\begin{tabular}{lrr} 
& \multicolumn{1}{c}{ Bulb. } & Stem. \\
Potassa, & 32.35 & 13.98 \\
Soda, & 8.04 & 14.43 \\
Lime, & 12.66 & 25.10 \\
Magnesia, & 2.70 & trace \\
Sulphuric Acid, & 8.34 & 16.50 \\
Silicic Acid, & 3.04 & 19.77 \\
Phosphoric Acid, & 15.09 & \\
Phosphate of Iron. & 13.29 & 10.06 \\
Chloride of Sodium, & 4.49 & trace \\
\cline { 2 - 3 } & & \\
& 100.00 & 99.84
\end{tabular}


We see from the above that a good soil for leeks abounds in potash, lime, and sulphuric and phosphoric acids. Ashes, bones, gypsum, and common salt, will supply the requisite salts if wanting, for this or almost any other garden crop. A compost of guano, gypsum and charcoal would be very beneficial.

Varicties.-These are two, the Scotch, which is the larger and hardier, and the London, which by many is considered the better of the two.

Culture.-The leek is raised solely from seed which may be sown at any time during autumn, winter, and spring, until the middle of April. February is the best month for the purpose, if but one crop is raised.

The soil for leeks as for the others of the onion tribe, should be light and rich; the blackest and most fertile soil of the garden, but the manure applied must not be rank. The same guano compost may be applied as for onions. Leeks are generally sown broadeast, but it is a much neater method to sow in drills. Hake the drills in the seed-bed eight inches apart, and about an inch deep, and scatter the seed rather thinly. Press the earth upon the seed as directed for onions. Some gardeners thin them out, and allow them to remain in the seed-bed, but the leek is so much improved by transplanting that this plan cannot be recommended. When the plants are three or four inches high, they must be weeded and thimned to one or two inches apart, and frequently watered in dry weather. The seed-bed must be kept clean and light by weeding, or the use of the hoe whenever required, until the plants are six or eight inches high, when they will be fit for transplanting. They must then be taken away from the seed-bed, the ground being previously well watered, if not already soft and yielding.

Having prepared beds four feet wide by spading in a 
quantity of well-rotted manure, lay it off in little trenches twelve inches apart, and as deep as the hoe will conveniently go. Dibble holes three inches deep, and six inches apart in the bottom of the trenches, in which set out the plants. Press the earth to the roots and neck only, and not to the leaves. The tops may be slightly trimmed and the roots slightly shortened. Some prefer planting them on the level surface of the prepared bed, by inserting them in holes made with the dibble, in rows ten inches asunder, and eight inches apart in the rows nearly down to the leares, with the whole neck beneath the surface, that it may be well blanched. Choose a moist time for transplanting, and give a little water should they droop A portion may remain in the seed-bed, six inches apart in the rows, but they do not grow as large as the transplanted ones.

The beds must be hoed occasionally to keep them free from weeds and loosen the soil. In dry weather they should be freely watered. By cutting off the leares a little about once a month, the neck will swell to a much larger size; earth them ip gradually if they stand on a level ground, and, if in the trenches, the earth should be drawn by a hoe, little by little, into the trenches, as the plants increase in growth.

If a very early crop of leeks is desired, they may be planted in September, and the plaints will be ready to set out the middle of February ensuing, and will come into use in June or July. Leeks can be planted between almost any other crop by giving six inches extra room.

For Seed.-Some of the finest roots of last year's growth, may be transplanted in February, eight inches distant in a row. When the seed stems arise, they must be supported by tying them to stakes. The heads should be cut when changed to a brownish color, with about a 
foot of the stalk attached, for the convenience of tying them into bundles of three or four to dry. When dry, they may be hung up in a dry place, and kept in the head until wanted, or threshed out and stored in paper bags; the seed will keep two years.

Use.-The whole plant is much used in soups and stews, but the most delicate part is the blanched stems. From its mild agrecable taste, it is esteemed by many above the onion.

To Boil.- Trim off the coarser leaves, cut them into equal lengths, tic in small bunches, and boil in plenty of water, which has been previously salted and skimmed. Serve them with melted butter. They need about twentyfive minutes boiling. If the water is changed when half done, they are much more delicate, the strong flavor being entirely removed.

\section{Allium Ascalonizm-Shallot, or Eschallot.}

'This plant derives its botanical name from growing wild at Ascalon, in Syria. It has a stronger taste than the onion; but as the strong flavor does not remain so long upon the palate, it is often preferred. The root is bulbous, similar to that of garlic, in being divided into cloves, included in a membrane. It rarely sends up a flower-stalk, and hence is often called the barren onion.

Cullure.-It is propagated from the offsets of the roots. Prepare the beds as for the rest of the onion tribe, but it will do with not quite as rich a soil. Let the soil be made perfectly light and friable. The last of September is the best time for planting the early crop, but they may be planted any time during the autumn and winter. The early planted ones come into use early in May. Make the beds four feet wide, and mark them off in drills an inch deep, ten or twelve inches distant, and put the offsets 
out six inches apart in the drills. Do not cover deeply; leave the point of the clove just even with the surface of the earth, and press the soil around. Keep the ground free from weeds, but be particular, in hoeing, not to earth up the bulbs. The leck is the only member of the onion tribe that is not injured by gathering the earth about its stem. Take up the bulbs when ripe, dry in the shade, and preserve as garlic. They may be kept until the next spring.

Use.-The shallot, though more pungent than some members of the onion family, is preferred by many in seasoning gravies, soups, and other culinary preparations, and by some considered almost indispensable in the preparation of a good beefisteak. It can be pickied in the same manner as the onion.

Shallot Vinegar.-P'eel and chop fine four ounces of shallots; pour on them a quart of the best vinegar, and let them steep a fortnight; then strain and bottle it.Mitiss Leslie.

Shallot Sauce.-Put a few chopped shallots into a little gravy, boiled clear, and nearly half as much vinegar; season with pepper and salt; boil half an hour.-MIrs. Hale.

\section{Allium. Scheencprasum-Chives, or Crves.}

A peremnial plant, growing wild in the meadows of Britain, as some varieties of the same genus do in this country. The bunches are made up of a mass of little bulbs, and produce pretty purplish flowers early in summer.

Culture-Any common soil will answer for this plant. Divide the roots in autumn or spring, and plant them on a bed or border, in little bunches of ten or twelve offsets, in holes made with the dibble ten inches apart. If kept free from weeds, they will speedily make large bunches, 
a few of which will supply a large family. Cut the tops smoothly off near the surface, when wanted, and fresh ones will soon spring up. Cives make a very pretty edging for beds in winter and spring. Renew this plant every four years by taking up and dividing the roots.

Use-It is an excellent substitute for young onions in winter and spring salading, and is also used like leeks and onions in seasoning soups, gravies, \&c. The leaves, cut up fine and mixed with meal and water, are often fed to young chickens as a preventive of disease. The little bulbs may be taken up and stored, and are a tolerable substitute for small onions.

\section{Allium Scorodoprasum-RocameoLE.}

or Spanish Garlic, as it is sometimes called, has its bulbs and cloves growing in a cluster, forming a kind of compound root. The stem also bears bulbs at its summit.

Culture.-It is best propagated by the root-bulbs, those of the summit being slow in production. 'The planting may be made at any time in the fall, winter, or spring. Insert the bulbs in drills, or with the dibble, six inches apart each way. Do not plant them deep. Keep clear of weeds, and cultivate and store like garlic. A very few roots are sufficient for any family.

$U$ se.-The bulbs are used in the same manner as garlic, and are preferred for cooking, being of much milder flavor.

\section{Apium.}

Plants of this genus flourish best in a soil moist, friable, and rather inclining to lightness. It must be rich, and that rather from former applications than the immediate addition of manure. Celery and Celeriac, however, appear benefited by its abundant application at the time of sowing and planting. 
The Parsleys like a tolerably dry soil. For all the genus it must be deep, and none of them thrive so well on a strong clay. They like an onen situation, free from the influence of trees. The common parsley bears best a confined and shady situation. They have recently been placed in the genus Petroselinum.

\section{Apum Graveolens-CelerY.}

Celery is a biemnial plant, a native of Britain, where the wild variety, under the name of Smallage, is found growing in low, marshy grounds, and by the sides of ditches, and is a coarse, rank weed, with an unpleasant smell and taste. It has also been found growing wild on the shores of the Chesapeake. No plant has been more improved by culture than this, which, under the gardener's hand, from a worthless, disagreeable, and, as some say, poisonous weed, has become, with its crisp, blanched stalk, and delicate aromatic flavor, a farorite regetable with the epicure There are seremal varicties of cclery, of which we shall notice but four, viz. :

Red Solid.-The hardiest variety, for winter use, withstands frost, and is distinguished by its color from the next.

White Solid is more crisp and delicate in flavor than the preceding, and a general favorite, on account of its color.

Seymour's Red, ant Seymur's White seem to be improvements on the old red and white solid, producing larger and finer stalks, but these depend for size and excellence very much upon the gimers. Any nue of the above rarieties will gire satisfaction, with proper culture.

An analysis of the ashes of celery has been made by Richardson, which we give below. One hundred pounds of celery gave $1_{100}^{1}$ pounds of ash, containing the following constituents : 


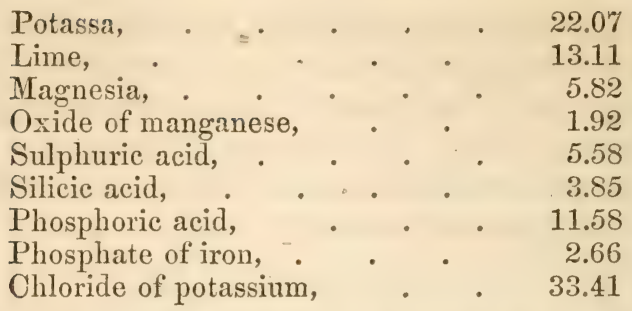

From the above we see that the soil for fine celery must be rich in potash, lime, phosphoric acid, and chloride of potassium. 'The abundance of potash and chloride of potassium explains the beneficial action of salt and ashes upon this plant. But it will not do to depend upon special manures alone, witum the addition of ammoniacal fertilizers.

Culture.-Celery can he very successfully cultivated in this climate. The ground for this plant must be quite rich, without the application of heating manure. It likes a cool, moist, but not wet soil. There are several modes of cultivation, of which we shall give but two. The best mode is to sow in February, March, or April, in drills seven or eight inches apart. As celery is a long while vegetating in the open air, it is desirable to sow the early crop under glass. Let the seed-bed be very rich, and with a little salt well mixed with the soil. Water freely in mild weather, when the soil appears too dry, taking off the sash in warm days, and giving air every day at noon until the seed comes up, which, if managed in this way, will not be long in making its appearance. After the seed is up, the glass should still be kept on nights, until mild spring weather, when it may be removed altogether. Celery is very much benefited, while in the sced-bed, by shading it at mid-day, and the April sowing must be shaded, or it will not come up. Frequent watering with 
guano-water, or liquid-manure, very much diluted, is exceedingly beneficial. The plants also should be kept clean and thinned out, while not over three or four inches ligh, to three inches apart. Choose damp weather for this purpose. Those which are taken up may be replanted in a bed prepared by thorough digging in the richest part of the garden. With the uppermost six inches of this bed should be incorporated as rich a coat of well-rotted manure as can well be mixed in. Plant them out three inches apart each way, and water them thoroughly every night, unless the weather be cold or wet. Keep them shaded during the day for a short time, until established. Here let them remain until fit to plant out permanently. Those which remain in the seed-bed should have their tops shortened, to make them grow more stoutly, and be frequently watered. The earth should always be stirred the morning after giving water, to prevent the ground from growing hard. The transplanted ones will make the finest crop; but for late celery, they should be cut off nearly to the crown, two or three times, to make them grow stout. When the plants are grown from six to nine inches high, it will be the proper time to plant those for early celery where they are to remain. And now, if you wish extra fine heads, trench your celery-patch, which must be very rich, twenty inches deep, turning the rich soil to the bottom, and the poor subsoil to the top, which will be just as good for blanching as the best. As the celery is to be planted in a trench, this will throw the best of the soil where the roots of the plant ean appropriate it. In the soil thus prepared, dig trenches three and a half feet apart, a foct wide, and the same in depth. Draw a line and mark out the sides by thrusting down the edge of the spade before digging out the earth, and then lay the soil taken out carefully on each side in the spaces between the trenches. 
If there is danger that the water from the adjoining parts of the garden should wash in and fill up the trenches, then the celery plantation must be protected by a ditch. The soil can hardly be made too rich; therefore, incorporate well-decomposed stable manure with the bottom soil of the trench, and intermingle it with good rich earth, so as to fill up the trench about four inches, leaving it eight inches deep. Add bone-dust, if you can get it, and let a pint of salt be added to every fifty feet of trench, and thoroughly intermingled with the soil. When celery is raised on a large scale, Professor Mapes directs the following eomposts to be put in the bottom of the trench:-One half cord well-decomposed stable manure, thoroughly mixed with ten gallons strong brine; or one cord swampmuck or leaf-mould from the woods, decomposed with the salt and lime mixture, well intermingled, with fifty pounds Peruvian guano, ten days before use; or one load chareoal dust, two hundred pounds guano, and two bushels of common salt: mix the salt and guano with water, to the consistence of cream, and thoroughly intermingle with the charcoal dust.

The last manure is much more powerful than the others, and a less quantity is required.

If the weather is not cloudy or damp when you wish to transplant, saturate your nursery-bed, two or three hours before planting, with water, and take up each plant with a trowel, leaving a ball of earth attached. Cut off the straggling leaves, shorten in the remainder, and remove the offsets, but do not disturb the crown of the plant. Transplant late in the evening, and if done with care, and they are freely watered, they will hardly need shading, unless it is rery hot. The plants should be six inches apart in the trenches. Stir the soil frequently, keep clear from weeds, and water copiously in dry weather with soap- 
suds, rain, or gnano water. Earthing-up is necessary, in order to blanch and sweeten the stalk.

If you wish very large plants, or to preserve for winter use, do not commence this until October; but if you desire a few, delicate and cxisp, for early use, begin, when from twelve to eighteen inches high, earthing up a little at a time in fine dry weather, but not too often; once in two or three wceks is sufficient, as, if disturbed too much, the stalks do not grow so large. Take care not to cover the crown bud. At every earthing up, a very slight sprinkling of salt in the trenches is advantageous. Continue the earthing up every two or three weeks, as the plant grows, through the season. In earthing-up, care must be taken that the mould does not get between and separate the leares, which induces decay. Hold the leaves tightly with one hand, and with the other draw the earth carefully about the stems. The earth should be fine and well pulrerized. Draw it evenly in a sloping direction from the base to near the top of the lcaf-stalks, and beat it compactly with the back of the spade to throw off violent storms. In the whole process of raising celery, the ground must be kept well pulverized and free from weeds, and liberal watering in continued dry weather is very necessary. Do not earth up celery while the plants are wet. The French bind the plants with straw bands, previous to earthing up, just as we do cardoons.

Market gardeners do not prick out their celery at all; they let it grow pretty thick in the seed-bed, and if the plants get too high before the time of setting out, they cut the leares off nearly to the crown. They make the trenches with the turning-plough, and after the earthingup has proce eded so far by hand as to make the trenches level with the surface, they use the plough between the rows previous to earthing-up with the hoe. They also 
take their late and early plants from the same bed; for late celery, cutting off the plants as often as they get too high. Plants can thus be kept in the seed-bed until the last of July, and by being thus cut down, the butts and stalks of the celery will be stocky, large, and fine.

Celery grows so quickly after the plant is established, that those plants put out the last of July, and earthed-up in October and November, make the finest butts for a main crop. There is beside no difficulty in their keeping. The very finest celery may be grown by the foregoing method; but celery, quite good enough for common use, can be raised after Mr. Peabody's plan, which we give in his own words :

"As the whole process of making celery is artificial, the soil must be very rich, without heating manure. The seed may be sown in February and March, and may be put in in drills, where it is desirable to have it stand for blanching (all the transplanting and trenching is nonsense); the seed should be sown very thin, and covered about half an inch, and the earth trampled quite hard on them, which will cause them soon to regetate. When the plants are up three inches, thin them out, to a stand of about six inches apart, and in elear, dry weather, draw the earth up to the plant, taking care to leave the crownbud uncovered. This must be repeated as fast as the plant grows, until a mound or ridge has been made around the plant some two or three feet high. It will now be fit for the table. On uncovering the stalks, they will be found to be beautifully blanched, and perfectly delicate and tender. A rough frame-work over the plants, covered with brush through the hottest part of the day, will be an advantage."

The advantage of growing celery in trenches, over Mr. Peabody's plan, is, that not only are the stalks larger, but 
in our dry climate the plants are far less affected by drought, as the trenches retain all the moisture received. Very good celery for common use may be raised by setting the plants, when ready for final transplanting, between the rows of Irish potatoes; as these have been hilled up, a trench already exists. This should be well dug, and plenty of rotten stable manure applied. By the time the celery begins to grow, the potatoes can be removed. As the celery advances in growth, draw the earth up to the stem, and continue this as long as it is in the ground. It will be just as good for soups as if grown in regular trenches, with not a tenth of the trouble, and in time gets large enough to eat as salad. Celery grown in rich ground is far more crisp and agreeable than on that less highly manured.

Celery, in this climate, need not be gathered or stored away, but may remain in the ground until needed for use. In taking up, the row should always be commenced at one end, and the earth dug away entirely down to the root. The plants can thus be easily extracted. If forced up, they break and are spoiled.

To save Seed.-Leave some plants where grown; in the latter part of February, take them carefully, cut off the outside leaves, and remove the side-shoots, and plant them out in moist soil, one foot apart. Select those which are solid and of middling size. Tie the seed-stalks to stakes, to preserve them from being broken off by violent winds. After the flowers open, while the seed is swelling, if dry weather occurs, water at least every other night. When the seed is dry, it may be rubbed out and stored in a dry place. They will keep good four years.

L 'se.-Celery has some little nutriment, but is cultivated chiefly as a luxury. The sweet, crisp stalks, used raw, with a little salt, form a most grateful salad. It is also 
much used as a seasoning, and is a great improrement to all soups and gravies. $\Lambda$ few plants for this purpose are as necessary and wholesome as onions. The unblanched leaves and seeds are sometimes employed in flavoring. The blanched stalks form a pleasant conserve, with the addition of sugar.

To Stew.-Wash the heads, and strip off the outer leaves; either halve or leave them whole, according to their size, and cut them into lengths of four inches. Pui them into a stew-pan, with a cup of broth, or weak white gravy; stew till tender; then add two spoonfuls of cream, a little flour and butter, seasoned with pepper, salt, nutmeg, and a little pounded white sugar, and simmer all together.-Mrs. Hale.

Celery Sauce.-Wash and pare a bunch of celery; cut it into pieces, and boil gently until tender; add half a pint of cream, and a small piece of butter rolled in flour; now hoil gently.-Mrs. Hale.

\section{Apium Rapaceum-Celeriac of Turnip-Rooted Celery.}

In Germany, this is esteemed an excellent vegetable, but it is not much cultivated by the Englishor Americans. Its root, well grown, is tender and of a sweeter flavor than the one last described.

Celeriac is propagated by seed, which should be sown at the same time, and the young plants treated in the same manner as celery. Like that plant, the seeds are slow in coming up. Keep the plants free from weeds and prick them ont when small, as directed in the last article; when the plants are six inches high they are fit for final transplanting; set them in rows two feet asunder, and eight inches apart in the rows upon the level ground, or in drills drawn with the hoe three inches deep, as they 
require but little earthing-up. When arrived to nearly their full size, they must be covered over with earth to the depth of four inches. In dry weather they should be watered plentifully every evening, as they like even more water than celery. The only additional attention required is to keep them free from weeds. 'The plant is more easily cultivated than celery.

Saving Seeds.-The directions for celery are in every respect applicable to celeriac.

Use.-This, though a very fine vegetable, seems to be little known. The stalks are used for seasoning soups \&ce, the same as celery from which they can hardly be distinguished. The roots are nice boiled tender, cut in slices and used in seasoning soups or meat pies; or scrape and cut them in slices, boil till very tender, draw off the water, sprinkle a little salt and turn in milk sufficient to cover them; stew four or fire minutes, and serve up with the addition of a little butter.-Mrs. Webster.

Bridgman says "the French and Germans cut it in slices and soak a few hours in vinegar-by such simple preparation it becames mellow as a pine-apple and affords a delicious and rery nourishing repast." The root is better than celery for seasoning soups.

\section{Apium Petroselinum*-Parsley.}

Parsley is a biennial plant from Sardinia and southern Europe. There are two varieties, the plain and the curlyleaved. The first is most cultivated, notwithstanding the greater beauty of the latter for a garnish. The curled plant however requires more care in selecting, or it soon degenerates into the plain-leaved variety. Some think the plain has the best flavor.

Culture.-Parsley is raised only from seed. Sow at * Petroselinum Satirum. 
any time from the first of October until April. The seed if kept through the winter regetates slowly and should be soaked twenty-four hours in water before planting. Parsley beds must be made annually if the plants are allowed to run to seed; but if the seed stalks are cut down as often as they rise, the plants will last many years. Many sow parsley as an edging to other beds or compartments. If sown in beds by itself, it is better not to sow broadeast, but in drills ten inches apart. Any good garden soil is rich enough for this plant. Pulverize the bed by thorough spading, and rake it level before making the drills. Sow the seed moderately thick in drills an inch deep, and press the soil upon the seed; a few radish seed may be sprinkled in the drills to mark them. 'The plants will not come up in less than three or four and sometimes six weeks. If sown late give it a shady border. Oetober is the best month to sow this plant. Should the bed get weedy before the parsley appears, pull the intruders out by hand. As soon as the rows can be seen, hoe between them and draw a rake crosswise to break the crust which has been formed, and the plants will grow vigorously. They will be fit for use when two or three inches high. When they get strong, thin them out to three inches and finally to nine inches apart, being careful to reject all plants from the seed bed that are not nicely curled. If they grow too rank in summer, cut them off close to the collar.

Soot is the very best manure for parsley, but it should be sparingly applied. A bed six feet long by four feet wide is large enough for almost any family. It is best to appropriate to it such a bed, where it will sow itself and yield a constant succession of new plants. Parsley needs no protection here, but grows all winter. Cut off the plants closely in October that they may send up a fresh growth for winter use. 
To save Seeds.-All you have to do, is to let some of the finest curled plants throw up seed-stalks; let them stand eighteen inches apart; when the seed ripens it may be stored in a dry place. It will keep grood several years, and it is singular that seed four years old will come up more quickly than that gathered six months before sowing.

Use.-Parsley is a rery agreeable and useful plant, affording a beautiful garnish. It is also used for its aromatic properties in seasoning soups, stews, and meats. The green leaves eaten raw diminish the unpleasant smell of the breath after eating leeks and onions. It can be dried in summer, pounded fine, and put away in bottles; but this is of no use in this climate, where fresh, green parsley can be had all winter from the garden. A tea made of the root is a good diuretic for children. The plant is also said to be useful in dropsy.

\section{Apium Latifolium*-Hamburgh Parsley.}

This plant is also known by the name of broad leaved or large-rooted parsley. It is not much cultivated ; it is propagated by seed, which may be sown from October to April. Sow thinly in drills, ten inches apart, in good soil, well dug and raked clean previous to laying out the drills.

The plants come up about a month after sowing. When tolerably well grown, thin them out to nine inches asunder. Clean the bed from weeds, either with the hand or the hoe. Hoeing as often as the weeds appear or the ground gets hard is all the cultivation they need. By the first of July the plants may begin to be drawn for use. 'They can remain in the bed during the winter, to be drawn as required.

To obtain Seerl.-Allow some of the best plants to re-

*Petroselinum — ? 
main and throw up seed stalks. When the seed is ripe, cut, and when perfectly dry beat out and store away in a dry place.

Use.-The root is the part used, and is about the size of a middling parsnip. By boiling, it is rendered very tender and palatable. It is eaten either as a sauce to meats or in soups like the carrot, but is not likelv to come into very general use.

\section{Arachis Hypogea-Ground PEA.}

'This plant is likewise known as the ground nut, pindar, and pea nut. Although not exactly belonging to the kitchen garden, a few hills should be allowed a place for the sake of the little folks, and indeed when baked fer of the older members of the family will find them unpalatable.

The ground pea was originally brought from Africa. It is also said to be a native of Mexico. This plant is a trailing annual, one of the few which ripens seed under ground. The yellow pea-shaped flower springs from the part of the stem near the surface of the earth, and after veing fertilized, the flower stem elongates, growing from four to eight inches, turning downward until the small tubercle which is to be the future seed-pod, reaches and penetrates the earth. From the lower extremity of each legume, in the early part of its growth filaments proceed, seeking moisture and probably nutriment from the soil. The seed of the ground pea abounds in a fine oil which is sometimes expressed for table purposes.

This oil renuters it a very valuable crop for fattening hogs, being for this purpose fully equal to, and probably better than corn. The vines are greedily eaten by most farm animals.

Culture.- The ground pea thrires and produces best on 
a light, tolerably fertile soil with a good clay subsoil. Like clover, it possesses a long tap-root which extends deep into the earth, drawing thence the fertilizing properties which are beyond the reach of many of our cultivated crops. The soil should be deep and mellow and well broken up, so as to be ready for planting soon after the heary frosts are over. The last of March or the first of April is a suitable time.

For field culture, they may be planted in the pod, two in the hill; but for the garden should be shelled. It is best to drop about four in a hill on the level ground; the rows being laid off three and a half feet wide and the hills two feet asunder; cover them two or three inches.

When they come up, thin them to two in a hill and, if there be any racancy, transplant. It is better to plant them level than on ridges, as they are less liable to suffer from drought. As they continue growing all the season, it is well to get them started as early as the season will permit. The only after-culture they require is to keep the ground clear and mellow, and a slight hilling up when they are laid by. They will produce from twenty-five to seventy or eighty bushels per acre, according to soil and culture, and are as easily cultivated as corn.

\section{Arracacha Esculenta.}

This is an umbelliferous plant, a native of Columbia, the root of which has been compared to the potato in excellence and even supposed by some, likely to supersede it. Its main root divides into several large prongs. It considerably resembles celery in the appearance of its leaves, and belongs to the same natural family. Its root is light, starchy, and wholesome, and to those accustomed to it, agreeable. It is said to thrive best in the elevated mountain regions where the medium temperat ure does not 
exceed $60^{\circ}$. It is propagated by division of the root an more rarely by seed. It is worthy of trial here.

\section{Artemisia Dracunculus-TARR AgoN.}

This is a perennial plant, a native of Siheria. It belongs to the same genus as the wormwood, but its fragrant smell and warm aromatic taste have introduced it into the kitchen garden. There is but one variety cultivated.

Culture.-This plant does not require a rich soil, and as it is a native of a cold climate, it is best to give it a bleak winter exposure. Poor dry earth is necessary to perfect its flavor. 'Tarragon is propagated by seed, slips, cuttings and parting of the root. 'The latter is the easiest mode and most generally practised. It may be planted in February, the plants being ten inches apart. Give a little water in dry weather until they are rooted. As they run up, if seed is not desired, cut down the seed stalks and they will shoot up afresh. Keeep them free from weeds. It has been cultivated here with success.

Use.-Tarragon is used in salads to correct the coldness of other herbs. Its leaves are excellent pickled or for flaroring vinegar to be used for fish sauces or with horseradish for beef steaks.

\section{Asparagus Officinalis-Asparagus.}

This plint has been cultivated as a garden vegetable, for at least two thousand years. Cato, 150 years before Christ, gives a full detail of its mode of culture among the Romans. Its culture originated probably in Greece, for its name is pure Greek, and signifies a bud not fully opened; and it is known throughout Europe, by names derived or corrupted from the Greek. 
The wild asparagus is found native in Japan, and on the sea coasts of most parts of Europe.

In its wild state, the stem is not thicker than a goosequill. From this plant, by the aid of manure and culture, our delicious garden varieties were raised. Miller has succeeded in efiecting the same result in modern times.

There are only two varieties of asparagus of any importance, the green and the red-topped. The latter with purplish green shoots, is the one principally cultivated. There are some sub-varieties, but these derive all their merit from superior cultivation.

'The following analysis of asparagus is by Thomas Richardson:

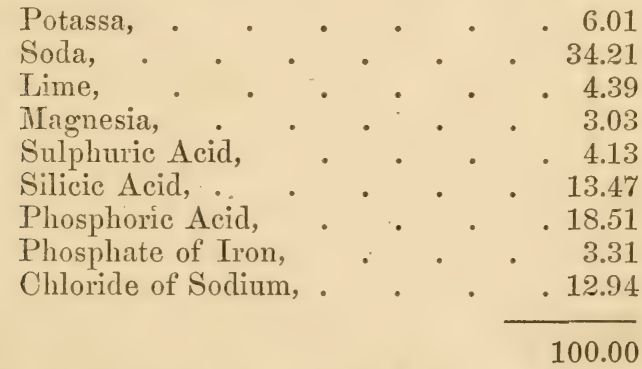

The per-centage of ash was only $\frac{47}{700}$ of a pound, from one hundred pounds of the undried plant.

In other analyses of asparagus the proportion of soda is considably reduced. Asparagus, like some other plants has the power of substituting the other alkalies, lime and potash, in the place of soda.

All of the analyses exhibit larger proportions of chloride of sodium, or its elements, chlorine and sodium, also of phosphoric acid.

In the present instance, over three-fifths of the inorganic elements of the plant, are made up of these constituents. 
This very clearly explains why salt and sea-weed are found so beneficial, and shows that the application of bone manure, or superphosphate of lime, in connexion with animal manures, may be beneficial. In the analysis of the wild plant, the proportion of these elements is quite as large.

Culture.-Asparagus is propagated only by seed, one ounce of which will produce a thousand plants. Sow the seed any time in February, or early in March. It likes a fresh and deep sandy loam, the richer the better-as free as possible from all shade of trees or shrubs. Soak the seed twenty-four hours before planting, and it will come up earlier; draw the drills one foot apart, and with a dibble make holes six inches distant, in which drop two or three seeds. Let the seed be covered an inch deep, and press the earth upon it. In very dry weather the seed-beds should be frequently watered. If unable to sow as early as directed, shade must be given to the bed, for which purpose pine boughs are well suited. These should be removed nights and cloudy days. Care must be taken to keep the secd-bed light and free from weeds, though this operation must be delayed until the plants appear well above ground. If two plants appear in the same hole, the weaker must be removed as soon as that point can be determined. Transplanted, theye will make pretty govel plants by fall. If they are to remain in the seed-bed until spring, which is best, when the stems are withered, eut them down and spread well-rotted stable dung orer the bed two inches deep, which will increase the vigor of the plants the next year, and also protect them from frost.

Asparagus treated in this manner will perfect seed the first year in this climate, and the roots one year old, make quite as good beds as if allowed to remain in the seed-plot another year. You may plant them out safely in autumn or any time during the winter, choosing a mild cloudy day, 
and protecting them when planted with a covering of manure overspread with litter; but the best time to transplant is when the plants begin to grow early in the spring, for if they remain torpid during two or three months, some of them will die, and all will be weakened.

As it should be a matter of pride to have this delicacy as early as possible, choose a site where the bed can be fully exposed to the sun. If you wish to prolong its season, another bed may be planted on a northern expors. The subsoil should be dry, and if not naturally so, mus : e well drained. It must be dug up thoroughly at least two and a-half feet deep, the pror soil removed, and its place supplied with rich light loam. On a plot of four square rods, sow from seventy-five to a hundred pounds of fine salt, and dig it in four or five inches deep. Asparagus is a seashore plant, and salt will not hurt it ; but is life and nourishment to it. Bury your manure and mix it well throughout the whole depth, as you can hardly make the ground too rich. Asparagus will grow, it is true, without all this trouble, but the size, sweetness and tenderness of the shoots, will pay for doing the work in the best manner.

After taking out the soil the bottom should be covered with at least six inches of well-rotted manure, as this can never be reached after the roots are once planted. Intermix nearly as much more throughout the bed, except the top four or fire inches, as the manure should not come in contact with the fresh roots. So manured and deeply dug, the plants will send down their roots too deeply to fear a drought.

Make the beds four and a half feet wide, and the paths two feet in width between the beds.

The plants should be carefully taken up without injury, choosing a mild cloudy day, but the ground must not be wet. A narrow dungfork is a good instrument for the 
purpose. Lay the roots separately and evenly together, that they may not be entangled and injured while planting; keep them while planting in a basket covered with a little sand. Plant your first row by straining a line four inches from the edge of the bed; then with your spade cut out a trench six inches deep with the side next the line perpendicular, in which set the plants twelve inches apart, if good large heads are desired. Place the roots against the perpendicular side of the trench, and spread them out evenly in the bottom of the trench, and cover them by drawing back the earth regularly over the plants about two inches deep. Draw the line again fifteen inches from the first, and proceed as above, leaving a path two feet wide, four inches from every fourth row. Some plant lettuce and radishes between the rows, but it is not advisable, though a crop of cabbages may be made in the alleys. After the beds have been planted, rake them smooth, and do not tread between the rows. Keep the edges of the bed smoothly trimmed and even. The beds are made narrow to avoid the necessity of treading upon them with the feet, as they should be left as light as possible, for lasting from ten to twenty years without working, the rains will render thein compact, and walking upon them would be very injurious. Water them daily in dry weather until the plants are well-rooted. Watering in dry weather in summer also is very beneficial. All weeds must be removed as they appear. As salt applied while the plants are young, is an excellent manure for this plant, the weeds may be easily kept down by its application. Old brine or refuse salt, in which meat or fish has been packed, is better than any other, as it abounds in the blood and juices of the meat, which are a most valuable fertilizer. You need not fear applying too much salt, as old beds have been covered an inch deep, and the plants 
continued to thrive; but a sprinkling just sufficient to make the soil look white, is enough. As soon as the plants have turned yellow in the fall, cut them down close to the ground, but be careful not to do this early, or they will throw up new shoots and be much weakened. Remove the stalks and all weeds from the beds-cover the beds with three or four inches of good stable manure, and let them remain until time for the spring dressing. If you have charcoal dust at command, a layer of an inch thick over the manure will be found quite useful in preventing the loss of ammonia. When the weather grows warm, the latter part of February, with a three-tined asparagus or manure fork, dig in the manure placed on the beds in the fall, and loosen the earth four inches deep, taking care not to wound the crowns of the plants. Give the beds a topdressing of salt as soon as growth commences, and water freely in dry weather. Applications of liquid manure are likewise very salutary. A good liquid manure for asparagus is an ounce of guano and four ounces of salt to two gallons of water. Guano or night soil composted with charcoal, so as to be entirely inodorous, is also beneficially applied at any time. Another slight covering of charcoal dust, after the spring dressing, will be of service, and make the shoots earlier. Until the bed is two years old, the alleys should be also deeply dug and well-manured, as the plants will derive much nourishment from them. After that period the roots will extend so widely that they cannot be worked without injury.

When the bed is one year old, it may, if it has been well-treated, be sparingly gathered from. The plants, if the season has been good, will be almost as well grown as those a year older at the North. It should be cut before the heads loose their compact form, when only four or five inches above the ground. Remove the earth to the bot- 
tom of the stalk, and cut it off sloping with a pointed knife, taking care not to wound any other shoots that may be near it, as they are constantly putting forth from the crowns. Too many shoots should not be cut from the beds, nor the gathering prolonged too late. Whenever the bed puts up weak and small shoots, these should be nllowed to remain, which will increase the size of the remaining shoots, and the future value of the bed. When green peas become plentiful, it is high time the asparagus bed should rest. After the cutting ceases, you may judge from the size of the summer shoots the productiveness of the bed the coming spring. These elaborate the food for the future crop. The manure applied in autumn thas but little effect on the next spring's shoots, but from its influence the strong growth of the succeeding summer will prepare an abundant supply of large shoots the second spring. The spring and autumn dressings should be continued while the bed lasts. Beds will remain productive ten or fifteen years. By planting a hot-bed thickly with thrifty roots, it comes into bearing in four weeks, and affords asparagus for a month in the winter season. Give plenty of air in mild weather.

For Seed.-Reserve some of the best shoots in the spring, and maxk them by placing a stake by each one, and let them run up and ripen their seeds. Take shoots with fine, round, close heads; fasten them as they grow up to the stake, and the seed will ripen better, Gather the seed when ripe, and wash off the pulp and husk, which will pass off with the water, if gently poured off, and the seeds will sink to the bottom. Dry them thoroughly, and store away for use. 'They are, for your own sowing, just as well kept and sown in the pulp.

Asparagus seed will keep four years.

Use-The tender shoots thrown up in the spring when 
from four or five inches long, are the parts in use, and are very delicate and much esteemed, though not very nutricious. They are excellent simply boiled, or as an addition to soups when in season.

To ccok Asparagus.-Select the large green stalks, wash them carefully, tie in bundles of twenty or thirty, put them into boiling water with plenty of salt; boil slowly twenty minutes; take them up with a skimmer without draining, and lay them upon toasted bread well buttered.

Another mode is to cut it into bits half an inch long, and boil the lower ends ten minutes before the points are put in; then put in the points and boil ten minutes more; serve as above.

\section{Atriplex Hortensis-Orach.}

A hardy annual, a native of Tartary first cultivated by English gardeners in 1548. The stem rises three or four feet high with oblong varicusly-shaped leaves, cut at the edges, thick, pale green, and glaucous, and of slightly acid flaror, flowers of same color as the foliage. There are two varieties, the pale green, and the red or purple leaved:

Culture-Orach flourishes best in a rich, moist soil. It is raised from seed sown in drills, fifteen to eighteen inches apart, the first of October. The plants soon make appearance; when an inch high thin them to four inches asunder. Those remored may be replanted, being watered occasionally until established. Hoe them in a dry day, keeping the ground loose and free from weeds.

Use.-The leares and tender stalks are cooked and eaten like spinach, to which it is preferred by many. They must be gathered while young, or they are worthless. It belongs to the chenopods, Jerusalem oak tribe of 
plants; a family whose wholesomeness is very suspicious. Its seeds are said to excite vomiting.

\section{Barbarea Precox-American Cress.}

A biemial plant, with yellow flowers, the radical leaves of which are lyre shaped, and the upper ones pinnatified, and cultivated in some gardens as a winter salad. Often it is called watercress at the South.

Sow cither in drills or broadcast in a moist place, the last of August, September, or early in October, giving water in dry, hot weather. Let the plants remain six n. eight inches apart. Preserve a few good plants for seed.

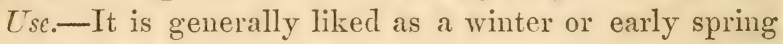
salad somewhat like the watercress, but more bitter.

\section{Barbarea Vulgaris-Winter Cress.}

Resembles the foregoing, but is a perrennial plant with larger leaves. The use and culture are the same. Less bitter than the foregoing.

\section{Beta-BeEt.}

Of this genus there are two species cultivated in gardens, viz. : Beta Cicla, and Beta Vulgaris-the latter of which has many varieties.

\section{Beta Vulgaris-Common BeEt.}

This is a biennial plant, a native of the seacoasts of the south of Europe, and is said to have been cultivated for its beautiful red roots long before its edible properties were discovered.

It was introduced into England by Tradescant, in the year 1656. Its name is said to come from the resemblance of its seed to the letter Bitil of the Greek alphabet. 
The catalogues contain a large number, of varieties of which the best are :

Ertra Early Turnip, or Bassano Bect.-The root is oral; color, pale red. Downing truly says "it is the sweetest, most tender, and delicate of all beets;" but the color boils out, so that it is not as beautiful as some others, yet it is the best early beet and one of the easiest grown. It is at least a week earlier than the Early Turnip Beet, an excellent variety that succeeds it.

Radish Beet.-Is named from its similarity to the scarlet radish in shape, though much larger. Color, very dark blood red. Roots of this variety over a-half yard long are not unusual. Its quality is excellent.

Londun Blocd Bect.-Is a brilliant, dark-colored beet of good form, and of a sweet and delicate flavor. The best of the late beets.

These beets are best for family use, but if the seeds are not obtainable, the Early Blood 'Turnip Rooted, Early Long Blood, Extra Dark Blood, and White's New Blood, are all good varieties. The Early Long Blood grows several inches abore ground, and is more easily gathered than any other variety.

The ashes of the beet root have been analyzed by Etti, who found them to contain the following constituents :-

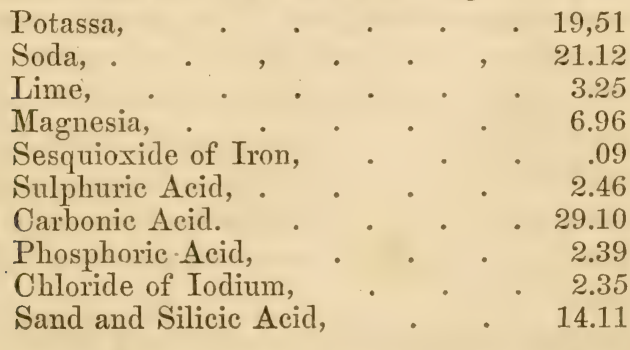


The bect being a native of the sea-shore abounds in soda, which can be supplied when deficient by an application of common salt the autumn before planting. 'This and leached or unleached ashes will afford nearly all the inorganic elements of the crop.

Beets can be planted in this climate, at any time from January to March, and as late as April, with a little care in shading and watering.

When the surface soil is rich and the bottom poor, it will be difficult to make the beet, carrot, and other taprooted plants produce fine, smooth roots. This difficulty will cease if the ground be deeply and thoroughly worked, mingling the soil and making it uniform throughout, and taking care to place at the depth of one foot below the surface a layer of good manure.

The best beets grow in sandy bottom lands, but any soil will answer for them if deeply and thoroughly worked and well manured. This is necessary with all tap-rooted plants, and especially with the beet. Beet seed is somewhat slow in regetating, and the later sowings may be soaked in water twenty-four hours before planting; make the beds four or four and a-half feet wide for convenience of culttivaing; spade them up at least a foot deep, eighteen inches is still better; mix in a good supply of well-rotted manure throughout, if the ground requires it. Rake the ground even and smooth, and mark out the rows twelve inches apart across the bed; draw the drills an inch and a-half or two inches deep, in which drop the seed two inches apart, and press the earth gently upon it. When the plants are up, thin them to six or eight inches apart, and keep the ground around them loose and free from weeds.

In planting crops of beets, carrots, and parsnips, particularly the two latter, it is well to sprinkle $a$ few radish 
seed in the rows to distinguish them. The radishes will be up in a week, and the ground can be hoed or weeded without any danger of destroying the young plants; and pulling the radishes is cultivation to the young crop. Drills can also be made between every two rows of beets, making a drill every six inches, which can also be sown with radishes or lettuce plants.

I would never think of making beds exclusively for lettuce plants or radishes, as these can be grown between other regetables without the loss of any room. But the ground must be very rich, as all garden soil should be, to bring forward both crops to perfection.

For early beets it is well to prepare a good bed under glass in which the rows should be marked out a foot apart. The ground should be deeply spaded and thoroughly manured. Mark out your rows for the beets, and between the first two draw a drill in which you can sow your early York cabbage; between the next two you can raise all the butter lettuce you wish to set out for heading. In the rows of beets theinselves you may sprinkle a a few radish seed; then a row of later head lettuce, tomatoes, egg-plant, peppers, \&c. The drills retained for the beets should be sown in this climate with the Bassano beet about the tenth of January. By the time the hard frosts are over, the beets, cabbages, \&c., will be fit to transplant. Thin out to six inches apart, planting out those pulled up in the open ground. In transplanting the beet a deep hole should be made with a dibble, and the root not bent. Those that remain in the bed will soon come into use, and by the time they are gone the transplanted ones will come on for a succession. For very late beets, sow in a cool, moist place early in April ; May or June would be still better, if the sowings were not so difficult to keep from being killed by the sun. Press the earth on the seed, and shade a 
little until the plants come up; being sown later they will keep much better, and indeed can be had in pretty good condition through the entire winter. For this sowing, the London blood beet is the best. A few radish seed may be sown with them; after they come up they must be thinned to ten inches apart, kept clean, and frequently hoed-keeping the soil light and mellow. Any vacant spaces in the row can be filled by transplanting. About the middle of Norember, or when there is danger of a hard frost, the roots can be taken up, dried a little and stored away in casks with layers of dry sand, where they will keep in good condition until spring. The mangel wurtzel beet is much cultivated in some countries for feeding stock, and is very good for the table when young and tender, but in our long season it loses its sweetness before winter. Here the swcet-potato, ruta-baga and other turnips are more promising.

For Seed.-Select a few of the finest looking plants, smooth and well-shaped. Plant the different varieties as far apart as possible, indeed it is better to save the seed of only one kind the same year for fear of intermixture and degeneracy. Keep them free from weeds and tic the seed stalks to stakes to support them. Gather and dry the seed as soon as ripe and put away in paper bags. Keep dry and it will be good for ten years.

Use.-The young and tender tops are an excellent substitute for spinach. When thinned ont, the young beets pulled up, if cooked tops and bottoms, are very sweet and and delicate.

When well grown they afford an agreeable variety to our table vegetables, being tender, sweet, and considerably nourishing. They also make an excellent pickle. If eaten moderately, they are wholesome, but in too large a quantity produce flatulence and indigestion.

The leaves 
are said to abound in nitre; the roots are full of sugar, and are largely cultivated in France for its manufacture.

To Boil.-Wash the beets, but do not ent or scrape them. Boil from two to three hours (one hour will do when they are young); when quite tender take them up and plunge them into cold water for a minute or two, and the outside skin will peel off easily. If they are young beets they are best split into long pieces and seasoned with pepper and butter; otherwise, slice them thin, when quite cold, and pour vinegar over them.

When the beets get old they loose a good deal of their sweetness, and are made fit for the table by sprinkling each layer of beets when ent up while still hot with powdered sugar, and after the slices have dissolved and absorbed this, add the vinegar and spices.

To Pickle.-Boil them sufficiently tender to easily put a fork through them; put them into cold vinegar, with a little salt, set them in a cool place, and stir them often to prevent any seum from rising.

\section{Beta Cicla-Swiss Chard, or White Beet}

This is also called the sea-kale bect. There are two varieties, the white and the green, which receive their names from the color of their foot-stalks. Either of these is good. The plant very much resembles the common beet, but the leaves and the stalks are much larger, thicker, more tender and succulent, and less capable of resisting frost.

The root of this plant is small, coarse, and of no value, only the leaves and their stalks are employed, especially the latter, which are cooked and eaten as asparagus.

Culture.-The culture is exactly the same as the com. mon beet, except the plants should be twelve or more inches apart. The soil may be richer and not so deep, 
and the plants are more benefited by copious watering, especially with liquid manure. The beds should be four feet wide for convenience in culture. For winter use, the leaves may be covered with litter and afford blanched leaf stalks all winter. If the soil be moist and kept mellow, and free from weeds, it will yield bountifully. Salt is a beneficial manure for this crop, applied while preparing the ground, as it keeps it moist. It is singular that a plant of so easy culture and yielding during the entire season after May a supply of the most delicate greens, has not come into more general cultivation. Those who have cultivated it once in good soil will hardly be willing to do without it. To preserve seed, see "Beta Vulgaris."

Use.-The leaves, stalks, and all are boiled as summer greens; or the midrib and stalk may be peeled and boiled separately from the rest of the leaf and prepared as asparagus for which they are an excellent substitute. In gathering, the largest outside leaves should first be taken and the inner ones left to increase in size, taking care to gather them while still perfectly green and vigorous. The leaf-stalks are greatly improved if earthed-up like celery.

To Boil.-Strip the leaves from their stalks ; boil them very quickly; drain and press very close, and serve with melted butter. The stalks tie in bundles; boil till tender; dress, and serve as asparagus.

\section{Brassica-The Cabbage Tribe.}

This tribe, perhaps the most important cultivated in our gardens, includes the cabbage, turnip, cauliflower, broccoli, Brussels, sprouts, rape, and kale. It seems to be one of the most ancient in cultivation, and was a well-known favorite with the Romans. Lindley observes, that of this genus there are nearly a thousand species scattered over 
the face of the earth, of which all are harmless, and many are highly useful.

For the seed-bed the soil should be a moist loam, but more dry in the case of plants which are to stand the winter.

For final production most plants of this genus like a fresh, moderately clayey loam, very rich. A moist cool bottom suits them adinirably; such of them as are to stand the winter in the open ground should be grown in a lighter soil, not over rich. Good well decomposed stable manure is usually employed in preparing the soil for this genus. Pure hog manure is objectionable, as it causes any of the cabbage tribe to become clump-rooted and loose their regularity of shape; if mixed with a very large proportion of leaf mould, or other carbonaceous matter, and thoroughly decomposed, it ceases to be objectionable. A plentiful application of salt the autumn before planting, say at the rate of eight or ten bushels per acre, is very beneficial to this tribe as it destroys the cutworm and keeps the soil moist and cnol. Bone-dust and especially superphosphate of lime has a very surprising effect upon them, far more than analysis would lead one to suppose.

The ground is advantageously dug twice the depth of a spade, and should be well pulverized by the operation. All of the cabbage tribe are particularly benefited by frequent and deep cultivation; they especially like to have the soil about them thoroughly worked while the dew is on them. There will be a very great difference in the growth of two plats of cabbages treated alike in other respects, one of which shall be hoed at sunrise, and the other at mid-day; the growth of the former will surprisingly exceed that of the latter. But you cannot hne the cabbage tribe too much for their benefit even if daily. The situation must be open and free from all shade or drip of trees; if 
shaded from the mid-day sun, it is an advantage, but it must not be by trees. In the shade of trees and other confined situations, they are much more subject to be infested with caterpillars, and to grow weak and spindling: In planting out, any of which the roots are knotted and clumped should be rejected.

\section{Brassica Oleracea-CABваGE.}

This vegetable has been long in cultivation. Pliny mentions the headed varieties, and it was then held in high esteem, not only as an esculent, but for its supposed medicinal properties; it is a sea-shore plant, indigenous in various parts of Europe and in England; the wild variety is known as sea colewort, learing but a few leaves, and those far from palatahle, unless boiled in two waters to remove its saltness. The cultirated rariety was probably introduced into England by the Romans, and the common name doubtless comes from the Latin Caput or head. This is one of the most useful crops in cultivation. Cabbages are eatable almost from the time they leave the seed bed until they have acquired a hard close head; it is a crop that can be put on every bit of otherwise idle ground. It can be planted between beds and rows of any and everything else to be eaten as greens when young, or left to head on the coming off of other crops, and if there should be a superabundance above the wants of the family and servants, nothing is better for the cow and the pig. For early cabbage it is necessary to rely upon English seed, as the seed of the early varieties, saved in this country grow later by our culture, soil and climate. For late cabbage, the American sceds are superior to the imported, and produce finer and larger heads. No seed for late cabbage is better than our own, if saved from fine large heads. But all the late cabbages in this hot climate without proper 


\section{CABBAGE.}

care, are prone to degenerate and run up into collards. There are many varieties of cabbage. The best varieties I have cultivated are the following:-

Early York has been cultivated for more than a century. Heads small, a little heart shaped and very firm; its small size enables it to be grown in rows a foot apart each way, giving over 40,000 heads to the acre. Its earliness and fine delicate flavor make it a favorite, as the very best early sort for general purposes.

Large Eurly York, or Landreth Large York, succeeds the above, and is equally desirable. It is of larger size, not quite so early and more robust, and bears the heat better, and in this latitude will often continue in eating all summer.

Early Dutch is an excellent variety that connects the early and late sorts, and is one of the very best in culture. It is succeeded by the

Flat Dutch or drumhead, which is a large spreading, short-stemmed variety, flat on the top, close headed, firm in texture, and if headed late keeps well and is of better flavor than

Bergen, which is also a drumhead cabbage, but larger; a little coarser and one of the best for late keeping.

Green Glazed, in this climate is a more sure variety, as it is more capable of resisting the caterpillar and other insects which infest the other rarieties, but it is a coarse variety with very loose heads.

Red Dutch, used principally for pickling, and should be sown at the same time with the drumbeads. Early York and Flat Dutch are the best of the above kinds.

The analysis of the drumhead cabbage is given below. One thousand pounds of the plant when burned, produced cight pounds and four tenths of ash, which was composed of the following constituents :- 


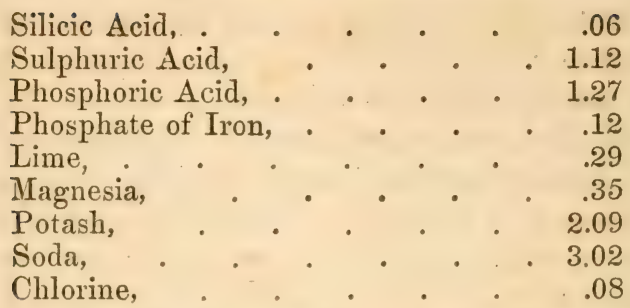

The above analysis is by J. H. Salisbury, who also analyzed several other varieties. He found them all to contain a very large proportion of azote; after evaporating the water, drumhead cabbage gives of azote 17.899 parts in a hundred; savoy 20.763 ; red 16.212; turnip rooted 19.052. We also find this plant remarkably rich in phosphorus and sulphur, hence its unpleasant smell in decay, like that of animal matter. It abounds also in soda and potash. Hence, common salt to yield soda and chlorine, wood ashes for potash, bone for phosphoric acid, and gypsum, to add sulphur and lime together with a soil saturated with manure of animals, especially the liquid excretion, all come in play in making fine cabbage. Frequent stirring the soil, too, will rob the atmosphere of its ammonia for the same purpose.

Culture.-For early use seeds of the Early York may be sown from January to March. If sown as early as the 1st of January, cover them slightly with litter to protect from frosts; but it is much better to sow them under a cold frame as directed in the article "Beet." If sown in the open air, as soon as the weather grows mild, take off the litter. The seed should be sown in drills, six inches apart, and one inch deep, and the ground deeply dug, but it need not be, for this sowing, very rich. Water in mild mornings if the weather be dry, and give them the advantage of the rains; give the young plants plenty of air 
every mild day, and by the time the weather will admit, they will be ready to transplant. At this sowing should also be put in a few seed of the Large York and Early Dutch to succeed the early crop.

Early cabbage seed may also be sown early in September or October in the open ground; watering every two or three evenings when dry, as it usually is this month. The plants will appear in about a week, and a little soot should be scattered over them to prevent the attacks of insects. When large enough to transplant, they can be set very thick in a cold frame or box, to stand over the winter. Cover over with glass, or boards if you have not glass, during severe weather, but give air every mild day and set out when the weather grows mild in the spring. A still better way is, instead of putting the plants in a frame, throw a piece of ground into high ridges, two feet apart, running east and west. On the south side of these ridges, set out the plants a foot apart, so that they will be shielded from the cold north winds, and enjoy the full warmth of the sun. Plant on the sides of the ridges and not in the trench. When the weather grows severe in December, cover slightly with straw or litter; remove it when mild weather returns, and cultivate as usual, gradually levelling the ridges, and you will have cabbages earlier than by any other mode; the ground should be good. If you raise your plants in the cold frame they will be ready to transplant from the 20th to the last of February. They will be very liable to be eaten off by the cutworm when transplanted. 'There are two modes of preventing this, either of which, with me, is perfectly satisfactory. The best method is to sow the ground intended for cabbage the autumn after being spaded up, with salt at the rate of eight bushels per acre. On a part of my 
garden thus treated last November, I have not found a cutworm this year (1852). If this has been done you may plant your Early Yorks at a distance of twelve inches each way. If you have not already sown your cabbage plat with salt, there is another plan to keep off the cutworm equally successful. Throw your ground into ridges and trenches sixteen inches apart; let these trenclies be at least six inches deep. In the bottom of these transplant your cabbages, one foot apart. Some use a dibble, brit a trowel is much better, as it does not leave the soil hard. Prepare your ground in dry weather, but choose a moist day for transplanting. It is a good plan to wet the roots before planting out. When they get rooted stir the soil gently about them, but do not fill up the trenches until the plants are so large that there is no danger of the worm. 'This method of protecting cabbages was pointed out to me by a negro gardener sereral years since, and I have tried it repeatedly. The worm will not go down into the trenches to destroy the plants.

When the plants get strong the ground should be deeply and repeatedly hoed. Do this while the dew is on, and retain its ammonia in the soil. The cabbage is partial to moisture, so hoe it frequently, and when you go out in the morning you will find the plat moist with dew, while the unstirred soil around is dry as ever. The only secret in raising early cabbage is, set your plants in rich ground and stir the soil. On poor ground (and even on rich if half tended) they will rum into collards. Stir the soil and less manure is required.

For the middle crop to last through the summer, the seed can be sown as above, or any time until the middle of March. The cultivation is the same, except that the plants should be set about sixteen to eighteen inches apart. 
The varieties are the Large York and Early Dutch. These will not head unless the ground be rich, rather moist, and, above all, diligently worked.

The late crop and the Red Dutch, for pickling; you may sow in February or Warch, or any other time thereafter, until the 1st of August. The best time is about the 1st of April. The early sown should not be transplanted until July or August. Let the ground be well-spaded, and thoroughly manured. They must be set in the ground up to the first leaf, no matter how long the slem may be, or they will not head. They also require a rich soil, but not from fresh manure. The manure for the cabbage crop should be thoroughly decomposed, or the plants will be covered with aphides or cabbage lice. The best way is to throw the ground into ridges from two to two and a half feet apart, making the trenches between more or less deep, according to the length of the stems; wet the roots thoroughly and transplant in moist weather, carefully transplanting them with a trowel, and when the ground gets dry draw the earth level, which should just reach up to the lower leaves. If seed of any of the cabbage tribe be sown after the weather grows warm, the soil must be pressed upon it by walking on a board, and it must be shaded by a covering of boards or pine brush during the day, removing it at night, until the plants get a little established. If the weather is warm and wet, the covering may be dispensed with.

After the late cabbages are transplanted let them be well cultivated by deep and frequent hoeing, and don't strip off the lower leaves if you wish them to head.

Many remedies are employed to keep off the green worm, so destructive to the cabbage tribe. An infusion of tobacco or of the ripe berries of the Pride of China tree, sprinkled on them once or twice a week from a water-pot, is said to be effectual. Sprinkling with ashes is a good 
practice; also to coop a brood of chickens near, as they destroy the worm without injury to the cabbage. Break off a leaf at night and place it on the top of the head. In the morning early most of the worms will be on this leaf. Brush them off into a dish of soapsuds. Repeat this daily until the worms are destroyed. Aphides are not so apt to be troublesome when the plants are in vigorous growth; an application of strong soapsuds generally destroys them. Dry charcoal dust mixed with Scotch suuff and dusted over them is however, the most certain remedy. Air-slacked lime in which a few drops of spirits of turpentine have been diffused, will generally drive away both aphides and the green worm. The green glazed not being liable to be attacked by worms or insects is much the most reliable for a late crop, if it was only as good for the table.

To preserve Cabbage.-Heel them in, in a dry situation, to their lower leaves, and cover slightly with plank, straw or pine brush, to keep them from freezing and thawing during the winter.

To save Seed.-This should be attempted in this climate only with the late varieties which should be planted at a distance from turnips and all other members of this family, or they will intermix. Set out some of the best heads in the spring, support the stems as they rise by stakes, and gather the seed before it scatters. Seed will keep four years.

Use.-Cabbage as an article of food is not so remarkable for its fattening properties as for its power of supplying strength for labor by producing muscle and bone, which it owes to its abundant nitrogen and phosphates. Hence it is very nutritious for, and much relished by laboring people in all parts of the world, but is apt to disagree with those of quiet and sedentary habits. With the latter it is more wholesome and digestible if eaten uncocked. Many 
persons can eat " cold slaugh" with impunity that are unable to use boiled cabbage without great inconvenience. It is by many much relished when made into sauer kraut. It is also pickled.

To Boil.-Remove the loose leaves quarter the stump end of the cabbage, wash it perfectly clean, and boil from half an hour to an hour. If not boiled with salt meat, add a little salt; a little saleratus improves its color.-Mrs. Webster.

Sauer Kraut.-Shred very finely six white cabbages, having cut out the stalks; mix with them half a pound of salt, and press them as closely as possible into a cask; put over a cloth, then a wooden cover, and upon that a heavy weight; let it stand in a warm cellar two months, keeping the liquor that rises on it, and it will be fit for use ; it should then be removed to a cooler place.-Mrs. Hale.

Sauer kraut for the table should be boiled or stewed.

To Pickle. Take off the outside leaves, quarter, cut out the stalk, shred the cabbage into a cullender and sprinkle with common salt; let the cabbage remain a day or two, when drain it, put it into jars, and fill up with boiling vinegar; add spices to your taste.

\section{Brassica Oleracea Subauda-Savoy Cabbage.}

The Savoy, which is one of the best winter vegetables, probably derives its name from Saroy in Europe. It differs from the cabbage in the rugosity of its leaves. All its varieties are hardy, being rendered more sweet and tender by frost. The only two varieties of Savoy worthy of culture are :

Curled Savoy.-An excellent winter variety, much improved in sweetness and tenderness by frost. It does not head firmly, but is very fine flavored, and even the outside leaves are tender and palatable. 
Drumhead Savoy is almost as large and firm as the drumhead cabbage, and keeps very well. The head is round, flattened at top. It is nearly as delicate as the curled variety.

The Savoys are not as certain a crop as the other cabbages, but far superior in delicacy. They are nearly equal to cauliflowers.

The chemical composition of the Savoy is similar to that of other cabbages, but it contains two per cent. less water. It culture from seed is precisely the same as drumhead cabbage. For cooking, see "Cabbage."

\section{Brassica Oleracea Subauda-(sub-rariety)-Brussels Sprouts.}

This plant is a hardy variety of the Saroy, producing an elongated stem, often four feet high and crowned with leaves similar to the Savoy, in the axis of which spring small green heads like cabbages. The leaves dropping off leave the little heads arranged spirally around the stem as the plant proceeds in growth. Like the other Brassicas, Brussels Sprouts are raised from seed, which may be sown in April. Set the plants in rows one and a half feet apart each way, and treat in all respects as directed for winter cabbage. Cut off the leaves at the top of the stem some ten days or a fortnight before the little heads are gathered.

For Seed.-Cut off the top of the stem and permit the flower stalks to spring from the little heads only. Keep at a distance from all the other varieties of Brassica if you would have pure seed.

Use.-'The top boiled for winter greens is very delicate in flavor and similar to the Savoy. But the little sprouts after they have been touched with frost, which very much improves them, are the parts most used. The 
sprouts are fit for use all winter, and may be left in the spen ground.

To Boil.-Soak them in clear water one hour, and wash free from dust and insects. Boil them twenty minutes or until tender in plenty of water. Drain them well, season with pepper, salt, \&c., to taste, a sauce of cream or floured butter, in which stew them gently, stirring them constantly; or they may be cooked simply as cabbages and eaten with meats.

\section{Brassica Oleracea Fimbriata-Borecole-German Greens.}

This is the easiest cultivated, and for this climate, one of the most valuable of the cabbage tribe. This plant has large curled or wrinkled leaves forming an open head or stool, and such a hardy constitution that it resists the severest frosts which serve only to improve it. It remains green and eatable all winter without the least protection.

The only two varieties I have tried are the German Greens and the Siberian Kale, either one of which is good enough as far as quality or ease of culture is concerned. They can scarcely be distinguished, but the Siberian Kale is a perennial, and is perhaps preferable on that account

Culture.-Raised from seed like the rest of the cabbage tribe, which you may sow in April with your winter cabbages and treat in the same manner. Transplant, if German Greens, into rows eighteen inches apart and twelve inches in the row. Give it a good soil.

The other variety requires about the same spaces as with cabbage. I have an excellent crop growing this year, 1852, sown the first of August, and treated exactly the same as Ruta Baga turnip.

The outside leaves can be cut off for use when from 
seven to nine inches long, leaving the others to come on in succession, affording a supply all winter. Its only enemy is the aphis or cabbage louse, for which try Scotch snuff and oil of turpentine.

Seed.- Select some of the best heads and leave for seed, at a distance from any others of this family, and proceed as with cabbage. The seed will keep four years.

Use-This vegetable affords very delicate winter and spring greens, far superior to cabbage, and nearly equal to the Savoy. It boils well and is most delicate, sweet and tender when touched by frost.

To boil.-Put in boiling water with a little salt, boil briskly twenty minutes, and serve as other greens.

\section{Brassica Oleracea Botrytis-Cauliflower.}

This plant was introduced into England from the Island of Cypress, in the early part of the seventeenth century. It is a kind of cabbage with long pale green leaves, surrounding a mass or head of white flower buds-in-short, " a giant rose wrapped in a green surtout," but much more like a mass of fresh curds than a rose. Since its introduction, it has been much improved by the skill of the gardener. The seed is generally imported from Europe.

Varieties.-There are several varieties early and late, but the late are the only ones that generally come to anything in this climate. Of the latter, there is the old variety, Late Dutch or Late London, which I have succeeded with, and is perhaps as good as any, though the late Walcheren comes highly recommended for hardiness, and may be worth a trial.

The ashes of Cauliflower have been analyzed by Richardson, and found to be composed of the following constituents : 


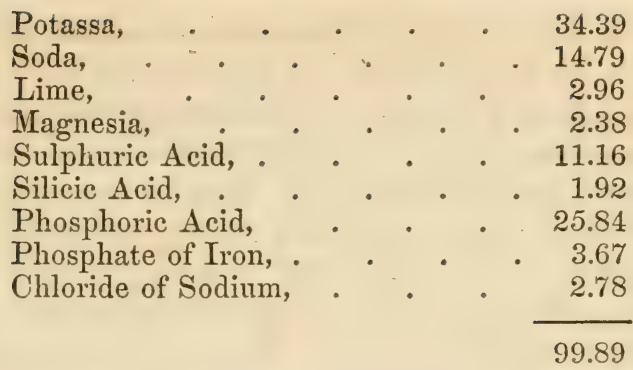

Cauliflower requires the same special manures as cabbage. There is much less difficulty in its cultivation near the sea-shore than inland. The ground should receive a dressing of common salt as directed for cabbage.

Culture.-It is very little use to try to raise the early cauliflower. Sow however in September, and cover through the winter in a frame; transplanted into beds ten inches apart under glass, giving air as much as possible; plant out as early as is safe in February, earefully taking them up with a trowel, in order not to disturb the roots, placing them in rich ground two feet apart. Insert the stem in the earth nearly up to the first leaves. Shield them with boxes from heavy frosts and some will come to perfection.

In a proper soil and location, the late varieties can be raised nearly as easy as cabbage. The best time to sow is about the first of April, though plants with care can be raised from that time until July. An ounce of seed will yield three or four thousand plants. The seed bed should be rich and deeply dug; if the weather be dry, shade them a little by day until the seed gets up strong, and water them occasionally. The drills may be eight inches apart in the seed bed. Thin out the plants to six inches. They can be planted out at the same time with 
winter cabbage. Protect them from the cut-worm, and insects in the same manner. If possible, give them a plat of moist bottom soil, made very rich with well decomposed manure. Take them up carefully with a trowel that the roots may not be injured, and plant in rows two feet asunder each way; water freely when needed, which in dry weather is every other day at least; if with liquid manure so much the better. Let them never suffer from drought; they will show when they need water by their drooping leaves. Soapsuds is an excellent application. Keep the ground hoed deeply and thoroughly about them, especially the day after each watering, that it may not bake.

The hills should be hollowed about the cauliflower like a shallow basin to retain moisture. The head may be blanched by bending the leaves and confining them loosely with a string. They will head in sucession during the autumn.

When a cauliflower has reached its fill size, which is shown by the border opening as if about to seed, the plant should be pulled, and if laid entire in this state in a cool place may be kept several days. They should be pulled in the morning, for if gathered in the middle or evening of a hot day, it boils tough. When there is danger of severe frost injuring the cauliflowers that have not already headed, they may be protected by pine boughs or empty boxes or barrels where they stand-or pulled up with the earth attached to the roots, and removed to a cellar or outbuilding, where they will flower in succession all winter. In the low country this will hardly be necessary, and the spring crop is I believe more certain with them.

For Seed.-Set out, in spring, some of the finest heads, with fine, close flower-buds, and proceed as with cabbage. It is very liable to intermix with the other Brassicas; so that it is best to depend upon English seed. Seed will keep three or four years. 
Use-The heads or flowers boiled, generally wrapped in a clean linen cloth, are served up as a most delicate dish. "Of all the flowers in the garden," says Dr. Johnson, " give me the cauliflower." It is one of the very best of regetable products, and so prized wherever known. It is nutritious and wholesome even for invalids, beside being: a very ornamental addition to the table.

To Boil.-Cut off the green leaves, and look carefully that there are no caterpillars about the stalk; soak an hour in cold water, with a handful of salt in it; then boil them in milk and water, and take care to skim the saucepan, that not the least foulness may fall on the flower. It must be served up very white, and rather crimp, with sauce, gravy, or melted butter.-IIrs. Hale.

\section{Brassica Oleracea Botrytis Cymosa-BrocoLI.}

This plant differs from cauliflower in its undulating leaves, its larger size, and its color. It is supposed to have originated from the cauliflower; is a hardier plant, but not so delicate in flavor. It has been cultivated about two hundred years, and was introduced into England from Italy. Brocoli is raised much more easily than cauliflower. The purple cape brocoli, producing large brownish heads, very close and compact, is the best for this climate. The analysis of brocoli, by Richardson, shows the following constituents :

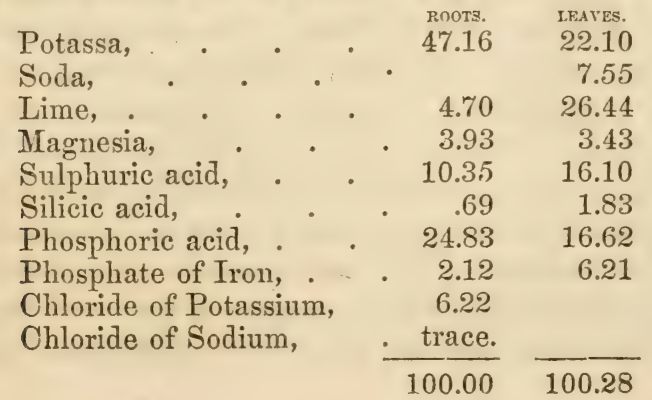


It requires the same special manures as the cabbage and cauliflower.

Culture.-Brocoli can be sown in April, or by shading the seed-beds during the day, until the plants get strong, as late as the middle of July. For this and cauliflower the seed-beds should be rich, and the plants well watered in dry weather. The drills should be eight inches apart, and the plants thinned out to six inches in the drills. The plants thinned out may be set out in another place to grow. These will make the best heads. Transplant, when each stem shows five or six leaves, covering the stem to the lower leaf, in rows two feet apart each way. Do this with a trowel, in dull, damp weather, and shade, if necessary, until the plants are established. Protect from insects with snuff, \&c., as directed for cabbage. Choose the same situation as for cauliflower, and follow the same mode of treatment throughout, especially the frequent hoeing and watering.

$U^{\top}$ se and Mode of Cooking.-Wee Cauliflower.

\section{Brassica Napo Brassica-Turnip Cabbage. Brassica} Caulo Rapa-Turnip-roo'ted Cabbage.

These two species of brassica are little cultirated. The turnip cabbage grows above ground, pretty well up the stem, in a globular form, with a few leaves on top. 'The purple-stemmed variety is best. Its culture is the same as the cabbage, except that in hoeing eare must be taken not to throw dirt into the heart of the plant, or the bulb cannot form. They should be hoed flatly. Sow in April.

The turnip-rooted cabbage is similar in quality to the above, but the bulbs grow near the origin of the stem. It does not succeed so well transplanted. It is cultivated exactly like the Ruta Baga turnip. There are two varieties, the white and the red. It is easily raised in any 
soil, if well manured. More weight per acre can be obtained by these crops than by the turnip, and they are of equal value.

Use--Turnip cabbage, when the size of a large turnip, is an excellent vegetable. If cut into slices one-quarter of an inch thick, and boiled until very tender, it resembles the cauliflower in flavor. The thick skin being removed, it may be cooked like a turnip. When full grown, it is used for feeding stock. It will endure our winter without protection.

\section{Brassica Rapa-Turvip.}

This root was held in considerable estimation by the Romans. Cato is the first writer that mentions it. "Sow it," says he, "after an autumnal shower, in a place that is well manured, or in a rich soil." Columella recommends its cultivation, "because that portion of the crop not wished for the table will be greedily eaten by the farm cattle." It is a biennial plant, now cultivated in all temperate climes. It is now extensively raised as a field crop in England, for feeding stock, and is considerably raised for the same purpose in our northern States.

Early White Dutch (strap-leaved).-A round, flat turnip, with short, narrow, strap-like leaves, is the earliest kind.

Early Rid Top Dutch (strap-leaved), differs from the preceding only in the red color of the portion of the roots which is above ground. Both of these, in a moist, cool fall, are fit.for the table six weeks after sown.

Yellow Dutch will stand any degree of frost uninjured, is fine flavored, and very nutritious. It is of a yellow color, round, handsome shape, firm and sweet, and keeps well. I prefer it to the Swedes for winter use, and would select this, if confined to one kind, for the garden.

White French resembles the Swedes, but not so smooth; 
flesh white, and exceedingly sweet and excellent; a fine keeper.

Purple-topped Suede.-Foliage differs from the foregoing, being smooth and covered with glaucous blooms. It is hardy and very nutritious. The roots are very large, of an oval tapering form and unlike the foregoing; the greater their size, the sweeter and more nourishing they become. It keeps until spring.

Skiveing's Improved Swede.-This is of still better form than the foregoing, the leaves not so large, less smooth and free from bloom; flesh fine, yellow, and very nutritious.

\section{Skirving's Swede.}

kOOT. I.EAVES.

Potassa, . $\quad 36.16$

Soda, . . . 4.99

Lime, . 11.36

Magnesia, . $\quad 2.44$

Sesquioxide of Iron, $\quad .28$

Sulphuric acid, . 11.26

Silica, . . . 1.63

Carbonic acid, . $\quad 9.54$

Phosphoric acid, $\quad 12.51$

Chloride of Potassium -

Chloride of Sodium, $\quad 9.77$

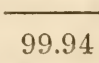

20.36

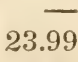

2.92

1.90

6.50

4.11

6.16

6.54

9.77

17.69

99.94
Common White. ROOT. LEAVES. $48.56 \quad 12.68$.

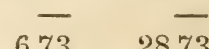

(20

2.85

.66 .80

12.86

7.83

.96

2.05

14.82

14.64

7.65

3.15

15.56

5.44

10.67

Per-centage of Ash in the dry substance, 7.30

11.30

7.40

15.20

Per-centage of Ash in fresh substance, $\quad$.88

The analyses here given are by Way and Ogston. They indicate that potash, lime, sulphuric, and phosphoric acid may be applied to this crop with advantage. In practice, however, it is found that the most important element to be added is phosphate of lime. Either bone dust, 
superphosphate of lime or guano, all rich in phosphoric acid, seems to supply everything this crop requires. Manured with these, it is soon beyond the reach of insects and casualities. A mixture of the two latter with the sulphate of ammonia, known as inproved superphosphate of lime, is probably the best of all manures for this crop.

Culture.-The turnip likes a rich sandy soil. If raised on ground manured by cow-penning, the crop rarely fails, as the urine deposited in the soil affords the phosphates so necessary for this crop, and in such places it is far less infested with insects. Soil fresh from the woods also suits them. 'The seed from the north is three or four weeks earlier than that raised here, and should be chosen for the early crop; for the main crop our own seed is good enough if carefully raised.

Sow early turnips in February, in drills one foot apart, in ground well dug and thoroughly manured. Draw the drills one inch deep. Keep the soil free from weeds. As soon as the plants get a little strong, thin out to two inches, and finally to six inches in the row. If the ground is not kept light and well worked, and the plants properly thinned, it is a mere waste of time and seed. The early white dutch from northern seed is the lind to be preferred. They do much better in drills than broadcast.

For fall turnips, sow the early white dutch, red top and yellow dutch any time in August and September, broadeast or better in drills, as directed above. If broadcast, thin them to about twelve inches apart or more. If sown just before a rain on the surface, the rain will bring them up at once. Soot, wood, ashes, and unslacked lime are all useful to promote growth and drive away insects. The red-top is an excellent variety for a general fall crop, and may be sown in October even with success. 
The Ruta Baga or Improved Swede should be selected for a crop to stand the winter. Plant pure seed or none; the middle or last of July or early in August, just before a shower if possible. Let the drills be two feet apart, and thin the plants by degrees until twelve or fifteen inches in the row. As soon as the plants appear, loosen the earth about them. It requires a richer soil than the other varieties. Any vacancies in the row can be filled by transplanting, which will make nearly as large roots as the others. Keep the soil light and mellow by the use of the hoe. Large crops can be tended with the plough and cultivator to great advantage. In good soil the yield is immense. The crop may be drawn as needed, some should be drawn before they begin to grow up to seed and stored in a cool place for late keeping.

To save Seed.-Select a few of the best roots, shorten the tap root and plant them two feet apart. Tie the stalks to stakes, keep them at a distance from all other members of the cabbage tribe. Ruta Baga will rarely make seed in this climate. Seed of the turnip should be changed every few years as the plant degenerates. It keeps three years.

Use-This is one of those useful vegetables that can be enjoyed with everything. The tops gathered in winter and spring make very good greens. 'The roots are wholesome, though they disagree with some stomachs. They are considerably nutricious also; four ounces of white dutch containing eighty-five grains of nutritive matter, and four ounces of Ruta Baga containing one hundred and ten grains of the same. Any over supply of this crop may be fed with great advantage to the cow or boiled for the pigs.

To Boil.-_Turnips are good vegetables with boiled or roasted meat. Wash, peel, slice, and boil until quite soft, then mash with a little butter, pepper and salt. 


\section{Brassica Eruca-RoquetT.}

This is an annual plant from France, of which the leaves are used as a salad. Sow thinly in drills a foot apart in February and March. Water frequently if necessary, which will lessen the acrid taste of the young leaves gather young; not much cultivated.

\section{Brassica Napus Oleifera-RAPE.}

Rape is a biemnial plant, a native of England, with glaucous radical leaves and yellow flowers, appearing early in Spring.

Culture.-Sow at the same time with cresses and mustard in winter and spring. Sow in drills or beds and follow the culture directed for white mustard. Rape sown like turnips the first of September, will survive the frosts and afford an abundance of fine greens the latter part of winter and early in spring.

Two or three plants sown in August and kept over, will flower and secil the next year abundantly.

Use.-The seed leaves are gathered young for a small salad with cresses and mustard. Later it is used like mustard for winter greens.' This plant is much cultivated in Europe to express the oil from its seeds.

\section{Brassica Napus Esculenta-Edible-rooted Rape, or French Turnip.}

This is sometimes cultirated as a substitute for the turnip. The roct is white, carrot-shaned, about the size of the middle finger. It is much grown in Germany and Trance.

Culture.-It is raised from seed which may be sown in August or September, and requires the same treatment as turnip. It likes a sandy soil, and if grown in too rich 
earth it loses its sweetness. In dry weather, the beds must be watered regularly until the plants get three or four leaves. To save seed, see "Turnip."

Use-It is much used in continental cookery, and enriches all the French soups. Stewed in gravy, it forms an excellent dish, and being white and carrot-shaped, when mixed with those roots upon a dish, it is very ornamental. In using, there will be no necessity of cutting away the outer rind, in which the flavor chiefly resides. Scraping will be quite sufficient

\section{Calodium Esculentum* -Tanyah.}

This is a large-leaved, bulbous-rooted plant much cultivated at the Sandwich Islands, and forms the principle ingredient in the favorite poi, a food much in use there, and remarkable for its fattening properties.

Culture.-It may be planted in any rich, well-drained low spot. Select the eyes or buds, and plant like the potato. The small roots are the ones generally reserved for this purpose. There are two distinct kinds named from their color the pink and the blue, of which the latter is thought by many to be the most farinaceous, but others prefer the taste of the pink variety. The sets may be put out in March or early in April, and the most attention required is to keep the soil clean and mellow. The rows may be three or four feet apart, and the plants two feet in the rows. It comes to maturity the autumn after planting and may remain in the bed until wanted. It keeps better than either the sweet or Irish potato. It is prepared for the table by simple roasting, and eaten with salt. By many they are much liked, as they are quite farinaceous. 


\section{Calendula Officinalis-Pot Marigold}

An annual; native of France, Spain, and the South of Europe. Its bright yellow flowers give it a place in the flower-garden. A few plants only are needed by any family.

There are two varieties, the single and double; the former of which is a little the highest flarored. Sow in autumn or early in spring on a good mellow soil in drills, one foot apart or broadcast; when the plants are up, thin them to twelve or fifteen inches apart, or transplant them that distance if you wish more plants. Water till established. 'The flowers, during the sunmer, must be gathered, dried thoroughly in the shade, and put up in paper bagss. Leave a few fine flowers for seed. The darkest-colored ones are the best. The flower is a valuable ingredient in soups, and the leaves were formerly infused for agues. The plant is now but little used.

\section{Campanula Rapunculus-RAMPION.}

This is an English biemnial plant, with a long white spindle-shaped root, lower leaves oval lanceolate, with a pannicle of blue bell-shaped flowers in June. It has a milky juice.

Culture.-Sow the seed in April in a rich, shady border. It likes a moist, rich soil not too stiff. The seed must be very slightly covered, but the earth should be pressed upon it. As the plants grow, thin them to four inches apart, and pull them before they run to seed.

To save seeds, allow some of the best plants to remain.

Use.-The root is eaten raw like a radish, and has a pleasant, nutty flavor. Cultivated only by those in search of variety. 


\section{Capsicum Annunm-PEPPER.}

Of this plant there are several species in cultivation, most of which are natives of tropical regions. It has been cultivated in England about a century. All of them are very pungent. The best varieties are :-

Bell Pepper.-Brought from India in 1750. Of low growth with large, bell-shaped fruit. Its thick and pulpy skin renders it the best for pickles. More mild than most of the varieties.

Tomato Pepper.-Named firom its resemblance to the tomato in shape. More pungent than the preceding.

Large Sweet is another variety much used for pickling, which I have not yet cultivated. It is said to be a good, mild variety.

Cayenne or Long, with small, round, tapering fruit, an extremely pungent. Excelient for pepper sauce.

Capsicum likes a rich, moist loam, rather light than otherwise. Guano and fowl manure are excellent fertilizers for peppers.

For early plants, sow the seed in drills, one inch deep and six inches apart, under glass, in February, and transplant after the frosts are entirely over, when three or four inches high in good soil, in rows fifteen or eighteen inches apart each way. Sow also in the open ground as soon as the settled warm weather comes on, say the last of March or first of April, and thin them out to the proper distance. An ounce of seed will give two or three thousand plants. They should be transplanted in moist weather onily, and must be watered until well-established. Shading a few days, at mid-day after transplanting, is rery beneficial. Cultivate and earth up their stems a little.

Seed.-A plant bearing the earliest and finest fruit should be selected. The varieties should be grown as far 
apart as possible. When ripe the pods are hung up to dry, ard kept until the seed is wanting for sowing.

Use.-These plants are very much used in all hot climates, where they enter as a seasoning into almost every dish. The large kinds are used for pickling, and for this should be gathered when full grown just before turning red. They are also dried when ripe and used for seasoning. Cayenne and the other small kinds are ground for table use, or made into pepper sauce by the addition of strong vinegar. Peppers are often rubbed upon meat to drive away insects, and are also considerably used in medicine, especially by botanic practitioners. The daily use of this plant in hot climates is decidedly a preventive of bowel complaints, which renders its cultivation so universal.

\section{Cichorium Endivia-Endive.}

Endive is a hardy annual, a native of China and Japan; first cultivated in England in 1548. The root leaves are numerous, large, sinuate, toothed, and smooth. The stem rises about two feet high, producing blue flowers. It is considerably cultivated in Europe.

VARIETIES.-The best varieties are:

Green Curled.-A fine, hardy variety, with beautifully curled leaves. It is the best for salads.

Broad-lented or Batarian has thick, plain, or slightly wrinkled foliage: It is principally used for cooking, and making a larger head is preferred for stews and soups, but not much used for salads. Besides these varieties, there is another species, Cichorium Intybus, or Succory, a good deal used as a winter salad in Europe, but it is mainly cultivated for the root, which is dried and ground for the purpose of adulterating coffee, and some even think it quite as good. It is a hardy perennial, and 
its blue flowers sometimes introduce it into the flowergarden.

Culture.-Endives delight in a light rich soil, dug: deeply to admit its tap roots, and to serve as a drain for any superfluous moisture in the winter standing crop. The situation should be open and free from shade of trees.

Sow the seed in Angust and September. Sow at this season if possible everything just before a shower-draw a furrow the depth of your hoe, in the bottom of which scatter your seed thinly, and cover slightly with earth, pressing it upon the seed. Plant in the evening, and water copiously with the fine rose of a water-pot in the drill; shade during the day, and continue watering in the evening until the plants get rooted. The drills should be twelve or fifteen inches apart. The Batavian likes most space; hoe freely and keep the ground free from weeds; thin the plants when two inches high; those removed may be transplanted to another location; choose moist weather for this purpose, trim the leaves a little and water molerately every evening, until the plants get established and during very long dronghts. Those left in the seed bed make the best plants.

In about three months after sowing, as they grow stocky and full in the heart, the leaves loing about eight inches long, some should have their leaves tied up every week or fortnight to blanch, and render them tender and remove their bitter taste. Perform this in dry days. The curled sort will sometimes blanch pretty well if neatly earthed up without being tied, but it is better to tie it. 'The broad leaved from its loftier and looser growth neerls a bandage. Fold the leaves round the heart as much as possible in their natural position, and tie them up with a string or shred of bass, then covering them entirely with sand in the form of a cone, rendering the surface smooth and firm. This 
must be done in dry, but not frosty weather, as the plants will rot if the leaves are wet or frozen. They may also be blanched under garden pots like sea-kale, or by merely tying them closely, winding the string several times round the plant and closing the top, so as to exclude the rain, drawing the earth around the base to support it. This is the best mode in hot weather; in autumn they will blanch in ten days, in winter they require nearly twice that time. Succory to blanch is taken up and planted in boxes of mold which are carried into a cellar or dark room and watered when necessary. The blanched leaves will be supplied all winter.

For Seed.-Let some of the best and most vigorous plants remain till February, and transplant if you wish to use the ground, in rows eighteen inches apart. Support the stems by stakes, and gather the seed vessels as they ripen. Dry them thoroughly on a cloth, thresh and preserve in paper bags. The seed will keep four years.

Use--Endive is cultirated for its stocky head of leaves, which after their bitterness is removed by blanching; are used in autumn and winter for salads and stews. It is very wholesome, and boiled is thought to be a remedy for the jaundice. It possesses a good deal of the virtues of the dandelion; it never disagrees with the stomach, but suits every constitution. 'The French use it in a variety of forms, raw, stewed, boiled, pickled, but it is chiefly employed as a salad.

\section{Cochlearia Armoracia-Horse RADISH.}

Horse-radish is a cruciferous perennial plant, growing naturally in moist places in England, and various other parts of Europe. The leaves are large, oblong, hollowed, and from some fancied resemblance to a spoon Cochlear, 
the botanical name, is derived. Its flowers are white, and appear in panicles in May. It has long been an inhabitant of the garden.

Culture.-Horse-radish delights in a deep rich mould, moderately and regularly moist-the roots are never of any size if grown in poor soil, or under shade of trees. It seldom produces seed, and hence is propagated by sets provided by cutting the roots and offsets into lengths of two inches. The tops and crowns of the roots make the best sets as they are earlier, and make a finer growth than thinse from the centre of the root. Each set should have two eyes.

Horse-radish may be planted from November to March, inclusive. The finest crops are made by trenching the ground two feet deep, planting the cuttings along the bottom of the trench, and the mould from the next trench turned over upon them.

They may also be inserted with a long blunt-pointed dibble the same depth; let the rows be eighteen inches apart, and the sets twelve inches in the row. After the beds are planted, smooth the surface and keep clear of weeds, and avoid treading upon the beds, as they should be kept as light as possible. If planted in March, a crop of radishes or lettuce may be taken off the ground before the plants make their appearance. They speedily root and send up long straight shoots, those appearing in April that were planted in autumn. The only cultivation is to keep them free from weeds, and remove the decayed leaves in autumn. Hoe and rake the bed over in autumn, and also the following spring. By the next fall, the roots are ready to take up as wanted. If the plants throw up suckers, they should be carefully remored as they appear.

If any manure is applied to horse-radish, it must be put at the bottom of the trench before planting, or the plant 
will send out side shoots in search of the manure, which would greatly injure the crop.

To take them up, a trench is dug along the outside row down to the bottom of the upright roots which are cut off nearly level with the original planting. The earth from the next row is turned over upon them to the desired depth, and so on until finished. The pieces of roots left will send up new shoots, and the same bed will produce well in this way five or six years, when the site of the plantation should be changed; when this is to be done every piece of root should be taken up, for the smallest of them will vegetate and prove troublesome if left. The best roots come from fresh plantations.

Use.-Horse-radish scraped into shreds with vinegar, is a well known and desirable accompaniment to roast beef. It is also used in fish and other sauces and chicken salads, and is thought to assist digestion. The shreds pickled in strong vinegar and closely stopped in glass bottles will kecp for years. Horse-radish in medicine is a valuable stimulant-useful also in hoarseness, sometimes serviceable in rheumatism and is especially valuable in cases of incipient scurvy.

\section{Cochleaira Officinalis-Scurvy Grass.}

A biennial plant, found near most sea-shores in temperate climates. Likes a soil similar to the preceding, and equally free from the shade of trees.

It is propagated from seed sown as soon as ripe in May or June, for if kept long it does not germinate well. Sow in drills eight inches apart and one-half inch deep. When they come up thin them to eight inches apart, transplanting those taken up, and giving water until established. Keep free from weeds, which is all the cultivation 
needed. To save seed leave some of the plants in place, and gather and sow when ripe.

L'se.-The small leaves are used like eresses; its great use medicinally is pointed out by its name.

Concolvulus Butatos, sc.-SweET Potato.

This valuable plant, first cultirated in England in 1597, by Gerrard, is the potato mentioned by Shakspeare and his cofemporaries, the Irish potato being then seareely known. "Let the sky rain potatoes," says Falstaff, alluding to this regetable, which was at that time imported into England from Spain and the Canary Islands, and considered a great delieacy. The sweet potato is a peremial plant, a native of China and both Indies. It has small leaves, with three fo five lobes, according to the variety-with herbaceous vines which run along the ground, taking root at intervals. Its roots are long, spindle-shaped or oral, often very large, and abounding in starch and sugar. Its nutritious properties and agrecable flavor have brought it into general use in all parts of the globe, where the elimate is warm enough to admit of its successful cultiration. The following are the most common rarieties, and perhaps as good as any.

Small spanish. - Iong, grows in clusters, purplish color, very productive, and of excellent quality.

Brimstene.-Sulphur-colored, long, of large size, and productive; keeps well with us, and is one of the best sorts; very dry, and excellent.

Red Bermuda.-Is of the Yam family; leares manylobed, and the best early potato-productive.

Common Yam.-Leares many-lobed; root oblong and something globular, the best long-keeper, and very productive. Has something of the pumpkin flavor. 
Analysis.-One thousand pounds of the roots contain:

Starch,

Albumen,

Coagulable Albumen,

Casein,

Sugar and Extract,

Dextrine and Gum,

Fiber,

Gum Resin,

Water,

Silicic Acid,

Sulphuric Acid,

Phosphates of Lime and Magnesia,

184.23

54.47

19.40

9.70

53.49

6.93

17.09

2.07

641.72-989.10

0.24

0.16

2.78

Lime,

Magnesia,

Potash,

Soda,

Chlorine,

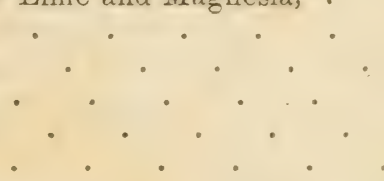

The above analysis was made by Prof. Emmons. Potash seems to be the element most necessary to supply the soil. A dressing of word ashes would be very beneficial to this crop. Next to potash it demands a supply of the phosphates.

Culture.-The sweet potato likes a rich, sandy loam, perfectly friable, and, as indicated by the analysis, abounding in potash. The soil should be well enriched. They do well on lands freshly reclaimed from the forests.

The Spanish potatoes are generally planted where they are to remain like the Irish potato, whole or cut up into sets. But both these may, and the yams must be proriagated by slips, as they grow larger and yield more abundantly.

To raise slips select a sunny spot sheltered by fences or buildings, and lay it off in beds four feet wide, with 
alleys of the same width between them; slope the beds a little towards the sun, dig them well and add plenty of well-decomposed manure, if not already rich. Do this the last of February or early in March. Choose large, smooth, and healthy-looking potatoes, and lay them regularly over the bed an inch or two apart, and corer them about three or four inches with soil from the alleys; rake the beds smooth and it is done. In large operations, ten bushels of potatoes should be bedded for every acre of ground.

While the slips are sprouting, prepare your ground to reccive them. It should be rich, or made so with wellrotted manure, and thoroughly and deeply broken up with the plough or spade. Lay it off just before the slips are ready, which will begin to be about the 15th of April, in low horizontal ridges or beds, the crowns of which are three and a half feet asunder, and about six inches high, on which plant out the slips with a dibble, eighteen inches apart, one plant in a place. Choose for this operation such a day as you would for cabbage plants, or do it in the evening. The sweet potato is readily transplanted, and if holes are dug in the mellow bed, deep enough to admit the plant, and the slips set upright therein, have the earth washed in about their roots by pouring water upon them from the open spout of a waterpot, finishing the operation by corcring over with a coat of dry mellow carth, brought up and pressed pretty closely about the slips to keep the moistened earth from baking. Very few will die even if they are set out at mid-day; but as the plants would be checked, a cloudy day, or just at night should be selected for the operation. This is an excellent mode of transplanting all plants, and is of great use both in the regetable and flower garden. If the slips are not washed in as above when taken up in dry weather, it is of great advantage to grout them, as well as all other plants 
you wish to transplant. This is done by immersing the roots in water thickened with rich earth. It refreshes the slips, and gives them a thin coating of earth as a protection against the atmosphere. Draw the slips when about three or four inches high, by placing the left hand on the beel near the sprout to steady the root, and prevent its being pulled up with the sprout, which is loosened with the right hand, taking care not to disturb the fibrous roots of the mother potato, for this continues to afford a succession of slips which may be successfully transplanted until the 1st of July. After the piece is planted go over it again in a few days to plant orer any place where the slips may have failed. As soon as the ground gets a little weedy, scrape it over, loosening the earth and covering up the weeds, but be careful not to injure the young slips. Faithful cultivation and frequent moving the snil are as beneficial to this crop as to any other. At one of the hoeings just before being laid by, the ground should be deeply moved with the plough or spade, but not too close to the plants. They should be laid by before the plants run a great deal, after which they should be undisturbed. Be careful not to cover the rines, but if they become attached to the soil, loosen them up from it, so that the vigor of the plants may be thrown into the roots and not into the rumning vines. Make the hills large and broad, not pointed. In hoeing draw the vines carefully over towards you while you draw up the earth and corer the weeds; then lay them carefully back, and finish the other side in the same manner. At this time it is an excellent plan to fill the spaces between the rows with leaves and litter while the ground is wet, to retain the moisture. After the rines have covered the ground too much to use the hoe, any large weeds that appear should be pulled up by hand.

The Yam Potato can also be raised from seed, but the 
Spanish variety, like the sugar cane and many other plants long propagated by division, rarely produces seed.

Just as soon as the tops are killed by frost, the potatoes should be gathered. In field crops they can be ploughed up and gathered by hands which follow the plough, depositing the potatoes in small heaps. but in the garden the potato can be gathered with the hoe or the potato hook, an implement much used in gathering crops of the Irish potato. It is better to do this in a dry day, and many prefer to dig their potatoes just before the frost kills the vines thinking they keep better.

Keeping potatoes is a rather difficult matter. The following is Mr. Peabody's plan: Let the small heaps dry during the day. In handling them, take care not to bruise or injure the skin. Put them up in hills, containing thirty or forty bushels each. Make a circular trench as large as the hill you wish to make. Elevate the earth surrounded by it about six inches, or sufficient to prevent the access of moisture. Cover this over with pine straw, and pile up the potatoes upon this in a regular cone. If the weather is good, cover them only with pine or other straw for two or three days, until the potatoes are well dried, before their final earthing up. Let the covering of straw be three or four inches thick; then cover it over with large strips of pine bark, commencing at the base, and cover as shingling unto the top, leaving a small aperture. Cover four or five inches thick with earth over all, except this aperture, which must be left open for the escape of the heat and moisture generated within.

Some cover this opening with a piece of pine bark, to keep out the rain, but a board shelter is preferable. When the weather gets warm, in the spring, take up the potatoes, rub off the sprouts, and keep on a dry floor. If put up with care, they will keep until July. One important 
step toward their certain preservation is to gather them carefully from the ground, as the least bruise produces rapid decay.

For seed, some of the finest roots of the most productive hills can be packed in barrels, and covered with sand, in a dry, warm place, free from all exposure to frost. My own garden crop keeps perfectly well in barrels, with a layer of leaves at the bottom, then a layer of potatoes, then a layer of leaves, and so on until the cask is filled. Use dry leaves, and store in a dry place.

Use.-This root is deservedly a favorite at the table, and the most wholesome grown. In nutritious properties, as we see by the analysis, it excels all other roots cultivated in this country, except the carrot. Weight for weight, it contains more than double the quantity of starch, sugar, and other elements of nutrition, that are found in the best varieties of Irish potato. For feeding: stock, three bushels are equal to one of Indian corn, yielding, on the same land, five or six times the food that is produced by this most profitable grain

A good baked sweet potato is almost as nutritive as bread. They are better baked than boiled. They are also used for pies and puddings, and sweet potato rolls are excellent. In short, the modes of cooking this excellent vegetable are innumerable, but perhaps the very best is Marion's mode of roasting in the hot ashes.

\section{Crambe Maratimu-SEA KaLE}

The sea kale is a perennial, a native of the dry, shingly sliores of Great Britain. The plant is smooth, of a beartiful glaucous hne, covered with a fine meal, and with large sinnated, radical leaves. The flower is of a rich white appearance, and a honeyed smell. It has probably been cultivated in gardens one hundred and fifty years, 
but not very generally until the beginning of the present century, though the English peasantry have been in the habit of gathering the blanched shoots as they pushed through the sand, and boiling them as greens, from time immemorial.

Wherever the climate will admit its cultivation, as all through our mountain region, if not in the low country, it will be found a very valuable addition to the scanty list of spring vegetables now upon our tables. It is partial to a cool climate.

The following analysis of the ash of this plant is by Herapath. The per-centage of ash in the undried plant was 2.42, the constituents of which are in the following proportions :

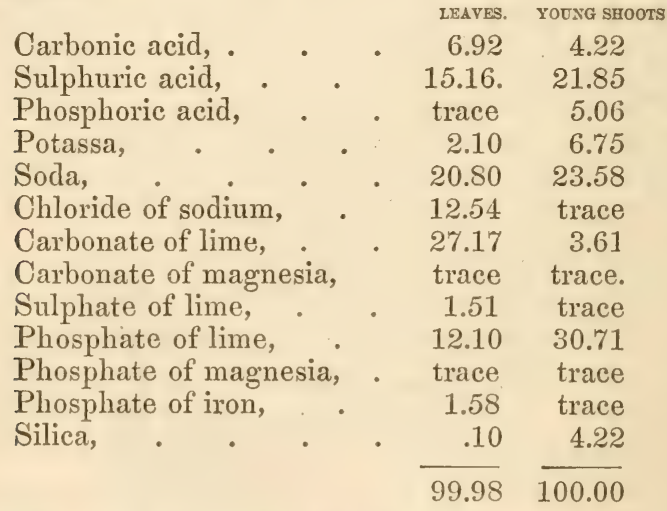

Common salt, bone-dust, and gypsum are pointed out by the analysis as beneficial special manures for sea kale.

Culture.-The native soil of sea kale is a deep sand, mingled with alluvial matter from the sea. It likes a deep mould, or sandy loam, and if poor, well putrified dung and half decayed leaves may be added. Upon the richness and proper preparation of the soil, not only the luxuriance 
but the continued existence of the plant depends. Common salt applied dry, in autumn, at the rate of even thirty bushels per acre, or watering the plants with a brine made with four ounces of salt to the gallon, applied around the roots in summer, is a very beneficial application. The situation must be free from all shade of trees. Sea kale is propagated by seeds, or offsets, or cuttings of the root; but the best plants are raised from seed. Sow the seed in a well prepared soil, rich, or made so with well decomposed manure, and shaded by a fence, or building, from the midday sun. Draw the drills one foot apart, and scatter the seed thinly along the drills. The beds should be about four feet wide, for convenience. Put in the seed from October to the middle of March, but December and January are the best months. Before inserting the seed, bruise the outer coat, but without injuring its vegetating power. By this practice, germination will be accelerated. The plants are very slow in appearing; never less than three weeks, often four or five months, and sometimes a full year. Water plentifully in dry weather, and keep the seed-beds free from weeds during the season. Thin the plants, as they appear, to an inch apart, and, as they grow strong, to two or three inches. The great difficulty in raising sea kale is in getting good, healthy, acclimated plants, to form the beds. The seed are difficult to regetate, and, after they do come up, apt to die off during the summer. In the autumn, when their leaves decay, clear them away and earth them up about the crowns with an inch or two of soil from the alleys, or leaf-mould from the woods, and cover over the whole bed, four inches deep, with long litter, and leave it to stand until the time of transplanting.

If you have been successful in raising your plants, in the latter part of the February ensuing, prepare your per- 
manent bed for those you wish to transplant. Those raised where they are to remain succeed best.

Let the soil be light, and well enriched with good compost manure. Leaf manure is better than hot dung. Dig it up deeply and thoroughly, at least two feet deep, and lay it off in beds three feet wide, with alleys between two feet in width. Upon each of these beds plant two rows of plants eighteen inches apart and the same distance in the row. Take up the plants very carefully with the trowel, so as not to disturb the roots. If you plant cuttings of old plants, put two in each place, to guard against failures. In all cases, be careful in transplanting that the roots are not broken or dried by exposure to the sun and air. During the dry, hot weather of summer the beds should be liberally watered, the first season after replanting, as upon their summer growth depends the next season's crop. Keep the soil clean, and after the plants get well rooted, dig over the ground between the rows at least ten inches deep, making the soil as fine as possible, and after a few days dig in the same manner, on the outside of each row, that the plants may not receive a check by having all their roots shortened at once.

The coming autumn, the earthing-up must be a little increased; give a coat of leaf mould or compost manure and orer this a thick coat of leares, which will bring the plants on early in the spring. The next spring remove the litter and dig in some of the manure into the alleys, and then if you blanch with pots, spread over the beds abont an inch deep of clean sand. The shoots may be blanched and a few cut for use but sparingly, as the plants must not be weakened. The better way is not to remore the covering of leaves until you have gathered what you desire. On a portion of the bed to produce early, the winter covering of compost and leaves must be yearly applied. 
Another portion must be left uncovered until the shoots begin to rise and then covered with eight or ten inches of sand for a later crop. Each spring give it a dressing of salt like asparagus. Each succeeding summer also, dig over the surface of the bed as before. Retain for each plant only four or five of the best suckers at regular distances around the stem; suffer none of these to seed, if you would not greatly injure the next year's growth.

Sea Kale is worthless unless white and tender, and before it is eatable requires to be blanched. This may be done by earthing-up the crowns eight or ten inches with sand, or light mould, or by retaining the coat of dry leares put over the beds in autumn.

This covering may remain until the cutting ceases in the spring, when all covering must ba' removed at evering or in cloudy weather. The shoors wili raise the covering when in a fit state for cutting. The aurscs of icares should be from five to tweive inches thich, accuding 'o the age of the plants, and ac "directed abore, may remain on all winter. But a large flow àr toct with the hole in 'the bottom stopped, and light at the edges circful yozcluêd by a coat of litter, is the best of all modes of blanching, when the plants get established.

For Seed.-A plant that has not been blanched or cut from, must be allowed to run to seed in the spring. A single plant will produce an abundant supply.

Use.-Sea Kale comes on early in March, when vegetables are scarce, and affords a very wholesome and agreeable table luxury. The young shoots and leaf stalks, before unfolding, are boiled and dressed like asparagus, and are also employed in soups.

To Boil.-Tie the shoots in bundles and put into boiling water with a little salt; boil briskly twenty minutes and serve on toast with nice melted butter. 


\section{Cucumis Sativus-Cucumber.}

This is a trailing annual, with rough heart-shaped leaves and yellow flowers, growing wild in the East Indies and in most warm climates. It is one of the earliest garden products mentioned in history and was cultivated from the ealiest times in Egypt. (N'umbers xi. 5.)

It has always been a vegetable peculiarly grateful and refreshing to the inhabitants of warm climates. It was probably early brought into Europe from the East, as it was in high esteem among the Romans, who so well understood its culture, that it appeared on the tables of the wealthy in winter.

In England, it was introduced as early as $15 \% 3$.

$\therefore$ Varzeizes,-There are many varieties, the best of which are:

Facily: Shart allite Prickiy growing five or six inches long rvitts wite prickles, remaining green longer than - most other varieties; prodirctive.

$\therefore$ Early Cluster.--Ig woll adapted to this climate, being very earl $_{y}$, anc $\mathrm{i}_{\text {j }}$ named from the fruit growing in clusters. The fruit is generally about five inches long, very productive. Early Russian is a smaller and earlier variety of this.

Tong Green Prickly.-Dark green color with black spines, grows about ten inches in length and bears abundantly; excellent for pickles.

Gherlin.-Cucumis Anguria, a species with very small and prickly fruit and leaves mucli divided, or palmated; a great bearer, but used only for pickling.

There are many other varieties, some of which grow two feet long, crisp and well flavored, but the foregoing are the best for family culture.

The ash of cucumber has been analyzed by Richardson. 
The per-centage of ash afforded by the plant in the undried state, is .63 , the constituents of which are in the following proportions.

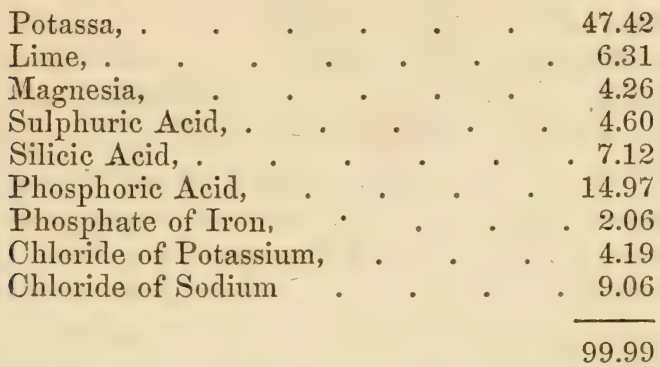

Ashes, Bone-dust and common salt are the special manures indicated by the analysis. Guano is the best manure.

Culture.-The culture of cucumbers in this fine climate is very easy. They will grow in almost any soil or situation, provided it has a good supply of moisture, but it likes a light, fresh loam, and to be somewhat shaded during the heat of the day. The seed may be planted about the first of April, or as soon as it can be done with safety, as this plant is very tender and will not bear the least frost. If the ground be deeply trenched, the plant is much less susceptible to drought. After the ground is regularly dug, dig out holes fifteen inches deep and the same in diameter, six feet apart each way, and partly fill them with well decomposed manure. A little guano, or fowl manure, sprinkled in the bottom of the hills will be very beneficial. Do not use fresh manure or the the plants will die out. Cow manure and leaf mould are excellent. Corer over the manure with rich, mellow loam. Raise the hills a little above the surface, and form them saucer-shaped, two or three inches deep so as to retain the moisture. Put 
eight or ten seeds in the hill, and when they get rough leaves pull up the poorest plants, and leave but three in a hill. Old seed is much better than new, as the plants will run less to vines and bear better.

As soon as the vine gets rough leaves, nip off the extremities to make them branch out and they will fruit the sooner. This is called stopping. Cucumbers are very sul,ject in cool, dry seasons to attacks of insects, especially the striped bug and the cucumber flea. Dry wood ashes or air-slacked lime dusted thoroughly upon the plants when the dew is on, will generally repel them, and bring the plants forward. But warm rains will soon bring up the plants beyond the reach of the depredators. Cucumbers should not be planted very late in this climate, as those that form after the middle of August are pretty apt to be destroyed by the melon worm. The best pickles are from the early planted vines.

Cucumbers can be very much forwarded by planting them in boxes covered over with glass. Two seven-by-nine panes are large enough to cover a hill, and such hills will not be troubled by the bugs, and the sind can be put in four or five weeks earlier than otherwise. The seed can also be planted in large pots under a frame, or in a greenhouse, to be turned out, when the weather gets favorable, into the open air, and they will scarcely show they have been moved. Or they can be raised wholly without removal, in hot-beds made as directed in a former article. They do best to start them in pots placed in a small hotbed, and to be transplanted when the leaves are two or three inches broad and they fill the pots, into new beds of a larger size. 'They must have plenty of air, and be placed near the glass, or they will be drawn up. If they hegin to grow long-legged, give them more air. The temperature of the seed-hed should range between $65^{\circ}$ and 
$85^{\circ}$. Always water the plants with tepid water, and do it about noon. Liquid manure, especially guano-water, is very beneficial. In planting in the bed for fruiting, do not break the ball of earth; take them out of the pots carefully at night, water gently, keep the sash down the next day, and shade at noon-day, to keep them from withering. It is necessary the beds should be shaded. with a mat, during the middle of the day; when the sashes are kept down, until the plants get well established. Stopping in the hot-beds is still more important than in the open air. The temperature now must be be kept between $70^{\circ}$ and $90^{\circ}$, by external coatings of fresh dung, if necessary. The shoots must be trained regularly over the surface of the bed. Leave only two or three main branches to each plant, removing the others as they appear. If the plants that have been stopped have extended their runners three joints without showing fruit, they must be stopped again. The vines should blossom in a month from the time of sowing. Impregnate the pistillate or female blossom (which may be known by its having fruit attached), by taking the staminate blossom and placing its centre within that of the pistillate blossom. They may be gathered in about two weeks after impregnation. Three plants are sufficient for one sash of the usual size.

For Seed.-Choose some of the finest fruit of each variety growing near the root. Do not raise the plants near other varieties, or the seed will mix and deteriorate. Let them remain until they turn yellow, and the footstalk withers; cut them off and keep in the sun until they begin to decay; then wash the seed from the pulp, and spread it out to dry. It will keep eight or ten years, and is even better when three or four years old, as the plants are less luxuriant and more productive.

Use-Cucumbers are a very popular, but not very 
wholesome vegetable. They are of a cold, watery nature, and beside are found to contain, in a small quantity, a chemical principle analogous to fungin, the poisonous principle of mushrooms. Many persons of weak constitution cannot eat them without positive injury. They possess scarcely any nutritive properties, but their cooling nature renders them to most palates very agreeable. They are eaten raw, fried, stewed, and pickled. The juice is said to be a cosmetic, and enters into the composition of many of the French pomades.

To tieep Cucumbers.-Cover the bottom of a cask or jar with salt; put on a layer of small cucumbers; then another layer of salt, and so on, until the vessel is full. Place a weight upon them to keep them pressed down. They will make their own brine, and keep any length of time. If the weight is taken off, they will rise to the top, grow soft, and spoil, as they require to be excluded from the air. They should be freshened, by soaking in warm water, before the additions of vinegar and spices.

To Dress Cucumbers Raw.-Pare freshly picked cucumbers, and slice them into cold water; pour off the water, and season with salt, vinegar, and pepper. A little salad oil may be added. Some add a small quantity of sliced onion, to impart the onion flavor to the vinegar.

To Pickle Cucumbers.-Upon freshly picked cucumbers pour a hot, strong brine of salt and water, and let them stand in the brine two days; then take them out, rinse in cold water, and let them drain three or four hours; then boil a sufficient quantity of the best cider vinegar, with a bit of alum, together with mustard, allspice, cloves, and black pepper. Pour this mixture, boiling hot upon them, cover them closely, and set away for use. Green Cayenne peppers and onions may be used for seasoning, if liked. 


\section{Cucumis Melo-MeLon.}

The melon, or musk melon, is supposed to be a native of Persia, but has been cultivated in all warm climates so long, that it is difficult to assign, with certainty, its native country. It has been cultivated in Southern Europe at least four hundred years. It is the richest and most delicious of all herbaceous fruits. In England its culture is a difficult and expensive process, but in this country the most luscious melons are raised almost without trouble.

There are three classes of melons, the green fleshed, yellow fleshed, and Persian melon. There are also several varieties of winter melon cultivated in Spain, which are said to be of good flavor, and in a dry room will keep all winter. In all, there are orer seventy varieties, the best of which are :

Christiana.-This variety originated near Boston, from a cross between the green Malta and some early variety. Mr. Harwell states: "It is very fine at Mobile; ten days earlier than any other variety, and of the finest flavor."

Beechwood.-A green-fieshed melon, one of the best and most productive of its class; ripens quite early, about twelve days after the Christiana. Fruit medium size, oval, netted; skin, greenish yellow ; flesh, pale green, rich, melting, and very sugary. If I had but one variety, should choose this.

Hoosaince.-A Persian melon. Fruit oblong, egg-shaped, of good size; skin, light green, netted; flesh, pale greenish white, tender, and abounding with sugary, highly perfumed juice; seeds large.

Sweet Ispahan.-Fruit, large oval; skin, nearly smooth, of a deep sulphur color; flesh, greenish white, crisp, thick, rich, and sugary. Ripens late. The most delicious of all melons. 
Pine-Apple, Cassabar, Netted Citron, and Rock, are also fine varieties.

'The melon has been analyzed by J. H. Salisbury. He found the per centage of water, dry matter, and ash, as follows :

$\begin{array}{ccr}\text { Per-centage of water, . . . } & 90.987 \\ \text { " " " dry matter, . } & 9.013 \\ \text { " " ash, } \quad \text { " " in dry matter, } & .271 \\ 3.007\end{array}$

The ash was found to be constituted as follows:

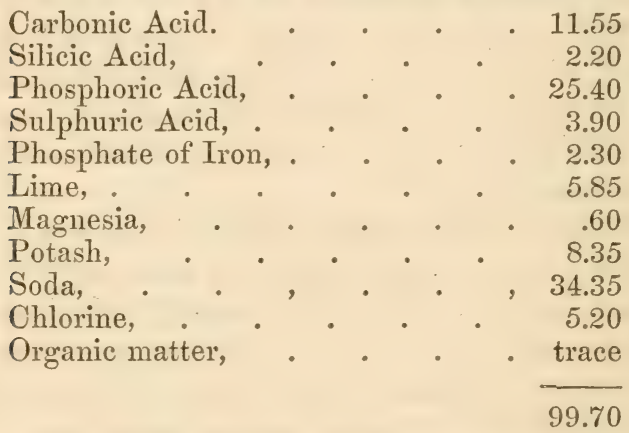

The analysis shows that superphosphate of lime, or bone-dust, to supply the phosphoric acid, and common salt, to furnish the soda and chlorine, are the special manures most likely to be required. Ashes, guano, and all kinds of animal matter, will also increase its growth and productiveness.

Culture.-The melon likes a rich, sandy soil, well manured, and deeply dug. If the soil is clay, it should be corrected by the addition of charcoal-dust, sand, or leaf-mould from the woods. 'The most luscious melons are grown on new land, fresh from the woods. They like, also, soil manured by cowpenning. In selecting seed, get the oldest you can, 
and take great care to get that which is perfectly pure, for the seed of melons raised in proximity to gourds, cucumbers, pumpkins, \&c., will produce new rarieties, destitute of flavor. All plants of this family are exceedingly liable to intermix, to their great detriment. They will deteriorate, if planted within one hundred feet of each other.

Plant in the open ground as soon as the frosts are well over here, the 1st of April and through the month; but in the low country the seed should be put in the ground in March. Make the hills six feet apart each way; dig a hole for them a foot deep and two feet across, and fill it half full with good well-rotted manure. Upon this throw six inches of good soil, and mix well together. Finish out with light sandy loam, or if a stiff soil, mingle in charcoal dust to correct its tenacity, so as to bring the hill just above the surface. Make the hill dishing, as for the cueumber. To guard against accident, plant abont ten seeds in the hill, and cover an inch deep. The cucumber bug may be driven off if troublesome, as directed for cucumber. A little guano sprinkled around the hill, not too near the plants, and intermingled with the surface soil, will also by its pungent smell, drive off the cucumber bug and flea, and also prove a very valuable fertilizer of the plants. Watering with guano water for the same purpose is very beneficial. When the plants make two or three rough leaves thin them out to three of the best in each hill, and pull up one of these soon after. When the vines begin to run, and show the first blossom, they must be stopped by pinching off the extreme bud as in the cucumber. 'This will ender them carlier and more prolific in large fruit. If watered liberally with soapsuds in dry weather, they will repay the trouble. Keep the ground about them freshdug, mellow, and free from weeds. Their whole culture is like the cucumber. Melons may be forced in all the 
methods described in the article on cucumber. As the melon worm generally destroys all the fruit after about the middle of August, it is important to get them early into bearing. This is a green worm, the progeny of some moth, which crawls up from the ground, eating its way into melons, squashes, cucumbers, \&c., admitting the air, and causing them to decay at once, and fill the atmosphere ahout them with a most disagreeable and sickening odor. Putting a board cr brick under each melon as soon as it appears, will sometimes prevent his entrance, but there is no certain remedy. But it is well to raise a part of the plants in pots to hasten the melon season as fast as possible. Good melons may be raised without this trouble, but in a garden the very best modes of culture should be pursued.

To Save Seed.-Select of each variety some of the earliest and best melons; wash the seed from the pulp, dry them in the shade, and put away in paper bags. They will keep ten years. Old seed is more prolific in fruit than new. Be sure and plant the oldest seed you can get if it appears well preserved; seeds will not be true if the varieties are within one hundred feet of each other.

Use.-The melon as a palatable and luscious fruit, very cooling in hot weather, maintains a high rank. It is usually eaten with salt alone, though many like the addition of sugar and spices. That it is wholesome is proved by its constant use while in season as an article of food among the people of Southern Europe. The musk melon contains but a trifle more water than the beet, and is quite as nourishing. It contains albumen, casein, dextrine and sugar, which combined with citric, malic, and tartaric acids, give its peculiar rich flavor. The green fruit may be cooked like the egg-plant, and is also made into mangoes. 


\section{Cucurbita Citrullus-WATERMELON.}

This is also a trailing annual, a native of the tropics, and of the same natural firmily as the musk melon, but belongs to a distinct genus. It is a large succulent and refreshing, but not high-flavored, fruit, and is probably the melon mentioned in the Bible.

The varieties just now in most repute in the Northern States, are Imperial, Black Spanish, Mountain Sprout, and Mountain Swcet, particularly the latter. The Orange Melon is also deservedly popular, the rind separating from the pulp like the orange. I have tried the above, but have never succeeded in getting as good melons as those raised from seed grown in the low country of our own State. The "Lawson melon" of Augusta, Ga., is probably the best grown. The Anderson is excellent. The Citron watermelon is a small, round, pale-green, marbled sort, liked by many for preserves. The watermelon has been analyzed by J.H. Salisbury. He found the percentage of water, dry matter, and ash as follows:-

Per-centage of water, . , . 94.898

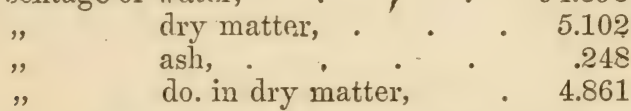

The ash wasfound to be constituted as follows :-

Carbonic acid, $\quad . \quad . \quad . \quad . \quad 11.42$

Silicic acid, . $\quad . \quad . \quad . \quad . \quad . \quad 1.21$

Phosphoric acid, . . . , 14.93

Sulphuric acid, $\quad . \quad . \quad . \quad . \quad 1.63$

Posphate of iron, . . . . . 4.52

Lime, . . . . . . . 7.32

Magnesia. $\quad . \quad$ • . , , 1.31

Potash, . . . . . . 23.95

Soda, . . . . . . 30.63

Chlorine, . . . . . . 1.81

Organic matter, . . . . . trace 
Phosphorus, potash, and soda are the chief constituents, and the special manures indicated are common salt, bonedust, or superphosphate of lime, and ashes. Guano and animal matter of all kinds are valuable manures.

Culture.-The water melon likes a deep, rich, sandy soil. Where this plant issmost successfully cultivated, it always grows upon sand. The hills should be seven or eight feet apart. In all other respects it is cultivated exactly in the same manner as the musk melon and cucumber. It should not be grown within one hundred feet of other melons, gourds, \&c., if you would gather pure seed. Protect firom insects as directed in the article, "Cucumber." The melon worm does not annoy the watermelon.

Use.-This is a wholesome fruit, very popular in summer from its beauty and the refreshing coolness of its juice. It is not very nutritious, as it contains ninety-five per cent. of water. It is not by any means as nourishing as the musk melon, and lacks its peculiar rich flavor. The outer rind is used for preserves. The seeds are valuable in urinary complaints. In many parts of Europe the juice is boiled into a pleasant syrup or made into beer.

\section{Cucurbila Melopepo-SQUash.}

The squash is a tender trailing annual, thought to be the connecting link between the melon and the pumpkin, and was first brought to England in 1597. It is a native of the Levant. It is a much esteemed garden vegetable, and in some of its varieties can be had for the table the greater part of the year. The best summer squashes are the Early Bush, of yellowish white color, and scolloped or patty-pan shaped, and the Early Bush Crooknecked, a small crooknecked sort, yellow, covered with warts, but excellent. These are very early, and their dwarf growth renders them most desirable for the garden. 
The best winter squashes are the Acorn, an old variety named from its shape, the seeds of which are difficult to obtain in a state of purity, the Lima Cocoanut, a large, long fine-grained kind, and the Boston Marrow, now much raised in the northern States. The Cashaw pumpkin is a pretty good substitute for the winter squash.

Culture.-It is planted at the same time as the cucumber and melon. Put six or eight seeds in a hill, and thin out to two or three when they get up. The bush squashes should be five feet apart, and the winter varieties at least nine or ten. For cultivation see Cucumber and Melon. Protect from insects in the same way. Squashes are much better grown in rich soil ; do not plant them near the cucumber or melon, if you would not have worthless seed from all the plants in their vicinity. Gather summer squashes while the finger nail can easily penetrate the rind; they must be gathered as soon as fit for use, or the fruitfulriess of the vines will be much impaired. To keep winter squashes, they must be put away in a cool, dry place, free from frost.

$U_{\text {se. }}$-The squash is a very wholesome and tolerably nutritious vegetable, prepared for the table in the same manner as the turnip, for which it is an excellent substitute to eat with fresh meat. To be fit for use after being boiled tender, it must be squeezed between two plates, for when full of water, as it is often served, it is not fit to be eaten. The winter squash should be boiled dry; it makes a good pie, like the pumpkin and the sweet potato.

To Boil.-While young and tender, boil whole, otherwise cut in strips, and remove the seeds; when boiled, mash, drain and season with butter, pepper, and salt. 


\section{Cucurbita Succada-Vegftable Marrow.}

This is a species of gourd from Persia, useful for the kitchen in every stage of its growth. It is cooked like the egg-plant when young, when half grown it is used as the squash, and baked into pies when matured; cultivated like the squash, but appears not to be very productive. Hills six feet apart.

\section{Cucurbita Pepo-Punpkin.}

Also a trailing annual, a native of India and the Levant, with globular or cylindrical fruit. It has become so crossed and intermingled with the squash, that it is difficult to say of some varieties to which species they should be referred.

The best variety for family use is the Cashaw, a long cylindrical curved variety; swollen at the extremity, of fine creamy yellow color, very solid and excellent to use as a winter squash and quite as valuable as any for the other purposes. The Valparaiso is also a good variety. Pumpkins are not as particular about soil as melons and cucumbers, but will grow well on any tolerably rich ground It is not best to grow them in the garden, as they will mix and corrupt the seed of the other varieties. They like a soil freshly reclaimed from the woods; the field is the proper place for their cultivation. Plant in March or April, when the main crop of corn is put in; let the hills be ten feet apart. Hoe frequently and keep clean. Let only one or two plants remain in each hill. Do not earth up the plants, but keep the soil about them light and loose with the hoe, until the vines prevent further culture.

Use.-In France as well as in New England, the pumpkin is much used for stews and soups. It is quite wholesome, and the most nourishing of any of this family of plants. The best kinds, as Cashaw and Valparaiso, are 
excellent substitutes for the winter squash, and make an excellent pie. 'They are also a valuable food for cattle. They can be preserved by boiling and drying the pulp in an oven, or by cutting in strips and drying by the fire, or will keep very well whole, if in a cool, dry place, free from frost.

Pumplin Pie.-Pare the pumpkins, cut them into small pieces, and stew them in just water enough to prerent their burning, let them stand over a slow fire until quite soft, then strain them through a sieve or colander, and to one quart of pumpkin add one quart of rich milk or cream, six eggs, one table spoonful of ginger, a grated nutmeg, a little salt, and sweeten with sugar or molasses to your taste. Bake very thoroughly without an upper crust.

\section{Cynara Hortensis and Scolymus-A RTICHoKE.}

The garden artichoke is a perennial plant, a native of the South of Europe, where it has been in cultivation from the time of the Romans. Columella mentions it, and says its name-cynara-is from cinere (ashes), because the soil for artichokes should be dressed with ashes. The plant is a sort of overgrown thistle, but more beautiful, with large pinnatified leaves, three or four feet long, with an ashcolored down, the head of which, when it is fit for use, before it begins to bloom, is about the size and somewhat the shape of a small pineapple.

As the artichoke is a native of a hot climate, it is perfectly adapted to the temperature of the Southern States and adds a pleasant rariety to our early summer luxuries, which should bring it into more general cultivation.

There are two kinds of the garden artichoke, the cynara scolymus or oval green, and the cynara hortensis or globe; as the edible parts of the latter are larger, and of a finer 
flavor, it is preferred as a garden vegetable, though the scolymus is more hardy and productive in cold climates. The ash of the artichoke has been analyzed by Richardson, and found to be constituted as follows :-

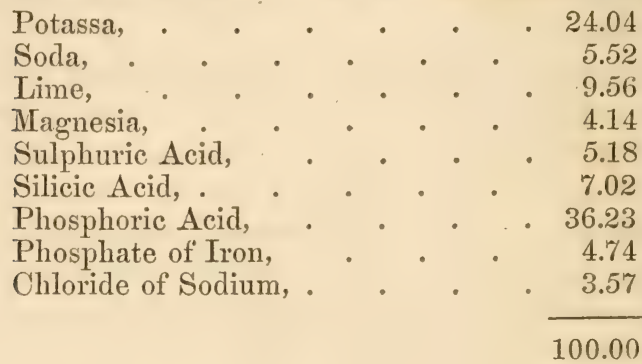

Potash and phosphoric acid are the most abundant constituents, indicating the application of ashes and bone-dust as the best special manures.

Propagation and Culture.-Artichokes are propagated by seed, or by off-sets from the old roots. If by seed, sow in February or the first of March, in drills an inch and a half deep, and a foot apart in very rich earth; if you have it to spare, they do still better by sowing them earlier in a cold frame. Transplant them when from six to twelve inches high into a very rich soil. If the beds are thimned out by transplanting, so that the plants are left a foot apart in the rows, they may remain in the seed bed until fall. The finest heads are procinced in a rich moist loam, and into such a soil they should be transplanted. The best compost is a mixture of three parts well decomposed hanure and one of leached ashes. They require an open exposure, free from the shade and drip of trees, or the plants will spindle and produce worthless heads. The rows must be four feet and a half apart, and 
the plants three feet in the rows. Plants from seed are better and more permanent than from off-sets.

If propagated by suckers these must be slipped off early in spring from the parent plant, retaining as many fibrous roots as possible. They should be selected when eight or ten inches high, and from those shoots which are sound but not woody. The brown hard part next the old stem must be removed, and if that cuts crisp and tender, the plant is good; if it is tough and stringy, throw the shoot away as worthless. Further, the large outside leaves must be removed, so that the heart appears above them, or their exhalations will exhaust the plant before it gets rooted. They are greatly invigorated if set in water three or four hours before they are planted. Set them in rows the same distance as above, with about half their length beneath the surface; water them abundantly until established and also during summer droughts. The only other attention they require during the summer, is the frequent use of the hoe. They will produce heads the same year from June to October, and annually thereafter from April to June or July, according to the season. The quality is improved, though at the expense of the quantity, by allowing only the head surmounting the main stem to grow on each stalk, removing all the laterals of the stem while young. As often as the head is cut, the stem should be broken down close to the root to encourage the production of suckers before winter. They should receive their winter dressing early in December. Cut away the old leaves without injuring the centre or side shoots, dig the ground over and throw the soil in a low broad ridge over each row, putting it close about the plants, but leaving the hearts clear. As soon as the shoots appear four or five inches above the surface, the ridges thrown up must be levelled and the earth removed from about the stock to below the 
part whence the young shoots spring. Remove all these shoots but two, or at most three, of the most vigorous, taking care to select those from the under part of the stock; the strong, thick ones from the crown, having hard woody stems, produce but indifferent heads.

Although the artichoke is a perennial, yet after the fifth year, the heads grow small and dry. The beds should in consequence be broken up at this time, or as soon as they begin to fail and fresh ones be formed on another site. Artichnkes are made to attain a much larger size than they otherwise would by twisting a ligature tightly around the stem below each, and thus preventing the reflux of the sap.

The artichoke is much benefited by the application of sea weed or any other manure containing common salt. This is probably in a great measure because salt keeps the soil moist.

For Sced.-Select a few of the finest heads and permit them to flower. Bend over the stalk and tie the head to a small stake to prevent the water from settling in the expanded calyx. When the flower has withered the seeds are ripe. One ounce of the seed will produce about six hundred plants, and for three years will vegetate freely if kept cool and dry. Put away in paper bags for use.

As the newly-made beds come into flower after the season for the old plants is over, those fond of this vegetable will prefer to make a new plantation every year.

Properties and Use.-The artichoke is wholesome, yet it contains but little nutriment, and is cultivated merely to please the palate. The heads are sometimes pickled. It is eaten by the French as a salad, with oil and vinegar, salt and pepper; the bottoms are often fried in paste like the egg-plant. The English gather them when they spread their scales and the flower appears about to 
open; the whole head is boiled and the scales pulled off, one or two at a time, dipped in butter and pepper, and the mealy part stripped off with the teeth. The bottom, when the leaves are disposed of, is eaten with the knife and fork. The flowers have the properties of rennet in curdling milk. Medicinally the artichoke is of little use.

T.o Boil.-Throw the heads as soon as gathered into cold water and let them lie two hours. After being soaked, put them into hot water with salt and keep them boiling until tender, which will take about two hours. Dress and trim them, and serve them up with melted butter and other seasoning to suit the taste.

Chards.--After the best heads have been cut, cut off the stems as low as possible, and the leaves within six inches of the ground. When the new leaves are two feet high, blanch them, as directed for Cardoons, which many think they excel.

\section{Cynara Cardunculus.-CARDooN.}

The Cardoon is a hardy perennial plant, a native of Candia, introduced into England in 1658. It resembles the artichoke, but is of larger size, some five feet in height with the leaves spreading out widely. In continental Europe it is considerably cultivated, but it is a fancy regetable, cultirated mostly as a curiosity, and being of no great merit as an esculent. There is but one variety cultivated.

The soil must be light, deep, well pulverized and tolerably rich. Sow the seed early in April, in drills ten inches apart, giving the plants, as soon as they come up strong, each five inches of space. They will run to seed too soon if sown earlier. Transplant carefully with a trowel, choosing a wet day, when six or eight inches high, into the place where they are to remain, being any ordinary 
compartment of tolerably rich, well-dug soil, five feet apart each way. Remove the long straggling leaves. Water in dry weather until they take root. Keep the ground loose about them, hoeing up all the weeds. When the plants are eighteen inches or two feet high they must be blanched.

The decayed leaves must be removed, and the rest closed together by strings or bass matting. Then bind up the plant carefully with twisted bands of hay or straw, beginning at the root. Select a dry day or the plants will rot. Bind up two-thirds of the height of the stem, then dig and break the ground and earth up to nearly the same height. As the plants grow, continue to tie and earth up. Watering liberally in hot weather is the only way to keep them from seeding. When the plants are blanched eighteen inches or two feet, they are fit for use. They will blanch fully in about two or three weeks. Do not let the earth get between the leaves or they will decay. They may be also sown in the rows where they are to remain, and thinned gradually to the proper distance.

For Seed.-Leave a few full-grown plants unblanched to stand the winter and they will shoot up to seed the next season.

Use.-The stalks rendered white and tender by blanching, are used in stews, soups, and salads, the leaves and stems being white and crisp for two feet in length. The plant is not very nutritious.

\section{Cyperus Esculentus-Chufas or Earth Almonds.}

A perennial, indigenous to Southern Europe, growing: in the form of a rush, some three feet high, producing small tubers the size of a common bean, and called by the Valencians " Chufas." It was one of the plants distributed 
by the Patent Office in 1854, and from its report this article is slightly condensed.

Culture.-It should be planted here in April, after the frosts are over, in bunches two feet apart each way, ten or twelve tubers in each, about six inches asunder. As soon as the first shoots appear, the ground should be watered, and every ten days thereafter, should there be no rain. Carefully eradicate the weeds, which is all the cultivation required. Pinch off the flowers when they appear, that the tubers may be of a larger size. When they arrive at maturity, they may be dug out of the ground and stored away. In drying they lose about onethird of their weight.

Use.-The tubers resemble in taste a delicious chestnut or cocoanut, and may be eaten raw or cooked. Soaked in water, they are eaten as a sauce. They are also mostly employed in making an orgeat, a delightful and refreshing drink, much used in Spain, Cuba, and other hot climates where it is known.

\section{Dancus Carota-Carrot.}

The carrot is a hardy biennial, found wild in Great Britain and various parts of Europe, growing in sandy soil or by road-sides. The root of the wild plant is small, white, dry, woody, and strong flavored; while that of the cultivated variety is large, succulent, and generally of a reddish yellow or pale straw color. The cultivated carrot is however thought to have been brought into Europe from the island of Crete, where it was early cultivated. It was carried to England by Flemish refugees in the days of Elizabeth, and the leaves were thought beautiful enough to be used in ladies' head-dresses. Cultivation has thus changed a wild, worthless plant into the most nutritious of all roots. 
'The best varieties for the garden are

Early Horn, which is very early, high colored, and sweeter than the other varieties. It does not grow so long as the others, and-may be known by its conical root shortening abruptly to a point. It will grow closer together, and is better on shallow soils than the other kinds.

Early French Short Horn is an earlier and superior variety of the above; for an early crop the best.

Altringham.-Color, bright red, and growing with the top an inch or two above ground, which sometimes freezes in very severe winters, if left in the ground. Of excellent quality.

Long Orange.-Is paler in color, and of great length, the root not above the ground. It is next in quality to the above, and best for winter use. The ash of the roots and leaves of carrots has been analyzed by Way and Ogston, and found to be constituted as stated below :

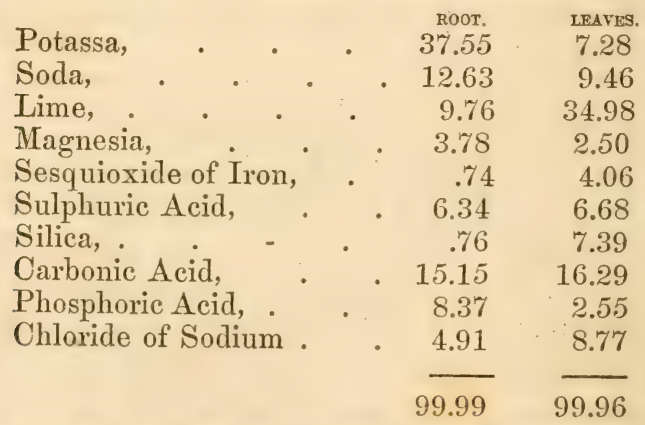

The salt and lime mixture, composted with leaf mould or swamp muck, a little plaster of Paris, bone-dust, and wood-ashes, are the special manures needed by the carrot. A little common salt is worth much more for this crop than its value in good manure.

Culture.-Carrots like a light and fertile soil, dug full 
two spades deep for the long varieties, as they require a deeper soil than any other garden vegetable. The manure should be put as near the bottom as you can get it; but the soil should be fertilized by a previous crop if you would have fine, smooth roots. Guano is an excellent application to this regetable. The seeds may be sorn in beds four feet wide, any time from January to April inclusive, thinly in drills, twelve inches apart. Cover the seed about half an inch deep. A carrot seed is very slow to vegetate. The short-topped, scarlet radish may be sown thinly in the same drills, just to mark the rows, that they may be cultivated before they are overgrown with weeds. By the time the carrots are well up, the radishes will be fit to pull. The ground should be kept well worked, light, and mellow. Thin the young plants, when two or three inches high, to six inches apart. In short, the culture of carrot is exactly the same as for the beet, which see. Six hundred bushcls have been produced from one acre. The carrots need not be pulled, but may be left safely in the ground to draw as wanted for use during the winter. In severe weather, they may be protected by a covering of litter; but it is hardly necessary, except for the Altringham.

For Sced.-It is much the best practice to leave some of the finest plants where raised, to blossom and seed the next summer; save only the principal umbels. Each head should be cut as it turns brown, dried in the shade, rubbed out, and dried in paper bags. The seed will not vegetate if more than two years old.

Use.-The carrot is a very wholesome food for man or beast. It contains almost six times as much nutriment as the Irish potato in the same weight. It not only gives sustenance itself, but renders other food more easily digest ible, according to Professor Mapes. 
It contains large quantities of pectin acid, which has the peculiar property of gelatinizing all fluids with which it is mixed, thus making them easily to be digested. This renders them, aside from their flavor, a very valuable addition to all stews and soups. It is also boiled plain, pickled, and made into puddings and pies. Boiled or grated it is an excellent poultice for foul and cancerous ulcers. 'The grated root is often added to cream to improve the color of winter butter. One carrot grated into cold water, will color cream enough for eight pounds of butter, without any injury to the flavor. One bushel of boiled carrots and one of corn, are said to be worth as much as two bushels of corn to feed to pigs. They are excellent for feeding horses and milch cows, and for this purpose are the most profitable of all ronts in deep fertile soils.

To Boil.-Boil, without peeling, stwo hours, or until tender; remove their skin, cut them in slices, and serve with butter and salt; pectin acid to the contrary, they are not very digestible unless perfectly boiled.

Carrot Pies.-These should be made like pumpkin pies. The carrots should be boiled very tender, skinned, and passed through a colander.

\section{Dioscorca Batatas-ChINeSE YAM. -}

This plant was introduced some six years since into France by Montigny, the French Consul at Shanghai. It has aniulal stalks or rines, and perennial tuberous roots. The leaves are opposite, triangular, cordate, acuminate above, with round basilar lobes, seven or eight nerved, converging towards the top. The length and breadth of the leaf is about equal, having a smooth and glossy surface, and of a deep green color. Its footstalks are half the length of the leaf, furrowed, and of violet color. Its flowers are diœcious, and of a pale yellow color. 
Culture-In autumn the smallest tubers are selected and preserved from frost by covering them in a pit with earth and straw. In spring these are planted near each other in a trench, in well-prepared soil. When they have put out shoots a yard or two in length, they cut off the joints and leaves containing the buds, and plant for reproduction. For this purpose they form the ground into ridges, on the top of which a shallow trench is made with the hand or a hoe, in which these joints are planted, covering them slightly with fine earth, and with the leares rising just on the surface. Should it rain they will shoot immediately; if not, water them gently until they do. In fifteen or twenty days they develop new stalks and tubers, the former of which must be removed from time to time to prevent their taking root on the sides, and thus injure the development of the tubers already formed. Another method is to cut the tubers into fragments of moderate size, placing their eyes in small pots, to be transplanted into a deep, rich soil when the danger from frost is over. March, in this latitude, would be the time for potting to transplant in April. Probably they should be planted about twelve inches asunder, in rows three or four feet apart, and cultivated like sweet potatoes, except no earthing-up is required. Where roots are required for reproduction, and not for the table, let the rines as they extend be buried horizontally, just beneath the surface, with the midrib of the leaves resting on the ground. Small tubers, about the size of a pea, will be formed at the angle of each leaf, which, if kept until the next spring, will grow with as much vigor as if produced from the cut tubers.

Use.-The roots, which are oblong and tapering, are the edible part. The maximum size to which they grow is two inches in diameter, the larger end tapering upward to the size of the finger. They are covered with a brownish, 
fawn-covered skin, pierced by numerous rootlets. Under this is a cellular tissue of a white opal color, very crispy, filled with starch and a milky mucilaginous fluid, with scarcely any woody fibre. When cooked it dries like the Irish potato, the taste of which it resembles. Each plant often produces several tubers, but generally only one, ranging in weight from eight ounces to three pounds. It is more nutritive than the Irish potato, which it may possibly rival in esteem.

The Japan Yam has been cultivated the present season (1855) in the United States, but mostly for the increase of small tubers for reproduction. A friend writes me that he has "cooked one and found it excellent." It is still too soon to say much about its mode of culture or value.

The other yams, Dioscorea sativa and alata, are cultivated on the gulf coast to some extent, and in the same manner as the sweet potato, except that the vines are supported by a stake or pole. The Alata sometimes grows three feet in length, and often weighing thirty pounds. (See Patent Office Report for 1854.)

\section{Ervum Lens-LentriL.}

The garden lentil is an annual leguminous plant cultirated in France for its flat seeds, of which two are contained in each pod. Lentils like a rich sandy soil, and are planted in April, with snap beans, as, like them, they are apt to be injured by late frosts. They are planted in drills covered lightly, and the young plants must be cultivated like the bean; which see. Harvest them when the pods begin to turn brown. Green or dry they are cooked like beans, and when dry, should be boiled two hours and a half. Soak in water before boiling. When done aud butter, pepper and salt. They are an excellent addition to soups, 
being very nutritious, but like peas and beans, do not always agree with persons of weak digestion. From seed obtained by me of the Patent Office, plenty of vine was raised but not much seed.

\section{Fedia Olitoria-Corv Salad, or Fetticus.}

Corn Salad, or Fetticus is a small annual plant, a native of English wheat-fields. It has long, narrow leaves of a pale glaucous hue, and very small pale blue flowers collected in a corymb. It has long been cultivated in English gardens as a winter and spring salad.

Culture.-Corn Salad likes a loam of moderate fertility not too heary. It is raised from seed, one quarter of an ounce of which will sow a bed four feet by fifteen. Sow seed of the preceding year's growth early in October, in drills six inches apart. The only culture needed is to thin the plants when well up to four inches in the drills, and keep free from weeds by frequent hoeing. Gather the leaves to eat while young, taking the outer ones as you would spinach. It will be fit for use all winter. If desired, another sowing may be made the first of February for spring use.

For Seed.-Leave some of the plants to shoot up to seed in the spring.

U'se.-It is used during winter and early spring, to increase the rariety of small salads, and as a substitute for lettuce. In France it is boiled like spinach.

\section{Helianthus Tuberosus-Jerusalen Artichore.}

This is a hardy perennial plant, a species of sun-flower, a native of Brazil, introduced into England in 1617, and was much esteemed as a garden vegetable until the Irish potato took its place. The crops obtained in good soils are enormous. 
The salts found in the ashes are mainly potash and lime, the former very largely.

Culture.-It flourishes best in a rich, light soil, with an open exposure, bit will thrive in almost any soil or loeation. Plant from December to March, either small tubers or the large ones, cut into sets of one or two eyes, four inches deep, in rows three and a half fect each way. Keep the ground free from weeds and earth up slightly. They will be fit for use in the fall. Take care to dig them up thoroughly, as the slightest piece will regetate. They will grow on land too poor for almost anything else. If the top be cut off one-half way down in Angust, it is said by some that the size of the tuber will be very much increased by the admission of air and light. This is doubtful.

U'se.-The roots are eaten boiled, mashed with butter, are considerably nutritive, and have a moist soft texture, and tolerably agreeable taste. It is however, rather a second-rate dish. They are better pickled in-vinegar. The plant is most useful in feeding cows and pigs, affording large quantities of food from quite poor soils.

\section{Hibiscus Esculentus-OкRA.}

This is an annual plant, a native of the West-Indies, and much esteemed and cultivated wherever its merits are known. It is of quite recent introduction into our gardens.

There are two rarieties of Okra, the round, smooth green, and the long fluted or ribbed white, but there seems to be little difference in quality or otherwise, except in the shape of the pods.

Okra likes a good dry soil. Any soil will produce it that is good enough for the cotton plant, to the natural family of which it belongs. The pods are not as pleasant 
or early on over-rich soil. It is not planted until the frosts are over, say about the first of April, as it is extremely tender, though it often comes up from self-sown seed. The time of planting cotton is a very good rule, though some may be put in as an experiment, two weeks earlier. Make the drills three feet apart, sow the seed rather thinly and thin out, when they grow large, to two feet apart in the drill. Those thinned out may be transplanted and will make productive plants. No seed should be allowed to ripen on those stalks from which the pods are gathered for eating. As fast as the pods grow hard or unfit for use, cut them off, for if left on, the stalk will cease to be productive. If not allowed to ripen seed, the plants will continue bearing through the season.

To Sare Seed.-Leave some of the earliest plants to ripen seed, if you would have this regetable in good season. Shell out the seed, and stow away in paper bags.

Use.-The pods gathered in a green state, and so tender as to snap easily in the fingers, are the parts employed in cooking. If old, they are worthless. They are very wholesome, considerably nutritious, very mucilaginous, and impart an agreeable richness to soups, sauces, and stews. They are also boiled simply in salt and water, and served up with butter, pepper, \&c. Okra can be preserved for winter use, by putting down the pods in salt like cucumbers, or by eutting them into thin slices and drying like peaches. When dry, put up in paper bags. The seed is used as a substitute for coffee, which I think it not very likely to supersede.

Okra Soup.-Wash and slice thin two dozen young: okra; add two onions chopped fine; put into a stew pan, with a knuckle of veal, a gallon of water, and a bit of bacon; add six peeled tomatoes; stew until quite thick, which will be in three or four hours and serve, with or 
without the meat, as you like. A chicken, or a piece of beef, may be substituted for the real.

\section{Humulus Lupulis-HoP.}

The hop is a plant with a perennial root, throwing out many herbaceous climbing stems, and is found growing wild on the banks of rivers in Europe, Siberia, and our own country. It was cultivated in England, on or before 1525, when the old doggerel states:

\section{"Hops, heresy, pickerel, and beer, \\ Were brought into England in one year."}

A few roots should be in the garden, as they are useful in making yeast and beer.

Culture.-It is propagated by dividing the roots in autumn and spring. Give the plant a deep, rich soil; put two or three plants, six inches apart, in a hill, making with the plants, when set, a triangle, and the hills six or eight feet apart. Keep the ground free from weeds, and well stirred. Manure them every year. Give them poles twelve or fourteen fect long, and two or three poles to each hill. Gather when of a straw color, and you find the inside of the hop covered with a plentiful yellow dust, and the seeds begin to be plump; dry them thoroughly, and put them up in bags for use.

Use.-We have said that the principal use of hop was in the preparation of yeast, \&c. The young shoots and suckers are boiled and eaten as asparagus. They are very largely cultivated in fields, and used in the manufacture of ale and strong beer. Its medicinal qualities are tonic and soporific. A pillow filled with hops will produce sleep, without the ill effect of opiates. 


\section{Lactuca Sativa-Letruce.}

The botanical name of this plant is derived from $l a c$, the Latin word for milk, on account of its milky juice. It is an annual hardy plant, of which the cabbage varieties probably originated in Egypt, The Cos lettuce, however, came from the Greek island of Cos, in the Levant. It has been cultivated in England since 1562.

Of the two great families of lettuce, the Cos varieties, which grow upright and of an oblong shape, and require blanching, though more esteemed in England, do not, unless sown early in October, succeed so well in this country. The cabbage rarieties are more hardy and free growing, and better adapted to our common gardens. The following have proved excellent with me:-

Butter or Early Cabbage.-Heads small, white, crisp, and closely cabbaged; leaves pale yellowish green; excellent for hot-bed culture, as well as open air ; early and hardy.

Brown Dutch (yellow seeded).-Heads much larger; equally tender and excellent, and closely headed; with brownish green leares. Will stand any frost, without protection.

About two weeks after these, if sown at the same time, will come into use the next three varieties:-

Royal Cabbage.-Black seed; heads larger, and leaves of a darker green than the early cabbage; equally firm and crisp.

Plitadelphia Cabbage.-Of the same season, and equally good.

Victoria Cabbage.-Withstands the heat rather better than the two preceding, and produces large white, crisp heads; perhaps the most desirable of the three.

After these come on:- 
Curled India.-Leaf of a light yellow green, and very much curled; a very distinct sort; heads large and close, but not so fine and crisp as the other varieties, but will continue to head much later. In a rich, shaded situation, if well watered and frequently hoed, it will make good heads most of the summer.

White Cos.-This is the best of the Cos varieties for this climate. Leaves long; growth upright and vigorous, like Endive, it should be tied a few days, and it will blanch beautifully.

Paris Green Cos.-An upright grower; crisp and excellent; also requires tying.

Here follows an analysis of the ash of the stalks and leaves of lettuce, made by Griepenkerl:

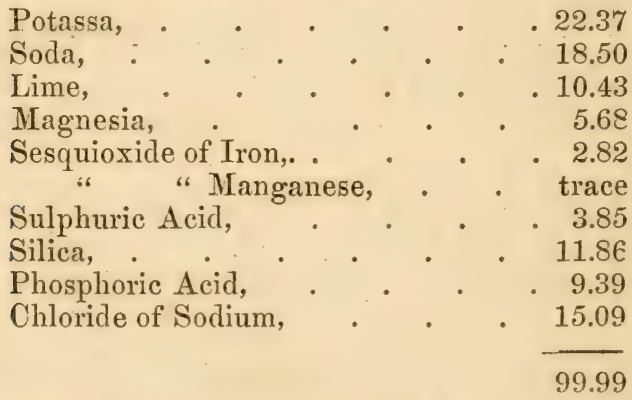

The analysis would seem to indicate the application of wood ashes and common salt as the most important requisites for this crop, besides animal manure.

Culture.-In raising good lettuce there are three things necessary, good seed, good soil, and frequent hoeing, and of these the first is perhaps the most important. There is generally no difficulty in making lettuce seed vegetate, but if it is not made from good heads it will not produce heads eren with the hest culture. Lettuce likes a good 
mellow soil enriched with well rotted manure. Do not think of getting good heads on poor ground. Few of the Cos lettuces, except the white Cos and Paris, do well here, and fine cabbage lettuce is less trouble to raise, and good enough for any table. Lettuce may be sown in October and November, and again from January to April. That sown in the fall, except the Cos varieties, will come on earlier, but is not so good as the heads from the spring sowing. Sow thinly in drills eight inches apart. An ounce of seed will produce about ten thousand plants. Let the seed be very lightly covered, and if dry weather, press the earth upon it by walking orer it on a board, or patting it with the back of the spade. Beds about four feet wide are most convenient. If the lettuce comes up too thickly in the drills it must be thinned, as the plants begin to crowd, to two inches apart. Transplant into the ground, where it is to remain when the plants show four leaves. The Early Cabbage may be planted nine inches apart each way; but the other varieties will not do with less than a foot. The soil into which they are to be removed to head must be rich, light, and mellow. Transplant in moist weather with a trowel, disturbing the roots as little as possible. Water the plants until established. Rabbits are rery foud of lettuce, but can be kept off by dusting the young plants with ashes. After the young plants get established, give them deep and frequent hoeings; and if you sowed good seed there can be but little danger of your not being rewarded with beautiful crisp heads. The October sowing should be of the Butter and Brown Dutch and Cos varieties. This will yield small salad in mild weather through the winter, besides plants for early heads. A second sowing of these should be made in February. The later kinds may be put in as late as April with success. If no lettuce has been sown in October or November, for heading early in the 
spring, a little should be sown in January in a cold frame under glass. Give it plenty of air, but keep it covered nights and cold days, and as the weather grows mild leave off the glass altogether a little while before setting out in the open air. The early sown Butter lettuce may also be transplanted under glass at nine inches apart, and the table be kept supplied in this way with fresh heads all winter. Plenty of air must be given them, and they should be covered in freezing weather only. Hoe deep and often. For a fall heading, a crop can be sown in August at the same time with turnips in a shady situation, which being transplanted, will give good heads in November and December. The fall and summer sowings do much better if thinned to a suitable distance, and allowed to head where they stand, as lettuce plants are rery impatient of transplanting in hot weather. The Butter and the Brown Dutch are the best for this sowing.

Seed.- Some of the finest and most perfect heads of the early sown crops should be selected. Unless from a good head the seed cannot be depended upon. Each variety must be kept separate, and all imperfect heading plants near them destroyed. Tie them to stakes and gather the branches as fast as they ripen. Dry the seed in the shade, and thresh and store in paper bags. Lettuce seed cannot be relied upon when more than two years old.

Use.-Lettuce is the most popular of all salads, and it is also sometimes used in soups. Boiled, it is quite equal to spinach. It is fit to boil from the time it is large enough until the seed stalk begins to shoot up. Its juice contains a narcotic principle somewhat like opium, which is in small proportions when young, but increases with the ago of the plant. This principle has not the constipating: effects of opium. A tea prepared of lettuce leaves is beneficial in cases of diarrhœa. For a common salad, let the 
leaves be carefully picked early in the morning, washed and drained before sent to the table, and provide salt, oil, sugar, and vinegar, that each person may season to his taste. The finer salads require hard-boiled eggs, mustard, and other spices, \&c.

\section{Lepidum Sativum-Cress.}

Cress, or "Peppergrass," as the best variety has been named from its pungent flavor, has been cultivated in England since 1548 , being probably a native of Persia or Cyprus.

Culture.-Cress likes a light, moist mould, and in summer a shady border is to be preferred. It is propagated from seed which, to keep up a succession of young and tender plants, must be sown every week or two. Give it rich earth that it may grow rapidly. It is best when an inch high, but is generally allowed to get two or three before cropping. Begin to sow in February, in the open ground, in drills six or eight inches apart; corer lightly, and pat over the bed with the back of the spade to press the earth upon the seed. Feep the ground clear, and water in dry weather. It can be had all winter by the use of the cold frame or hot bed, and in the latter case can be grown fit for use in forty-eight hours; give plenty of air. A few rows left uncut will produce seed abundantly.

Use.-The young and tender leaves give to salads a warm, pungent, and agreeable taste. It is generally used in connection with lettuce and other salads.

\section{Ocymum-BasiL.}

Ocymum Basilicum, Sweet Basil, and Ocymum Minimum, Bush Basil, are the names of the two species in cultivation. Both are annuals and natives of the East Indies, with small leaves ant small white flowers. Sweet basil is the 
species most cultivated, and was introduced into England in 1548.

Culture.-Basil likes a rich, light soil, free from shade. The plants may be started early in March, under glass, and transplanted when of sufficient size where they are to remain. Basil is rather difficult to transplant, but can be carefully lifted in tufts with the balls of earth attached, in a moist time, with complete success; give water until established. They can also be sown on the borders where they are to remain, but if sown too early in the open air, the seed is apt to rot or the young plants to be killed by frost as they are rather tender. April is the month for sowing in the open ground. Do not cover the seed deeply, but press the earth upon it. Make the rows ten inches apart, and thin the Sweet basil to ten inches and the Bush to five inches in the row. Weeds must be kept under and the soil mellow by frequent hoeing. Basil also makes a very pretty edging. It should be cut not too closely just as it comes into flower and hung up in small bundles in the shade to dry for winter use; thus cut it will soon grow up again. When thoroughly dried it may be pounded fine and kept any length of time in closely stopped bottles.

Seed.-Let some of the finest plants remain uncut and gather the seed as they ripen.

Use.-The leaves and small tops are the parts employea and give a delightful flavor in cookery. They have a strong flavor of cloves, and are much used in soups and sauces, and other high seasoned dishes. They are much employed in French cookery.

A small sprig of basil, on account of its odor, is an agreeable addition to a bouquet of flowers. It is the most agreeable of the pot herbs and the most useful after parsley and sage. 


\section{Origanum-MARJORAM.}

The name Origanum in Greek signifies delight of the mountain, and this plant is thus named from its growing in dry, elevated situations. Four species of this plant are cultivated, of which two are sufficient for the garden. These are

Origanum Marjoram.-Sweet marjoram, a hardy annual or biennial plant, a native of Portugal, and introduced into English gardens in 1573. It has small, acute leaves, and it flowers in small, close heads.

Origanum Heracleoticum.-Winter marjoram, a hardy perennial, a native of Greece, and first cultivated in England in 1640. Leaves like the preceding, but flowers in spikes.

Culture-Marjoram likes a dry, tolerably rich soil, and free from shade. Sweet marjoram is propagated from seed; the other, by seed or by dividing the roots in the spring and fall. The plants must be watered until established. Plants of Sweet marjoram should be six inches apart; while twelve is not too much for the other variety. Sow from February to April. As the seeds of the marjoram are very small, the ground must be prepared very finely, and a very light mark made for them, covering them by drawing over them the back of the rake. The culture is like basil, which see. To preserve the tops for winter use, and to save seed, also see "Basil."

Use.-Both species are aromatics of sweet fiaror, much used in soups, broths, stuffings, \&c. The young and tender leares are used while green, and the tops dried for winter use.

\section{Pastinaca Sativa-PARSNIP.}

This is a biennial, a native of Sardinia and various parts of Europe. It has long been an inmate of the garden. In 
its wild state, it is said to have poisonous properties; but it is rendered by cultivation sweet, palatable, and very nutritious for man and beast. The garden parsnips have smooth and light-green leaves, while those of the wild variety are dark-green and hairy; but the two do not differ so much as the wild and cultivated carrot. This plant is of the liardiest nature, being improved by remaining in the ground exposed to frost during the winter. The best variety for the garden is the Hollow-crown or Sugar parsnip. Its roots are smoother, more handsome, and better flavored than the other varieties. It is distinguished by the cavity or cup which crowns the root. The ash of parsnips has been analyzed by Richardson, and found to be constituted as follows :

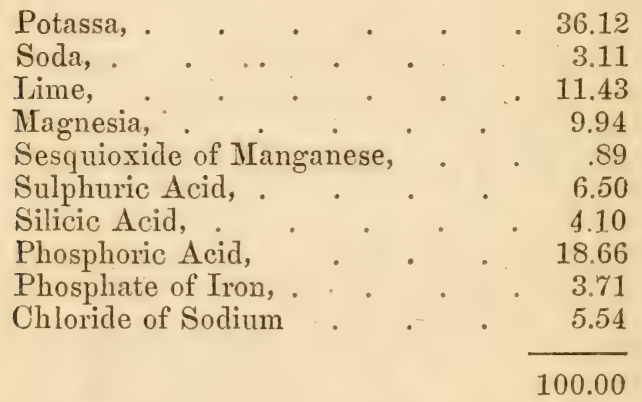

Potash and phosphoric acid are the elements most likely to be wanting in the soil, in sufficient quantity for this crop. Bone-dust and wood-ashes will be the best addition which can be marle.

Parsnips like a rich, sandy loam, the more deeply dug the better. They do exceedingly well on rich bottom lands, but do not succeed well in stiff clays. The manure should be applied to a previous crop. If the soil be dug two spades deep, or trench-plowed, it will improve the crop. 
Parsnip seed can be sown in January, February, and March, in drills fourteen inches apart: scatter the seeds thinly in the drills, and also sow radish seed thinly as directed for carrots, to mark out the rows, as the seed is slow in vegetating. If you do not need the radishes, cut off the tops, and leare them to decay in the soil which they will enrich. Pulling out the radishes lets in the air and fertilizing gases to the roots of the young parsnips, and the radishes are quite fit to pull by the time the parsnips are well up. As they mark out the rows the beds can be hoed before they get full of weeds. If sown alone the beds are full of weeds before the parsnips are ready to hoe, and the labor of culture is much increased. Thin out the plants gradually to three, then to eight inches. Lettuce and cabbage seed may be sown in drills between the rows of parsnips to be transplanted early. Parsnip seed may also be planted in the fall; but there is no advantage in it. The details of the culture of parsnip are exactly like carrot, which see. 'The roots need not be pulled until needed for use.

For Seed.-A few of the best roots may remain where grown. Keep free from weeds and they will yield abundantly. They may also be taken up and set out two feet apart in a border; but they do better to remain undisturbed. 'The seeds cannot be depended on for more than one year.

Use.-The parsnip is a rery wholesome and nourishing root, though its peculiar sweetish taste is disliked by many persons. It is horrever a very agreeable addition to our supply of winter regetables. Its fattening properties are great, and it is therefore an excellent root for feeding all kinds of farm stock. Cows fed upon it will yield milk abundantly, and butter of the best quality. Its seeds are sometimes employed in intermittents. 
To Boil.-Parsnips are cooked as carrots, but they do not require so much boiling. They are often served up differently, being mashed with some butter, a little cream, and seasoned with pepper and salt.

\section{Phaseolus Vulgaris-Bush-BEans or SNaPS.}

An annual, a native of India, brought to England in 1597. The rumning beans belong to a different species, and are treated of in a separate article. Bush-beans are generally called snaps from their breaking crisply. The following are good varieties:-

Eurly Molacwk.-Pods long, beans large oval with darkcolored specks; it bears very well is the earliest variety, and is least injured by frost. In good seasons, fit for the table about five weeks after sowing.

Early Valentine.-Pods round, and continue crisp longer than most other varieties. The beans are pink-speckled on a salmon ground; bears well. Sown with Early Mohawk, is about five days later.

Late Valentine.-Pods similar to the foregoing, equally crisp and tender, color dark brown speckled; a better bearer and grows more thrifty than the foregoing. One of the best sorts. About ten days later than the Mohawk.

Royal Kidney.-Pods long, beans finely flavored, white, and large, but later than any of the other varieties. Sown at the same time, is a fortnight later than the Mohawk. Of this variety the ripe beans, if they are gathered and dried in an oven to prevent their destruction by the bug, are excellent for winter use.

Besides the abovenamed, I have tried Turtle Soup, Yellow six weeks, and several other varieties, but the foregoing are the best.

Here follows an analysis of the ash of kidney beans made by Richardson:- 


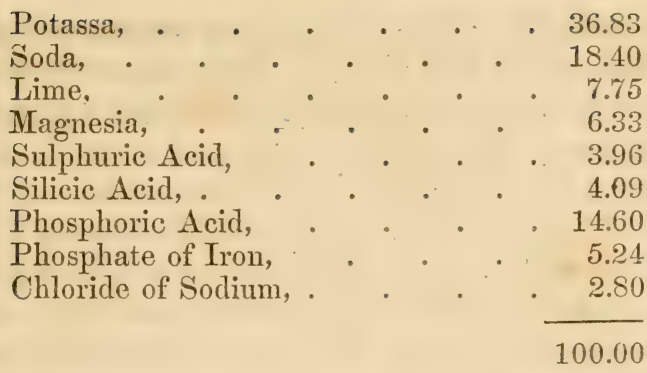

Wood-ashes and bone-dust or superphosphate of lime, will supply the soil with the most necessary elements for this erop, which, by the way, like most legumes, draws most of its sustenance from the atmosphere.

Culture.-Snap-beans are of the easiest culture in this climate, and are less particular about soil than in colder latitudes. The soil for the early crop should be dry and light; if wet or tenacious the seed often decays without germinating or comes up spindling and unproductive. For the summer-sown crop, a soil slightly moist but still inclining to a sand, is to be preferred. As beans are very tender and easily destroyed by frost, there is no use to put them in the ground too early. A few may be planted in March, but about the first of April is the proper time for the first large planting. They may be planted for a succession in moist weather from this time to the last of August. Plant in drills eighteen inches or two feet a part, and the seed two inches apart in the row. Corer the seeds about an inch and a half deep. A pint of seed will plant about one hundred and twenty five feet of rows. When the plants come up, thin them gradually to six or eight inches in the row and they will be much more vigorous and productive. The Refugee or Late Valentine does best in hills eighteen inches apart. Plant four or five 
beans to a hill. Keep them clean always and the soil light and mellow with the hoe. Draw the earth carefully about their stems when about to flower, making broad low hills to protect the roots from heat and drought. If well cultivated the same plants will continue to bear well a long time. Do not hoe any of the kidney beans whether dwarf or rumers when the foliage is wet, as the plants will rast and be greatly injured, if not destroyed. Choose dry weather for working them. For saving seed and use, see "Lima Bean."

\section{Phaseolus Limensis et ATulliflcrus-PoLe on Runving} BEANS.

The Phaseolus Mrultiflorus includes the Scarlet Runners, London Horticultural, and many other good varieties, but they do not continue long enough in bearing to warrant their culture in a hot climate. The Lima beans are also much better flavored. Of the Phascolus Limensis, there are the green and white Lima and Carolina Sewee. They are natives of South America. The white Lima is not quite so large as" the green, but bearing with greater abundance, is to be preferred. It is also not quite so hardy and productive as the Sewce, but is much larger and richer flavored.

Sewee or Carolina.-This is the well-known and favorite butter bean of the country. It closely resembles the Lima bean, but is less in size, earlier, harder, and bears much more abundantly, and though not quite so rich, is for general culture the best running bean for this climate.

Culture.-Lima beans require a rich, strong soil, and will thrive on heavy loams, where the other running beans and snaps would not flourish. They are still more tender than snaps, and should not be planted until settled warm weather, as the seed will rot in cool weather, and the 
slightest frost will destroy them if they chance to regetate. The tenth of April is early enough in this climate. Plant in hills five feet apart each way, arotind a good pole eight or ten feet high, driven two feet into the earth. If the poles are too high they are late in coming into bearing and out of reach in gathering. In planting the Lima and other beans, place the eye downward and the narrow end the lowest as the bean always rises from the ground in that position, and if not planted right it has to turn itself over in the soil, and if prevented by any obstruction from turning orer it is sure to rot in the ground. Planted in this way, they come up sooner, better, and more evenly. Cover about an inch and a half deep. Put four or five beans around each pole, and when well up take out the weakest, leaving but three plants. A quart of butterbeans will plant about four hundred hills. The subsequent culture consists in keeping the ground frequently hoed when the vines are dry. They will continue in bearing until cut off by the hard frosts.

For Seed.-Gather both the Lima and Kidncy beans when ripe and dry them thoroughly. The seed should be kept pure by planting the varieties at a distance from each other. As they are certain to be deroured by bugs, if saved in paper bags, put them up in glass bottles or earthen jugs well corked. Into each one pour before corking, a teaspoonful of spirits of turpentine. 'The turpentine odor will destroy the bugs without injuring the vitality of the bean, if the ressel is tightly corked.

Use.-The tender fleshy pods of snap-beans are a farorite summer vegetable, very delicate, wholesome, and moderately nutritice. They are boiled and also pickled, and may be preserved for winter use, by cutting them into pieces and laying them down in salt. They will make their own brine, and must be kept covered by it or 
they will spoil. Cook them in two waters to extract the saltness. The Lima beans and the snaps when full grown, are shelled and afford in proportion to their weight, more nutrition than most other vegetables. Wheat contains but 74 per cent. of nutritive matter, while kidney beans contain 84 per cent. They abound in the constituents that produce muscle and fat, and will supply better than most vegetables, the place of animal food. They can also be preserved for winter use. Gather them in their green state when full grown, and dry them carefully in the sum. They are better gathered in this state than if delayed until ripe, and are also free from bugs. They must be soaked over night before being boiled. They can also be laid down with layers of salt like snap beans. They are very good gathered when ripe, and dried carefully in an oven in order to keep them free from insects.

To Pickle.-Beans may be pickled in a manner similar to cucumbers.

To Boil Snap-beans.-Cut off the ends, strip off the strings, put in boiling water with salt and boil till tender. Do not omit the salt in cooking vegetables; add butter and pepper to the taste.

To Boil Lima Beans.-Put them into just enough boiling water to cover them, boil until tender, turn off almost all the water; season with butter salt and pepper.

To Bake.-Take two quarts of beans and three pounds of pickled pork. Pick the beans over carefully, wash and turn them about with a gallon of soft water to a pot. Let them soak in it luke-warm over night; set them in the morning where they will boil till the skin is tender and about to break, adding a teaspoonful of saleratus. Take them up dry, put them in your dish. Gash the pork and put it down in the dish so as to have the beans corer all but the upper surface; turn in cold water till the top is 
just covered; bake, and let the beans remain in the oven all night.

\section{Pisum Sativum-English Pea.}

The Pea is a hardy annual, probably a native of the South of Europe, China, and Japan, but has been cultivated from time immemorial. It is a climbing plant, producing its seeds in legumes or pods which usually grow in pairs. The pea is now one of the most desirable culinary plants. Numerous varieties have been originated differing in the color of the blossoms, height, and time of ripening, and also in productiveness. Of these, four or five kinds are sufficient for any garden. Among the best are:

Prince Albert.-The earliest pea known, grows two and a half feet high. Pods and peas are both small but well flavored. A good bearer.

Landreth's Extra Early.-This celebrated early pea comes into use about five days after the preceding, and with the Ceilo-Nulli. The whole crop ripens at once. It is not very productive. Two and a half feet high.

Cerlo-Aulli comes into use with the preceding, and is a much finer pea. It has a longer pod, which is better filled. The vines are taller, and it bears about twice as many pods to the stalks as the Extra Early; the most prolific of early peas, and continues long in bearing; two and a half to three feet high.

Fuirbank's Champion.-This is the very best large pea: a wrinkled marrow, of the highest excellence; grows about four feet high, and bears abundantly with me, and is the pea $I$ prefer to all others for the main crop. The peas are very large, slightly shrivelled, and of a bluish cast, when dry. It is about three weeks later than the Prince Albert. 
Knnght's Tall Marrow.-Grows about six feet high; bears a long time and abundantly, and is of first-rate excellence; later than the above.

New MIammoth.-A pea of the same height, and of equal excellence with the foregoing; comes into use about the same season; productive.

If the above are not to be had, Early Frame, Early Charlton, Early Grotto, Dwarf Blue Imperial, Blue Marrow, Banksian Marrow, Blue Prussian, Knight's Dwarf Marrow, and Woodford's Prolific, are among the best remaining sorts.

The best three varieties for a succession are Prince Albert, Cedo-Nulli, and Champion of England. If confined to two, I should reject the Prince Alvert, though the earliest of the three.

An analysis of the ash of the seed and straw of peas has been made by Erdmann, and is as follows:-

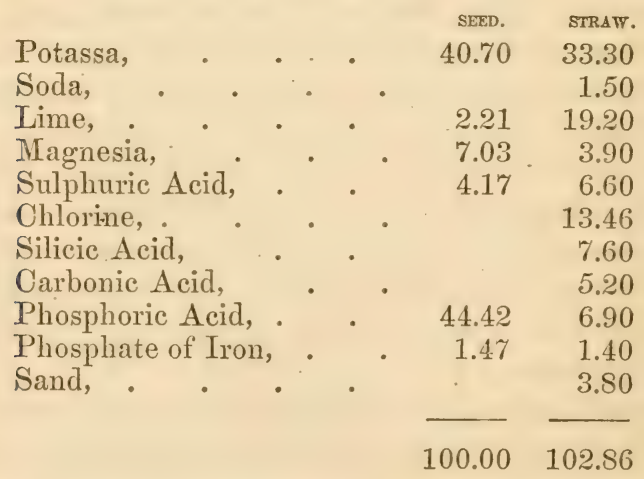

Potash and phosphoric acid are large constituents of the ash of the pea. Ashes and bone-dust, or superphosphate of lime, especially the former, are likely to be the special manures most needed. 
Culture.-A moderately rich and dry soil is best suited for the early pea and the dwarf varieties. The late peas and the lofty growers do better in heavier soil, and a cool, moist situation. The manure should be applied early the preceding autumn, to be well reduced by the time the crop of peas are ready to feed upon it. In poor ground, fresh stable manure is better than none. If the ground, howerer, be extremely rich, there will be more vines than fruit. Plant the early kinds from the first of January to March, and the later ones until early in April. Somo plant in December. Plant the seed in double drills (made with a line, if you would have the garden look neat), and six to nine inches apart, according to the kind, and two inches deep. Then corer them an inch deep with mellow earth. The rows of early peas should be three feet apart. Champion peas should be four, and the taller kinds six. It is a good plan to plant them all six feet apart, and a row of melon or cucumber hills between them, to come on afte: the peas are gathered. The space between the melon hills can be used for lettuce or radishes. Early peas should be planted in the drills, about an inch apart. The medium growers an inch and a half; while for the tall kinds, as Knight's Tall Marrow, and the Mammoth, two inches are not two much. A quart of seed of these varieties will plant not quite fifty yards of double rows, while a quart of early peas will plant inearly seventy twice as thickly. After the peas are about two inches high, hoe them well, drawing the earth a little toward them, and loosening the soil between the drills, destroying every weed. Repeat this once or twice, before brushing, which should be done when the plants are six or eight inches high. This may be done by sharpened branches of trees prepared fan-shaped, and of a height proper for the pea to which they are to be applied, or stakes may be driven 
down every six feet each side of the drills, and lines of twine stretched from one to the other. Pea brush is, however, the best, as the vines lay hold of it more readily. It should be placed firm in the ground, between the drills. After brushing, draw up the earth on each side, to help support the rine. Market gardeners do not employ brush or twine, but let them fall over and bear what they will. This does tolerably well with the early varieties, if the spaces between the rows be filled with straw or leaves.

Peas may be had in Norember, by sowing the early kinds the last of August; but the crop is uncertain. A little further south, peas may be planted not only in August and September, but through the fall and early winter months, and will continue in bearing until the warm weather comes on. They are very hardy, and the vines will ordinarily hear a temperature of only $?^{\circ}$ Fahrenheit, without injury. If a hard frost necur while the plants are in bloom, the crop is lost.

Seed.-The seed for early peas should be raised in a cold climate, in in this latitude, like many other plants, they rim into later rarieties. The plants of the rows intended for seed should not be gathered from for any other purpose. When the pods begin to dry, gather and dry them theroughly, and store them in bottles, pouring into each a little spirits of turpentine, as directed for preserving bens. The bean and pea bugs belong to the genus Bructus of Limmens, a family devouring the seed of many leguminous plants, and the eggs of both species are deposited by the parent beetle in the soft pods, and directly over the seed. 'The maggots work their way into the seed, where they obtain their perfect form. The pea bug does not usually destroy the germ, but its congener, the spe. cies that infests the bean, is much more destructive, several often inhabiting a single bean, and leaving nothing but the 
outer skin and a mass of yellow dust. Spirits of turpentine appears to be fatal to them.

Use.-The garden pea is very wholesome and nourishing, and an almost universal favorite. To have them in perfection, they should be freshly gathered, and by no means allowed to stand orer night before use. They can be shelled and dried in the shade, and form a tolerably agreeable dish in winter, but they are much inferior to those freshly picked. They should be soaked a few hours in water before using. Green peas should be boiled half an hour or more. A very agreeable dish can be made, when a few peas begin to be fit for use, by shelling them and boiling them, pods and all, in the usual way. Then tone, remove the pods, season to your taste, and pour the peas and liquor over toasted bread. The pods, when fresh, abound in the true pea flavor, and when boiled with the peas and removed, contribute much to the richness of the dish.

\section{Poterium Sanguisorba-Burnet.}

A peremial British plant, not much cultivated, and probably never will be. It likes a dry, calcareous soil. The leaves are green all winter. It is propagated by sceds, cuttings, or dividing the roots. Sow the seed in Feuruary or March (or better in the fall, as it is slow to regetate), in a drill, six inches apart, and cover lightly. Thin to six inches. Keep clean, and free from weeds. A dozen plants will be enough. Make new plantations once in three years, by dividing the roots in October.

Use.-The young leaves from young plants are to be preferred. They are used in cool tankards and salads, and also by the French in soups, as they give a warm, pleasant taste. 


\section{Raphanus Sativus-RADISH.}

The radish is an annual, a native of China and Persia, and was cultivated as early as 1584 , being one of the plants mentioned by Girard. The lower leaves are lyrate; stem about two feet high, with pale violet flowers; the root fleshy, spindle or globular shaped, of various colors. There are two kinds of radish, the spindle-rooted, and the globular or turnip-rooted. These are again divided into early and late varicties, anong which we will notice :-

Early Scarlet Short Top.-Root long and spindle-shaped; leares very short. It is the earliest, most crisp and mild flavored, and requires less space than the other varieties.

Salmon.-A few days later; not so high colored; otherwise similar to the above.

Red Turnip.-Named from its shape, and bears the heat better, without becoming hard, but not so good as the above.

White Turnip.-Like the last, in everything except color.

Iellow Summer.-This is a turnip-rooted variety, named from its color, and will stand the heat better than any other variety.

Black Winter or Spanish.-T'urnip-shaped, and very large; sown in August or September with turnips. It can be gathered from the ground as desired during the winter.*

*arly Oval Rose Radish, and Chinese Rose Winter Radish, are two new sorts. The former Mr. Barry considers the best variety for forcing and the early crop, coming into use sooner than any other varicty. The latter he describes as "fir superior in appearance, as well as in tenderness and delicacy, to any other winter sort, and keeps well." These are good varieties, as I have proved; so also is the Field Radish, introduced by the Patent Oflice from France for stock; a grood winter variety for the table, and liked by stock." 
I have tried all of the above, and finally settled down upon the Scarlet Short Top, and the rarieties from Mr. Barry, as the only ones worth cultirating. The Scarlet is much more crisp and digestible than any rither, and by successive sowings can le had in the open air, or under glass, from October until the middle or last of May, by which time one gets tired of radishes. The Salmon is a very good radish, but most of the summer and winter varieties are about as wholesome and digestible as a raw turnip, and very little better flavored.

The following analysis is by Richardson :-

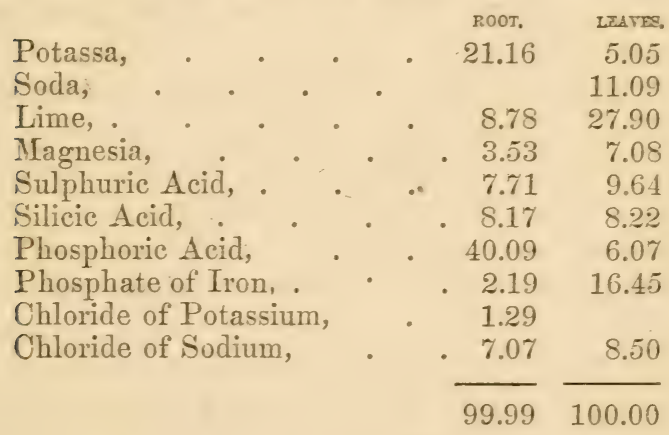

Potash and phosphoric acid are the most important constituents, and the plants would probably be benefited by the application of ashes and superphosphate of lime as special manure.

Culture.-Radishes like a rich sandy loam, dug a full spade deep. Their culture is rery simple. If manure be freshly applied, it should be at the bottom of the soil, or the roots will divide. The short-top variety is of great use (we quote Professor J. J. Mapes) " in assisting seeds of slow germinating powers to break the ssil. They also mark the rows at an early date, and enable weeds to be 
cleaned out from between them. With carrot, parsnip, parsley, leck, celery, and many other seeds that germinate slowly, the leaf of the radish will shade the rows, and prerent the hot sun from baking these more delicate seeds. They also prerent the growth of weeds, their long roots bringing up moisture from the sub-soil, and pulling the roots makes deep holes to admit air and moisture; thus cultirating the standing crop more thoroughly than can be done with a lone." They can also be sown in drills between the wide drills of many of the above vegetables, as well as spinach, peas, beans, Irish potatoes, yielding large crops, and taking up no room arailable for other purposes.

From the first of Torember until March a succession of this variety can be grown under glass. All that is required is a bect of good rich loam, watering them oceasionally, and giving air" every day, when it does not absolutely freeze. Let the sash be off every rain, and let the earth come within seven or eight inches of the glass. The open ground crop can be sown for fall use, if there should be a wet spell in October, and in our low country from that time until A pril. Here, however, the first of February is soon enough for the earliest spring crop, and you may continue the sowing's of scarlet radish at intervals of two weeks, until the middle of April. If you wish later radishes, choose the summer varieties for a month or longer. Sow in drills an inch deep, and ten inches apart, dropping the seeds three inches apart in the drills. They are of such rapid growth, that they will generally take care of themselves after planting in a good soil, but hoeing once will hasten their growth.

For Seed.-Some of the finest and earliest can remain where grown, or be removed to another bed and inserted up to their leaves. Water frequently until established, and 
while the flowers are opening. Let the roots be three feet apart, and do not permit any others to flower near them, if you wish pure seed. When the pods turn dry, gather, dry, thresh out, and save in paper bags. The seed will keep three years. It is best to get seed from a colder climate for the early crop, as the roots will come sooner into use. From these, seed can be raised for the main crop the ensuing year.

Use.-The tops used to be boiled for greens. The seminal leaves, when they first appear, are used as a salad, with cress and mustard, and the seed-pods, gathered young, form a good pickle, and are a substitute for capers. But the roots are the parts mainly used. They are much relished, while young and crisp, for the breakfast table. They contain little beside water, woody fibre, and acrid matter; so they cannot be very nourishing or wholesome. When young, and of good rarieties, they are much more digestible than when older and more fibrous. The juice of radish is said to be good for hoarseness and difficulty of breathing.

\section{Rheum Rhapontrcum-R RUBARB.}

The Garden Rhubarb is a perennial, a native of Asia, first cultivated in England in 1573. The leaves are rery large, and supported by large petioles, which are the parts used in cooking, and in the finer rarieties are an inch or two in diameter. It has not been much cultivated in this country until within a few years; but now is in large demand in all the northern cities, where the culture is rery easy. The best varieties are

Buist's Early Red, with stalks about three feet long, and a week earlier than Myatt's Victoria. Being an American plant, it stands the heat better than the European varieties. Grows large. 
Myatt's Victoria.-A strong grower of excellent flavor and quite early. These two varieties I have growing.

Downing's Colossal.-This is an Amcrican seedling, raised by the late A. J. Downing, and of course may be expected to be more hardy and worthy of culture in our dry climate than the English varieties. I have not seen it, but it is represented to be a very strong grower of the highest flavor.

Iyatt's Linncus.-An imported variety, is now most popular at the north.

The following analysis of the ash of rhubarb was made by J. H. Salisbury :-

\begin{tabular}{|c|c|c|c|}
\hline Silicic Acid, & $\begin{array}{r}\text { R.00т, } \\
4.595\end{array}$ & $\begin{array}{l}\text { IEAF.STALK } \\
1.557\end{array}$ & $\begin{array}{l}\text { LEAF-BLADB } \\
8.928\end{array}$ \\
\hline Phosphates, & . 34.788 & $\begin{array}{r}1.007 \\
.24 .702\end{array}$ & $\begin{array}{r}8.928 \\
. \quad .22 .792\end{array}$ \\
\hline Lime, . . & . 5.414 & 2.754 & 6.744 \\
\hline Magnesia, . & 3.375 & .227 & 1.363 \\
\hline Potash, . . & 8.349 & 5.883 & 9.247 \\
\hline Soda, & . 28.607 & 37015 & 32.143 \\
\hline Sodium, . . & .166 & 1.837 & 2.479 \\
\hline Chlorine, . • & .255 & 2.799 & 3.772 \\
\hline $\begin{array}{l}\text { Sulphuric Acid, } \\
\text { Organic matter }\end{array}$ & 5.957 & 5.868 & 5.017 \\
\hline own down by & 8.494 & 17.358 & 7.515 \\
\hline & & 0.000 & 100.000 \\
\hline
\end{tabular}

Rhubarb is remarkable for the quantity of phosphates and soda it extracts from the earth. Crude soda might be added to the soil. Guano and bone-dust are very beneficial.

Culture.-My first experience in raising rhubarb in this climate was not very fortunate. A friend, to whom I am indebted for many really valuable plants, but unaequainted with this, hearing that I had sent for the seed, kindly offered me several roots which had been given to him for 
xhubarb, then growing in his grounds, as his family did not like the plant. In consequence, I transplanted a dozen roots in my garden. The leaves were too small to agree with my notion of rhubarb; but being winter, I supposed it a different variety from the one I had before seen. In the spring, when the plant sent up its leaves, it proved to be nothing in the world but Patience Dock. The seed sentfor, came on in season from Mr. Buist, and was planted early in March. It came up finely, and proved to be the genuine rhubarb. It was planted on the north side of a fence, in a rich, moist soil, and grew fincly in the early part of the sunmer, but died out entirely in July and August, which it is apt to do without great care in shading in ordinary seasons. The next autumn I procured from Mr. Buist half a dozen roots of his early and Myatt's Victoria rhubarb, and after subdividing them, planted them in a very deep, moist soil, on the north side of a fence. They have grown vigorously the last summer, and we were tempted to try them for a rhubarb tart, but did not disturb them for fear of injuring the roots. The crowns, now December, 1852, appea: very healthy and filled with good buds. I have but little doubt that in their present situation the plants will do well.

The soil best adapted for rhubarb is a light loam, rich and moderately moist. It should be trenched two spades deep. In this climate, it will scarcely endure the meridian sun, but should be sheltered by fences and buildings; not by trees. It is difficult to raise the roots here from seed. 'They can easier be imported. Set out thirty inches apart. Cover them in the fall about two inches deep, with wellrotted manure, which dig in the spring. Hoe them often, and give a good watering occasionally in dry weather.

Rhubarb, to be good, must be quickly grown. This plant is forced at the north in a cask which is put over it 
and covered all around with hot dung; but in this climate it would endanger the life of the plants. Do not let the plants run up to seed. Every six or eight years the old soil should be removed from the roots, and its place supplied with fresh loam; or the plants themselves removed to a new site. A dozen plants will be sufficient for most families.*

Use.-The leaf-stem of this plant, when the external skin is removed, is cut up in thin slices, and having an agreeable acid, is used exactly like the apple for pies, tarts, and sauce, at a time that other fruits cannot be obtained. Gather them while young, just as they attain their full size, before they lose their fine flavor. They can be gently slipped from the root without using a knife. All medical writers state that this is a wholesome regetable, and it is certainly an agreeable luxury.

When the roots are old, they possess the properties of Turkey rhubarb, but in a less degree. Buist states that the stems of the varieties used in cooking, if stewed with sugar, and eaten with bread, are an infallible remedy for dysentery in children.

\section{Rumex Acetosa-Sorrel:}

A peremnial plant of remarkable acidity, growing wild in various parts of the world, and indicative of a sour, barren soil. The garden varieties are natives of Italy and the south of France. The French sorrel has broad leaves, and is the most pleasant flavored. Sorrel will grow in

* Many of my roots clied in 1853 and ' 54 ; but those which were left produced abundantly, continuing in use about three months in the early part of the season. I have now on trenched ground, two spades deep, this year (1855) my whole stock. The exposure is open, and they seem to prefer it to the partial shade I deemed desirable when the foregoing article was written. 
any light, moist soil. It is propagated by seed or dividing the roots. Sow the last of February, in shallow drills ten inches apart, and as they come up, thin them to ten inches in the row ; or part the roots in the autumn and spring, and set them out at the same distance. Water them occasionally until well established. Keep the plants free from weeds; cut down the stalks occasionally in the summer, and cover the crowns with a very little fresh earth that they may send up large and tender leaves. When, in two or three years, the plants begin to dwindle, replant them in a fresh soil. For seed, let some of the stalks rum up and gather when ripe.

Use.-Sorrel is much used by the French in soups, sauces, and salads, and also cooked as spinach, and when cooked in this way with turnip tops is thought to improve their flavor. Some use the leaves in pies as a substitute for rhubarb. Sorrel is refrigerant, antiseptic, and a sovereign remedy for the scurvy.

\section{Salureja-SAvory.}

There are two species in cultivation; the Summer sarory, Satureja hortensis, a hardy annual; and Winter savory, Satureja montana, a shrubbly perennial-both natives of Italy, and cultivated for their warm aromatic tastes.

Both may be propagated by seed. Sow in March, moderately thick in small drills nine inches apart, and rake in lightly. The soil need be but moderately rich. The plants may remain to be thinned to six inches apart for summer savory or the thinnings may be transplanted to the same distance. Winter savory requires more room, the plants should be a foot apart. This can be propagated also by slips, cuttings, or division of the roots. All the care required is to keep free from weeds. Seed can be 
gathered as it ripens from a root or two left uncut for the purpose.

$U_{s e}$. - The leaves of these herbs are much employed in soups, salads, stuffings, \&ce, on account of their agreeable pungent flavor. They are also said to possess the desirable power of " expelling fleas from a bed." Formerly, they were much used in medicine. Gather when they come into bloom and dry for winter use in the shade, pound in a mortar, pass through a sieve, and put up in bottles closely stopped and they will retain their fragrance any length of time.

\section{Scandix Cerefolium-CherviL.}

An annual plant, a native of Southern Europe, with finely divided leaves somewhat resembling parsley. Formerly it was much cultivated.

It is propagated from seed and should be sown in the autumn or in February and March. Make the drills very shallow and nine inches apart, and cover lightly with the back of the rake. When the leaves are three or four inches high they are fit for use. Keep them closely cut and they will afford a succession for some time. Keep the soil light and free from weeds, and let a few shoots remain uncut to run up to seed.

Use.-The young leaves have a milder flavor than parsley and are used in soups and salads, and also boiled. "Chervil should be eaten" says an old writer, "with oil and vinegar, being first boiled, which is very good for old people that are dull and without courage; it rejoiceth and comforteth the heart and increaseth the strength." It is now nearly out of use, and seldom cultivated.

\section{Scorzonera Hispanica-Sconzonera.}

Scorzenera is a hardy tap-rooted perennial, a native of Spain, Italy, and the South of France, and cultivated in 
England since 1576. The stem is two or three feet high, few leaved, branched at the top. The flowers are yellow and syngenesious.

Culture.-It is raised from seed which must be sown yearly. The soil like that for most root crops, must be mellow, deep, and fertile. Sow in February or early in March, in drills ten inches apart and half an inch deep. When the young plants are two inches high, thin them to six or eight inches in the drill. Keep the soil mellow and free from weeds as they adrance in growth. In short, cultivate exactly like salsify. Give water in dry weather. The roots will be fit to use in August, and may remain in the ground to be dug as wanted.

To Sare Seed.-Let some old plants remain in the spring, which will shoot up tall stems, and produce ripe seed.

Use.-The roots are agreeable to the taste and nutritive, but before use, the bitter outer rind must be scraped off: It is then boiled and used like salsify or carrots. The roots continue good all winter. The plant is too similar to salsify to render its cultivation an object where that is grown.

\section{Sinapis-MUSTARD.}

There are two species of sinapis cultivated, the Alba, usually employed in salads, and the Nigra of which the seed furnishes the well known condiment.

The soil for mustard should be a good moist loam, but for a winter crop it may be more dry. White mustard may be sown any time of the year for a salad in the same manner as cress, which see. It must be used when the seed-leaf is just expanded, for if it gets into the rough leaf it is fit for nothing but greens. For use, cut them off with a sharp knife. They should be used soon after 
gathering or their good qualities will be much impaired. The black mustard may be sown from September to March. It will stand any frost and may be gathered for greens at any time during the winter. Sow in drills thinly, eighteen inches apart, hoe the plants as soon as they get their fourth leaf, thin to three inches, and finally to ten in the drill. Keep the ground clean and mellow by the use of the hoo during the season. When the pods change color, gather,and thresh when perfectly dry. Seed of the white variety may be raised in the same manner, or a few plants may be left uncut in the salad bed for this purpose.

Use.-The tender leaves of both species are used for salads and should be more cultivated for this purpose. They are also much cultivated for winter greens, but the German greens are much superior in quality, and being quite as hardy and easily cultivated should take their place. The seeds of the white variety are ground, forming the condiment known as the Durham or London table mustard, but the flour of the black mustard is that from which our American table mustard is, or ought to be, made. The seeds may be ground in a common spice mill or crushed by a roller on a table. In this country the flour is usually sifted after grinding, but the French do not separate the husk, and thus make a brownish flour, more powerful and palatable than the other. 'The mustard of commerce is much adulterated, being often a compound of wheat flour and red pepper colored with turmeric. The seeds used whole are an excellent seasoning to various kinds of pickles. Mustard is a very agreeable condiment, assisting digestion and promoting appetite. It is also much used in medicine both by the faculty and in domestic practice. It is an acrid stimulant, and in large quantities acts as an emetic. The proper dose for the latter is from a tea to a tablespoonful in a glass of water. Small 
doses of mustard seed swallowed whole in water are often useful in dyspepsia. Mustard seed is also a local excitant applied to the skin in a cataplasm, made of the ground meal with vinegar or lukewarm water; if mixed with boiling water the acrid principle will not be developed:

\section{Sisymbrium Nasturtium-W ATER-CRESS.}

This is a perennial English plant, growing in rumning streams. There is but one variety in use. I give its culture that it may be tried in some of our clear up-country streams.

The Water-cress likes a clear, cool, running stream, fresh issuing from a spring, the nearer its source the better, with the water about an inch and a half deep, with a sandy or gravelly bottom. They must of course at first be raised from seed which can be sprinkled at the source of some gravelly stream. If once established they will soon propagate from self-sown seed. If the stems get choked with mud and weeds, they must be taken up and the beds cleared and replanted. The shoots ought always to be cut, as breaking injures the plants.

Use.-Water-cresses are generally liked for their warm pungent taste, and are used alone or in mixed salads. They are an excellent antiscorbutic and purifier of the blood and a great favorite wherever known.

\section{Sium Sisarum-SKirRet.}

Skirret is a perennial umbelliferous plant from China, and known in Europe since 1548. It grows a foot high with pinnate lower leaves. The root is composed of several fleshy tubers, the size of the little finger, joined at the crown.

Culture.-Skirret likes a light, rich, rather moist soil, with the manure applied at the bottom. It will not do 
well in very dry ground in this climate. It is propagated by seeds or by off-sets of established roots. Seedlings produce the best roots. Sow any time in march, in drills an inch deep and ten inches apart. Sprinkle a few radish seed in the drill as directed for carrots. When the plants are an inch or two high, thin to six or eight inches apart. Cultivate like salsify and keep clear from weeds. They will be fit for use in August but can remain in the ground, to use as wanted, all winter. Slips of the old roots may be set out nine inches apart and cultivated in the same manner. Leave some of the plants in the ground and they will throw up seed-stalks and ripen seed during the summer following.

$L^{\top}$ se.-The tubers are boiled and are very sweet, somewhat like the parsnip, and are thought more palatable. They are boiled and served up with butter, or cold witl vinegar and oil, and are also cooked like salsify in batter. It was formerly esteemed as "the sweetest, whitest, and most pleasant of roots."

\section{Solanum Lycopersicum-Toмато.}

The Tomato is a tender annual, a native of South America, and introduced into England in 1596. It belongs to the same genus with the potato and egg-plant. It is scarcely twenty years since its culture was commenced in this country. "In 1828-9" says Buist, "it was almost detested ; in ten years more, every variety of pill and panacea was "extract of tomato." It was long cultivated in the flower garden for its beautiful red and yellow fruit, which was not used for food, but by many considered poisonous. It is now one of the most popular regetables in cultivation, and springs up self-sown in all our gardens. There are many varieties.

The Large Red which is cultivated all over the Union, is 
one of the best. It is patty-pan shaped, and extra large specimens are sometimes six inches in diameter, or as large as a common bush-squash. One of the best flarored and very desirable.

Large Smooth Ped is a new rariety, equally well flavored and a favorite in the kitchen, as it grows regular and free from knobs.

Cherry is the most common and productive with us, and is excellent for pickling. It is named from its size and shape.

Pear-Shaped is of a pink color, firm flesh and few seeds. Much used for pickling, and excellent for the table.

Large Yellow is early, and of a rather different flavor. It is a beautiful and excellent sort for preserves.

Gallagher's Mammoth is the best for home use, a variety of the large red, having few seeds and very superior in size and flavor, especially for eating uncooked with pepper, salt, and vinegar.

The analysis of Large Red tomato, has been made by J. H. Salisbury. One thousand pounds of the undried fruit will produce $3 \frac{41}{100}$ pounds of ash constituted as follows :-

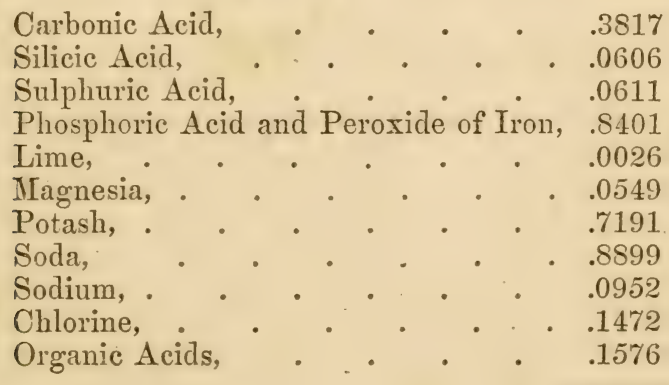


Soda and the phosphates are the most abundant elements, and may be supplied by common salt and bone-dust if wanting in the soil, but any soil almost will produce tomatoes.

Culture.-The tomato likes a light loamy soil, moderately rich. Common salt may be applied as a manure in small quantities. If the soil is too rich, they will run to vines, and the fruit ripens late. The culture of the tomato is very easy in this climate, as abundance of seed will sow itself if it is once introduced into the garden. But the finest fruits are not gathered from volunteer plants, but produced from the seeds of the best specimens maturing early, and this regetable is so desirable that it should be produced as early as possible. A few plants should be started in the house in boxes, or in a cold bed under glass in the latter part of February, or carly in Mareh, giving them air, except whe: there is danger of frost. 'They can be sown thinly in rows eight inches apart, and transplanted into the open ground as soon as frosts are over. Plants should be kept in reserve, in case of a late frost. The seed may be sown in the open ground from the middle of March to the first of May; sow in drills eight or ten inches apart, and when they come up, thin them to three inches. Protect them from frost, as they are exceedingly tender. 'They are the easiest things in the world to transplant, and can be safely removed from the time they are an inch high until the blossoms appear. It is best however to take them up carefully with a trowel, that their growth may not be checked. Plant them three feet apart each way, or more in rery rich ground. When the young plants come into blossom, support them ly sticks as you would peas. The fruit is thus earlier and better flavored; mulching with leares or straw is beneficial. Plants for early use should be set out in a warm exposure, and as soon as the lower fruit is half 
grown, cut off the upper part of the plant above the larger fruit, that its growth may be stopped, and the firuit below will be larger, and several days earlier. Ninety per cent. of the fruit grows within eighteen inches of the ground, but a large portion of the vines grow above that height. Tomatoes like the soil about them well hoed, and free from weeds. Plants grown in the open air, are the more abundant in bearing, than those forwarded under glass. In well-trenched ground, they will continue bearing until frost.

To Sure Sced.-Select the largest early fruit, mash with the hand, and wash the seed from the pulp; spread out upon plates and dry in the shade; when dry, put them in paper bag's.

Use.-Few regetables are prepared in as many different forms as the tomato. It is pickled when green, and preserved when ripe, it is eaten raw or cooked, it enters into soups and sauces, and is prepared in catsups, marmalades, and omelets. The French, and the Italians, near Rome and Naples, raised them by the acre, long before used by other nations, and it is said, prepared them in an almost infinite variety of ways. There are very few preparations into which it enters, which are not improred by the addition.

\section{Solanum Melongena-EgG-Plant, or Gurnea Squash.}

The egg plant is a tender annual, a native of Africa, whence its name Guinea Squash. It was introduced into England in 1597. The rarieties of purple egg-plant are the only ones used in cooking, the white variety being raised for ornament. Egg-plant derives its name from the white variety, which when small bears a close resemblance to an egg. The egg-plant when first introduced, was not regarded with much faror for culinary purposes, but is now rapidly working its way upwards in general esteem. All the egg-plants grow finely in this climate. 
Large Priclily-Stemmed Purple is the largest variety, often growing to a diameter of eight inches, shape slightly oval, and dark purple color.

Long Purple is perhaps the best kind for family use, as it is ten days earlier than the other varieties, and though not growing so large, is very prolific in fruit.

The fruit of the purple egg-plant has been analyzed by J. H. Salisbury. One thousand pounds of the undried fruit will yield $6_{i 00}^{-4}$ pounds of ash, constituted as follows:-

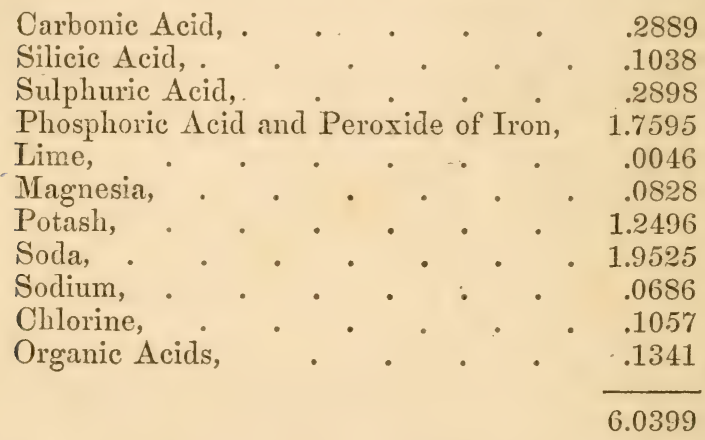

Over two-thirds of the fruit is made up of potash, soda, and phosphates. Salt, ashes and bone-dust, or better, superphosphate of lime, may be freely applied to the soil for this crop.

Cullure.-Egg-plants require a light, loamy, rich soil to bring their fiuit early to perfection. They like the soil manured with half decayed leaves, well dug in. To have them early, sow them in a hot-bed, or in a cold frame under glass, the latter part of February, or early in Maren. The rows may be six or eight inches apart, made shallow and the earth pressed upon the seed. Keep the sash carefully closed until the plants are up, and then give air in warm days. Egg-plants succeed best with a small frame to 
themselves, as they like a higher heat than is desirable for other plants; if this should be a small hot-bed, it suits them all the better. When the plants are two inches high, transplant into another frame under glass and put the plants two inches apart, and they will grow stout and more hardy for out-door planting. It is a good plan to prick them out in small pots. They can thus be planted out with the ball of earth entire. Do not put them out until settled warm weather, for if the plants get chilled while young, their growth is so checked that they never fully recover.

Plants can also be raised in the npen ground, but must not be sown until early in April, for these one transplanting will be sufficient. Prepare the final bed for egg-plants by making trenches three feet apart, burying in them old cabbage stumps, corn stalks and other vegetable refuse, and covering them with soil twelve inches deep, in which plant out the egg-plants two feet apart in the row. Water abundantly until established. Keep the ground well hoed and free from weeds, and earth up the plants a little from time to time. Twelve to twenty plants will be enough.

For Seed.-Allow one of the largest fruits from a prolific plant to ripen seed. It will keep three or four years.

$\tau^{r}$ se.-Egg-plant is used by the French in various ways in soups and stews, but generally cut in thin slices, and fried in batter. They are not commonly liked at first, but after a few trials become very agreeable to most tastes, and are esteemed a delicacy. They are fit for use when some two or three inches in diameter, and continue until the seeds begin to change color. They are not unwholesome, but cannot be very nourishing, as they contain a very large proportion of water.

To Fry.-Cut the egg-plant in slices a quarter of an inch thick. To remove the acrid taste, pile the slices on 
a plate, with alternate layers of salt; raise one side of the plate, that the juice may run off. In half an hour wash them well in fresh water, and fry them quite brown in batter.

\section{Solanum Tuberosum-Ротато.}

The Irish potato is a perennial plant, cultivated for its tuberous roots. It is reported to have been brought into England from Virginia, by Raleigh in 1854, but as he never visited Virginia, he probably obtained it from some other portion of this continent. Though called the Irish potato it is really a native of the mountain parts of South America, whence roots have recently been obtained differing very little from the cultivated varieties. Notwithstanding its excellence and complete adaptation to the English climate, it appears to have come slowly into use. Raleigh planted it on his Irish estate near Cork, but it is only within about a hundred years that its culture has been general even in Ireland. In 1780, very few individuals in this country raised as large a crop as five bushcls. Of the numerous varieties at this time, the best perhaps for garden culture are :-

Fox Seedling.-A medium sized, round, white potato, of fine flaror when it first matures, but does not keep for winter. Liable to the rot.

Mercer.-Long, kidney shaped, flattish, full of eyes, and often knobbed, spotted with pink at the small end. It is early and productive, but liable to the rot.

Mammoth Nutmeg.-Is a new variety, highly recommended by Mapes as productive, and not liable to decay. It produces seed, showing that it still possesses more constitutional vigor than most other varieties.

Many other varieties have great celebrity in different sections of the country, among which are Early Kidneys, Pink Eyes, Foxite, Blue Jackets, \&c. But the fact is, al! 
are constitutionally liable to the rot. Besides for this climate we need an Irish potato that will continue in growth nearly all the season, as they ripen too early with us to be easily kept in their dry mealy state. Any one who would obtain the potato balls from the wild plant in its native habitation, and originate therefrom new varieties adapted to the climate of this section of the Union, would deserve the thanks of the entire South. We buy northern tubers which are infested with disease, and after our crop is matured, frequently one-half decays. The potato disease is a very mysterious malady, and the only ground of hope of ever seeing it eradicated or even checked is by resorting: to the wild plant, and raising from it a new and rigorous stock. This may not be successful, but it is really worthy of trial, and if not brought about by private enterprise, should be an object of public attention.*

The analysis of the ash of Axbridge kidney potatoes, by Herapath, is given below :-

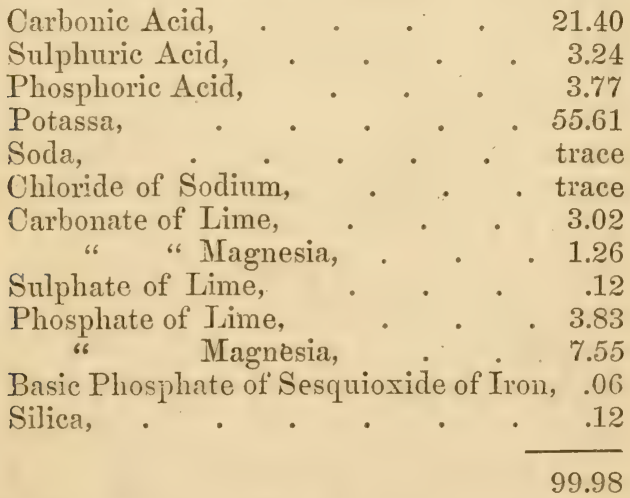

* This has been undertaken by Mr. C. E. Goodrich, of Ctica, New York, by whom tubers and seeds raised directly from the wild plant, and in some degree free from the tendency to disease, are offered for sale. 
Potash and phosphate of magnesia are the most important inorganic elements of the plant. Wood ashes will furnish most of the constituents required from the soil.

Culture.-The Irish potato likes a cool moist climate, and a cool moist soil like that of Ireland. The soil should be well enriched with regetable and not with animal manure. The best potatoes in this country are grown in the cool and hilly sections of the north, and the best there are grown by simply turning nicely over a meadow sward; upon this the rows are laid off shallow, and the clover sods are often so tough with matted roots when planting (having been newly turned over), that earth is with difficulty obtained to cover the potatoes. Snon decomposition commences, a gentle heat is given out, and by the time the potatoes are ready for the first working they can be ploughed with ease. At the second working, when the plants are laid by, the soil is mellow as an ash heap, the young plant the mean while being supplied with moisture, and the very food required to perfect its tubers, and render them farinaceous and nutritive. At the south, in our gardens we camnot obtain such a soil, but we can very much improve the yiold, and especially the quality of our Irish potatoes by imitating it as near as possible. We can dig into the soil vegetable matter to decompose, such as leaves, garden refuse of all kinds, and pine straw. Even tan bark is not a bad application to the potato crop, and the potato and strawberry are the only plants to which I would apply it. I applied it to a small plat at the rate of fifty two-horse loads to the acre, with plen'y of leached ashes. The potato crop was excellent both in quantity and quality, and I think the tan materially promoted its growth. The soil has not a trace of undecomposed tanbark in it; but from a poor red clay is now a light dark garden mould. A great reason for applying vegetable 
manure to this plant is the superior quality of the tubers produced. Liebig first remarked that ammoniacal manures injure the quality of the potato, though they increase the size and quantity. If manured with stiong animal manure the tubers are moist and waxy, while if grown upon a soil manured with ashes, lime, and an abundant supply of carbonaceous manures, such as decaying vegetable matter, the produce is far more starchy and nutritive. This is reasonable, for starch and the woody fibre of decomposing vegetable matter are very similar in chemical composition. Apply strong dung, if you like waxy potatoes. I believe some really prefer them. Indeed an excellent old lady with whom I boarded was one. We had been using for some weeks from her garden some of the most waxy and indifferent potatoes I ever tasted, the product of a soil altogether too rich in ammoniacal matter for this plant. One day at the dinner table, a dish of dry white farinaceous tubers made their appearance, whose jackets bursting with mealiness would have made an Irishman's eyes water. It was a change, and we were quietly enjoying it, when our good hostess broke the silence with the remark: "These potatoes are not so good to-day as we have been having from our own garden; somehow they don't seem to be as juicy!"- the last characteristic to be thought of in a good potato.

Peabody's mode of raising Irish potatoes in this climate, cannot be improved. "As soon after Christmas as possible, plow or spade up the piece of ground designed for the potato patch, and lay it off in furrows two feet wide, and eight or ten inches deep; now fill the furrow with decomposed straw or leares (wheat or pine straw will answer), cut the potatoes once in.two, and place them six inches apart cut side downwards upon the straw; now 
level the top of the ridge, covering seed, straw and all with earth; then cart on straw scattering it evenly eighteen inches deep; two feet will be better. The winter rains will beat down the straw compactly; decomposition commencing in the straw in the furrow, and in that next the ground, the potato sprouts force their way up through the straw, and should an untimely frost nip the tops, the tubers are not affected by it as when in the ground, the tops will push up through the straw, and erentually cover the whole patch with their dark green foliage. The eremness of temperature with the moisture of the decomposing straw, will keep the potatoes always mealy. In the dryest season the yield will be greater than when planted in the ordinary way, and when once planted, it is an end of culture until they are taken out for the table. The same picce of ground will improve in productiveness for years as the straw decomposes. Many have failed in this mode of culture from the fact that they have not applied half straw enough."

But good as the above mode undoubtedly is, many of us camnot get the straw required for this manner of culture, while we are not disposed to do withunt Irish potatoes. All we can do is to incorporate with the soil abundance of vegeta7 le matter of any kind we can get, and plant the early crop in January, and the main crop the last of February, laying off the ground in deep furrows or trenches two and a quarter feet apart; in these depositing a good sprinkling of lime, charcoal, leached ashes, and bone-dust, or such of these as can be obtainerl. On this the cut potatoes are to be laid at eight inches apart, as above. If on each set a teaspoonful of gypsum or plaster of Paris be sprinkled, the yield will be very much increased. The seed is better, if cut a few days before planting and spread out to dry. Large pota 
toes will make three or four sets. Fill up the furrow with earth, and if this be mixed with tan-bark, the potatoes will like it all the better.

When the young vines appear, if there is danger of frost, they can be protected by covering them with earth. This should not be done unless needed, and the earth should be carefully drawn back after the danger is over. It is better to plant the main crop sufficiently late to aroid all danger of frost. As soon as the shoots appear, give the young plants frequent and deep hoeings, keeping the soil deep and mellow, and drawing a little earth up to the stem in a broad, flat hill. Cease working them when the blossombuds appear. When the tops decay, and the plants are ripe, dig them, and spread in a cool, dry place. If they spront, the shoots should be rubbed off, as they injure the flavor of the potato. A change of seed once in three or four years is an adrantage, but there is no use in buying: fresh seed every year. It is believed that potatoes cultivated and manured as directed above are much less subject to the potato-rot, the ravages of which have recently almost depopulated Ireland. Schleiden attributes the rot to the long continued use of nitrogenous manures. Still the great hope of a permanent escape from this disease is to go back for our seed once more to the healthy wild stock. To keep them eatable, rub off the sprouts as fast as they appear. If allowed to grow they become waxy.

Use.-The tubers of the Irish potato, consisting chiefly of starch, and having no peculiarity of taste, approach nearer in their nature to the flour of grain than any other root. Hence it is almost universally liked, and can be continually used by the same individual, without becoming unpalatable. Potatoes are boiled, baked, roasted, or fried. When long kept, the best ones are selected, boiled, 
and mashed, before going to the table. Starch can be manufactured from potatoes; also ardent spirits.

To Boil.-A very common way, described by Peabody, is to "put them into cold water, boil them a couple of hours or so, peel them, and grease them over with rancid butter, and place them cold upon the table. This is the acme of the gastronomic art with some." A very good way is the following:-Wash the potatoes, and cut off the ends; put them into boiling water, and boil briskly from twenty minutes to half an hour; drain off the water, and they are ready for the talule. The skins may be removed before bringing to the table; but this is not so good a plan. If the potatoes remain, after cooking, without being brought to the table, they should be kept warm and dry in the pot, uncovered, near the fire

\section{Spinacea Oleracea-SPINACH.}

Spinach is a hardy amnual, native of Spain and Persia; cultivated in English gardens since 1568, and probably long before. Some refer its origin to Western Asia. The leaves are large, stems hollow, and the male and female flowers produced on different plants. Its name, spinacea, is derived from the Latin, spina, a thorn, on accomt of the prickly seed of one variety. There are two sorts in general cultivation, viz. :-

The Priclly is much raised in cold climates; being hardier, and more able to endure the severity of the winter. It has triangular leaves, and is much inferior to the Round-Lenved.-Leaves more round, and still more full and fleshy; will stand our winters without protection, and is the better variety for this climate.

Flanders spinach has prickly seeds, and is a good variety, though little known here. 
Spinach has been analyzed by Richardson, with the following result :-

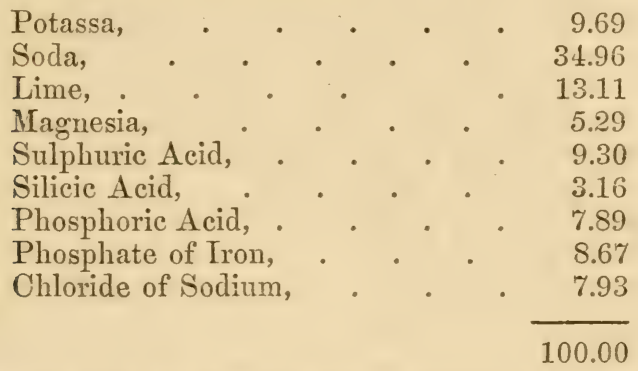

The lime and salt mixture with superphosphate of lime will supply most of the inorganic elements required by spinach.

Culture-For the winter crop, a light dry, but fertile soil is preferable; while for spring sowings, to have them long in use, a rich moist loam is desirable. Give them an open situation. The carth should be well pulverized before sowing, as fine tilth greatly promotes vigorous growth. Spinach is propagated from seed so easily, and is so valuable for winter greens, that $n o$ garden should be without it. The first crop should be sown early in October, in drills an inch deep, and a foot apart, scattering the seed thinly. Sow the seed, if possible, in showery weather, or if dry, water it, for if moisture be wanting during the early stages of vegetation, not half the seed will come up. Thin them by degrees, separating. them at first only an inch or two as the plants grow fit for use. Thinning should commence when they attain four leares an inch or so in breadth. The piants must finally stand for the prickly spinach, five inches, and the round leaf, eight inches in the drill. Keep the rows frequently hoed and free from weeds. Hoe in dry weather. Spinach 
kept clean and thinned to the proper distance, is not so liable to die out in winter. Frequent hoeing greatly promotes health and growth. This sowing will be fit to gather in November, and last until spring. Another sowing should be made in January and February, to keep up a succession, until other vegetables come on abundantly. Regular gathering greatly promotes the health of the plants. The outer leaves only should be used, leaving the centre uninjured to sipply successive crops. At the end of the winter, the snil between the rows of the wintes: standing crop should be gently stirred to assist their production in early spring. For spinach and all other plants cultivated for their leares, the soil camnot be too rich.

For Sced.-Some of the latest plants of the standing crop should be allowed to run up to seed; let these plants be eight or ten inches apart. Spinach is diøecious, and the plants left that do not bear seed must not be pulled up, as they are neecied to fertilize the others until the seed is set. When ripe, pull the plants, dry thoroughly on a cloth, and beat out and store the seed in paper bags. Spinach seed will keep three years.

Use.-Spinach and German Greens are the best plants to raise for a supply of winter and early spring greens. No frost will hurt them, and one who has tried them will hardly be induced to fall back upon mustard and turnip tops. It is really one of the most valuable plants in the garden. Spinach eaten frecly is laxative and cooling; it is not very nutritive, but very wholesome. It is so innocent that it is permitted to be eaten in diseases where most vegetables are proseribed. The leaves are very tender and succulent, and of a most beautiful green when boiled. The juice is often used for coloring various culinary preparations.

To Boil.-Cut off all the roots, wash out all insects and 
grit, and put in boiling water with a teaspoonful of salt; boil ten or fifteen minutes. When done, drain through a colander, press out the moisture, and serve with butter and a little salt.

\section{Tetragonia Expansa-New Zfaland Spinach.}

An annual plant brought by Sir Joseph Banks, from New Zealand, in 1772, with thick, succulent, pale green procumbent leaves, deltoid in shape, and with small green inconspicuous flowers. It grows four or five feet high. The common Spinach fails entirely in summer, but this rariety, if well watered, grows freely and produces leares of the greatest succulency in hot weather. White Beet or Swiss Chard, however, is a vegetable more easily cultivated and preferable in every way for general cultivation in our climate.

Culture.-New Zealand Spinach may be sowed early in April. The best soil is a deep, moist loam, deeply dug: and enriched by a liberal supply of good manure. Make the drills three feet apart, and scatter the seed about six inches apart in the drill, and cover them an inch deep. Thin out the plants, when well established, to twenty inches apart. 'Those taken up after filling any vacancies in the drill may be reset in another bed. Take them up with the trowel and balls of earth, so as not to check their growth. Water until the plants are established, and liberally in dry weather all summer. Keep the ground thoroughly tilled and free from weeds, that the plants may make a luxuriant growth. In five or six weeks the young leaves may begin to be picked off. Preserve the leading shoot, and the branches will continue long in bearing, as in autumn they survive a pretty heavy frost. Twenty plants are enough.

Seed may be gathered as it ripens, dried carefully in the shade, and put up in paper bags. 
UTse-- It is prepared for the table like common spinach. It has somewhat the spinach flavor; but there is a softness and mildness about it, which make it preferred by many. The seeds in a green state, make an excellent pickle.

\section{Thymus Vulgaris-Thyмe.}

Common, or garden thyme, is a low, evergreen undershrub, a native of Spain, Italy, and Greece, cultivated in English gardens since 1548 , and probably earlier. Its name, $T / y$ mus, comes from the Greek word for courage; as it was thought to renew the strength and spirits. It has a pleasant aromatic smell, and a warm pungent taste.

Lemon Thyme ('Thymus Citriodorus) is also a low trailing evergreen shrub, seldom rising above four or six inches high. It has a strong smell of lemons, which gives it its common name.

Culture.-Thyme is raised by seed, cuttings and dividing the roots. A poor, light, dry soil, is suitable. The root slips may be set out in rows six inches apart each way. The seeds are very small, and should be sown in moist weather, and the soil for their reception made very fine. Sow the last of February or early in March, and rake the seed in lightly with the back of the rake. Press the surface gently with a board or the back of a spade. Make the drills six inches apart and very shallow. Water lightly in hot dry weather, hoth before and after the plants are up. Let them remain in the drills, or transplant when two or three inches ligh. Thin the plants to six inches apart, keep free from weeds while the plants are small.

Thyme is often used as an edging. A very small plat is enough for any family.

For Seed.-It bears seed abundantly, if permitted. The 
spikes should be gathered as it ripens, before it is washed out by the rain. Dry upon a cloth in the shade.

Lse.-The young leaves and tops are used in soups, stuffings and sauces. They can be dried and preserved like other herbs; but in this climate it is unnecessary, as it is evergreen. Thyme tea is a cure for the headache, and an excellent tonic. The essential oil contains camphor.

\section{Tragopogon Porrifolius-Salsify or Vegetable Oyster.}

Salsify is a hardy, tap-rooted biemnial, a native of England and various other parts of Europe, with long tapering root of a fleshy white substance, the herbage smooth glancous, and the flower-stem three or four feet high, the flower of a dull purple color and syngenesious.

Salsify likes a light, mellow soil, dug very deeply, as for carrots and other tap-rooted plants. Sow in February or March (earlier if you choose), in drills an inch deep, and a foot apart. Sow rather thickly. An nunce of seed will sow a square rod. Scarlet radish may also be sown thinly in the same drills. When an inch high, thin the plants, and continue by degrees until the plants are six inches apart. If the soil is deep and moist, they will grow all summer and not run up to seed. Watering in dry weather, especially with guano water, will greatly invigorate the plants. Cultivate the soil, and keep it free from weeds, as you would for beets and carrots. The roots will be fit for use in August, and may remain in the ground all winter, to be pulled as wanted.

For Seed.-Leave, or transplant some of the best plants in spring, which will produce seed abundantly. Gather and dry in the heads, where they may be kept until wanted. 
Use.-The stalks of old plants are sometimes cut in the spring, as a substitute for asparagus. The roots are boiled or stewed like carrots, and have a mild, sweet flavor, being wholesome, palatable and tolerably nutritive. They are said to be excellent for consumptive patients; but are mostly conked to imitate oysters, to which the flavor has some resemblance.

To Cook.-Scrape the roots lightly and soak in water one hour. Boil until tender. Take out, drain, and make a batter of milk and eggs beaten up with a little flour; grate the roots fine, add an egg well beaten and press them into small, flat balls the size of oysters, dip them in the batter and roll in grated cracker or crumbs of bread, and fry in hot lard until of a light brown color, and they are ready for the table.

\section{Tropocolum MTajus-Nasturtium, or Indan Cress.}

The nasturtium is here a hardy annual, a native of Peru, where it is a true perennial. It was introduced into England in 1681. The stalks are long and trailing, leaves have their petioles fixed at the centre. Flowers are helmet-shaped, of a rich, brilliant orange, and continue, from their first appearance, all summer; and if not so common, would be thought very beautiful. Tropaolum Minor, the Indian cress, is less productive.

Culture.-Nasturtiums flourish in a moist soil, but do best in a good, fresh loam. If the soil is too rich, the plants are luxuriant, but do not bear so abundantly, and the berries are of inferior flavor. Give them an open sitvation. Sow the secd early in March, three or four inches apart, in drills an inch deep, covering the seed threefourths of an inch. The seed must be of the preceding year's growth. They may be sown by the side of a fence or trellis. If more than one row is sown, they should be at 
least four feet apart. Thin the plants, when they are well up, to a foot in the drill. Hoe the ground well, and keep down the weeds. If sown in the open ground, support them as you would peas with lattice or brush. Give the plants a little assistance in fastening themselves to the trellis. Water in dry weather. Gather the fruit when full grown, while still fresh and green.

For Seed.-Let some of the berries mature, gather them as they ripen, spread them to dry and harden, and store in paper bags.

Use.-The flowers and young leaves are used in salads, and have a warm taste like water cress. The flowers are used with those of borage in garnishing dishes. The berries, gathered green and pickled, form an excellent substitute for capers.

\section{Vicia Faba-Exglish Broad Bean.}

The English Broad Bean is an annual, from two to four feet high, with white, fragrant papilionaceous flowers, with a black spot in the middle of the wings; seed pods thick, long, woolly within, enclosing large, ovate, flat seeds, for the sake of which it is much cultivated in Europe. It is a native of Egypt, and has been cultivater? from time immemorial.

Mazagan is sweet and agreeable in flavor, and produces well if planted early. Far the most productive variety with me.

Long Pod.-Stalks rise about three feet high, bears well; the pods are long, narrow, and well filled with seeds.

Culture-'This is not a very important crop in this climate, as the other beans are far better and more easily cultivated. To give variety to early garden products, a few may be planted in drills eighteen inches apart, and two 
inches in the row, in October, November, or December. They like a dry soil, moderately rich, and a sheltered situation, to promote their growth during the winter. The frost will not injure them. When two inches high, hoe between and draw the earth about the stems of the plants. Continue this during their growth. When the plants come into bloom, take off two or three inches of the tops of the stems, which will increase the crop and hasten its maturity. The crop should be gathered before they are full grown, while they are still tender and delicate.

To Save Seed.-Allow a portion of the crop to remain until ripe. Thresh for use.

Use.-The English use these beans while young and tender, as we do green peas. They must be cooked very young, and in the same manner; or may be boiled with bacon.

\section{Tea Mays-Indian Conn.}

Indian Corn is a native plant, found distributed in all the milder climates of America at its discovery. It is of more universal culture than any other plant on this continent, and can be made to produce more food per acre than any other grain.

The best garden varieties are the

Extra Early -with short ears, small cob, and large grains, which are of excellent flavor. It can be grown fit for the table in six weeks from the time of planting.

Eightt-rowed Sugar.-Ears of larger size, grow two or more on a stalk, remain in a milky state, and fit for the table a long time; grains, when dry, are small and shrivelled; of very sweet and excellent flavor when boiled.

Old Colony Sweet.-A new variety, of the highest reputation, I have not yet cultivated.

Stowell's Evergreen Sweet Corn.-A twelve-rowed variety, 
with ears larger than the Eight-rowed. The grains resemble the Sugar Corn, but are thinner when dry. It produces well, and is quite as good. It is also said, if the husks are allowed to remain on the ears, secured by a string at the smaller end, and kept in a cool, dry place, the grains will continue milky, and fit for use for sereral months after being picked. It is doubtful whether they could be thus kept in our climate; but, at all events, it is a rery excellent table corn, and keeps green longer than any other variety.

The three latter varieties are more injured by the cornworm, as our planters call the insect that eats into the end of the ear, than the common cern of the country. The insect chooses the high-flarored rarieties in preference. He should be crushed wherever found.

Spengel found in 100.000 parts of maize grain, 1312 parts of inorganic matter, and in 100.000 parts of maize stalk, 3985 parts of inorganic matter, eonsisting of

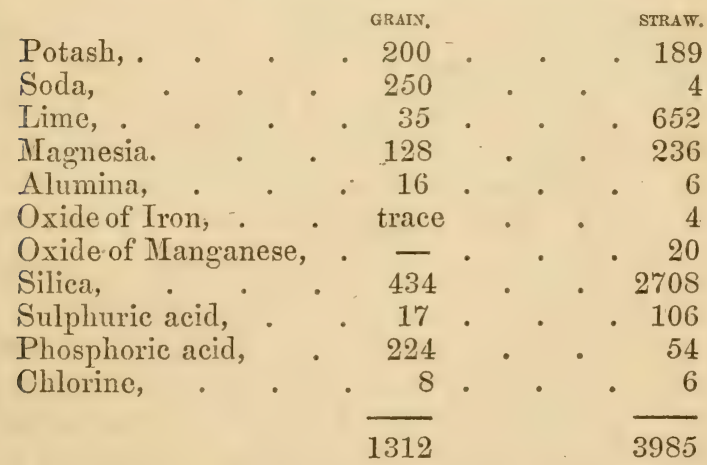

Maize likes a soil abounding in soluble silica. Gypsum and ashes, experience has proved, the best special manures. Sweet corn has much less starch than the other varieties; 
but much more sugar and extract. It has also a greater portion of dextrine and gum.

Culture.-In the Northern States, a dry soil and a hot season are required to produce large crops of corn. Here we raise far better crops in moist seasons, and on moist bottom lands. Rich, deep loam affords the plant plenty of moisture and nourishment, which the corn likes. The garden corn will bear very thick planting. Get your seed from the north at least every two years, if you would have early crops, as the earliest sorts gradually grow later here. Plant as soon as the season gets mild, about the first of March in this climate, or when the peach is well in bloom.

Let the ground be deeply ploughed or spaded; then lay off in hills three feet apart each way. If the ground is not rich, place a shovelful of decayed manure to each hill. Fresh dung can be immediately applied to corn, if spread before ploughing, and well turned in. Plant five grains to a hill, and cover two inches deep. When they are up, thin out to three. Ifoe deeply, and often. In fact, corn cannot be hoed too much for its good while young. Draw the earth each time a little over the stalk. Plant on any spot that happens to be vacant, every three weeks, until the first of August here, and a month later in the low country, if the early varieties are used. Corn is a gross feeder, and cannot get too much manure. It should be soaked in a solution of saltpetre twelve hours before planting. A sprinkling of guano about the hill is beneficial, if it does not touch the seed. Corn is much improved by giving the plants, at their first hoeing, a teaspoonful of gypsum to each hill, or a pint of ashes, or as much of the charcoal poudrette. Chickens, birds, and squirrels can be prevented from pulling up the corn, by soaking it twelve hours before planting in water, then stirring briskly the 
seed in a vessel containing a little tar mixed with warm water; thus giving each grain a thin coat. After which, for convenient handling, it is to be rolled in as much ashes, gypsum, or lime, as it will take up. One-half bushel of corn requires a pint of tar and a gallon of warm water, with as much ashes as will stick to the grain. It is effectual against birds, squirrels, \&c.; while the seed vegetates freely, if previously soaked.

For Seed.-Select the best ears from stalks that bear more than one.

Use.-Indian Corn is prepared in a greater variety of ways for the table than any other grain. In fact, the modes of preparation alone would almost fill a volume. That from the garden is mostly boiled green. Green corn can be very easily preserved for winter use, by cutting off the kernels after boiling, and drying in a shaded, airy place. The sweet corn only should be used for this purpose. 


\section{MEDICINAL HERBS.}

A FEw roots of the most useful of these should be found in every garden. The following is a description of those most used in families, including their medical qualities, and ample directions for their cultivation. The medicinal properties of many of these depend upon their aromatic qualities, and they are never so fragrant and full of virtue when grown upon ground lighly manured. Chamomile, lavender, rosemary, rue, wormwood, and many others, lose much of their strength when forced into rank growth. Common garden soil, without manuring, is quite good enough. Whenever the plants begin to decline, take away the old surface soil, and apply fresh, or set out new plants in fresh ground.

Medicinal, pot, or sweet herbs, as a general rule, should be gathered when in bloom, and dried carefully and thoroughly in the shade. When thoroughly dry, press them closely into paper bags, or powder them finely; sift, and keep in closely-stopped bottles.

\section{ANETHUM.}

\section{Anethum Graveolens-DiLL.}

An annual, a native of Southern Europe, and also of the Cape of Good Hope. Cultivated for its seeds, which have an aromatic odor, and a warm, pungent, and somewhat bitter taste. Medicinally, they are good for flatulence and colic in infants. The leaves are sometimes used for culinary purposes, and the seeds are occasionally added to pickled cucumbers to heighten the flavor. 
Sow the seeds either early in the spring, or soon after they are ripe, in a light soil. Thin, if crowded, and keep clean.

\section{Anethum Faniculum $\rightarrow$ EenNel.}

Fennel is a hardy, aromatic, perennial plant from the South of Europe, growing wild on the banks of rivers, and perhaps quite as properly belongs to the culinary as the medicinal department of the garden. It has a finely divided leaf, and tall umbel-bearing stems, crowned with small yellow flowers.

Culture.-Fennel will grow in almost any soil. It is propagated by offsets, parting the roots, or by seed; all which morles may be successfully practised at any time between October and April.

The best season, however, for sowing the seed is when it ripens in the fall. If planted, set them one foot apart. If sown, in drills twelve inches asunder. The seed may be sown moderately thick, about half an inch deep, and the earth pressed upon them. When the young plants are four or five inches high, thin them out to ten or twelre inches. Those taken up may be planted out to enlarge the bed. Water them freely, if the weather is dry. Keep the plants free from weeds, which is all the cultivation required. If the seed is not desired, the stems should be cut down as often as they run up; for, if allowed to ripen seed, the old plants will last but few years. But this is of little consequence, as plenty of self-sown seedlings will be ready to take their place. Eight or ten roots are enough for any family. It should be kept within proper limits, as it is much inclined to spread.

Use.-Fennel is a good deal used, in continental Europe, in soups, fish-sauces, garnishes, and salads. It is also considerably used in England, but less with us. The Italians 
blanch and eat the stalks like celery. A little fennel seed sometimes gives an agreeable variety in flavoring applesauce and pies. But it is most used medicinally. 'The seeds are carminative and stimulant, and in an infusion are excellent for the flatulent colic of infants.

\section{Angelica Archangelica-Angelica.}

A native of many parts of Northern Europe. It is a biennial plant, rising from three to five feet ligh. The whole plant is powerfully aromatic. Its roots have a fragrant, agreeable odor, and at first a sweetish taste which soon turns acrid in the mouth. Its medical proporties are aromatic, stimulant and gently tonic.

Its stalks were formerly blancheỉ and eaten like celery, but it is now mostly cultivated to make a sweetmeat from them when young and tender. They are also candied by the confectioners.

Sow the seed one foot apart in August or September, and when they get abont four inckes high, the next spring, set them in rows two feet apart. Though the plant is only a biennial, yet by cutting down the seed-stalk whenever it rises, the same plant may be preserved several seasons. Angelica likes a moist, cool soil.

\section{Anthemis nobilis-ChanoniLe.}

A peremial, a native of England, cultivated for its flowers, which have a bitter aromatic taste, and are in small doses a useful tonic, but given largely, act as an emetic. An infusion of them improves digestion and gives tone to the disordered stomach. The flowers are sometimes chewed as a substitute for tobacco.

It is best propagated by dividing the roots in spring. Keep the ground free from weeds. 
Gather the flowers when just in full bloom and dry in the shade.

\section{AR'TEMISIA.}

\section{Artemisia Absinthium-Wornwood.}

A native of Europe, perennial, cultivated much in gardens. Its odor is strong and fragrant, and its taste aromatic but intensely bitter. It is cultivated for the torys or extremities of the branches. Its properties are trinic, diuretic, and it is a vermifuge. The dried leaves steeperd in vinegar are a very useful application to fresh bruiscs, for which it is well wrortl cultivating. It is also usefully employed in antiseptic fomentations.

Wormwood likes a calcareous soil, and may be raised either by euttings, seeds, or dividing the roots. Cultivated same as hyssop; roots being eighteen inches apart. A dry, poor soil is necessary to bring out the peculiar virtues of this plant.

\section{Artemisia Abrotanum-Southervwood.}

Is very nearly allied to the above, both being species of the same genus, and similar as to medical properties. Like wormwood, it has a grateful odor, but it is not much used in medicine from its nauserns taste. It is a stimulant, rermifuge, and emmenagogue.

For culture, see "Hyssop."

\section{Borago Officinalis-Borage.}

An annual European plant. The tender tops, young leaves, and flowers, are srmetimes used as a salad by the French, and boiled by the Italians.

Medicinally it was formerly thrught enirowed with very great virtues, and numbered among the four crimedial flowers.

nld Girard says, "Those of our time do use the fower: 
in salads, and to exhilarate and to make the mind glad. There be many things made of them used for the comfort of the heart, to drive away sorrow and increase the joy of the minde." The plant is not much used now except as an ingredient in the drink called " a cool tankard," made of wine, water, lemon-juice, and sugar, to which a few of the tender leaves seem to give additional cnolness.

Sow early in March or last of February, broadcast, and a little thinning and weeding is all the attention that will be needed.

\section{Carum Carui-CaRaway.}

A native of England and various other countries of Europe. It is a biemnial plant, well known to the ancients. Pliny mentions it. Caraway is cultivated for its seeds, which are useful in confectionery; as in cakes, comfits, $\& c$. and the leaves are sometimes used in soups. The roots are said to excel those of the parsnip, being formerly cooked and used in the same manner. Medicinally the seeds are used in an infusion for flatulence. Sow in March or in the autumn, and thin so as to give each plant a foot of room. Keep free from weeds. The autumn sowing will give seed the next season.

\section{Centaurea Benedicta-Blessed 'T'his'tle.}

An annual from Spain, and the Levant. An infusion of the leaves is used as a stomachic, to produce an appetite : if strong, it promotes perspiration.

Sow the seed in autumn, in light earth. Thin, and keep free from weeds. Gather the herb in flower and dry with great care, as it is very apt to mould.

This plant had formerly a great reputation, but it is now little used. The taste is very bitter and the smell disagreeable. 


\section{Coriandrum Sativum-CorinNDER.}

An annual from the East; also grows naturally in the South of Europe. Some like its tender leaves for soups and salads, but it is raised mostly for its seeds which have a pleasant aromatic taste, though the smell is disagreeable. Coriander seed is carminative and stomachic. It is often used to disguise the taste of medicines, but it is principally employed in confectionery.

Sow the seed in March, where they are to remain, in drills ten inches apart. Do this in dry weather and thin the plants to four inches, and keep free from weeds.

Eupatorium Perfoliatum-Thoroughwort, or Boneset.

A native of most of the United States, which, if not found growing wild in the vicinity, should be cultivated, as it is one of the best herbs in family practice. It has a faint odor, an intensely bitter taste, and is slightly astringent. Its medicinal virtues are diaphoretic, tonic, and in larger doses, emetic and aperient. It is principally used as a diaphoretic in colds, catarrhs, and rheumatism, in intermittent, remittent, and inflammatory diseases, or given cold as a tonic in dyspepsia. A strong infusion given warm in bed is almost a sovereign remedy for a cold. To a pint of boiling water, add one ounce of the leaves and flowers, and take it hot at two or three doses.

Boneset is a perennial, and can be raised by transplanting the roots or sowing the seed.

\section{Glycirrhiza Glabra-Liquorice.}

A hardy perennial from Southern Europe, the saccharine juice of the root of which is useful in catarrhs, fevers, sc. Its taste is sweet and mucilaginous, and it is much 
used as a demulcent, either alone or combined with other substances, for-lung diseases.

A few roots of this plant when once started, will be of very little trouble in the garden. The plant is propagated by cuttings of the roots. Dig the soil at least two feet deep. Take the horizontal roots of established plants, five or six inches long. Every shoot planted should have at least two eyes; make the rows three feet apart, and the plant twelve to fifteen inches in the rows, and cover the roots well with mould. Onions, lettuce or radishes, may be grown between the rows the first year; afterwards keep the soil free from weeds, dress the surface with manure every autumn, and at the end of the third year take up the crop as soon as the leaves are fully decayed, and dry the roots thoroughly. In shallow or poor ground it will not succeed.

\section{Hyssopus Officinalis-HYssop.}

Hyssop is a hardy evergreen undershrub from the South of Europe, of which the leaves and flower-stalks are the parts used medicinally. It has an aromatic odor, and a warm pungent taste. It is stimulant and expectorant, and employed in humoral asthma and chronic catarrh.

Hyssop is propagated by slips or dividing the roots in the spring, or by sowing the seed in March. Transplant the young plants in July to where they are to remain, or you may thin the young plants to six inches apart, and let them remain in the seed-bed until autumn before transplanting. It likes a dry sandy soil, and about eighteen inches space should be given to each plant.

\section{Inula Helenium-Elecampane.}

A native of England and Japan. It is a perennial plant, and loves a moist soil. It is cultivated for its thick, 
fleshy, carrot-like root, which is useful as an aromatic tonic and expectorant. It is very beneficial in chronic coughs and catarrhs, and also in dyspepsia. An infusion of the root is excellent for a common cold. Cut up fine and fed with their corn, the root is a great relief to the distemper in horses.

It is propagated by offsets, or by parting the roots in antumn.

\section{Lavendula Spica-Lavender.}

A hardy undershrub, a native of the South of Europe. It is cultivated for its fragrant spikes of flowers, which are used for the distillation of Larender-water. Being dried and put up in paper bags, they are also used to perfime lineir. Both flowers and leaves are very aromatic. It has an agreeable pungent bitterness to the taste, and its medical properties are stimulant, cordial, and stomachic, and the essential oil mixed with proof spirits is very useful in cases of frinting and paralysis, but the chief use of the plant is as a perfume.

Larender is very hardy and easily cultivated. It may be propagated by seeds, slips, or cuttings. Sow the seed in drills ten inches apart, and transplant the next spring to a dry soil of but medium richness, and it will be more highly aromatic. Give each plant about two feet of space; for drying gather the flowers before they begin to fade in the least.

\section{Mentha-Mrnt. Mentha Piperita-Peppermint.}

A perenuial; a native of Europe. It has a strong, agreeable odor, a pungent, aromatic taste, giving a sensation of coldness in the mouth. Its medical properties are aromatic, stimulant, and stomachic. It is much used to 
obviate nausea and relieve flatulent colic. The essential oil and essence are the forms in which it is employed in medicine, and they are also largely used in confectionery and cordials.

\section{Mentha Viridis-SPEARMINT.}

Is a European perennial, and belongs rather to the culinary than the medicinal department of the garden. It is employed in sauces and salads, as well as dried for soups in winter. A few sprigs of mint boiled a little time with them, and then withdrawn, are thought by some to improve the flavor of green peas. It is also used in preparing mint-julep. Its medicinal properties are aromatic, stimulant, and stomachic. 'The leaves boiled in milk are useful in diarrhœa. Its infusion is gnod to prevent nausea. There are two varieties, the broad and narrow leaved, equally good.

Mint Sauce.-Three tablespoonfuls of young spearmint minced, mixed with two of sugar, and six of vinegar. To be eaten with roast lamb, to which it imparts a delicious flavor.

\section{Mentha Pulegium-Pennyoyal.}

Pennyroyal is more acrid than the other mints, and its taste and smell are less agreeable. It possesses their warm, pungent flaror, and other general properties, but is not so good a stomachic. It is used for colds, and also as an emmenagogue. Its essence will sometimes relieve the tonthache. The American pennyroyal belongs to a different genus, Hedeoma.

This genus of plants requires a tenacious soil, which is all the better if moist or even wet.

A border sheltered from the mid-day sun, but not ontirely secluded from its influence, is always to be allotted 
them, as in such a situation they are most vigorous and constant in production.

They are readily propagated by dividing the roots in the winter or spring, or by cuttings planted in moist soil during summer.

The only after culture required, is an occasional slight manuring, and the destruction of weeds.

New beds should be made as often as once in four years.

\section{Melissa Officinalis-B ВLм.}

A hardy perennial, native of Switzerland and the South of France, but has long been cultivated in gardens. It has an aromatic taste, and a grateful fragrant smell, a little like lemons.

It is a square-stemmed plant, rising about two feet high. It is used in making balm-tea, a grateful drink in fevers, and for forming a pleasant beverage called balm wine. The infusion promotes perspiration, and is thought good for complaints produced by a disordered nervous system. Balm is a great favorite with the bees.

Any garden soil will do for balm. It is readily propagated either by slips, or by parting the roots in spring. Plant ten inches apart, giving water if dry weather.

\section{Marrubium Vulgare-Horenound.}

A perennial plant, a native of most parts of Europe, growing in waste grounds among rubbish in warm dry situations. It has a strong aromatic smell, and a bitter, pungent taste, which is permanent in the mouth; medicinally, horehound is a tonic, somewhat stimulant and diuretic, and in large doses laxative. It is useful in asthma and jaundice, and is a favorite remedy in pulmonary complaints.

Obstinate catarrhs have been cured by taking the ex- 
pressed juice in new milk. It enters largely into the composition of cough syrups and lozenges.

Sow the seeds in the spring, in any common soil. It scarcely needs any attention. It may also be propagated by dividing the roots.

\section{Pimpinella Anisum-Anise.}

An annual, a native of Egypt. It is cultivated for its seeds, and its leaves which are occasionally used as a garnish, and for seasoning like fennel. The seeds have a fragrant agreeable smell, and a sweetish pleasant taste. 'They are useful in weakness of the stomach and bowels, in dyspepsia, and colic, and in restoring the tone of the stomach generally.

The plant grows about 18 inches high. Sow the seed where it is to stand in April, in a dry, light soil, and thin out the plants, if too thick, to three or four inches apart.

\section{Rosmarinus Officinalis-Rosemary.}

A hardy, evergreen shrub, a native of the South of Europe. It has a fragrant, grateful odor, and a warm aromatic bitter taste. Its medicinal virtues are tonic, stimulant, and resolvent, and it is a useful, but powerful emmenagogue. It is employed in chlorosis, uterine obstructions, and nervous headaches generally.

It was formerly believed this plant gave strength to the memory. The tender tops are the parts used in medicine.

Rosemary may be raised from seed, or by planting slips or cuttings in the spring or autumn. Sow the seed in drills sixteen inches apart. Transplant the next spring or nutumn. Two or three plants will be enough. 


\section{Ruta Graveolens-RuE.}

A perennial, evergreen under-shrub from the South of Europe. It flowers all summer, and is very well known from its peculiar strong, unpleasant smell. Its taste is bitter and pungent, and the leaves so acrid as to blister the skin. It is a very powerful medicinal agent, and must he employed with caution. It is tonic, stimulant, antispasmodic, and an emmenagogue, owing its power to the essential oil of the leaves. Rue is much used in hysteria and nervous complaints, also for flatulent cholic. A strong infusion as a clyster is found useful in the convulsions of children. The plant is too powerful to be generally used in family practice.

Rue is propagated by seeds, cuttings, or slips. It must not have a very rich soil, nor be suffered to run to seed. Sow the seed and cultivate as hyssop.

\section{Salvia Officinalis-SAGE.}

Sage is an evergreen under shrub, a native of the South of Europe. It has been cultivated from the earliest times, was classed among the heroic remedies, and considered the best of medicines for prolonging human life. An old Latin adage is "Cur moriatur homo cui salvia crescit in horto," "Why should a man die while sage is growing in his garden." Sage grows about two feet high, with wrinkled ashy green leaves, and terminal blue flowers in long spikes. It has a fragrant smell, and a warm bitterish aromatic taste.

Culture.-Sage is raised from seed, slips or cuttings. It likes a dry, fertile soil. Sow the seeds in February, May, or March, in shallow drills eight inches apart. Press the earth upon the seed, covering them not over half an inch deep. 'Thin the plants when well up to half a foot apart, planting 
those taken up at a similiar distance. Keep the soil light and free from weeds. In the autumn or the next spring, plant them out in rows eighteen inches each way. Layers and rooted offsets may be set out at once at this distance, Cuttings of the outward shoots of the current year's growth, planted out in a shady border in moist weather, readily take root; set them in rows six inches apart. In autumn or spring, take them carefully up and set them out in their final stations. Trim the plants to a round, bushy head. Gather and dry the leaves for winter use, but do not trim the plants too closely, especially in autumn or winter.

Use.-The leares are used for seasoning stuffings, sauces, and many kinds of meat, as well as to improve the flavor of various other articles of conkery. Medicinally its infusion is given warm as a sudorific, or mingled with vinegar and alum is an excellent gargle in sore throat. It is stated by Bomare, that it was exported formerly by the Dutch to China, and it was so much preferred by the Chinese to their own tea, that they willingly exchanged two boxes of it for one of sage.

\section{Salvia Sclarea-Clary.}

A biennial from Italy. The leaves of this plant were formerly used in soups, and its flowers are now made use of in a fermented wine.

The medicinal virtues of the plant are cordial and astringent, and it is used either in its fresh or dried state. For propagation and eulture, see "Sage."

\section{Sesamum Orientale-Bene.}

An annual, a native of Africa and India. Introduced into this country by the negroes. It grows from three to six feet high, bearing numerous pods, filled with smallish 
seed. These are used for food in many parts of the world, and are also cultivated for the oil with which they abound. It resembles that of olives, and is nearly as good. The leaves abound in mucilage; one or two stirred in a pint of water, will form a bland mucilaginous drink very useful in cholera infantum, dysentery and summer complaints generally. The leaves should be freshly gathered, and enough may be added to make the water ropy without affecting its color or taste. Give this drink to the little sufferers in moderate quantity, and it will afford great relief.

Sow a row in April, on the edge of a plat or border, and thin out as the plants require room. A few plants will furnish all the leaves desired.

\section{Tanacetum Vulgare-TANsy.}

A peremnial, a native of Europe, long cultivated in gardens. It was formerly used to give flavor to pudding's and omelets.

Its medical properties are tonic and stomachic. It is also a vermifuge. It is much used as a domestic remedy beneficial in dyspepsia, hysteria, arising from uterine affections, aud in gout. It was formerly of very general use in the preparation of alcoholic bitters.

Divide the roots, and set out a few slips in autumn or spring. After it is well rooted, be careful you do not get too much of it. 


\section{THE FRUIT GARDEN.}

Since the publication of the "Fruit and Fruit Trees of America," by the late Mr. Downing, fruit culture has received increased attention in all parts of the Union. 'The raluable Treatises of Thomas, Cole, and Barry, soon followed, and more recently that of Elliot; each containing much additional matter which, with the monthly issues of the Horticulturist, Hovey's Magazine, and for a time the Western Horticultural Review, leave little in pomological literature to be desired for the Northern States. But, unhappily for us, many of the varieties described in these works are wholly unsuited to our climate. This is especially true of the apple. The modes of culture and prun ing there recommended, are in the main as well adapted to this latitude as to any other, bearing in mind that mulching is more beneficial here, that we must prune much more closely in transplanting, and form the heads of the trees necessarily much nearer the earth than is abso- lutely required in a cooler climate. Insects too, of all linds, are more annoying, and require more vigilance to keep them under. So, upon the whole, more care is required to keep our trees in a perfectly healthy condition. Besides, fruits decay so quickly with us, that it is more C.ifficult to get them to market in good condition, or to preserve them long for home use.

On the other hand, our climate has some peculiar adrantages. A tree well cared for, makes fully twice the growth it will do as far north as New York. It will come generally some years sooner into bearing. Besides, $(300)$ 
many fruit trees can be readily made to grow from cuttings; and trees thus propagated come very soon into bearing, and are in general equally healthy with those grown by other modes.

Our lists below are not very long, and doubtless some varieties named in them will give place to native sorts, when the latter become more widely diffused. Every owner of a choice native fruit should interest himself in disseminating it. Our great deficiency, at present, is in late-keeping fruits, especially of the fall and winter pears and apples, in sufficient variety. Peaches, too, of fine quality, that will ripen here in September, and a few ripening still later, are very desirable, A few years more experience and the fruiting of many varieties now collected, will doubtless render it possible to improve the lists that follow-though with the exception of the varieties of the Orange family and the Olive, there is hardly a fruit in them, that is not a familiar acquaintance to the writer, and these lists may be relied on as embracing the most valuable varieties that have fruited in this section up to 1856 . The collections of Dr. Ward, Mr. Camak, and others, planted as far back as 1836, and now in full bearing, and more recently $\mathrm{Mr}$. Van Buren's, at Clarksville, together with my own, have rendered it less dificult to form select lists of the most desirable kinds. Besides the varieties fully described, a list of those worthy of trial is occasionally added, embracing those found most desirable in other sections, which are likely to prove of equal or superior value here. As these come into bearing, notes of their quality will be given from time to time in the "Southern Cultivator." Most of them will fruit the next summer (1856) in my ground.

The main requisites for a fruit garden are protection from pillage by a suitable hedge or other enclosure; with- 
out which a garden is more annoyance than pleasure; freedom in its aspect from a full southern or eastern exposure, that the sun's rays may not strike the trees when the frost is upon them; thorough drainage to carry off surplus moisture before it stagnates, and a soil of medium texture and good quality, of great depth, naturally, or made so by subsoiling or trenching. Over rich soil is not desirable-especially if made so by animal manures; but it must be of at least good quality, and above all deep. Trees can neither make growth nor swell their fruit (drawing so largely as they do in both eases, of moisture from the soil), during our protracted droughts, unless the soil is deeply trenched. In a soil two or three feet in depth they will hold their fruit, maintain the deep, healthy green of their foliage and continue their growth in our most trying seasons. It is much less expense to prepare the ground thoroughly before the trees are planted. While the trees are young, sufficient manure from time to time can be applied to keep the soil in good condition, and almost any low growing hoed crop can be raised anong them. Corn is very objectionable, as it shades and nearly starves the young trees. It is necessary to keep the soil well cultivated to ensure rapid growth. After the trees are well grown, it is better to give them the whole ground and turn in, daily, during the fruit season, poultry or swine to devour the fallen fruit and to destroy insects. The whole orchard should receive a shallow plowing every autumn, and may be sown with barley, to keep the soil fiom washing during winter. This must on no account be allowed to ripen, but be fed off by swine or turned into the soil as green manure, in the spring. A good winter veteh would be very desirable for this purpose, as legumes draw most of their food from the air, while barley is nourished mostly from the soil, to the greater detriment of the trees. 


\section{Amygdalis Communis-ALnond.}

The almond is a native of Asia, and Northern Africa. It is a tree of medium size, nearly allied to the peach in habit and general appearance. The leaves are similar to the peach, having glands like some varieties of the latter fruit, and flowers of similar shape, but much larger and more ornamental, varying in color from snowy white to a fine blush. The chief difference is in the fruit, the stone of the almond being flatter, not so hard, and covered with a woolly skin that opens spontaneously when the kernel is ripe.

In southern Europe, the almond is much cultivated, and large quantities of nuts exported. The kernel is the part in use; the sweet varieties, whether green or dry, form a very nutritious article of food, and a most agreeable addition to the dessert. Almonds are used in confectionery, cooking, perfumery, and medicine. The Bitter almond is the kind used in perfuming and flavoring. It owes its flavor to the prussic acid it contains, which, though a violent poison, is not thought injurious in the small quantities required for these purposes.

Cultivation.-A warm, dry soil is most suitable for the almond, which is cultivated exactly like the peach, and is subject to the same diseases. It may be budded on the almond, peach, or plum stock. I have not been able to find any analysis of the ash of the almond tree. It probably differs little from that of the peach. The varieties are:

Common Almond.-Nuts one and one-fourth inches long, hard, smooth, compressed, and pointed, with a kernel of agreeable flavor. The hardiest and most productive variety, and is the common, hard-shelled almond of the shops. Flowers expand before the leaves.

Long, Hard-shelled Almond.-Nut of the same size, 
but kernel larger and better flavor than the preceding. Flowers large, rose-colored, and the tree very ormamental when in blossom.

Ladies' Thin-shelled Almond.-The soft-shelled almonds of the shops. Flowers are of a deeper color than the foregoing variety. Nut oval, one-sided, pointed, with a porous, light-colored shell, so tender that it may be crushed with the fingers. Kernel sweet, rich, and highly esteemed.

Bitter Almonds-are of several varieties, differing in the hardness of the shell, closely resembling the others, except in the bitter kernel. Blossoms pale pink. Leaves larger, and of a darker green than the other varieties.

\section{Amygdalus Persica-Peach.}

The peach is a native of Persia, whence its cultivation has proceeded westward; but it has nowhere found a soil or climate more congenial to it than in these Southern States. Indeed, the peach is the favorite, and, in many instances, the only fruit tree cultivated by our planters. Requiring a soil of but moderate fertility, its enemies and diseases are so few, and the return so speedy, that there is no excuse for being without good peaches.

We entirely escape the yellows and the curl, I beliere, except in the case of northern importations, which generally recover, though checked for a season. The borer is not very abundant, but is on the increase. The worm in the fruit is very troublesome, especially in the white-fleshed rarieties. The borer can be prevented from entering the tree, generally, by covering the collar therenf with lime or leached ashes. If already in the tree, which is shown by the gum exuding from the collar, he may be dug out with a knife; or hot water can be poured about the base of the tree and into his haunts at any time, which will destroy 
the, grub withont injury to the tree. The worm in the fruit is lest prevented by permitting pigs or fowls to consume all the fallen fruit of the orchard as it drops.

A somewhat serious difficulty, in peach culture, is the result of bad pruning. It is the tendency to overbear and break down the limbs from the excess of the crop. More peach trees are destroyed or badly injured from this cause than any other. The peach trees hould always be pruned at the extremities of

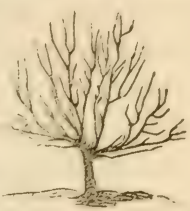
the branches, by cutting off, close to a bud, one-third, or, if very luxuriant, one-half the last year's growth. (See plate of tree properly pruned in the figure.) The fruit is produced on these small branches; and by reducing the top in this manner, overbearing is prevented, the fruit is effectually thinned, and is larger, finer flavored, and nearly as much fruit can be taken from each tree without danger of breaking. The tree is also kept low and close, and more trees and larger crops can be grown to the acre. This method of pruning is called shortening-in, or heading-in, and is expeditiously done with a pair of pruning shears.* Pruning can be performed upon the peach at any time when the leaves are off. If it is wished to throw young trees rery carly into fruit, they may be shortened the last of July, the year they are transplanted. In shortening-in, the top must not be sheared evenly all orer like the side of a hedge, which would cause a thick, impenetrable mass of shoots on the outside, and shut out all light from the centre, but the centre should be kept somewhat open. Large limbs must, if pruned, be cut off close to a branch.

* When this is inconvenient, larger portions of the branches may be taken off once in two years, leaving the head in a neat, rounded form, and taking care to cut at a fork so as to leave no bare stumps. Old trees may be restored in this manner. 
Care should be taken that the branches are not permitted to divide in forks, as they are exceedingly apt to split, to the great detriment of the tree. The peach, like all other fruit trees, should be suffered to branch low within twelve or eighteen inches of the surface, and kept in as near either a pyramidal or vase form as its nature admits.

But the loss of peaches by decay, as they approach maturity, is more annoying than anything else in peach culture. If the season is warm and wet, very few kinds ripen well if on moist or very rich soils. There is a very common opinion, that peaches propagated from the stones of fruit not fully ripe, are more liable to rot than those propagated from the pits of fully matured peaches. Is there any evidence to sustain this opinion? Some also think decay and dropping of stone fruits is caused by planting the trees too deep. It is however, certain, that some varieties are much more subject to decay than others placed in the same position. Much, also, depends upon the soil. The most suitable soils, to ripen sound and high-flavored fruit, are dry, and but moderately fertile-a hill-side being as good a situation as any. If it faces the north, the crop will be less liable to be cut of by spring frosts, but will hardly be as fine flavored. Thinning the fruit, so that no two peaches touch each other, is very necessary in order to prevent decay at the point of contact.

Uses.-The peach is mostly used in its fresh state for the dessert, and is generally considered the most delicions fruit of temperate climates. When allowed to ripen on the tree, it is the most wholesome of fruits, and as an article of food is considerably nutritious. Peaches are also used for pies, are preserved in brandy or sugar, and are excellent, when dried, for winter use. For culinary purposes, the clings are most esteemed. Peaches and milk form a delicious dessert dish. For drying, take those of 
the best quality, just as they are ripe enough to eat; halve them, remove the stones, and sprinkle over them, in the hollow from which the pit was taken, a little nice sugar, and dry them in a brick oren, after the bread, \&c., is withdirawn. Thus prepared, the aroma and flavor is retained, and they are free from insects. If the peaches are fully ripe, no cooking is required, but the dried fruit is simply soaked out in cold or warm water. Sufficient sugar, varying with the acidity of the fruit, is added before drying. The firm yellow-fleshed peaches, of a high vinous flavor, are best for drying. Peaches thus prepared are only inferior to the fresh fruit, of which they retain much of the flavor. Dried in the usual way, from unripe fruit, exposed to the sun, much of the flavor is dissipated. Peaches are excellent, preserved, in Arthur's Self-sealing Cans, according to the directions given with the cans.

Analysis.-We give an analysis of the peach, by Salisbury :-

\begin{tabular}{|c|c|c|c|c|c|c|c|c|}
\hline & $\begin{array}{c}\text { Bark } \\
\text { of } \\
\text { Trunk. }\end{array}$ & $\left|\begin{array}{c}\text { Wood } \\
\text { of } \\
\text { Trunk. }\end{array}\right|$ & $\begin{array}{l}\text { Bark } \\
\text { of } \\
\text { Root. }\end{array}$ & $\begin{array}{c}\text { Wood } \\
\text { of } \\
\text { Root. }\end{array}$ & Leaves. & Pits.* & $\left|\begin{array}{l}\text { Bark of } \\
\text { Limbs } \uparrow\end{array}\right|$ & $\begin{array}{l}\text { Wood of } \\
\text { Limbs. } †\end{array}$ \\
\hline Potash, ..... & 1.20 & 7.11 & & $\begin{array}{r}8.58 \\
15.92\end{array}$ & $\overline{12.41}$ & $\begin{array}{r}18.47 \\
5.21\end{array}$ & 8.85 & $\begin{array}{r}19.21 \\
8.11\end{array}$ \\
\hline $\begin{array}{l}\text { Chloride of so } \\
\text { dium }\end{array}$ & 0.04 & & 0. & 5.6 & & 2.70 & $0.2 \varepsilon->$ & 0.24 \\
\hline of $\mathrm{Po}$ & 0.04 & U. & & & & & & \\
\hline id; & 4.19 & 1.51 & 3,4 & $0.5=$ & $\begin{array}{r}0.36 \\
12.12\end{array}$ & $15.1=$ & 6.18 & 8.07 \\
\hline & 42.17 & 23.26 & 38.4 & 0.11 & 14.77 & 16.80 & 31.98 & 24.64 \\
\hline & 2.16 & 6.40 & 28 & 0.01 & 8.00 & $\begin{array}{l}1.00 \\
1.35\end{array}$ & 6.00 & 9.76 \\
\hline & 0.45 & 0.32 & 30.40 & 1.02 & 2.47 & 1.33 & 1. 60 & 0.60 \\
\hline Lime,. & 18.79 & 29.19 & 310.40 & 18.10 & 10.44 & 17.98 & 8.50 & 13.20 \\
\hline & 0.01 & 1.34 & & 30.00 & 3.15 & 0.02 & 0.20 & 0.2 \\
\hline $\begin{array}{l}\text { matter } \\
\text { e Sili- }\end{array}$ & 3.30 & 5.20 & 3.60 & 2.55 & 0.86 & $6 \cdot 61$ & 5.00 & 8.40 \\
\hline c & 4.15 & 1.35 & $9-4$ & 6.46 & 6.42 & 10.00 & 4 & 1.00 \\
\hline Coa & & $\cdots \cdots$ & 1.40 & & & & 1.00 & \\
\hline & & & 104.562 & 89.02 & 86.85 & 128.77 & 99.03 & 3) \\
\hline
\end{tabular}

* Analysis made with two grains of ash. +Peach limbs half an inch in diameter. 
Lime, potash, and the phosphates, are the chief elements the peach requires in the soil. Bone-dust and wood-ashes are valuable applications, much more suitable than common animal manures. They may be dressed with compost of woods earth (leaf-mould), or swamp-muck, if the soil is very poor.

When the trees are planted, the holes may be made large, and enriched with well-decayed manure, to give a good growth of wood. For this purpose, guano is an excellent application; but it is fatal to the tree, if it touch the roots. I have applied it, with success, to all kinds of fruit trees. After the holes are dug, a little guano is sprinkled in the hole; this is covered at least two inches deep with fresh loam, on which the tree is placed. If the soil is very sandy, two inches might not be sufficient to protect the roots. When the roots are entirely corered, another sprinkling may be given, which is covered over with more earth. Two or three tablespoonfuls are sufficient for a tree, and but a small quantity is required for a large orchard. For this purpose. as well as manuring most shrubs, rose bushes, \&c., few applications are so cheap or so satisfactory. But guano must not touch the roots, in its dry, caustic state. After the tree begins to fruit, application of lime, ashes or leaf-mould are much better than those which excite rank growth, since they do not impair the flavor of the fruit, or induce decay.

The peach is best propagated by budding and grafting upon seedling peach stocks. There are, however, many varieties, of the clings particularly, that can be raised true to their kind by planting the seed, especially if the tree from which the stone is taken stands apart from other varieties. It is believed that the stone of a seedling is more apt to reproduce its kind than if taken from the fruit of a budded or grafted tree. Seedlings often escape frosts 
that are fatal to the finer varieties; but the highest flavored seedlings are often quite as susceptible of injury as those budded or grafted. High-flavored varieties are usually tender.

Plum stocks are recommended by foreign writers; but they are of little use in this climate, for the graft soon outgrows the stock and breaks off.

Peach stocks are raised by planting the stones two or three inches deep, in the autumn or winter. If the stones are cracked, they are more sure to grow. Abundance of stocks can often be secured by taking the volunteers that spring up under the trees early in the spring, when about an inch high, and transplanting in rows two and a half feet apart and sixteen inches in the row. Plant them in good soil, where they will grow rapidly; for on this, more than anything else, the success of budding depends. If the season is good, the best will do to bud in June. When the bud starts, the top may be headed down, and if the stocks are vigorous, they will make sufficient growth to be fit for transplanting the next winter. Budding may be continued, while the bark rises freely, until the first of October; the last will make no grow th until spring, It should, however, be performed as early as the stocks will admit. It is best in budding, when you do not wish to preserve the scion a day or two, to leave a portion of the leaf, say half an inch, attached with the leaf-stalk to the bud, as it attracts the sap, and the bud is more likely to take. The bud should be put in the north side of the stock, to screen it from the sun. Any of the trees which have failed in taking the bud may be taken up, and grafted in the root the ensuing winter; a mode of propagation which fortunately succeeds well here, as it enables us to procure scions of valuable varieties, in a dormant state, from all sections of the Union. 
Peach trees raised or varieties originating in the Northern States, are not at all unfitted for our climate. We know of trees from the North, imported in 1836, and others almost every year since, growing side by side with good native varieties, and giving as profitable results. It will be many years, before we get twenty-five as good southern varieties that ripen in succession as can be selected from any nursery catalogue. Still every superior variety-especially of those that ripen late, for such cannot be procured at the North-should be disseminated at once. It sometimes happens that a fruit which originates in one locality, is better fitted for some other section. Some few European varieties of fruits are found to succeed better on this continent than even where they originated.

Peach trees, in transplanting, are usually set twenty feet apart each way; which gives one hundred and eight trees to the acre. They may, if shortened in yearly, be set out fifteen feet apart, which will give one hundred and ninety-three trees, or in small gardens twelve feet, giving three hundred and two trees per acre. In gardens, fifteen feet is generally the best distance.

Peaches are so much alike in general character-the difference in outline, color, flavor, and texture being less than with other fruits, it is necessary in order to determine the name of a variety, to resort to other methods of distinction.

The two most obvious divisions are into free-stones and cling-stones; or, as we call them, soft and plum peachesthe flesh of the former parting freely from the stone, and being of a melting consistency ; and that of the latter adhering to the stone, and being of a firmer texture. The English name these divisions, melters and pavies. Both these grand divisions are subdivided into classes according 
to the color of the flesh-viz.: those with light-colored and those with deep-yellow flesh. These classes are again subdivided into three sections.

At the base of the leaf, of some varieties, will be found small glands which are either round and regular, or oblong and irregular, or kidney-shaped; while others have no glands, but are more deeply cut or serrated like the teeth of a saw.

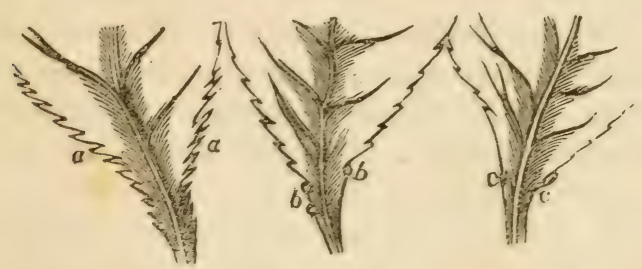

SERRATED AND GLANDLESS. GLOBOSE GLANDS. FENIFORIY GLANDS

Hence the three sections, viz.: 1 ., Leares serrated withont glands, $a . ; 2$. Leaves with small, round, or globose glands, $b . ; 3$. Leares with large irregular reniform glands, $c$.

From the blossom, another characteristic is derived, giving us two sulpsections. The first embracing large flowers, red in the centre, and pale at the margin. The second, small flowers, tinged with dark at the margin. Most of the native peaches, in this vicinity, belong to the first class; but the great mass of the finest fruits have small flowers.

Varieties.-The following varieties have been tried in in this vicinity, and are found among the most desirable. They are classed pretty much in the order of ripening.* A full list of good clingstones in succession, from the

* In 1852 , two or three weeks earlier than the next year; so the times of ripening; and even the order cannot be fully relied on. 
beginning to the end of the peach season is yet to be obtained. All named are good bearers.

Columbus June.-Glands reniform ; flowers small ; fruit medium to large, flattened, or slightly hollowed at the apex; suture shallow; skin pale yellowish white, with rich, red cheek ; flesh slightly red at stone, melting, juicy, and high-flavored; excellent; ripens here 20th June productive. Free.

Serrate Early Yorli-Leaves serrate, glandless; flowers large ; fruit-size medium, roundish oval; suture slight; skin thickly dotted with pale red on a greenish-white ground, in the shade-dark red in the sun; flesh greenish-white, tender, melting, full of rich, slightly acid juice ; ripens 20 th June. Free.

Walter's Early.-Glands globose; Howers small ; size above medium; color, nearly white, with a fine red cheek; flesh, whitish, slightly red at stone-melting, juicy, sweet, and fine-flavored; not so easily injured by frost as some others; likes sandy soils; succeeds as far south as Mobile; ripens 1st of July.- Free.

Early Newington Free. - Glands globose; flowers small; fruit medium to large, round; suture distinct; one half larger than the other; skin yellowish-white, dotted and streaked with red; cheek rich red; flesh white, red at stone, to which it partially adheres; juicy, melting, and vinous. Ripens early in July.

Grosse Aignonne.-Glands globose ; flowers large; firuit large, roundish, apex, depressed, suture distinct; skin dull white, mottled with red, and with a purplish red cheek; flesh red at the stone, melting, juicy; with a rich, ligh vinous flavor; stone small, very rough; perhaps, the best free-stone peach in cultivation; ripens July Sth. If it has a rival it is

George IV.-Glands globose; flowers small ; fruit large, 
round, with broad suture; skin white, dotted with red, and rich, dark-red cheek; flesh pale, melting, very juicy, with rich, luscious flavor; stone small ; ripens July Sth. Free.

Crauford's Early.-Glands globose; flowers small; a yellow-flesh peach ; fruit very large, oblong, with a prominent, swollen point; skin yellow, with a fine, red cheek; flesh yellow, melting, sweet, and excellent; ripens middle of July. Free.

Belle de Beaucaire.-Glands globose; flowers small; fruit very large, roundish, with protruding point, suture shallow, but distinctly marked; skin light-yellowish green, with cheek slightly reddened. Flesh pale greenish yellow red at the stone, a little coarse, but melting and delicious, full of rich, vinous juice; skin slips readily from the flesh, without the use of a knife; ripens last of July. Free. Variable, but in perfection most excellent.

Old IIixon Cling:-Glands globose; flowers small; fruit large, roundish oval; suture at top; skin yellowish white, dotted with red, red cheek; flesh light, melting, juicy, with a rich, high, luscious flavor. Ripens last of July and early in August. There is no better peach known.

Late Red Rareripe.-Glands globose; flowers small; fruit large, roundish, oval; skin downy, grayish-white, marbled with red in the sun; flesh pale, juicy, melting, and of a rich, luscious flavor. Ripens last of July.

Late Admirable.-Glands globose; flowers smali; fruit large, roundish, oval; suture distinct; apex swollen, acute ; skin pale, yellowish-green, with pale, red cheek, marbled with darker red; flesh pale, melting, and fine-flavored; Ripens 10th to 15th August. Free. A superb peach.

Crawford's Taale-Glands globose; flowers small; i magnificent yellow peach; very large, roundish ; suture shallow, but distinct; skin yellow, with dark red cheek; 
flesh deep yellow, red at stone; juicy and melting, with rich, vinous flavor; early in August. Free.

Newington Cling.-Leaves serrate; flowers large ; fruit large, roundish; suture slight; skin pale yellowish-white, with fine, red cheek ; flesh pale, yellowish-white, deep-red at the stone; melting, juicy, and rich. A cling. Ripens 10th August.

Lemon Cling.-Glands reniform; flowers small; leaves long; fruit large, oblong, narrowed at top, with a swollen projecting-point; skin rich, dark-yellow, reddened in the sun ; flesh fine yellow, red at the stone, with a rich vinous flavor. Ripens 10th of August. Cling. Pitt's LemonCling is an improvement on the above.

President.-Glands globose; large, roundish, oval ; suture shallow; skin downy, pale, yellowish-green, with a dull, red cheek ; flesh pale, but deep red at the stone, very juicy, melting, and high-flavored; stone very rough. Middle of August. Free.

Iellow Blanton-Cling.-Leaves large; glands globose ; Fruit large, and shaped like Lemon-Cling, with the same projecting, swollen point ; skin rich orange, with a slightly reddened cheek; flesh orange yellow; firm, but full of a delicious vinous juice. Later and better than the Lemon-Cling. To my taste the best of the clings. Reproduces itself from seed. Ripens August 10th.

Tippecinoe-Cling.--Glands reniform ; flowers small; fruit very large, nearly round, with a point; skin yellow, with fine red cheek; flesh yellow, juicy, with fine, vinous flavor. Ripe the last of August.

White English-Cling:--Glands globulose; flowers small ; fruit very large oval; suture slight, with a swollen point at top; skin clear creamy white, with a slight hue of red on the sunny side; flesh delicate white, free from red at the stone, to which it firmly adheres; very rich, juicy, 
and high flarored. As it is free from color, one of the best for preserving in sugar or brandy. Doubtless originated from the Heath Cling, with which it is almost identical.

Baugh.-Leaves with globose glands; fruit medium, roundish, terminated with a small point; suture obscure; skin pale yellow, almost white, with a slight blush towards the sun; flesh yellowish white, melting and juicy, with a sweet, pleasant Aaror. Free. Ripens 1st October.

Baldwin's Late. Free.-Fruit large, oblong, with a distinct swollen point at the top; skin greenish white, with a slight red cheek; flesh rery firm, juicy, melting, and well flavored. Ripe last of October, and will keep several weeks in the house.

Freestone. ${ }^{*}$-Disseminated by Dr. Baldwin, of Montgomery.

Edward's Late White and Pride of Autumn; the latter especially, are described as excellent late Peaches. Lady Parham, Mr. Afflech writes, is the only October Peach he knows of first rate quality. Free.

Scott's Late October is said by Mr. Summer to be a large Cling, with a dingy greenish skin; flesh firm and remarkably sweet, ripening last of October.

While this work is going through the press, Mr. Nelson, in the Southern Cultivator, gives the following select list as those his large experience proves most desirable :-

May Peach-ORipens last of May. Small white; flesh white, sweet and pleasant. Free. Early Anne.-Round, pure white, small size, very juicy and delicious. Ripens first week in June. Free. Early Tillotson.-Ripens 15th June. Early York (Serrate).-Ripens 20th June. Flewcllen.-The earliest Cling; flesh deep red, exceedingly 
juicy and refreshing, of high, vinous flavor. Ripens July 1st. Yellow Rareripe.-Large, deep orange, juicy and well flavored. Ripens July 4th-free. Walter's Early. -Ripens July Sth. Gross Mlignonne.-Ripens July Sth. Vanzandt's Superb.--White, nearly covered with red, juicy, melting, and high flavored. Ripens July 10th; too tender for market-iree. Bergen's Yellow.-Best of Yellow Peaches; dingy yellow, covered with dark, dull red; flesh orange, very juicy-free. Ripens July 10 th. Crawford's Early.-Ripens July 12th. Red Rareripe.Resembles Gross Mignonne externally; a week later; ton tender for market, but delicious for home use. Ripens July 16th. George Fourth. Old Mixon Free.-Ripens July 18th. Very juicy and fine. Congress Cling.-Lile Old Mixon Cling, large, very juicy, sweet, and well flavored; excellent for market. Ripens July 20th. Napoleon.-Large, oblong, skin dingy green, considerably covered with red; flesh firm, marbled with blood red, very juicy and rich. Ripens July 20th. Green Catherine.Large, oblong, creamy white, with red cheeks, firm, sweet, and delicious. Ripens July 20th-free. Late AdmiraZle.-Ripens July 20th. Breevoort.-Large, firm, and well flavored-free. Ripens July 20th. President.Ripens July 24th. Crawford's Late-Ripens July 24th. Columbia, or Pace.-Ripens August 3d. Druid Hill.Greenish white, slight red cheek, juicy, melting and rich. Ripens August Sth. Newington Cling.-Creamy white, red cheek, red at stone, very juicy and well flavored. Ripens August 10th. Late Rareripe.-Greyish green, marbled with red, very downy, dark red cheek, juicy, melting and rich. Ripens August 10th. Lemon Cling.Ripens August 20th. Lagrange.-Large, oblong, very downy; skin pure white, marked with dark spots; flesh white, firm, and juicy-free. Ripens August 20th. 


\section{Amydalus Vulgaris Var Loris-Nectarine.}

The nectarine is merely a variety of the peach with a smooth skin. It is impossible to distinguish the tree from a peach, except that the fruit is without down. The same characteristics of the leaf, flower, stc., which are used to describe the varieties of the peach, are brought into requisition in distinguishing those of the nectarine.

Nectarines usually produce nectarines from the seed; but the Boston nectarine originated from a peach stone.

The tree is cultivated and pruned like the peach, and is propagated by budding or grafting on peach stocks. The great difficulty in raising nectarines (and the same is true of the apricot), is the curculio. The smooth skin of these fruits offers an inviting place for this insect to deposit its eggs. The injured fruit may be known by being marked with a small semi-circular impression as if cut with a "baby's nail." It is useless to plant the nectarine or apricot, especially in sandy soils, unless the trees are daily jarred, and the insects collected on shects as they fall, and immediately destroyed. A limb may be cut off the tree, and the stump hit a few times with a mallet smartly, since if gently shaken the insect will not loose its hold. Or another very good method is to plant the plums, apricots, and nectarines by themselves, and admit poultry, and swine to eat the fallen fruit, which will, if other fruit gardens are not contiguous, protect the crop the succeeding year.* The borer infests the nectarine as well as the

In preventing the curculio, I am inclined to think that forls are much more serviceable than swine. The latter are of less use the current season, and mostly beneficial as regards the ensuing crop; but the chickens and ducks will take the perfect insect, whenever he falls upon the earth, or rises from it in the spring. 
peach. Aside from the curculio, the nectarine is as hardy and easily raised as the peach; though scarcely equal to the best peaches in flavor. Fine fruit is not to be expected unless the trees are shortened-in annually, as directed for the peach.

The analysis of the nectarine scarcely differs from the peach-it requires exactly the same soil. The best varieties are:

Hunt's Tauny-Leaves serrate; flowers small; fruit, medium size, roundish, oval, with swollen point; skin pale orange; dark red in the sun, mottled with russet specks; flesh orange, juicy, melting, and rich; a good bearer. Ripens 10th July. Free.

Tiolette IIative or Early Tiolet._Glands reniform; flowers small ; fruit, large, roundish, pale, yellowish-green, with purplish red cheek, mottled with brown; flesh whitish-red at the stone, melting, juicy, and delicious. Ripens 20th July.

Downton.-Glands reniform ; fruit, large, roundish-oval : skin, pale green, red at the stone, melting, and most delicious. Ripens 20th to 25th of July.

Elruge. - Glands reniform; Hower small; fruit medium, roumdish-oval; suture slight; skin pale-green, with deep violet, or blood-red cheek, and minute brown specks; flesh pale-green, pale-red at stone, melting, juicy, and rich ; stone oval, rough, and pale-colored. Ripens July 25 th.

Boston.-Glands globose; flower small; fruit, large, roundish-oval ; skin, bright yellow, with deep-red cheek; flesh yellow, not rich but sweet and pleasant. Ripens last of July.

New White.-Glands reniform ; flower large; fruit large, nearly round; skin white, with slight tinge of red in the sun; flesh, white, tender, juicy, vinous, and rich ; stone small. Ripens 1st of August. 
The best Clingstone nectarine is the Early Newington; and the best of all nectarines is said to be the Stanwick, the quality of which is yet to be ascertained in this country. Temple's is said also to be a fine variety.

\section{Armeniaca Vulgaris-APRICOT.}

The apricot is a fruit somewhat resembling both the plum and the peach. The tree is ornamental as well as useful; larger than the plum, with glossy, heart-shaped, large leaves, and white blossoms, which appear so early that they are often cut off by frosts. But as with the nectarine, the great obstacle to its culture is the curculio, which may be warded off as in the case of that fruit. In favorable seasons, when protected from the curculio, the apricot is exceedingly productive.

The apricot is a native of Armenia, and other parts of Central Asia. In quality it is second only to the peach; but coming earlier (with the earliest plums) it is very acceptable. For jellies, tarts, and preserving in brandy or sugar, it is much esteemed, and is excellent when dried as directed for the peach.

The apricot is generally budded on the plum stock. It is sometimes propagated on its own ront, and also upon the peach. The plum is the hardier stock, and produces the best tree. It may be root-grafted on the Chickasaw plum by the method of whip-grafting. Those propagated by seed, are usually very hardy and productive. On the peach stock, the tree is liable to be destroyed by the borer, and the fruit is inferior.

Apricots are so apt to bloom too early in the spring, that it is better to plant them in northern exposures where they will be retarded in blooming, by the shade of buildings there is less danger of severe frost. It is just as necessary to shorten in the young branches of the apricot 
as those of the peach. The best soil is a deep loam ; cultivate and manure the same as the plum or peach. I can find no analysis.

The hardiest Apricots are Dubois, Orange, and Breda. The best varieties are:

Dubois and Early. - Fruit small, roundish-oval; pale orange ; moderately juicy, sweet and good; very productive and hardy. Ripens early in June.

Large Early. - Fruit medium size, oblong and compressed; suture deep; skin sligtly downy, pale orange in the sharle; bright orange or ruddy in the sun; flesh separates freely from the stone, orange colored; rich and juicy; kernel bitter. Ripens 10th of June.

Orange. - Fruit medium, roundish, with suture hollowed at the stalk; skin firm, orange, with a ruddy tinge; flesh dark orange, rather dry and somewhat adhesive to the stone, which is small and roundish ; kernel sweet; not first rate; but excellent for tarts, preserving or drying, and often bears a full crop when others fail. Ripens June 10th

Breda.-Small romudish, deep orange - darker in the sun; flesh deep-orange, high-flavored, rich and juicy; separating from the stone; kernel edible. A native of Africa, hardy, productive and fine for dessert or preserves. Ripens middle of June.

Peach.-Fruit very large, size of a medium peach, roundish, sides compressed, and with a distinct suture ; skin yellow, but deep orange mottled withbrown in the sun; flesh deep yellow, juicy, rich, and delicious. The finest variety in cultivation; stone perforated. Ripens last of June.

Moorparli-Large roundish oval; skin orange, with ruddy cheek; flesh bright orange, free from stone; juicy and of rich luscious flavor; stone perforated. Hardly differs from the preceding, except in being not quite so large and a little later. Ripens 21st of July. Very productive. 


\section{Castanea, etc-Chestrut and other Nuts.}

There are several kinds of nuts worthy of cultivation by every planter, many of which are ornamental shade trees, besides being valuable for the fruit they yield. For convenience we class them all under one head.

Castanea Tesca.-The Chestnut is a lofty forest tree, and common to both continents. The Spanish Chestnut, or Marron produces a very large, sweet nut, and is propagated by grafting on the common sorts. There are several varieties of this, of which "Marron de Lyon" is the best. It will bear the second year from the graft. Chestnuts are difficult to transplant when taken from the woods. The improved rarieties are much superior to the wild sorts. The Chestnut as a shade tree is very effective in landscape gardening.

Carya Alba. - Shell Bark Hickory. This tree is found in fertile soils all over the Union, producing the common thin shell white hickory nut. The tree is very regular and beautiful for ornamental purposes. There is considerable difference in the size and flavor of different varieties. It is generally propagated by seed. The largest and finest flavored varieties only should be planted.

Carya Olivaforma, or Pecan nut, is still more worthy of cultivation.

Corylus Avellana (Filberts) - are generally raised from layers. They should not be allowed to sucker, but trained to form low heads near the ground, which should be kept tolerably open, and the young shoots shortened back every spring. Of the varieties:

Cosford is a large, oblong, oval nut, with a thin shell and of fine flavor. Prolific.

Frizzled, known by its frizzled husk, nut of medium 
size; oval, compressed, husk, hairy, shell thick; kernel sweet and good. Productive.

Red Filbert, known by the erimson skin of the kernel, medium sized, ovate, thick shelled, sweet agreeable kernel, husk long.

White Filbert.-Like the last, but with a light yellow or white skin. Husk long and tubular, nuts ovate.

Juglaus Regix.-Maderia nut is a fine lofty tree, with a liandsome spreading head, producing the well-known nuts of the shops. It is produced from the seed or by grafting. Likes a rich moist sail.

Juglaus Pracparturiens is similar to the above, but bears when three years old, and is valuable on this account for the garden.

Tuglaus Nigra, or Black Walnut, should also have a place in the grounds as a fine shade-tree as well as for its nuts.

Pistacia Tera (The Pistaco nut).-An ornamental tree, producing agreeable flavored nuts, is much cultivated in Southern Europe. The tree is diœeious, so that to produce, the male and female trees must be planted together. The nuts are oval, the size of the olive, slightly furrowed, with a mild flavored, oily nut. They begin to be produced when the tree is five or six years old. The tree itself grows to the height of fifteen or twenty feet. Nuts of this tree have been distributed in various parts of the Union by the Patent Office, and the tree will be likely to succeed in the low country.

\section{Cerasus Vulgaris-ChenRY.}

The Cherry, it is said, was brought from Asia, by Lucullus, the Roman General; and from Rome, its culture spread over Europe. In cooler latitudes, some of the varieties are quite ornamental on account of their fine foliage and early white blossoms; but it stops growing and 
drops its leaves too early in this climate to be esteemed for this purpose.

The Cherry, in favorable climates, is highly esteemed as a pleasant and refreshing fruit. The rich, luscious flavor of some varieties, and the delicacy and juiciness of others, renders it a very desirable dessert fruit. The tender acid sorts are preserved in sugar or brandy, and are excellent for pies and tarts; dried slowly by artificial heat, with the addition of sugar, the stones being removed; they are excellent for winter use. Cherry gum is very similar to Gum Arabic. The Cherry is a very difficult fruit to bring to perfection in the South, except the common Morello; and even this does not average a really good yield oftener than once in two or three years. It likes a mellow loam, so deeply trenched that it will not suffer from drought, and pretty well enriched. A thin mulching of chip manure or tan bark about the roots, is a beneficial application.

I have been able to obtain an analysis of the fruit and stalk only, which is by Richardson:

CHERRY.

\begin{tabular}{|c|c|c|c|}
\hline & & \\
\hline & Entire Fruit. & Stalk. \\
\hline Potassa, . & & 51.85 & 42.66 \\
\hline oda, . & & 1.12 & 6.17 \\
\hline Lime, & & 7.47 & 22.29 \\
\hline Magnesia, & ${ }^{\circ}$ & 5.46 & 2.71 \\
\hline Sulphuric Acid, & & 5.09 & 2.98 \\
\hline Silicic & & 9.04 & 2.5 ? $-x-1)$ \\
\hline Phosphoric " & & 14.21 & 14.89 \\
\hline Phosph. of Sesquior & xide of & Iron, 3.74 & 2.35 \\
\hline Chloride of Iron, & & $\quad 2.02$ & 2.39 \\
\hline & & $\begin{array}{r}100.00 \\
0.43\end{array}$ & $\begin{array}{r}99.00 \\
2.37\end{array}$ \\
\hline er-centag & • & & 2.57 \\
\hline
\end{tabular}


Cherries are generally badded or grafted on the Mazzard or wild European stock, though the Mahaleb or perfumed cherry stock, is far better here. Our common Morello seems to do better for stocks here, than the Mazzard. If grafted, it must be done very early in the spring, as well as all other stone fruits. Cherry trees must be cut back so low when planted, that they will throw out branches within eight or ten inches of the soil, in order to shade the roots and trunk; then keep them shortened-in, like the peach. Without this mode of training, it is useless for us to plant the finer varieties, as the sun will kill them by scorching the bark. 'They should be planted in a cool situation, as the north side of a building, or on any northern exposure, where they will be screened from the mid-day sun, as the young fruit is liable to blight from heat, as well as the tree to be injured.

If caterpillars, or insects of any kind attack the foliage, they must be exterminated by some of the modes given under the head of insects. The bug is best destroyed by throwing ashes or lime up among the leaves, or syringing with soap and tobaceo.

After the cherry arrives at maturity, the finer kinds are generally stolen by the birls, against which, powder and shot is the most effectual remedy. Dwarf trees may be protected by nets.

It is not probable that the cherry will be very successfinlly cultivated in the South, until we have varieties raised here from seed, that are adapted to our wants. Cherry seed should be planted immediately, because if they become dry, they seldom grow.

Of the rarieties described below, the Elton, May Duke, and common Morello, have borne fine crops here. The Kientish, Late Kentish, Belle Magnifique, Reine Hortenso, and English Morello, will probably prove as hardy as 
the common Morello; while Downer's Late, Kirtland's Mary, Gov. Wood and Rockport Bigarrean, are American seedlings, and with the Black Heart, are likely to succeed as well as the Elton. Time of ripening can be given only of the Elton and May Duke. The Duke and Morello cherries are the hardiest in our climate.

Iny Dute.-Fruit, roundish, medial size and in clusters; skin lively red at first, dark red when ripe. Flesh, reddish, tender, melting, very juicy, rich and excellent when fully ripe. Ripens early in May. 'The best for this climate.

Doctor.-A heart cherry, small, roundish, heart-shape, distinct suture, bright yellow and red blended and mottled. Flesh, white, tender and juicy, with a sweet delightful flavor. Worthy of trial here.

Rocliport Bigarrean.-Very large, heart-shaped; color, deep red on amber ground; flesh, yellowish, fine, juicy, with a sweet, rich flavor.

Elton.-Very large; acute, heart-shaped; skin, thin, pale yellow, with a cheek mottled with bright red; stalk, long and slender; flesh, firm at first, becoming tender, juicy, with a rich, luscious flavor. Has produced good crops here, in a northern exposure, the past two seasons (1852-3). Ripens May 10th to 20th.

Kentish.-Fruit, small to medium, round, a little flattened, borne in pairs; skin, fine bright red, growing dark when fully ripe; stalk, one and a fourth inches long, stoutly set in pretty deep hollow; flesh, melting, juicy and of a rich, acid, sprightly flavor. A hardy sort and excellent for conking, \&c.

Late Tentish.-Resembles the above, but is two weeks later, a little larger and excellent for cooking, preserving, and drying.

Irirtland's Mary.-Very large, roundish heart-shaped, 
light and dark red marbled on a yellow ground; stalk, moderate size; flesh, light yellow, half tender, rich, juicy, with a sweet, high flavor.

Black Heart.-Large, heart-shaped; skin, glossy, dark purple, changing to black when ripe; stalk, one inch and a half long, in a moderate cavity; flesh, half tender, becoming, when ripe, tender and juicy, with a rich, sweet flavor. A large, hardy tree.

Downer's Late.-Fruit medium, roundish, heart-shaped, inclining to oval; skin smooth, of a soft but lively red, mottled with amber in the shade; stalk in a slight depression; fruit borne thickly in clusters; flesh tender, melting, with a sweet, luscious flavor. Tree grows well with me; has not borne yet.

Bell Magnifique.-A large, red cherry, rather acid, tender, juicy, and rich; fine for cooking and for the table, when fully ripe. Tree of slow growth, but bears profusely.

Reine Hortense.-A new, French cherry, of great excellence; large, bright red, tender, juicy, nearly sweet, and delicious; tree vigorous; bears well. IIas fruited since the above was written. Excellent.

English Morello.-Tolerably large, roundish, nearly black; flesh reddish purple, tender, juicy, of a pleasant sub-acid flavor. (The common Morello of this country is a smaller and inferior variety of the foregoing. Ripens May 25th.)

Plumstone MLorello.-Large, dark red, rich, and fine; the best of all the Morellos. Tree of slender, slow growth.

Most of the above have fiuited at Pomaria, S. C., and have proved excellent. See Southern Agriculturist, May, 1853. 


\section{Citrus-The Orange Family.}

\section{Citrus Aurantium-The Orange.}

The orange is a native of Asia. The rich, golden fruit displayed among its dark, evergreen foliage, renders it the most beautiful of fruit trees. The tree usually rises twenty-five or thirty feet, with a round, symmetrical head, the bark of the trunk being an ashy gray, while that of the twigs is a soft green. The leaves are of a fine, healthy, shining; green; its blossoms are delicately fragrant, with an aroma that never satiates or offends; and as the tree is in all stages of bearing at one and the same time in flower and in golden fruit, nothing can surpass an orange grove in the combination of attractions.

IVild or bitter oranges are found in the various parts of Florida, as far north as $28^{\circ}$. Where they are found, a gond soil is indicated. It may have originated from the Seville orange, introduced by the Spaniards. The orange is considerably cultivated in Florida, and somewhat on the sea-coast of Carolina and Georgia.

It has been analyzed by Rowny and How. Like other fruit trees, it requires a soil well supplied with lime, potash, and the phosphates.

\begin{tabular}{|c|c|c|c|c|c|}
\hline Potassa, . & $\begin{array}{r}\text { воот. } \\
15.43\end{array}$ & $\begin{array}{r}\text { STEMr. } \\
11.69\end{array}$ & $\begin{array}{l}\text { LEAVES. } \\
16.51\end{array}$ & $\begin{array}{r}\text { FRUIT. } \\
36.42\end{array}$ & $\begin{array}{r}\text { SERD. } \\
40.28\end{array}$ \\
\hline Soda,. & 4.52 & 3.07 & 1.68 & 11.42 & \\
\hline Lime, . & 49.89 & 55.13 & 56.38 & 24.52 & 18. \\
\hline Magnesia, . & 6.91 & 6.34 & 5.72 & 8.06 & \\
\hline Sesquioxide of Iron, & 1.02 & 0.57 & 0.52 & 0.46 & \\
\hline Sulphuric Acid, & $5.7 \mathrm{~S}$ & 4.64 & 4.43 & 3.74 & 5. \\
\hline Silicic Acid, & 1.75 & 1.22 & 4.83 & 0.44 & 1. \\
\hline Phosphoric Acid, & 13.47 & 17.09 & 3.27 & 11.07 & 23. \\
\hline Chloride of Sodium: & $1.1 \mathrm{~S}$ & 0.25 & 6.66 & 3.87 & \\
\hline
\end{tabular}

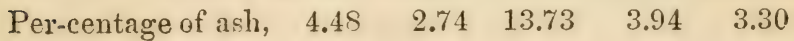


The orange seems to demand a calcareous soil. Lime would, doubtless, prove a beneficial application in most localities.

The best soil for the orange is a deep, fertile loam. The seeds of the wild orange give the hardiest stock. They should be sown early in spring, and may be budded the same season, or early in the next. They may also be whip-grafted in the spring, just before the time the sap comes into brisk motion. The hardiest kinds should be selected for open air culture.

The scale insect (Coccus Hisperidum) and others have, of late years, proved a formidable enemy to the extended culture of the orange. The female insects, in spring, are found in a lifeless state, from which the eggs being hatched by the warmth of the season, the young insects crawl forth, puncturing the tender shoots and leaves, and sucking their sap; they gradually increase in size, and in about eight days permanently attach themselves to the trunk and branches to undergo their transformations. During the summer, all the young leares and branches become rapidly and successively covered with the scales of these insects, of which there are successive generations during the season. In the green-house, this insect is kept down by a strong tobaceo wash, heated to the temperature of 100 degrees Fahrenheit, and applied to the whole affected surface. The warm liquid irritates the insect, so that it looses its hold, permitting the fluid to enter between it and the bark, by which means it is destroyed. Applied at ordinary temperatures, tobacco water has no effect.* To be of much benefit, the application must be universal.

Varieties.-There are about forty sorts of oranges cultivated, of two principal classes, viz., the Sucet or China Orange, and the Bitter, Seville or Wild Orange. The latter

Burst. 
class is much the most hardy, but is of no value as a dessert fruit. They are used in cooking, and for flavoring liquors.

Of the Sweet Oranges, the Maltese has a thick and spongy rind, pulp red and delicious, but with sometimes a trace of bitterness. The glands which secrete the oil are prominent.

St. Michael's.-Small, with thin smooth rind, and small glands; pulp, light colored and, of a luscious, sugary taste; often seedless. The most delicious of all oranges.

Mandarin is a small flattened fruit, with a thin rind parting freely from the pulp, frequently separating of itself ; pulp, dark orange, juicy and rich.

The Harana, or common sweet orange, is a well known fruit, of good size, and moderately rough rind; pulp well filled with delicious juice.

The St. Augustine Oranges, are a large variety of the Havana, much better than those brought from Cuba.

Bergamot.-Has small flowers and pear-shaped fruit. The leaves, fruit, and flowers are all very fragrant, and much used by perfumers.

The following varieties of the orange tribe are cultivated in the same manner.

Citrus Limonum (The Lemon).-Is cultivated like the orange, but has longer, lighter, colored leaves, with naked footstalks; flowers tinged with red, externally; fruit, pale yellow, oblong, with a swollen point, and an acid pulp. Used mostly for flavoring and preparing lemonade, and other cooling drinks.

Citrus Limetla (The Lime).-Has smaller flowers than the lemon, which are white, and small, roundish, pale yellow fruit, with a slight protuberance at the end. The fruit is acid, and used for the same purposes as the lemon. The green fruit makes a delicate preserve. 


\section{Medica (The Citron), has large, oblong, wingless} leaves, and flowers tinged with purple without. The fruit is lemon-shaped, but larger, with warts and furrows. Rind, thick and fragrant; pulp, sub-acid. Chiefly used for preserves.

C. Decumana, or Shaddock, has leaves winged like the orange; flowers, white; fruit, globular and very large, weighing often six or eight pounds; rind very thick; pulp, sweetish or sub-acid, but not very desirable, except for its showy appearance.

\section{Cydonia Communis-QuineE.}

The quince is a small hardy tree, seldom growing over twelve or fifteen feet high, thickly branched, with roundish or ovate leaves, whitish underneath, on short petioles; the flowers which open late are white, or pale pink; and the fruit appears on shoots of the same years growth, varying in shape, but having a general resemblance to the apple and pear. It is when ripe, highly fragrant, and of a fine golden yellow, making the tree quite ornamental.

Quinces are seldom eaten raw ; but for stewing, preserving, marmalades, or in pies and tarts along with apples, they are much esteemed. They are, also dried for winter use, giving an excellent flavor to dried apples and peaches. For these purposes the quince has been long in cultivation, having been in great esteem by the Greeks and Romans. The mucilage from the seeds was formerly used in medicine, instead of gum-water. The juice is cooling, astringent and stomachic.

The quince is propagated from seed, layers, slips, or cuttings. The latter planted in autumn, in a shady situation, very seldom fail, and are not as liable to throw out suckers as those raised from suckers and slips. Quinces generally produce the same from seed, but occasionally vary. 
Quince stocks are very much used for budding and grafting the pear, for which the Angers Quince is preferable, being easily raised from cuttings or layers. The other kinds are of less vigorous growth, and more shortlived. I have not been able to find an analysis of the quince. A large amount of soda and chlorine, will probably be the chief difference between it and those of the apple and pear.

The quince likes a deep, light, moist soil, and a cool exposure, growing naturally on the banks of streams. It will, howerer, succeed in a rich, deep, dry soil; trenching will afford a due supply of moisture. No tree is more benefited by manuring, especially with regetable matters. Salt is a very beneficial application every winter-ministering to the growth of the tree directly, and by keeping the soil always moist. If applied occasionally during the summer, in small doses, at a distance from the stem, the fruit will not drop. It will bear an application annually of ton bushels per acre. Plant the trees ten feet apart.

The quince is slightly subject to the blight, like the pear and apple, and is also attacked by the borer, which infests the apple; the blighted branches must be cut off and burned as with the pear. The borer must be dug out as directed under the head of Insects.

In training, the best fruit is obtained from those trained in tree form; but on account of the borer, it is best to use the bush form, with three or four main stems (not more), so if one is destroyed, there are others left to take its place. Thus trained, the bush should be pruned moderatcly open, or the fruit will be inferior. If there is an over-crop, the fruit must be thinned. Trees will commence bearing in two or three years.

Tarieties.-Apple-shaped, or Orange. This is the common variety, with large roundish, or apple-shaped fruit, 
with a short neck; skin light, golden yellow; flesh firm, but stewing tender; leaves oval, shoots slender. It bears abundantly. Earlier than the other sorts.

Pear-shaped.-Fruit of larger size, pyriform; oblong, tapering to the stalk; skin, yellow; flesh of firmer texture, when preserved, and not quite so good in flavor and color as the foregoing; fruit ripens a fortnight later, and when picked, keeps much longer; leaves, oblong, ovate. Tree of more vigorous growth, but does not bear so well.

Portugal (Cyilonia lusitanica). - Fruit still more oblong, of lighter color, milder flavor, and better quality than the preceding kinds; leaf, larger and broader; shoots stouter; ripens between the other two; a shy bearer. Pretty good as a stock for the pear. Tree larger than the other varieties.

Angers.-A variety of the last, the strongest grower of all the quinces, and best for pear stocks. The fruit is said to be larger and better than any other kind.

The Chinese and Japan quinces are fine ornamental shrubs.

\section{Ficus Carica-Fig.}

The fig is a large shrub, or a low spreading tree-some varieties growing to the height of twenty-five, or thirty feet, in favorable circumstances ; but it does not generally reach over half this height. 'The leaves are large, cordate, and deeply cut, from three to five lobed, thick, and pubescent beneath. The blossoms are not apparent, but concealed in the inside of the fleshy receptacle that becomes the fruit; which consists of a pulp, containing numerous pericarps enclosed in a rind, various colored in the different varieties. Though the flavor at first is too sweet and luscious for most unaccustomed tastes, it soon becomes a great favorite, and is perhaps the most wholesome and nutritious of all fruits. 
The fig is a native of Asia and Africa, and has been cultivated from the earliest times. It is perfectly at home in all the low country and middle portions of the South, and as universally cultivated below the mountain section as the peach itself.

Large quantities of dried figs are imported into the United States, and even sold in our midst. These at a very little expense could be put up at home and exported at a profit. A good way to dry them, is to gather them dead ripe; when dry, boil them in a preserving kettle in a syrup of nice sugar, about five minutes. Take then out, drain them dry in a brick oven, after the bread is withdrawn, or in a kiln made for drying fruits; when dry, they can be put away in drums or boxes.

Imported figs are dipped in a hot lye made of fig ashes, and dried on hurdles in the sum. When sun-dried here, they are apt to be infested with insects. The fig is worth culture for feeding fowls, pigs, \&c.

The fig is readily propagated by cuttings either of the shoots or roots, planted in the fall or spring. Suckers also can be taken off the old plants, or layers made. Cuttings should be eight or ten inches long, and include half an inch of old wood at the base of each. Planted in hot beds in January, they will form handsome plants the same season.

Figs should be set out twelve or fifteen feet apart, and the winter after planting, they may be cut nearly to the ground. The next year, they will throw up vigorous shoots, of which one or more may be retained, and the rest rubbed off. The Celestial Fig is best trained as a low tree.

Analysis.-The following analysis of the ashes of the fruit of the fig is by Richardson. I have met with none of the tree itself :- 


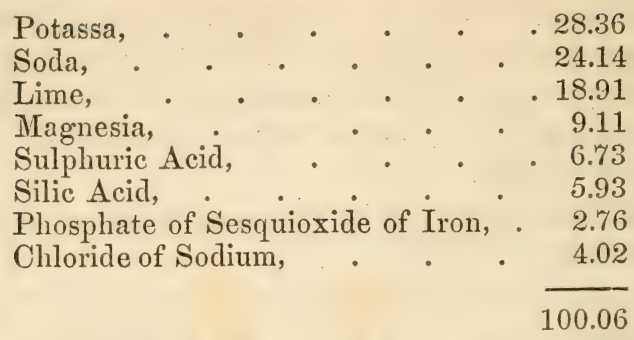

The best soil for the fig is a mellow loam, of a calcareous nature. Ashes, marl, or composts, prepared with mild lime, form the best manure. If the soil is too moist, the fig continues its growth too late in the season, when the new wood is killed by the frost. While young, it is best to protect the tree during winter with evergreens. I have found young trees will mature their fruit and wood much more perfectly, and better endure the winter, if the young shoots are broken off at the tips, and if all fruit forming after that is removed, and no more growth permitted, after the middle of September. As a general rule, however, with the fig, "the more you prune, the less your crop." This, however, does not apply to root pruning'. If from too rank growth of wood the tree drops its fruit, cut off all the roots that project more than half the length of the branches at any time during the winter. Root pruning can also be applied with success to the pear or any other fruit tree, rendered unfruitful by too luxuriant growth of wood.

The nomenclature of figs is still very uncertain, few being described with minuteness and accuracy. The names of several of our common varieties do not appear in the books; or they are there so imperfectly described, that we do not recognise them.

Brunswick.-Fruit very large, long, pyriform, with an oblique apex; eye depressed; stalk short and thick; 
skin pale green, tinged with yellow in the shade; dull, brownish red in the sun, sprinkled with pale brown specks; flesh reddish brown, pinkish at the centre, semi-transparent, rich, sweet, and high-flavored. If I have the true variety, the leaves are deeply eut, and generally sevenlobed. Wood of strong growth; very hardy; indispensable.

Brown Turkey.-Fruit large, oblong or pyriform; skin dark brown, covered with a thick blue bloom; flesh red and delicious; said to be very hardy and prolific. May be our common blue variety. My tree, procured under this name, proves to be the Brunswick.

Broun Ischia - Fruit medium or large, roundish, obovate; skin chestnut brown; flesh purple, sweet and excellent; five lobed, leaves broad.

Small Broun Ischia.-Fruit small, pyriform, with a short footstalk; skin light brown; flesh inclining to purple; highflavored; leaves less divided than the other sorts. This and the Brown Turkey are generally considered the hardiest varieties.

Black Genoa.-Fruit large, long, obovate, tapering to the stalk, which is slender; skin almost black, glossy, covered with purple bloom; pulp bright red, of excellent flavor. Continuing to bear fruit abundantly until frost. Leaflets narrow, and leaf seven-lobed like the Brunswick. Indispensable.

Celestial.-Fruit quite small, pyriform; stalk slender; skin very thin, dark-colored, covered with purple bloom; pulp light red, and of very delicious flavor. In dry weather, it hangs on the tree until it shrivels, improring in sweetness and flavor. Trees grow quite large, and are very productive, yielding constantly from July to October. Leaves five-lobed. May prove the Malta of Downing and others. As hardy as any variety cultivated, and probably the best. 
The Common Blue is rather inferior in flavor to the foregoing; but it is very hardy and productive. Fruit larg'e, oblong, bluish purple; early, and produces two crops.

WHITE, YELLOW, OR GREEN

Round White, Common White, Lemon Fig. (Figure Blanche Rondo.)-Fruit turbinate, flattened; stalk short; skin pale, yellowish green; flesh white and sweet, not high-flavored. Ripens quite early; is a good bearèr. Its color renders it very valuable for preserves.

White Genoa (White Italian).-Fruit large, globular, a little lengthened to the stalk; skin thin, yellowish when ripe; pulp light red, and of sweet, delicious flavor. If protected, the fruit is the first to ripen. A good bearer here. Indispensable.

Nerii.-Fruit small, roundish, obovate; skin light, greenish yellow; pulp red, slightly acid, delicate, and rich. Has borne here some years, and is a very nice little fig.

Pregussatta.-This is really a colored fig; but being omitted in its place, I will describe it here, where it is usually but incorrectly placed. Fruit medium, roundish, flattened; skin purplish brown in the shade, dark brown in the sun; pulp deep red, high-flavored, and luscious.

Alicante. - A very large and delicious purple fig, bearing early in the season abundantly, until frost, in the low country, but not suited to this latitude, as it is more tender than those described.

Black: Ischia and White Ischia are said to be good. The above list I know are. The White Marsailles, Gentile, and Yellow Ischia are worthless; the first from inferior fruit-the others are poor bearers.

\section{Fragaria (of Species)-STrRAwberRy.}

The strawberry is a well known small, creeping plant, with perennial roots, and generally ternate leaves. Its 
botanical name is derived from the delightful fragrance of the ripe fruit. Its common name, strawberry, has arisen from the ancient practice of laying straw between the roots to keep the ground moist, and the fruit clean. This fruit is fragrant, delicious, and universally esteemed. The first offering of the season in the way of ripe fruit, nothing: that comes after can excel "a dish of ripe strawberries smothered in cream," or eaten fresh from the plant. It is, indeed, the most popular and wholesome of all the small fruits consisting of matter almost entirely soluble in the stomach, and neither there, nor when rotting in heaps, does it undergo the acetous fermentation. Hence, it is very wholesome, and may be safely eaten by gouty and rhenmatic persons. Besides its grateful flaror, the subacid juice has a cooling quality, peculiarly acceptable in summer. When taken in even large quantities, there are few constitutions with which they disagree; and, indeed, they are positively salutary in cases of the gout and stone. They promote perspiration, and also remove the tartareous incrustation of the tecth. In addition to its excellence for the dessert, it is a favorite fruit for making jams, ices, jellies, and preserves.

The English Wood strawberry was the first brought into cultivation. Says old Tusser:--

"Wife, into the garden and set me a plot With strawberry plants the best to be got, Such growing abroad amid trees of the wood, Well chosen and picked, prove excellent good."

'Turning over its cultivation to the ladies, as beneath his attention.

The best varieties now cultivated have originated from the Scarlets and Pines, which are natives of America. Plants taken directly from the field into the garden rield 
at once a tolerable crop. This climate is well adapted to the culture of this fruit ; since by giving the plants a due supply of moisture, fruit can be gathered the greater part of the year. The great strawberry market of the world is Cincinnati, where over five thousand bushels have leen sold in one season. But Mr. Peabody, of Columbus, in this State, is probably the most successful of strawberry growers, having fruit in the open ground sometimes nine months in the year.

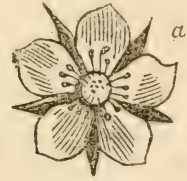

$a$, stamisate.

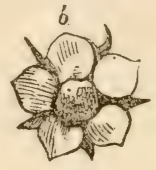

$b$, Pistiluate.

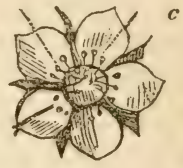

.c, HERMAPHRODITE.

In its natural state, the strawberry generally produces perfect or hermaphrodite blossoms. The hermaphrocite are those which have both the stamens perfect, and the pistils so well developed, as to produce a tolerably fair crop of fruit. Cultivation has so affected the strawberry, in this respect, that there are now three classes of varieties :-1st. Those in which the male or staminate organs are always perfect, like $a$, in the figure; but the female or pistillate organs are so defective, that they will very rarely bear a perfect fruit. These are called staminate. $2 d$. Those in which the female or pistillate organs are perfect, (see $b$, in figure,) but in which the male organs are generally so defective that they cannot produce fruit at all, unless in the neighborhood of, and fertilized by staminate or hermaphrodite plants. Impregnated by these, they bear enormous crops. These are pistillate. 3d. (See figure c.) Those, like the native varieties, which are true hermaphrodites, that is, they are perfect in stamens, and more 
or less perfect in pistils, so that they gencrally produce a tolerable crop, and in favorable seasons, the pistils being fully developed, they will produce a good one. 'This is the staminate class of the boclis. The first of these classes, the staminate, rarely producing fruit, and ruming exuberantly to vine, should be dug up wherever they are found, since the hermaphrodite are productive, and equally useful for fertilizing. It is to the pistillate varieties, fertilized by the hermaphrodite, that we must look for large crops of fruit.

In beds of each of these varieties, seedlings will spring up, differing from the parents; but runners from any variety, will always produce flowers of the same class, and similar in all respects to the parent plant. By the due admixture of hermaphrodite and pistillate plants, five thousand quarts have been picked from an acre at Cincinnati, where the strawberry season is usually less than a month.

Analysis.-'The strawberry has been analyzed by Richardson :-

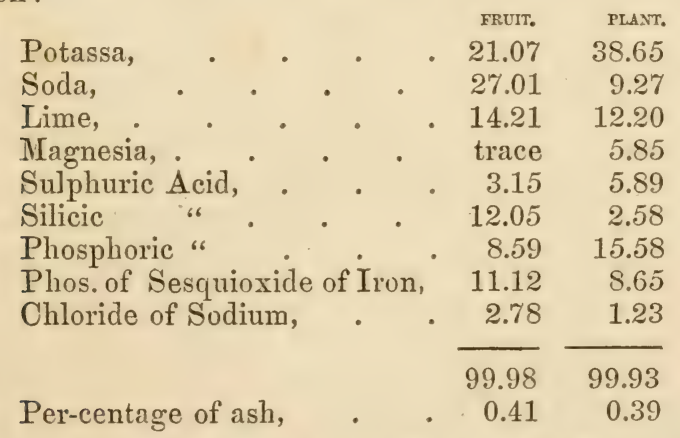

Potash, soda, and phosphoric acid are the elements most likely to be wanting. Wood ashes and the carbonates of potash and soda, prove very beneficial applications. The 
good effects of applying the phosphates or lime, has not been so apparent, perhaps, owing to there being enough already in the soil.

Propagation and Culture.-To raise the strawberry in perfection, requires good varieties, a proper location, careful cultivation, regetable manure, mulching the roots, and regular watering.

We shall notice the varieties hereafter. The strawberry bed should be situated in the lowest part of the garden, succeeding best on a bottom near some little stream of water, where the soil is moist and cool. No trees or plants should be allowed to overshadow it, to drink up the moisture of the soil. New land is the best and the most easily kept free from weeds. The soil should be dug at least two spades deep, to enable the plants better to withstand drought. It is not required to be rich, unless with decayed vegetable matter, as animal manures produce only a growth of vine.

If the soil is poor, give it a thick coat of swamp muck; or wood's earth, and leached or unleached ashes, which must be turned under. After the soil is prepared and levelled, mark oif your rows two feet apart. Plant thereon, selecting the young, healthy runners from old stocks, three rows of pistillates, then a path, then a row of a good hermaphrodites, another path, and then six rows of pistillates, and so on until the ground is planted. Let the plants be fifteen or eighteen inches asunder. Choose damp weather for the operation of transplanting. The roots of the plant must be well spread out just as they grow; when transplanted, set them firmly and wash them in with water like sweet potato slips, if the ground is not moist. Cover the space between the plants, but not the plants themselves, with a thin mulching of partially decomposed leaves, straw, or decayed tan-the latter is ex- 
cellent. As the runners appear, unless desired to make new beds, they should be cut off-not pulled, which disturbs the roots. As soon as the blossoms begin to appear, the great necessity is water. Unless it rains twice a week, give water by hand, water to swell the fruit, and water to form new fruit stems. In this way, Mr. Peabody has crops of Hovey's Seedling, from March until hard frosts. Kill all grass and weeds as fast as they appear, with the hoe. After the plants have done fruiting, let the beds remain until winter, when they should be well hoed, thinned out to twelve or eighteen inches in the row, the cut-up vines dug in, and a new coat of leaves, straw, muck or decayed tan given the whole bed, except the crowns of the plants. Keep the proportion of male and female plants, the same as when planted. A very easy way to get a good spring crop is by cultivating in altemate strips. Prepare your soil as before, strike out the rows three feet apart, and plant eighteen inches apart in the row, giving a due proportion of the different sexes as before; let these rumners fill up every alternate section of three feet, keeping the other bare, by destroying all rumers, and the whole patch free from weeds. The strips of rumers will give a heavy crop of fruit, and the open

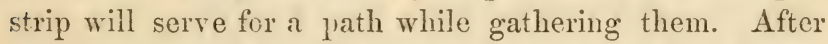
the fruit season is orer, dig and prepare this alley for the occupation of new runners for the next crop; dig in plenty of decayed tan, swamp-earth, or leaf-mould, trench two spades deep. The runners from adjacent vines will soon cover this strip. 'The plants will need thinning in order to be erenly distributed. When the strips are well covered, which they will be by August, dig under the old plants, and add a light coat of manure. Here a crop of turnips or spinach may be raised and removed before the next fruit season. By thus changing each season the 
strips occupied by the plants, the same plot of ground will remain productive many years. To produce superior crops, in this mode as well as the former, liberal watering is required.

VARIETIES.-As the season of this fruit, with the exception of Large Early Scarlet and Hovey's Seedling, is very short, but few varieties are required. Having tried Hovey's Seedling, Boston Pine, Hudson, Burr's New Pine, Moyamensing, Rival Hudson, Black Prince, Cuthill's Black Prince, Bishop's Orange, Longworth's Prolific, British Queen, McAroy's Superior, Walker's Seedling, Buist's Prize, English Red, White Wood, and several others. Of these I have selected for my own grounds the following rarieties, as decidedly the most desirable:-

Large Early Scarlet.-An American variety. Frnit pretty large, roundish, ovate, regular, light scarlet, seeds decply imbedded; flesh tender, and of a rich excellent flavor, leaves broad, deep green, flowers large and perfect. The most valuable Hermaphrodite variety. It will stand dry weather better than most varieties; bears well; in a bed of pistillates it is easily distinguished by its foliage.

Bishop's Orange. - Fruit light scarlet, somewhat ap. proaching orange, of large size; shape conical, regular, borne in large clusters lying on the surface; flesh firm and of high flavor. A fine bearer and a favorite with me, requires but little care. In flavor, excellent; flowers pistillate.

Horey's Seedling. - When we consider the size, flavor, and its habit of long-continued bearing where well cultivated, this is the finest of strawberries. Like all the pistillate varieties, it needs a fertilizer. It is the best market strawberry known, and when fully ripened, it is excelled in flavor by few varieties. Leaves large, bright green, foot-stalks long and erect; fruit very large, round- 
ish, oval or slightly conical, deep shining scarlet, seeds slightly imbedded; flesh firm, with a rich agreeable flavor, nearly equal to Bishop's Orange. Pistillate, originated by C. M. Hovey, of Boston.

Burr's New Pine. - Large light orange scarlet, always of the highest and most delicious flavor. With me it often shows fruit most of the season; but so far it is not sufficiently productive, and it lacks the hardiness of the foregoing varieties. Plants seem to be easily killed by extremes of heat or cold. The hardiness and productiveness of Hovey's Seedling would render this the most desirable of strawberries. Needs further trial.

IIcAroy's Superior. - This won a prize of $\$ 100$ at Cincinnati, as the best pistillate variety for size, flaror, and fruitfulness. Leaf dark green, serrate; foot-stalk long, trusses of fruit, full; berry large of rich dark color, irregular, roundish conical, seeds large slightly sunk; flesh crimson and white, tender and juicy, core of rather open, coarse texture, too soft for market. With me not as desirable as Hovey or Mroyamensing.

Mloyamensing.-Fruit rather large, roundish, conical, deep crimson; seeds crimson set in rather deep depressions, with rounded intervals; flesh red, flower very fine, quality "best," pistillate; leaf large with creuate serratures. This is first rate with me in every respect, a capital market fruit from its firm texture.

Of these the first, second, third, and sixth, are mast desirable. Walker's Seedling, a staminate variety, promises well. McAvoy's Extra Red will probably prove a good market fruit. Boston Pine occasionally bears well, and is of excellent quality. Crescent Seedling proves here nothing remarkable. Longworth's Prolific I have tried but one season, when it did not do very well, but may prove a good sort. 


\section{Morus-MulberRy.}

This genus includes two species worthy of cultivation on account of their fruit, both hardy deciduous trees, ripening their berries in May, with the later strawberries. The fruit is of very agreeable flavor, and of abundant subacid juice. It is cooling, laxative, and wholesome for, like the strawberry, it does not undergo the acetous fermentation. An agreeable wine may be made of the juice.

All the species of the mulberry are of the easiest culture, and are generally propagated by cuttings of the branches or roots. The former should be shoots of the last season, having one joint of old wood; they may be three feet long, and buried half their depth in the soil. The tree requires little or no pruning. The soil should be a rich, deep, sandy loam. The fruit falls when ripe, hence, when the tree commences bearing, the surface below should be kept in short turf, that the fruit may be pickled from the clean grass. The black mulberry, morus nigra, is a native of Persia, and is a slow-growing, low-branehed tree, with large, tough leaves, often five-lobed, producing large and delicious fruit, fiequently an inch and a half long, and an inch across; black and fine-flavored. Tree a very poor grower.

Morts Ruba.-Is a native of our woods; leaves large, rough, and generally heart-shaped; fruit an inch long, sweet and pleasant, but much inferior to the last. The vigorous growth and fine spreading head of this species, makes it deserving of culture as an ornamental tree. If the eherry is planted near the house, and the mulberry a little more remote, the latter will often attract the birds from the more valuable fruit. There is an everbearing variety of this, very desirable for affording a succession of fruit until frost. Mr. Charles Downing has also another variety, said to be nearly equal to the black in flavor. 
The varieties of the white mulberry produce fruit of no value, and are only cultivated for the silk worm.

\section{Olea Europea-OLIVE.}

The olive is a low, branching evergreen tree, rising to the height of twenty or thirty feet, with stiff, narrow, bluish-green leares. The fruit is a berried drupe, of oblong, spheroidal form; hard, thick flesh, of a yellowishgreen color, turning black when ripe. The tree is a native of Greece and the sea-coast ridges of Asia and Africa; it has been cultivated from time immemorial for the oil expressed from its ripe fruit. Where cultivated, it answers all the purposes of cream and butter, and enters into every kind of cookery. Unripe olives are much used as pickles, which, though distasteful at first, to most persons, become by custom exceedingly grateful, promoting digestion and increasing appetite. The ripe olive is crushed to a paste, when the oil is expressed through coarse, hempen bags into hot water, from which the pure oil is skimmed off. If the stone is crushed, the oil is inferior.

Muller has analysed the various parts of the olive tree:

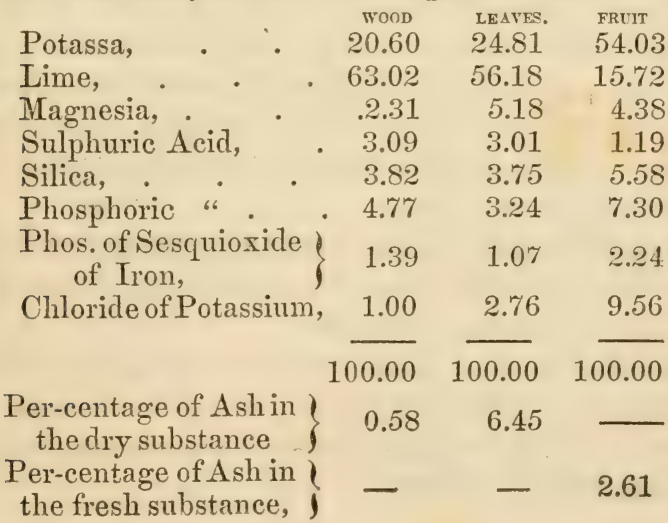


Lime and potash are the chicf sorts the olive requires in the soil.

Propagation und Culture.-Olive plantations are generally formed from the rooted suckers which rise abundantly from the roots of old trees. It also grows readily from cuttings and seeds. Knots and tumors form on the bark of the trunk, which, being removed with a knife, are planted like bulbs, an inch or two deep, when they take root and become new trees. The cultivated olive may, perhaps, also be grafted on our Olea Americana, or Deril Wool, which abounds on the seacoast. The best trees are from seedlings, which commence bearing in five or six years, but are not remunerative until ten or twelve years old. The trees produce about fifteen or twenty pounds of oil per year, and their longevity is greater than any other fiuit tree. 'The olive is hardier than the orange, but is most hardy and prolific when grown on a dry calcareous sandy or rocky situation. Such situations on the steep cliff's of the Mediterranean, planted with olives in the dry crevices of the rock, afford abundant and prolific crops. It grows more luxuriantly in strong, rich, clayey loam; but in such situations will not endure so great an extreme of cold. The dry limestone soils of Florida would probably become exceedingly valuable if planted with the olive. It should be tried wherever the orange will survive the winter. In planting, the trees are usually set thirty-five or forty feet apart.

VArieties.-Of the many varieties of the catalogues, the following are described in the French "Bon Jardinier," as the hardiest and best.

Olea Angulosa.-A hardy variety with scanty foliage; fruit reddish, with a long stem. It is preserved in some places. "Oil of medium quality," says Gouan, but very good according to others. 
Olea Amygdalina.-The variety most commonly cultivater. Fruit almond-shaped; it is often pickled. Its oil is very sweet.

Olea Cranimorpha, or Weeping Olize.-The largest and finest tree of the genera; branches bending towards the earth; very productive; fruit small, crooked, pointed, very black; stone sharp at both ends; excellent; oil pure and abundant.

Olea Spharic7.-Fruit more round than any other rariety. Oil delicate, and yield abundart.

Olea Oblonga (from Olirier Picaline).-Fruit best for pickling; oil fine and sweet; produced abindantly. Tree hardy.

\section{Prunus Domestica, etc.-Plun.}

The plum-tree is probably a native of Asia, whence it was early introduced into European gardens. The tree grows some fifteen feet high or more, and is conspicuous early in spring, with its white blossoms. London asserte, that it is probable that the natural color of the fruit is black; but the cultirated rarieties are of the rarious shades of green, yellow, red, and bluc. It is a delicious dessert fruit in its best varieties, and is very much esteemed for pies, tarts, and preserves. It is also dried for winter use. The prune or dried plum, enters considerably into commerce. When fully ripe; and the plum should always be allowed to become perfectly matured before eating; they are, in moderate quantity, very nutritious and wholesome; but in an unripe state, are more apt to disagree with the stomach than most other fruits, producing cholic, diarrhoa, and cholera morbus. Medicinally, they are emollient, cooling, and laxative; and, especially in the case of French prunes, are useful for persons of costive habits.

Prunes are generally dried by artificial heat. They are 
laid singly, without touching each other, on plates which are placed in ovens after the bread is remored, or in kilns prepared for the purpose, and occasionally moved and turned. In order to have them fair and glossy, they must be suddenly cooled when taken from the oven. If deprived of their skin and stone, they are called prunettes-the stone is pressed out the stem end-the skin is taken out by pouring hot water over them. They should be dried carefully and gradually. They are also excellent when dried with sugar, as directed in the case of peaches.

The following analysis of the plum is by Salisbury :-

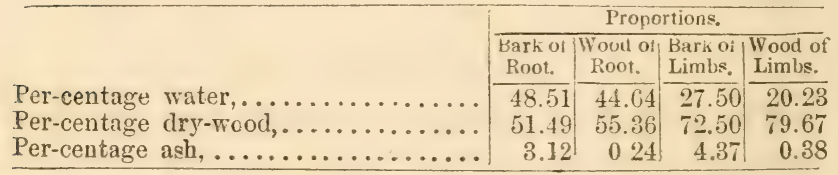

\begin{tabular}{|c|c|c|c|c|c|}
\hline & \multicolumn{5}{|c|}{ Analysis. } \\
\hline & $\begin{array}{l}\text { Plum } \\
\text { Pits * }\end{array}$ & $\begin{array}{l}\text { Bark of } \\
\text { Root. }\end{array}$ & $\begin{array}{l}\text { Wood of } \\
\text { Root. }\end{array}$ & $\begin{array}{l}\text { Bark of } \\
\text { Limbs. }\end{array}$ & $\begin{array}{l}\text { Wood of } \\
\text { Limbs. }\end{array}$ \\
\hline Potash, & 13.92 & $\overline{9.86}$ & & 8.59 & 11.63 \\
\hline & 10.08 & 6.63 & 40.31 & 19.49 & \\
\hline Chloride of Sodium,..... & 2.25 & 4.22 & $0.103 !$ & 1.03 & 0.1 \\
\hline $\begin{array}{l}\text { Sulphuric Acid, . . . . . } \\
\text { Carbonic Acid,....... }\end{array}$ & 6.11 & 5.22 & 4.64 & 4.09 & 20.5 \\
\hline Lime & 23.30 & 22.74 & 0.17 & 39.42 & 8.12 \\
\hline Mag: & 4.80 & 0.98 & 0.20 & 3.76 & 6.56 \\
\hline Perox. of Iron, ? & & 6.90 & 1.20 & 2.30 & 0.60 \\
\hline e of Lime..... & 8.00 & 7.62 & 31.98 & 7.50 & 24.99 \\
\hline (ia,...) & & 3.28 & $17 \cdot 12$ & trace & 1. \\
\hline Orga & 6.65 & 1.76 & 2.50 & 1.40 & 4.60 \\
\hline Silica, . . . . . & 27.20 & 21.40 & 1.80 & 8.40 & 0.70 \\
\hline Coal & .... & 3.60 & 0.90 & .. & 1.60 \\
\hline & 102.31 & 94.21 & $100 . \overline{923}$ & 95.95 & 80.53 \\
\hline
\end{tabular}

The quantity of snda indicates the partiality of this tree for common salt. Like other fruit trees, lime, potash, and the phosphates are the chief special manures required.

- This analysis was made with two grains of ash. 
Although the quantity of silica is large, the plum is decidedly better on a clayey soil. Any soil has sufficient silex to supply the wants of the plant, so far as its clements are concerned; but silex is probably not available, unless ammonia is also present. Burnt clay, swamp muck, common salt, and wood-ashes are among the best fertilizers.

Propigation and Culture.-The plum is generally budded or grafted upon stocks raised from the seed of some free-growing variety. 'The Chickasaw plum, however, makes a very good stock. It should be grafted at the collar, and planted so deeply that the scions can also throw out roots. This stock makes rery pretty dwarf trees for the garden. By this mode the tree can be propagated at any time during the winter months. Stone fruits require to be grafted before or during the first flow of sap. In transplanting to remain, plum trees should be twelve feet apart. The best soil for the plum is a heary loam, moderately rich. In sandy soils the curculio is more prevalent. The fruit, too, is of better quality in a heary soil. In sandy soil clay should be applied to the surface.

There are three obstacles that have to be overcome to raise the plum successfully. The first is the curculio, which infests all smooth-skinned stone-fruit. The only really satisfactory mode of dealing with this insect, is admitting pigs and poultry into the fruit garden. It is better not to raise plums at all, unless measures are taken to destroy this insect; for, if allowed to increase, it will beeome so abundant that the peaches and apples will also be attacked. Another, and quite as serious a difficulty, is the rot. To prevent this, the varieties least subject to decay must be selected and planted with the roots not too deep, and the fruit should be so thinned upon the tree that no two touch each other. The third obstacle to plum culture 
is, happily, not very prevalent in the south. It is a black excrescence or tumor found growing upon the bark and young wood. The bark swells and bursts, and finally assumes the appearance of a "large, irregular lump, with a hard, cracked, uneven surface." 'The flow of sap is obstructed by the tumor, and its poison is gradually disseminated over the whole tree. The dark-colored fruits are mostly infected. The disease also attacks the common Morello cherry. It appeared here, for the first time, in the year 1853 , on a tree from the north. The tumor was very small, and contained a worm within. None have appeared since.

The only remedy is to cut off every branch or twig that shows a tumor and burn it at once. Look orer the trees at least twice a year, and remove and burn every affected branch. If on the large limbs, cut out the tumor deeply, and apply with a brush a solution of chloride of lime.

As the plum is apt to throw out long straggling branches, which are unsightly and mproductive, these should be remedied by pinching, or shortening, so as to form a round handsome head. Most stone fruits require shortening in some degree, after the manner of the peach, or the growth becomes too straggling.

\section{Varieties.-Prunus Chicasa-Chickasaw Plum.}

A tree or two of both the red and yellow varieties of this our indigenous plum, should should be admitted into the garden. The firuit is much enlarged by garden culture. Some trees produce much better fruit than others. Leaves lanceolate, more like the peach than the plumb; branches thorny; fruit small; skin either light, red, or yellow ; flesh yellow, very juicy and sweet; but somewhat astringent about the stone, to which it adheres. Ripe here 20th May; lasts a month. Doubtless many excellent native varieties 
will be originated from this hardy native fruit. Some are now found almost entirely free from astringency. This plum seems free from curculio, and never fails of a crop.

The following are varieties of prunus domestica:-

Ser or Early Purple.-Ripens the 8th of June, and is with us the earliest of cultivated plums. Fruit small, roundish; skin brownish purple, with a scanty light-colored bloom; flesh, greenish yellow, sweet, juicy, and parts freely from the stone; highly perfumed. This nice little plum was, I believe, first introduced here by some grafts received from Germany. Has now borne some years; maturing so early, it is one of the most valuable. I do not find any description in the books with which it coincides. It does not rot.

'Prince's Yellou-Grage.-Fruit, medium size, broadest towards the stalk; suture slight ; skin golden yellow, slightly clouded, and with copious white bloom; stalk an inch long inserted in a small cavity; flesh, deep yellow, sweet, inicy, and fine-flavored; free stone ; tree very productive. The fruit lasts a long time. One of the best for this climate ; ripe, June 10th.

Columbia-Very large, roundish; skin brownish purple, with fawn colored specks; bloom, thick and blue; stalk an inch long, stout, in a narrow cavity; flesh, orange, not very juicy, sugary, rich and excellent; free stone, ripe, June 20th. A nagnificent rariety of excellent quality. Tree hardy and sufficiently productive.

Bingham.-Fruit, large, oval ; skin, deep yellow, spotted with rich red toward the sun; stalk in a small cavity; flesh, yellow, juicy, rich and delicious; clingstone. Tree a fine grower and good bearer. Ripens July 1st.

Elfrey.-Branches small; fruit of less than medium size, oval; skin, blue; flesh, greenish, sweet, juicy and excellent; freestone. In this climate the Elfrey is one 
of the most desirable plums. It generally escapes the curculio and the rot also, if properly thinned. Tree, thrifty and hardy. An indispensable variety. Ripe July 1st.

Imperial Gage.-Fruit, above medium size, oval; suture distinct, pale green, tinged with yellow, and marbled with dark green stripes, and covered with a copious white bloom; stem an inch long, slightly sunk; flesh, greenish, melting, juicy, luscious, and almost too sugary; mostly freestone. Ripens July 1st. Matures gradually for a month-not much injured by curculio; but rots considerably, unless the fruit is well thinned. A good bearer, and a fine hardy tree.

Red Mragnum B:num, or Purple Egrg.-Large and beautiful. Egg-shaped. Violet red, deeper in the sun, with small gray dots; flesh, greenish, rather firm, juicy, and agreeably subacid; freestone. A fair plum for the table, and makes the very best of preserves. Ripens July 10 th. Not much subject to rot. Indispensable.

Blue Plum.-A native plum generally raised from suckers. Fruit, medium size, roundish, scarcely oval; suture very obscure; skin dark blue, with a fine light blue bloom; stalk three-eighths of an inch long, inserted in a shallow cavity; flesh, yellowish green juicy, sweet, and refreshing; adheres to the stone; shoots, smooth ; leaves, rather small. A very pleasant and agreeable plum, and the tree is a fine bearer. Does not rot.

Jefferson.-Fruit, of the largest size, roundish, oval; stalk, an inch long, pretty stout; suture indistinct; skin, golden yellow, purplish red towards the sun, and covered thinly with white bloom; flesh, deep orange, a little dry, good, not equal to the description in the books. But as the tree bears abundantly, and the fruit ripens late, hangs long on the tree, and is totally free from decay, it 
is indispensable. The handsomest of all plums. Ripens last of July or first of August, and lasts a long time.

Besides the above, the St. Catharine, Italian Damask, Bleeker's Gage, and Duane's Purple, do well here, but are not equal to those described. Several varieties have been tried here and rejected. Those who wish a larger collection, can select from the following, viz.: Peach, Hudson's Gage, Imperial Ottoman, Green Gage, Lawrence's Favorite, Red Gage, Purple Gage, Schenectady Catherine, Huling's Superb, Diapreé Rouge, Purple Favorite, Lombard, Coe's Golden Drop, Blue Imperatrice, Madison, Frost Gage, Ickworth Imperatrice and Reine Claude de Bavay-the latter has proved delicious this season (1855), and ripened Sept. 1.

\section{Punica Granatum-Ponegranate.}

The Pomegranate is a low, deciduous tree, rising some twenty feet high, with twiggy branches, armed with small thorns; leaves long, narrow, of a glossy green color with red veins. The flowers are produced at the ends of the branches on the shoots of the same year, coming out either singly or three or four together, and are quite beantiful, especially the double-flowering varieties. The calyx is thick, fleshy, of a fine red color, crowned with petals of a bright scarlet. The fruit is a berry covered with a hard, coriaceous rind, of a deep yellow color, spotted with red and fine deep red next to the sun, beautifully crowned when ripe with the tube of the calyx. It ripens in September or October, remaining on the tree, uninjured, a long time.

The Pomegranate is a native of China and Southern Europe, where it is sometimes used as a hedge plant. The tree is quite ornamental. The fruit has a very refreshing acid pulp; and its singular and beautiful appearance ren- 
ders it a welcome addition to the dessert. It is also used medicinally in fevers, on account of its agreeable cooling. nature; but it is not half as much cultivated as it deserves to be. It might be profitably exported to any extent.

Propagation and Cullure.-This tree is propagated from seeds, layers, suckers or cuttings; also, by budding and grafting. Seeds must be sown as soon as they ripen. Any good soil will do for the pomegranate. It requires little pruning-only taking out some of the weaker shoots, shortening in or pinching those that are overgrown, to make them throw out new fruitful shoots all over the tree.

The only varieties worth cultivating for the fruit are:

1. The swect-fruited pomegranate-Pulp sweet, and juicy.

2. The sub-acid-fruited pomegranate or common variety.

3. The wild or acid-fruited pomegranate, of brisk, acid flavor-is used for making a nice syrup.

\section{Pyrus Communis.-Pear.}

The Pear is often found growing wild in hedges in various parts of Europe, China, and Western Asia. It is a thorny tree with upright branches, tending to the pyramidal form. The wild fruit is exceedingly harsh and astringent; but no fruit whatever, is more deliciously sugary and melting than its best improved varieties. The pear was early brought into cultivation; there were thirty-two varieties in Pliny's time, yet they were " but a heavy meat unless boiled or baked," and it was not before the 17th century that this fruit became really worthy of culture for the dessert. Indeed, within the last fifty years, the majority of the best varieties have originated.

The pear, under favorable circumstances, is a long-lived tree. 'The Endicott Pear tree, still living' in Danvers, 
Mass., was planted by Gov. Endicott, in 1628, or eight years after the landing of the Pilgrims. M. Bose mentions trees in Europe, which are known to be 400 years old. Eren in this State, trees that were in full bearing thirty-seven years ago, are still healthy, vigorous, and productive.

It will endure, in suitable soils, greater extremes of heat than the apple, succeeding well in latitudes too warm for the latter food to flourish. It is better adapted to our climate than the apple, while in cold climates it succeeds as well.

The pear is the most delicious of fruits for the dessert; and in this latitude, by choosing proper varieties, we are able to have them ten or eleven months of the year. The finer kinds often sell in the cities for one or two dollars per dozen. It is also excellent for baking, preserves, and marmalade. It may be dried like the apple and peach; and with or without sugar, will keep for years. Perry is made from the juice, as cider from the apple. The wood is finegrained and compact; and dyed black, is used for pictureframes, \&c., instead of ebony.

Dessert pears should have a sugary, aromatic juice, and a soft, melting, sub-liquid texture. Some few of a consistency, crisp, firm, or breaking, are very good. Pears for stewing or baking should be large, firm-fleshed, and moderately juicy. The harsh, austere kinds are thought best for perry.

Gathering and I'reserving the fruit.-Most varieties of the pear are much better if picked from the tree, before fully mature and ripened in the house. Indeed, some few kinds like the Heathcote, Bartlett, and Von Assene, will ripen well if gathered at any time after they are over half grown. When a few begin to turn yellow, and ripen on the tree, then gather the whole. Many of the most delicious 
varieties, if allowed to ripen on the tree, become dry, insipid, second or third rate. They will also ripen more gradually, last longer, and are less liable to loss or injury if ripened in the house. It is said, however, few varieties do best to ripen on the tree. When gathered, some few kinds ripen more perfectly by exposing them to the light and air. Most of them, howerer, in kegs, or small boxes, or on the shelves of a cool, dark fruit room, each one separately enreloped in alsorbent paper or loose cotton. 'This is not necessary with the summer varieties. Pears, like apples, must be gathered by hand, with the same precaution, to prevent bruises, or they will soon decay. Winter Pears should hang as long as may be upon the tree. When it is time to ripen, bring them for a week or two from the fruitroom into a warm apartment, which will much improve their flavor.

Propagation and Culture.-Pears are propagated by budding or grafting on seedling pear stocks or on certain varicties of the quince. Suckers should never be employed for this purpose ; for they seldom have good roots and the trees are short-lived; a great deal of prejudice exists against pear culture from this canse. Seedlings raised from the thrifty growing, indifferent fruits that are often cultivated about the country, are much more healthy than those raised from the improved varieties.

Sow the seed thickly in Autumn, in drills eighteen inches apart. Let the soil be deep, rich loam. Ashes are an excellent application to the seed-bed. The soil must be moist as on vigorous and continued growth the first season, much of the value of the stock depends. Take them up in Norember or December, shorten the tap-root, and reset them in rows four feet apart, putting those togegether which are of about the same size. The best of them, if in a good, deep, moist soil, will be fit to bud during 
the next summer, and nearly all the balance can be whipgrafted the ensuing spring.

Most kinds of pears grow well on the quince, and come some years earlier into bearing. The common quince is not sufficiently vigorous to form a good stock; but for this purpose the Angers Quince-an upright, quick-groming variety, which takes readily from cuttings-is used. The fruit produced from trees on this stock are usually larger and of better flaror than on the pear. The trees can also be set much nearer each other; they come into bearing in two or three years, but are not so long-lived as on the pear.

In planting, the trees on the pear stocks should be set twenty feet apart; but as these will be several years before they come into bearing, the spaces should be filled up with dwarf trees growing on the quince stock, so as to leave them when planted ten feet apart. Thus a plantation of sixteen trees, set in a square, on the pear stock, would require thirty-three on the quince to fill the intervals-making a square of seven trees on a side. The dwarf trees should be planted so deeply as to cover every trace of the quince stock, in order to permit roots to be thrown out from above the point of union. This will prevent the quince borer, and add to the longerity of the tree. The soil must be kept clean and well tilled; but should not be deeply spaded within two feet of the trunk. No fruit tree will be healthy or bear well if the ground is deeply spaded near its stem.

The pear likes a deep, stroug loam, similar to that required by the apple. Iron is very beneficial; hence the pear succeeds well in our red clayey loam, if deeply dug and sufficiently manured. On the quince the soil should be deep and cool. 
ANALYSIS OF THE ASH OF THE PEAR.

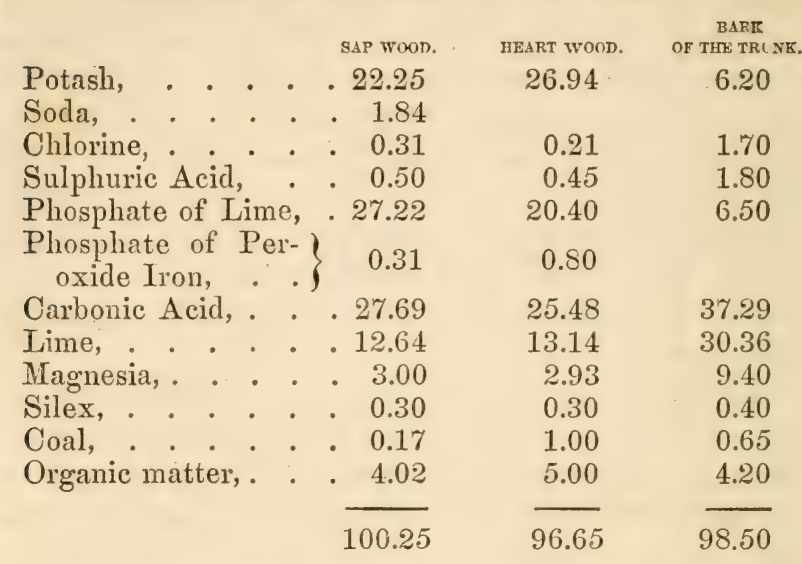

The above analysis is by Prof. Emmons. The root of the pear contains less lime and magnesia, but more chlorine, soda, phosphate of lime, and silex. Wood ashes will supply the potash, and bone manure or superphosphate of lime the phosphate of lime.

In pruning the pear, the object is to make it throw out branches within a foot of the ground, and to encourage its growth in its natural pyramidal shape. Not much pruning is required the first year; but any shoot that by overgrowth threatens to destroy the beauty of the tree, should be pinched in at once. When the tree is transplanted, if it has been out of the ground for any time, it must be severely shortened in. If you have good roots, the top will soon be renewed. Severe pruning at this time is the only way to make the tree branch out near the soil, so as to shade the trunk, and give a fine pyramidal shape. The object is to form a tree like $c$. in the cut. To secure 
this plant maiden trees, or those one year from the bud. When they have grown one year, they will be something like $a$. Cut off the branches where the lines are dotted,
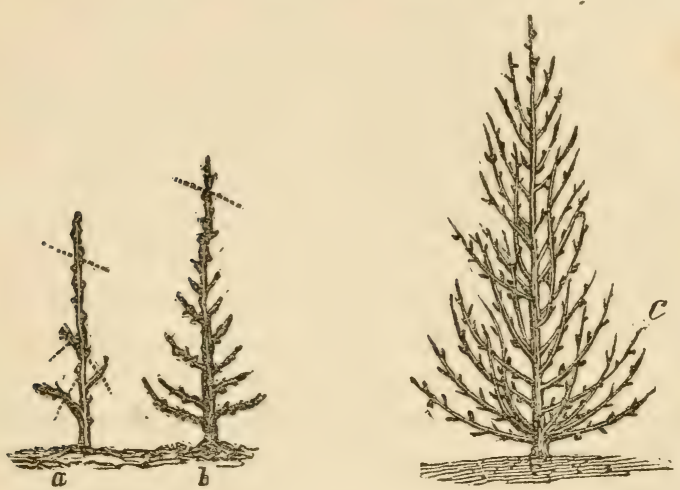

in the winter, and pinch in any shoots during the summer, that would destroy the symmetry of the tree, or remove them entirely if superfluous. If this is done, the tree at the close of a good season will resemble $b$. Head back the leader to strengthen the side branches, each year. The leader must be shortened more or less according to its vigor. A little practice will enable any one of ordinary judgment to form his trees in the desired shape. Do not let the branches remain so close together that when they come to bear, they will cause the fruit and foliage in the interior to suffer for want of air. Keep the lower shoots the longest by pinching those above, when disposed to overgrow them. The main thing is constant attention that the tree may not waste its strength in forming wood where it will have to be cut out to keep the tree in good shape. The whole process is concisely detailed in the following from the "Gardener's Chronicle :"- 
"The process consists in shortening the first year's shoot of the apple or pear tree, called the graft shoot, to one foot at a full bud. The first year, on pushing out in spring, rub off all laterals, except four or five at the bottom of the stem, to garnish it with a first tier of branches for future years. Train the leader to a stick quite perpendicular. 'The next winter proceed as before, by shortening the leader twelve inches at a full bud. Remove all intermediate buds as before down the leader, and leave those at the bottom to form a second tier of laterals; and shorten the lower ticr to an outside bud. After the second year shoot, the summer pruning consists in rubbing off the laterals forming now the lower tier, above and below the branch, so as to keep them as horizontal as possible. Strengthon those that grow horizontal by pinching off the ends if necessary. Each tier should be as near as may be twelve or thirteen inches, one aloove the other; and, if possible, the branches of each succeeding tier should be so grown as to be above the intervals of the tier below." This makes a beautiful symmetrical tree, ormamental even in a flower garden."

The great obstacle in pear culture is the blight, a disoase whose virulence is almost peculiar to this fruit tree. The causes are not well known. Hon. John Lowell, of Boston, attributes it to a minute insect described by Peck, in 1816, as the scolytus pyri. The insect in this latitude lays its eggs late in May or June, close to a bud; and as they hatch, the grub enters the shoot, perforating and devouring it. While the tree is in its full growth, shoots at the extremity of the branches suddenly shrivel, the leaves turn lack and die; the wood also is dark and discolored, and dries very hard. Prof. Turner attributes this disease to another minute insect, scarcely perceptible to the naked eye, which covers the branches in myriads. This 
form of blight can be prevented by the application of limewash, soft soap, or soda lye. But these will hardly account for all the forms of blight in the pear. Sometimes in fine growing weather, nearly the whole tree is suddenly killed by this insidions disease. Perhaps, when the shoots are very tender, succulent, and full of sap, they are unable to endure a high degree of heat. Again, trees that are growing in very rich ground, sometimes do not ripen their wood perfectly, when a sudden frost, followed by a hot sun-shine, bursts the tissues of the shoots, and corrupts the sap, causing the shoots to perish, and if not timely arrested by severe pruning, totally destroys the tree. This disease is quite frequent in cold climates. Whatever may be the causes of blight, it is certain that those varieties making rapid growth, are most affected by it. The Seckel pear growing slowly, is free of it. Again with us, if old trees are headed down severly in order to graft on, they are almost sure to be blighted, the ensuing summer, in the vigorous young shoots.

Mr. Van Buren, one of our best pomologists, thinks the disease caused by an insect, which punctures the bark on the trunk, and large limbs at those points, where it is changing from the smooth to the rough state. It first appears as a dark spot, as if a little powder had been burned there. The spot enlarges, the bark sinks down to the wood, and at length becomes surrounded with a crack or seam, separating it from the healthy part. Soon as the spot occupies a considerable portion of the trunk or limb, the leaves at the end of the twig turn black and die; as dnes also more or less of the diseased limb itself. The leaves die on the same side of the tree that is cliseased below. Hence, when the leaves begin to die, or even refuse to grow, you will generally find the bark below somewhere diseased. When not larger than a pea, they 
may sometimes be seen while the health of the tree is affected, only so as to stop growth. Upon cutting into the spots the bark is dark and discolored; with two punctures generally about one eighth of an inch apart (occasionally there is but one). At first they do not reach the wood, but only to the cellular integument. If the affected part is removed with a knife, the wound immediately heals, and the health of the tree is restored. Cut out the diseased bark, if it extends nearly around the trunk. Trees with soft, thick bark are more liable to be affected. When the leaves turn black, the branch will have to be cut oft below the affected part. It is not certain whether this variety of the disease is caused by an insect, or a fungus. This form of blight I have never seen.

In all cases of blight, whether it is caused by insects, or disease of the circulation when the twigs begin to die, the remedy is the same, and must be promptly applied, or the tree is lost. Cut off the infected part at once, a foot below where it appears shrivelled, and burn it. If it spreads further, cut more deeply. Examine daily; cut promptly and unsparing; you may as well kill the tree yourself, as have it destroyed by blight, and the disease spreading from tree to tree. The best method of prevention is not to feed the pear too highly with nitrogenous manure, but rather with leaf mould or swamp muck, composted with the mineral constituents found by analysis necessary for the pear.

Varicties.-A greater number of varieties of the pear are in cultivation than of any other fruit. Of those which have fruited here, the following are the most desirable. The varieties do not always observe with us the order of succession laid down in the books.

The earliest pear is Amire Joannet, which ripens in May; but it is small and of rather indifferent quality, though it 
bears well, and is desirable in a large collection. Not many of the later pears (which are the most desirable), have yet fruited here; but so far as tried, they are equal or superior to the same fruits ripened at the North.

1. Madeleine-Fruit medium, obovate, tapering to the stem; stem long, slender, set on the side of a small swelling; skin smooth, yellowish green; calyx small, in a shallow basin; flesh white, melting, juicy, sweet, and perfumed. Ripe between the first and middle of June. Tree sometimes blights; but it is very desirable, unless Doyenne d'Ete, which ripens at the same time; should supersede it, as it probably will, being a more healthy tree.

2. Slinless.-Fruit small, long, pyriform; skin thin, smooth, pale green, turning to light yellow, speckled with light red in the sun; stalk long, slender, curved in a very slight cavity; calyx enclosed in a small basin; flesh white, juicy, half melting, sweet, and perfumed. A very productive and excellent little pear, and deserves a place in every garden. Ripens June 18th.

3. Bloodgood.-Fruit medium size, turbinate, thickening into the stalk; skin thin, yellow, dotted, and marked with russet, and has a musk perfume; calyx open; stalk short, dark brown, set obliquely; fleshy at the base; flesh yellowish white, buttery, melting, very sugary and aromatic; core small. The best flavored early pear. Ripens 25 th of June, Muscat Rubert ripens at the same season with this fruit, and is a rery prolific bearer and a good pear, although inferior to Bloodgood.

4. Dearborn's Seedling.-Fruit rather small, turbinate, regular; skin smooth, light yellow, with a few minute dots; stalk slender, over an inch long, in a slight cavity; calyx spreading in a shallow basin; flesh white, melting, sweet, and sprightly. A very juicy and delicious little pear, 
quite productive, and one of the best. Ripe the last of June. Indispensable.

5. Julienne.-Fruit medium size, obovate, regular; skin smooth, fine yellow ; stalk light brown, over an inch long, rather stout, in a very shallow cavity; calyx small, closed in a shallow basin; flesh white, melting, buttery, sweet, and moderately juicy. A very early bearer, and a hardy and productive pear, and of very good quality, if houseripened, but sometimes astringent. Ripe 1st of July. Desirable and profitable.

6. St. Ghistlain.--Fruit rather small, pyriform, tapering to the stalk; skin pale yellow, with a few gray specks; stalk an inch and a half long, curved and joined to the fruit by fleshy rings at its base; calyx small, open, in a shallow basin ; core small ; flesh white, melting, juicy, with a rich, sprightly flavor. Ripens July 6th. This little pear is a favorite with me, producing enormous crops, which continue to ripen successirely for some six weeks or more, and when house-riped, they are invariably excellent.

7. Sterens' Genesec-is a most excellent variety. Fruit roundish, obovate (varying to turbinate); stalk an inch long, stout, thicker at the base, and set in a slight, onesided caity ; calyx with short, stiff divisions, in a moderate basin; flesh white, half-buttery, of rich, aromatic flavor.

8. Golden Beurre of Bilboa.-Fruit above medium size, obovate, regular; skin thin, smooth, golden-yellow, sprinkled evenly with small, brown dots, a little russet near the stalk; stalk an inch and a half long, slender, in a moderate cavity; calyx small, closed in a slight basin ; flesin white, buttery, malting, and rich. Ripens the last of July, before the Bartlett. A nice looking and good pear, producing well-needs house-ripening to bring out its flavor. 
9. Napolecn.-Fruit large, obtuse, pyriform, varying in form; skin smooth, pale yellow when ripe, with a darker cheek; stem stout, half an inch to an inch in length, set in a slight depression; calyx open in a medium basin; flesh tender, sprightly, juicy, and excellent if houseripened. Growth free on quince or pear upright; shoots olive colored.

10. Bartlett.-Fruit of large size, pyramidal, irregular; skin thin, smooth, clear yellow, sometimes a slight blush to the sun, rarely a little russeted; stalk an inch long or over, stout, in a shallow basin; flesh white, fine grained, buttery, juicy, vinous, and perfumed. Ripe August 1st to 20th. The tree is apt to blight, and the fruit is sometimes acid, and never of the very highest flavor. In unfavorable seasons, the fruit rots where exposed to the sun; but its size, fine appearance, and productiveness make it very popular and desirable. Will ripen finely in the house when two-thirds grown, where blown off by the wind.

11. Secliel.-Fruit small, regular, obovate; skin dull yellowish brown, with russet red cheek; stalk short, curved, in a slight cavity; calyx small, in a slight basin; flesh, whitish, buttery, very juicy, with a very sweet, rich, spicy flavor, considered the best of all pears This fruit is generally larger than at the north. It bears abundantly every year, seldom blights, and is always delicious. Ripens Ang. 15th. Does well, and bears larger fruit on the apple as a stock.

12. White Dryenne (Virgalieu, St. Michael's, Sc).-Fruit medium to large, regular obovate; skin smooth, light yellow dotted, and often with a red cheek; stalk from threefourths of an inch to one and a fourth inches long; slightly curred, and in a small cavity; calyx small, closed in a shallow basin; flesh white, buttery, melting, high-flavored and delicions. Ripens 15th August, and in succession a long time; always of fine quality here; never cracks, and 
in every respect is of the highest excellence. Succeeds on pear or quince.

13. Louise Bonne de Jersey.-Fruit large, pyriform ; skin smooth and glossy, pale green overspread in the sun with brownish red, sprinkled with gray dots; stalk an inch long, curved, inserted obliquely, without depression in a fleshy base; calyx open, in a shallow basin; flesh greenish white, juicy, melting, rich and excellent. Ripens August 25th. Proves here equally good on pear or quince stock; an early bearer always fair, beautiful and of excellent though not the highest flavor. (Mr. Van Buren writes it does not succeed with him.)

14. Duchessed'Angouleme.-Fruit very large, oblong, obovate with a knobby surface; skin dull, greenish yellow, streaked and spotted with russet; stalk long, very stout, bent, and deeply set in an irregular cavity; flesh white, buttery, very juicy, rich and delicious. Said to succeed best on the quince, does well here on pear stock; a very desirable sort on account of the fruit being of excellent quality, and immensely large.

15. Belle Lucrative.-Fruit medium size, round, obovate; skin pale yellowish green, slightly russet; stalk an inch long, stout, set obliquely in a slight cavity; calyx, short, open, in a moderate basin; flesh, melting, exceedingly juicy, sugary, rich and delicious. Ripens August 25th. To my taste fully equal to the Seckel, very melting and delicious, and a first-rate pear in every respect. Napolean and Heathcote are desirable pears; ripening about the 20th of September, and increase the variety of fruits at a season when peaches and apples are not usually plentiful.

16. Beurre Bosc.-Fruit large, pyriform, tapering gradually to the stalk; skin dark yellow, nearly covered with cinnamon russet, slightly tinged with red to the sun; stalk long, slender, curved; calyx in a shallow basin; flesh white, 
melting, buttery, rich and delicious; begins to ripen the middle of September; decidedly one of the best. Has a delicious flavor, and is a constant and abundant bearer. Succeeds best on pear stock.

17. Beurre Diel.-Fruit larger, obovate, varying to obtuse pyriform; skin thick, lemon yellow, turning to orange, somewhat marbled with russet, and marked with large brown dots; stem rather long, stout, in an uneven cavity; flesh yellowish white, a little coarse at the core, rich, sugary, buttery, and delicious. Ripe the 15th of September. Thought to succeed best on the quince, but here very fine on either. The trees for two or three years past, appears more subject to blight than formerly; very desirable.

18. Messire Jean.-Ripens at the same time with the latter. Fruit, medium size, turbinate; skin somewhat rough, yellow, mostly covered with brownish russet; stalk an inch long, in a small wide cavity ; calyx small, open in a shallow basin. Flesh, white, crisp, juicy, breaking with a very sweet, rich flavor. Second rate at the North. A good bearer, and worth cultivating in a warm climate. A highly excellent breaking pear.

19. Soldat Liboreur d' Esperin.-Fruit large, oblong, pyriform; skin greenish yellow, when ripe, somewhat striped and dotted with russet; stem full, stout, curved, depression slight; calyx open; flesh a little coarse, but juicy, melting, and sweet. A very strong, growing, vigorous, upright tree. On the quince, has borne fine specimens with me the last two years on quite a young tree. Ripens in October, and keeps some time.

20. Lawrence.-Fruit medium to large, long, obovate, narrowing to an obtuse end; color dull, pale yellow, marbled with greenish brown russet at the ends; calyx large, closed in a furrowed basin; stem stout, swollen at the point of junction with the tree, in a round, deep cavity. Tree 
hardy, of moderate growth, shoots thorny, light yellowish brown. October and later.

21. Glout Morcean.-Fruit rather large, oval, obovate, varying in shape; skin, thin, pale greenish yellow, with brownish patches; stem long, slender, in a small cavity; calyx open, in a deep basin. Flesh white, fine-grained, buttery, melting, saccharine and rich. Ripens gradually through October, lasts often until January. Excellent.

22. Winter Nelis.-Fruit medium size, roundish, obovate narrowing to the stalk, yellowish green, dotted with gray russet and nearly covered with russet patches towards the sun; stalk long, curved in a narrow cavity; calyx open, in a shallow basin; flesh yellowish white, fine grained, juicy, melting, with a rich sugary flavor. Tree apt to blight, but the most delicious of late pears. Ripe last of October and through November. Nearly or quite equal to the Seckel.

23. Jaminette, or Josepline.-Fruit medium to large, obovate, narrowing to the stalk; skin, pale green, marked with brownish russet and speckled with round dots; stalk, rather short, thick, obliquely set without a cavity; calyx open, in a moderate basin ; flesh, white, melting, juicy, with sugary aromatic flaror. Ripens Nov. 6th. Valuable.

24. Beurre D' Aremberg.-Fruit, obovate, narrowing to the stalk; skin, pale greenish yellow spotted with russet; stalk short, fleshy and obliquely set; calyx small, in a deep basin; flesh white, buttery, melting and juicy, with a rich vinous flavor. Ripens in November. Promises well.

25. Franklin.-A native of this State; large, oblong, turbinate, very irregular, narrowing to the eye ; green, clouded with dark green, and thickly sprinkled with dark green dots. A very indifferent looking pear which bears abundantly, and when ripe in January, the flesh is sweet, 
melting, juicy, and delicious; calyx in a shallow one-sided basin; stem an inch long, set on one side of the fleshy protuberance.

26. Passe Calmer.-Fruit large, obovate, varying to obtuse, pyriform; skin yellow, sprinkled with brown russet; stem inserted in an uneven cavity or without depression; calyx open, in a shallow basin; flesh yellowish, buttery, juicy, rich and sweet. This fruit has not borne here; but in other sections of the South, is much liked. The tree is apt to blight.

27. Easter Beurre.-Fruit large, roundish, obovate; skin yellowish green, sprinkled with russety dots, with sometimes a brownish cheek; stem short, blunt, in an abrupt cavity; calyx small, closed in a broad plaited basin; flesh white, fine-grained, buttery, melting, and of a rich, sweet excellent flavor. Has been kept here till March. Sereral trees should be planted of this variety, as it remains in eating all winter, and is valuable for market. It succeeds best, it is said, on the quince.

28. Catillac, (a cooking pear).-Extremely large, broad, turbinate; skin yellow, dotted with brown, and with a brownish red cheek; stalk stout, curved, in a narrow cavity; calyx in a wide deep plaited basin; flesh hard and rough, but cooking tender and of a fine light red color. Ripens in November.

29. Elack Worcester.-Fruit large, obovate or oblong; skin thick, rough, green, covered with dark russet; stalk short, stout, in a slight cavity; calyx small, in a moderate basin; flesh hard during the winter, but cooks well, and towards spring becomes tolerably good for the table.

30. Easter Bergamct.-Fruit medium to large, roundish, obovate, narrowing to the stalk; skin smooth, pale green, speckled with light grey dots, becoming pale yellowish at maturity; stalk in a slight cavity; calyx small, in a shal- 
low basin ; flesh white, crispy, juicy, melting and sprightly, The tree is thrifty, furnishes fruit fit for cooking a long time; and as they ripen, they become agreeable for the table. Ripens December and January.

In addition to the above list, Beurré Giffart, Doyenné d'Ete, Ott, Rostiezer, and Tyson, are esteemed early rarieties; Belle et Bonne, Beurré, Brown, B. d'Anjou, B. Oswego, Gansels Bergamot, Bonne des Zées, Brandywine, Doyemné Boussock, De Gris, Flemish Beauty, Henry IV., Leech's Kingsessing, Lodge, Onondaga, Paradise d'Automne, Urbaniste, Van Assene, and Washington, of the middle season; and Buerre Bretonean, B. Gris d'Hiver Noreau, B. Langeliers, Columbia, Doyenné d'Alencon, Elize d'Heyst, Josephine de Malines, Lewis, Princes St. Germain, and Suzette de Baroy, of the late varieties, are worthy of a trial with those seeking variety, or desiring a large collection. The native pears ripening the last of August, viz., Comaks, Green Cluster, and Horton, and the Nabours a little later, are very desirable.

Mr. Summer, of Pomaria, S. C., has published in the Southern Agriculturist a select list of fifty-one sorts, including Nos. 1, 3, 4, 6, 7, 8, 9, 10, 11, 12, 14, 15, 16, 17, 21, 22, 21, of the above described. Mr. Van Buren, of Clarkesville, gives, as his choice of best sorts, Nos. 3, 7, 9, 10, 11, 12, 15, 16, 24, 27, and Onondaga and Brown Buerre. II. A. Swasey, of Yazon City, Miss., recommends, in the Southern Agriculturist, Nos. 2, 6, 10, 11, 14, 22, 27, and Jefferson, Jargonelle, Carolina Sugar, Buffam, Prince of Orange, Capiamont, Pound Mammoth, and Le Cure. Dr. J. C. Jenkyns, in Southern Cultivator and Report to the American Pomological Society, speaks highly of Nos. 1, $3,5, \mathrm{~S}, 10,11,12,13,14,15,16,17,21,22,24,26$; also, among others, Doyenne d'Ete, Beurre Giffart, Rostiezer, Tyson, Summer Franc, Real Beurre Gouboult, Leech's 
Kingsessing, Doyenne Grey, Brandywine, Long Green, and Vicompte de Spoelberg St. Andre, most of which bear a ligh character every where. Mr. Van Buren rejects Maria Lonise and Vicar of Winkfield, also Louise Bonne de Jersey and Pass Colmar. Maria Louise here is subject to blight, and Vicar of Winkfield or Le Curé always cracks and is worthless; hut Louise Bonne de Jersey is one of the very best in tree and fruit here, and Passe Colmar generally succeeds in the South.

\section{Pyrus Malus-The Apple.}

The apple probably originated from the European erab; but, in its improved state, it is so superior to its parent, in size and flavor, that some deny the original identity of the two. But centuries of cultivation might certainly cause as great a change in the quality of this fruit as, in the case of the dahlia, we have seen a very few years produce in the beauty of a flower.

The apple was early brought into cultivation-in the time of Pliny twenty-two varieties being known to the Romans. They probably introduced its culture into Great Britain. It succeeds, howerer, in this country better than in Europe, especially in the fresh soils of the middle States, or in the cool mountain regions of the South, localities which have originated many choice varieties.

Where the apple can be grown and preserved in perfection, it is the most useful of fruits. Varieties can be selected which will afford a succession through the entire season. They can be thus preserved in our own mountain region, from which excellent fruit is brought as late as the first of May.

The best varieties of apples are excellent dessert fruits. Medicinally, they are slightly laxative, and, used moder- 
ately, keep the system in proper tone. Children are more healthy if allowed to use, in moderate quantity, fully ripe fruit. Apples, indeed, are really nutritive, and are often employed in feeding domestic animals. For the table they are prepared in many ways (in all of which they are wholesome), as by baking, stewing, in pies, tarts, puddings, jellies, and preserves. They are also dried for winter use. Chnose for this purpose those which will cook tender, and are of fine, brisk flavor.

The apple may be propagated by cuttings, which may be planted like most other cuttings, with both ends bent downward like an inverted $\mathrm{U}$, thus $\Omega$. The upper part of the bow should be crowned with a bad, which should be just beneath the surface of the soil. But the best mode is by budding or grafting on seedling stocks. The seed should be planted in good soil, at any time during the winter months, in rows eighteen inches apart. Keep them clean during the summer, and, if the soil and season have been farorable, they may be taken up the next spring, the roots shortened, and then whip-grafted just above the surface. Reset them in good soil, in rows three feet apart, and one foot in the row. Those which were not large enough to graft may be also reset, and will do to bud during the summer. The next winter, those well grown may be set where they are to remain. If any of the plants are infested with the woolly aphis, wash them wish tobaccowater; or, if you have enough without them, burn them up. The plants should be placed in the orchards twentyfive or thirty feet apart. The intervening space, for the first few years may be filled with dwarf pears, quinces, plums, or peaches, which can be cut down when the apple trees require the whole ground. A thin mulching of leaves, straw, or decayed tan-bark, is a useful application about the roots of the tree. 


\section{ANALYSIS OF THE APPLE.}

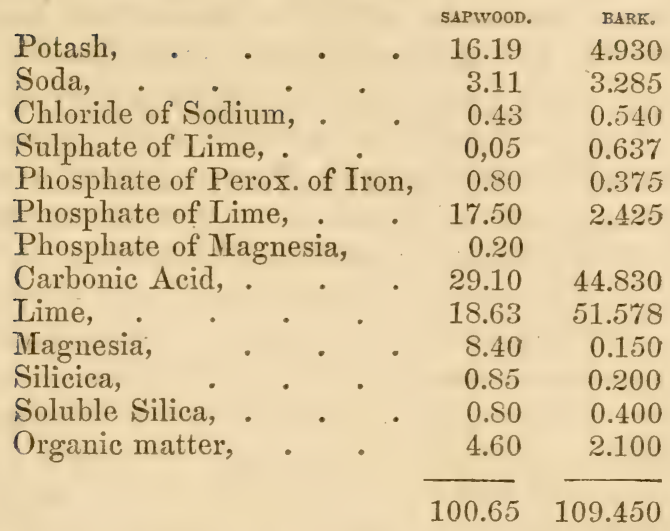

One-half of the ash of the bark of the apple, and over nne-sixth of that of the sap-wood, it will be seen, is pure lime. When this mineral is not pretty abundant, the tree cannot be kept in health. Swamp-muck or leaf-mould composted with this, with the addition of bone-dust, potash, or ashes, are the best applications.

The best soil for the apple, in this climate, is a deep, cool, moist loam. In bottom-lands they generally do well, if there be no stagnant water, since the roots find abundant moisture, and the later varieties will continue growing until the proper time to gather for winter use. If planted on dry, shallow soil, unless deeply trenched, all the winter varieties will drop before attaining perfection. The best manure for the apple is swamp-muck, or woods earth composted with the lime and salt mixture; to which may be added wood-ashes, old plaster, and anything containing lime.

The apple, in this section, is a dificult fruit to culti- 
vate. A tree full grown, and entirely free from disease, is a rarity. I have had them die at the root suddenly, while the top was apparently free from disease, and both entirely free from the woolly aphis. Sometimes they die slowly, perhaps from the too intense action of the sun upon the soil and roots; or, it may be, from the great deficiency of lime in this soil. A large proportion of our trees are diseased and decayed on the south-western side of the trunk, where the sun falls in the heat of the day. Then we have the bark-lice, borers, and caterpillars. Then, worse than all, is that pest of the orchard, the woolly aphis, or Ameriean blight. Now these are serious obstacles in the way of the orehardist; but they may be surmounted. Bark-lice, caterpillars, and borers, a little care, in season, will destroy here, as well as anywhere. The sum-burning of the trunk can be prevented by planting trees of but one year's growth from the bud, and so shortening them in, when planted, that they will throw out branches near the soil. The thick foliage will thus screen the trunk from the sun, and, by keeping the roots shaded, will improve the general health of the tree. The lime and other constituents lacking in the soil can from time to time be applied. Old plastering, and the refuse lime of the tamner, where they can be had, will cheeply supply this element.

The aphis is more troublesome. If they are on a single tree in the garden, the wind will soon carry them enveloped in the down from one end to the other. If you are free from them at first, it is better to raise trees from seed, get scions and graft them yourself, than to incur the risk of introducing the aphis with your purchases. If you do buy, beware of those trees with roots full of warts, caused by its minute lacerations. If there is the least token of the presence of the aphis, either by the downy matter in 
the crack of the bark of the young tree, or by the warts on the ronts, wash the roots thoroughly in tobacco water, and paint the stem and branches with whitewash, comprosed of soap-suds, thickened with quick lime. You will thus be free from this pest to begin with; afterwards every place where they appear should be coated with this paint. This, on moderate size trees, is an effectual remedy, and besides a beneficial application to the tree. Some trees, like tho Meigs, are seldom troubled with the aphis, while the Early May is almost always infested with them. When the aphis infests the roots it is best destroyed by uncovering the roots, and pouring strong tolsacen water upon them wherever affected. In pruming the young tree, the first olject is to make it throw out shoots near the earth to shield the trunk from the sun. All fruit trees should be thus trained. Never let a fruit tree be bare of branches more than twelve inches from the grround, or allow it to shoot up, with a long naked stern. Peaches, pears, plums, \&c., are all more healthy and productive thus trained. This is effected by shortening or pinching the upper shoots, for which sufficient directions are give in our article on the 'Pear.' The apple, hrowever, does not generally require as close shortening in of its leading shoot as the pear. All needless branches, and those which interfere by crossing and rubling against each other, should be removed while sinall. If a large limb is removed, cover the stump with grafting wax, or the shellac solution.

Gatulerwg tue Frutr. - Those intended for keeping or sending to market, should be carefully piclied from the tree, and handled with great care, to prevent bruising. Those that fall of themselves must bo kept separate, as the least bruise will cause decay. They must be frequently looked over, and every one the least decayed, must be carefully removed, or it will infect the others. They should be 
kept at a uniform temperature in a dry cool, situation Choice specimens may be wrapped in absorbent paper, and laid singly on shelves. They should not be exposed to much frost, and still less to extremes of heat. Specimens may thus he kept in good condition until March. A fruitroom should be kept as cool as possible, and if the temperature could be kept uniformly at $32^{\circ}$, no decay would take place. Packed in ice, they are sent in perfect safety to the East and West Indies.

In selecting varieties for cultivation, as it is a matter of some difficulty to raise a good supply (the apple being adapted to a more northern climate), we must guard against orer refinement. It is not our first question, What varieties are of the very highest flavor; but is the tree hardy and productive enough to bear fruit at all. Will it produce enough to be worth cultivating. It is then quite early enough to select from those possessing these indispensable good qualities those of the lighest flavor for the dessert or kitchen.

Of northern varieties, those classed as Summer Apples almost invariably succeed here. Some of the Early Autumn varieties also do well, and, of course, are summer apples with us. But the winter apples, as a class, are entirely unsuited to our climate. We need good Autumn and Winter varieties, and for them we must rely upon those of southern origin, as the northern winter varieties usually fall and decay before the middle of September; besides here very few of them exhibit any choice qualities. Some fifty sorts have been tried here, and failed. Any one possessed of native varieties that ripen in October and November, or later, will confer a benefit on the entire South by disseminating scions among our Southern nurseries.

1. Early May.-Fruit small, roundish, sometimes slightly 
oblong; skin thin, yellowish green when ripe, with sometimes a brownish cheek; stem short, in a shallow cavity; calyx small, closed in a shallow basin; flesh yellowishwhite, tender, of a mild acid and rather pleasant flavor; begins to ripen the 15th or 20th of May. The earliest of apples, which is its only merit. Probably the White Juneating of Downing. Liable to the aphis.

2. Early Harvest.-Fruit medium size, round, sometimes flattened; skin smooth, with a few white dots, and of lightest straw color; stalk half to three-fourths of an inch long, slender in a moderate eavity; calyx in a shallow basin ; flesh white, tender, juicy, crisp; flavor rich, sprightly, andsubacid. Inclined to overbear. Ripens last of May.

3. Red June.-Fruit medium, generally oblong, but occasionally flat; skin smooth, green in the shade, changing rapidly at maturity to a fine dark crimson; stem half to three-fourths of an inch long, inserted in a moderate cavity; calyx in a shallow basin; flesh white, tender, mellow, and digestible, fine grained, slightly acid, moderately juicy, but not rich. A good fruit and a hardy, productive tree. Ripens early in June. This is not the Red Astracou, which, being more acid, is better for the kitchen, and not so good for the dessert.

4. Julian.--Fruit medium size, roundish, tapering somewhat to the eye, rather one-sided; calyx small, in a narrow basin; stem short, in a moderate carity; skin thin, yellowish white, striped and marbled with carmine, of a beautiful waxen appearance, sprinkled sparingly with whitish dots; flesh white, tender, juicy, and fine flarored; indeed, the finest summer apple known north and south. Ripens about the middle of July.

5. Sinclair's Yellow.-Fruit small to medium, flat or roundish; skin smooth, of a fine orange color, darkened in the sun; flesh pale yellow, with a rich subacid flavor. 
A good bearer, and excellent for both the table and kitchen. Ripens June 15th.

6. Bough.-Large oblong ovate; skin smooth, pale greenish yellow; stalk rather long, in a deep, narrow cavity; calyx deeply sunk; flesh white, with a rich sprightly saccharine flavor. Ripens late in June.

7. Maiden Blush.-Fruit medium size, flat, smooth, and fair; skin thin, clear lemon yellow, with a fine blush to the sun; stalk short, in a wide, deep cavity; calyx closed in a moderate basin; flesh white, tender, sprightly, subacid. Excellent for drying and culinary uses, and a fair dessert fruit. Ripens first of July to August.

8. Cane Creek weet.-Medium or large, oblong, regular tapering to the eye; skin pale green; stalk long, slender, in a deep cavity, often slightly furrowed; calyx closed, in a narrow, plaited basin; flesh white, tender, moderately sweet, when in perfection juicy, but becomes mealy if over ripe. Quality very good. From Burke Co., N. C. Ripe 15th July.

9. Toccoa.-Rather large, conical,irregular; skin yellow, striped with red; stem short, in an irregular cavity; calyx closed in a small, irregular basin; flesh yellow, with a brisk rich Spitzenburgh flavor, moderately juicy; core large. A native of Habersham Co. Ripens first of August.

10. Horse Apple. - Size medium to large, roundish, narrowing to the eye, sometimes conical and somewhat irregular; skin thick, greenish yellow in the shade, but rich, dark orange, or blush, towards the sun, often marked with a few russet lines, or flecks, about the stem; stem short, rather large, in a shallow cavity; calyx in a narrow basin; core large, hollow; seeds few; flesh yellow, firm, coarse grained, with a rich acid flavor. Well ripened, a good table apple; excellent for cooking. Ripens last of July Productive, hardy, and valuable, continuing long in use. 
11. Male Carle.-Fruit medium size, regular, narrowing to the eye; skin smooth, waxen, lemon yellow in the shade, with a light crimson cheek; stalk an inch long, slender, in a narrow, regular cavity; calyx in a deep, narrow basin; flesh white, moderately juicy, tender, of delicate flavor. A native of the south of Europe; succeeds well here. Ripens in August.

12. Fall Pippin.-Fruit very large, roundish, flattened, obscurely ribbed; stalk three-fourths of an inch long, in a shallow, round cavity; calyx small, in a deep, narrow basin; flesh tender and mellow, with a rich, aromatic, subacid flavor. A splendid apple here. The Cameusar or Elgin Pippin (Reinette Blanche d'Espagne) resembling this, but oblong, is a little later, and proves, with Dr. Jenkyns, near Natchez, the best of all apples. It ripens there last of July, and through August. Fall Pippin ripens here in August.

13. Carthouse.-Fruit of medium size, roundish, oblong; skin smooth, handsome, streaked with red and yellow; stalk short, in a deep cavity; calyx in a deep, regular basin; flesh yellow, firm, juicy, and rich, when fully ripe tender and sprightly. A fine cider apple. Ripens first of September. From Virginia.

14. Buffs.-Fruit of the largest size, irregular, roundish, flattened, and slightly angular in form; skin thick, ground color, yellow, but striped and overspread with red, very dark next the sun, marked with a few greenish russet spots; stem three-fourths of an inch long, in a medium cavity; calyx in a large, irregular basin; flesh yellowish, and when well ripened, tender and excellent, sometimes indifferent-lacks richness and acidity. Ripens November to March. Indispensable.

15. Meigs.-Fruit large, regular, oblong, narrowing to thee ye, sometimes slightly ribbed; skin yellow, but mostly 
concealed with a marbling of red, and sprinkled with prominent yellow dots; calyx small, closed and set in a narrow basin; stalk very short, thick, in a deep, narrow cavity; flesh yellowish white, tender, juicy, with a rich slightly subacid flavor. The best apple I know of our native fruits. Growth very thrifty, and less infested with aphis than many others.

16. Waddel's Hall or Shockley.-Fruit, medium, roundish, oblong, narrowing to the eye ; skin, yellow, clouded, and striped with red, and with blotches of very dark-greenish russet; stalk long, slender, inserted in a deep, narrow cavity; calyx closed, set in a shallow basin; flesh firm, saccharine, of good second-rate flavor; ripe in October, and will keep till March.

17. Limbertwig.-Fruit large, dull red; flesh yellowish, firm, not very ligh-flavored, but a good deal cultivated in our up-country. 'The pendant branches give the tree its name. Originated in Virginia. It keeps through the winter.

The following additional varieties are described by $\mathrm{Mr}$. Van Buren, of Clarkesville, Ga., as very superior, and most of them recommended by the Fruit Committee of the Southern Central Agricultural Society. They are now in the nurseries:-

18. Carnation.-Fruit medium size; a delicious sub-acid apple, fully first-rate; dark-red, splashed with russet; flesh white, brittle, and very juicy; both the calyx and stem are sunk in deep depressions; no antumn apple is superior; ripe August 10th.

19. Hugh's Crab.-Small size; green striped, and splashed with dark red; stem short, inserted in a moderate cavity; flesh sprightly, subacid, and good; a good bearer; ripe August 10th.

20. Batchelor or King.-Fruit of the largest size; roundish, flattened a little, broader at the base; skin lemon yellow, 
washed with sively red on the sunny side, (sometimes obscurely striped), and sprinkled sparsely with greyish specks; calyx small, open in a rather deep basin; stalk very short, thick, and inserted in a moderate regular basin, which is often russeted; flesh white, tender, fine grained juicy and most agreeable subacid flavor. It is from North Carolina (November).-A magnificent fruit.

\section{WINTER VARIETIES.}

21. Maverick Sweet.-Very large, roundish, irregular, sometimes slightly conical, stripeu with bright red, sprinkled with greenish flecks; stem short, in a rather large regular cavity; calyx open; basin medium; skin rather thick; flesh fine grained, tender, of sweet, excellent flavor. Ripens November and December.

22. Nickajack.*-Size very large, flattened; color yellowish green, covered with red stripes and splashes, and sprinkled with minute white specks; calyx large, open, set in a broad basin; stem short, in a regular cavity; flesh juicy, tender, brisk, acid. Ripens late, and in the mountains keeps until May. Originated in Franklin, N. C.; one of the very best.

23. Span.-Large, flattened; green, striped with red, a little russet about the stem, which is short, thick, in a broad cavity; a good acid apple, nearly first-rate ; keeps till January or February; tree upright, thrifty, and a good bearer.

24. Murray.-Medial, oblong or conical; very regular; calyx in a deep basin; stem short, moderately thick, in a rather deep, regular carity ; color fine yellow, inclining to orange; flavor fine, brisk, subacid; keeps till March. Tree a good bearer.

"Or Summerour? $-\nabla$ B 
25. Walker's Yellow.-Large, oblong, or oval; skin yellow, with a slight blush to the sun; fine flavored; tree upright and vigorous; a seedling of George Walker, Esq., Longstreet, Pulaski Co., in the lower part of this State, where it ripens in October; will prove a fine winter apple in most of the Southern States.

26. Cullasaga.-Large, regular, a little conical; skin yellow, covered with fine crimson stripes; calyx small, in a moderate basin; of pleasant, aromatic, subacid flavor; a first-rate apple, and keeps well.

27. Berry.-Large, roundish, slightly flattened, regular; skin yellow mottled with dots, covered with broad stripes of dark red; stem medium cavity broad, calyx in a broad shallow basin. Flesh yellow, firm, rich, of slightly acid flavor. Tree thrifty, upright and very prolific. Ripens late in October, and keeps through the winter.

28. Disharoon.-Large, regular, slightly conical; calyx small in a narrow basin, skin yellowish green, with many roundish spots made darker by minute specks. Flesh of fine aromatic subacid flavor, resembling that of the Newtown Pippin. Early winter, or late autumn.

29. White-Medium to large, regular, slightly conical; calyx in a hollow basin; color lemon yellow, with spots and splashes made darker by minute black specks on a greenish ground. Flesh crisp, tender, juicy. Keeps until January. Rather acid for the table, but fine for cooking.

30. Catooga.-Large to very large irregular, broadest at the base; yellow mottled, with black dots, and sprinkled with flecks of green, stalk of medium length, slender; cavity deep, calyx open in a deep basin. Flesh yellowish, with a mild pleasant subacid flavor.

31. Camaks' Sweet.-Fruit, medium to large, roundish, conical; whitish green, mottled with green russett, the patches of which are made up with small dots, with a fine 
flush, or red cheek towards the sun; flesh firm, scarcely sweet, juicy and fine flavored, very good, stalk short, cavity and basin broad; calyx closed December.

32. Never Fail.-Medium, roundish, conical, greenish yellow, a little russeted, striped and nearly overspread with red; stem short, in a small regular cavity; calyx small, nearly closed; flesh yellow, firm, with a rich aromatic sub-acid flavaor. Ripens in December.

33. Qucen.-Size, medium to large; form ovate, very regular; calyx slightly sunk; stem three-fourths of an inch long; color, a fine golden yellow. Very beautiful, and quality first-rate.

34. Wall.-Large, oblong, flattened at each end, slightly ribbed; color, dark green, nearly covered with dark red; calyx large. Of fine quality, and tree prolific.

35. Hangum.-Size medium, regular, slightly conical; stem small, in a narrow carity ; color green, nearly overspread with large red stripes. Of excellent quality, and keeps till March.

36. Norton.-Large, roundish, regular; color, green, broadly striped with red. A beautiful and good fruit which keeps till May. Tree vigorous and prolific.

37. Red Warrior.-Fruit very large, form nearly globular, but a little angular; color orange yellow, striped and marbled with bright and dark red, with a few dark brown spots sprinkled over it; stem medium size, three-fourths of an inch long; cavity medium; calyx closed in a smooth deep basin; flesh white, moderately acid, with plenty of juice; quality very good. Montgomery, Ala., Dr. Baldwin keeps till March a first-rate variety for winter.

38. Carter.-Fruit roundish, narrowing to the eye ; size medium to large; color fine orange yellow in shade, nearly overspread with smooth blended red towards the sun; the yellow is speckled with faint russet; stem three. 
fourths of an inch long, fleshy, springing from a wide deep cavity; calyx large open in a wide deep, somewhat ribbed basin. Very highly spoken of at the fair for 1S56, at Montgomery, Ala. In a milder climate is said to hang on the tree until January. Probably the best winter apple for the climate of middle Alabama, Miss., \&c.

39. Oconee Greening is said to be a very fine winter apple, in appearance much like Disharoon with which it may prove identical.

For a select list, Mr. Van Buren recommends Red June, Bruce, Julien, Bough, Cane Creek, Toccoa, and Defiance, for summer. Disharoon, Tender Skin, Batchelor and Fall Pippin for the middle season, and Nickajack, Camak, Sweet Cullasaga, Wall, Catooga, Berry, Maverick Sweet, Shockley, Neverfail, and Duckett for winter.

For a select list, I would recommend Nos. 3, 4, 6, 10, $12,14,15,16,20,21,22,26,27,28,31,32,35,37,38$. Mostly native Southern varieties, and whatever else we buy abroad, it is certain that our apples should be got from our Southern Nurseries.

\section{Ribes-Currant and Gooseberry.}

Ribes Rubrum-CurRant.

The currant is a low shrub, a native of Great Britain and the northern parts of Europe and America, with smooth branches, doubly serrate pubescent leaves, and yellowish green flowers, appearing early. The fiuit ripens with the later strawberries and raspberries. It succeeds and thrives admirably in our mountain sections, and will live and bear tolerably well here in a cool, northern exposure; but would probably die out, the first summer, near the coast.

The fruit is of an agreeable acid taste-ripe, it is used 
with sugar at the dessert; and also alone, or mixed with raspberries, for jams, jellies, and wine; and both green or ripe for stewing, tarts, and pies. In cool climates, it is the most easily cultivated and most useful of small fruits. Medicinally, it is like the lemon and other subacid fruits, cooling and antiscorbutic. When perfectly ripe, it is useful in some cases of diarrhœa. The jam of black currants in sore throat is useful.

The currant is propagated by cutting's, which should be planted in the fall in a shady situation. It requires moist, rich, deep loam, and should be trained as a bush. It bears on wood of previous year's growth; but mostly on two years old wood. As soon as the fruit is off, thin out the old wond, learing only stems of the present and last year's growth. Clip off three or four inches of the former to make a growth of spurs for the next crop.

Vurielics. - Red Dutch. Fruit of large size, oblate, borne in large clusters, and less acid than the common red. Color fine transparent red.

White Dutch.-Large yellowish white, less acid than the red kinds.

Black Naples (Ribes nigra) -is the largest and best of the black varieties; but none of these are desirable.

\section{Ribes Grossularia-Gooseber ry}

The Gooseberry like the currant is a native of Europe. Green, it is used for pies, tarts and puddings-- ripe, it is a very agreeable dessert fruit. But it is even more impatient of heat than the currant, and cannot he expected to thrive except among our mountains. It is propagated from cuttings, likes the same soil and exposures, and is cultivated in exactly the same manner as the currant. it has in one or two instances produced fruit here from imported plants, but they have been rery short lived, yiclding only one or 
two crops. Our gardens can be occupied with more productive and desirable kinds of fruit. Houghton's seedling is the hardiest variety.

\section{Rubus-RASPBERRY AND BLACKBERry.}

\section{Rubus Idens - RASPBERry.}

The Raspberry plant has small shrubby stems of biennial duration, but perennial roots. The leaves are pimnate. The flowers appear in panicles on the new growth upon last year's canes -- the fruit ripens in a few weeks after the flowers appear. It is a native of both continents in low moist situations. The fruit is highly grateful, being fragrant, cooling, allaying heat and thirst, of a pleasant subacid flaror and is much esteemed either alone or in connection with the currant for preserres, tarts, sances, jellies, jams, and ices. Wine is made of the juice by the addition of water and sugar. Raspberry shrub, a refreshing drink, is made of the unfermented juice, by adding sugar and water. Currant shrub prepared in the same way, is still more cooling. Raspberry juice, like that of strawberries, dissolves the tartar of the teeth, and the fruit nerer fermenting in the stomach may be used by invalids.

This plant flourishes on reep, rich, moist loam. A bot- tom near a stream is the best location. If this is not to be obtained, trench the ground deeply and mulch during: the summer. Permit no grass or weeds among the bushes. Rasplerries grow admirably where they can receive the drainage of buildings. Downing says a slight dressing of salt is a raluable application. The raspberry is propagated from suckers or offsets from the main roots. It may also be raised from seed by which new varieties are obtained. Seedlings bear in two years. In planting offsets two or three are planted together to form a stool in rows five feot asunder and three feet in the row. The black Raspberry 
is propagated by layering the branches. When the crop is gathered, cut away all the wood, and leave but five of the new canes. Manure the ground, in autumn, with a coat of swamp muck or leaf mould, which dig in. In the spring cut off from six to twelve inches of the young shoots as the extremities are feeble and worthless. Mrulch in April, directly after a good rain, with leaves, pine straw, or litter. By cutting off the canes near the ground in the spring, later fruit may be obtained. A plantation will continue in bearing five or six years. 'The fruit is better where the canes are neatly tied to rnds or low espalier rails.

Vurieties.-The American Black, and a variety known as the English, succeed finely here. Mr. Affleck, of Miss., finds the Yellow Magnum Bonum productive and delicious. We describe those most worthy of trial; but, so far, the black is worth all the others.

Antwerp Red.-Large, conical; dull red; flesh firm, rich, juicy, sweet, and high-flarored; canes moderately strong and pale brown; leaves, large.

Antucerp Iellow.-Large, nearly conical; pale yellow; sweet and excellent; canes strong and vigorous; light yellow, and spinous; bears a long time.

American Black (Rubus occidentalis).—Small, flattened; black, or dark purple, with a whitish bloom; later, and more acid than the preceding; the well-known Thimbleberry, succeeds well here. From its rich, acid flavor, it is the best variety for cooking, as in tarts, pies, puddings, \&c. It is much improved by pruning and culture, and should be set at wider distances than the other varieties, because it grows more rampant. Ohio Ever-bearing is a variety of this, but bears through the season.

Franconia.-Fruit large, obtuse, conical, dark purplish red; of rich, brisk acid flavor; canes strong, spreading, branching, Jellowish brown, with seattered stout spines; 
leaves narrow, long, deep green. Said to bear abundantly.

Fastolff.-Very large, roundish, conical; bright purplish red; tender, rich, and high-flavored; canes strong, erect, branching; with strong spires.

C'ushing._-Originated by Dr. Brinckle, of Philadelphia. A fine new crimson sort, which will doubtless succeed here here better than the European varieties. The same remark will apply to Brinklé's Orange, and Wilder, both of which are light-colored varieties.

\section{Rubus Villosus, \&c.-BLACKBERRY.}

The blacklierry is a native American plant, found growing abundantly from Labrador to the Gulf of Mexico. 'The Riubus villosus, or High Bush, which includes several varieties, and Rubus canadensis, both produce excellent fruit. The wild fruit is so alundant in most localities, that it will be long liefore it comes into general cultivation.

U Tse-The blackberry is an excellent dessert fruit, continues a long time in bearing. and is also used for tarts, pies, puddings, jams, and preserves. From the juice a palatable wine is produced. The ripe fruit eaten fresh, or preserved, is found useful in summer diseases.

The blackberry will grow in any soil, but is produced in the greatest perfection in that which is deep, rich, and moderately moist, especially if newly cleared from the forest. It abounds in all rocky lands, by the side of old fences, and other spots rich with regetable mould. Ashes, swamp-muck, or leaf-mould, composted with animal matter, are the best manures. It is best propagated by offsets selected from those plants producing the best flavored fruit. It is cultivated like the raspberry, cutting away the old wood, \&c., in the same manner.

The High Bush, in its varieties, is perhaps worth culti- 
vating. Fruit large, long, ovate, bright black; tender, juicy, and sweet, with an agreeable bitter, or rather aromatic flaror; growth upright, becoming recumbent at the top. There is said to be a white variety. One, more common, is of light red color, with fruit sweet and good. We have also a variety in this State with blossoms perfectly duble, but the fruit is abortive. The New Rochelle is probably the best rariety now known. The fruit is the shape of Hovey's strawberry, very pulpy, and of excellent flavor, and continues for some weeks in use.

\section{Vitis of Species-The Grape-Vine.}

The vire was one of the first plants breught into cultiration. The foreign grapes are all varieties of Vitis Tinifera, and came originally from Asia. Of native grapes, we have Vitus Labrusca, of which the Isabella, Catawba, and Diana are rarieties; Titis Cordifolin and Titis -Estivalis, from one of which the Elsinburgh and Ohio originated; Tilis Rufundifclin which is the parent of the Scuppernong; our most valuable grape, and some other species from which no valuable varieties have yet been produced.

Of the other fruits, as the apple, pear, \&c., we are cultivating kinds remored many generations from their natural state, and improved in quality by a long course of culture; but our American grapes are chance seedlings of the wild rarieties taken within a few years from their native woods. Seedlings from these generally revert to the original wild species; but the Catawba is the parent of the Diana grape, one degree further removed from its original type; from this we may expect seedlings will be derived, stiil more improred, until they rival in sweetness and freedom from pulp, the fine European varieties.

Foreign grapes do not generally succeed in our climate. The exceptions are the Black Burgundy, the Sherry, and

o Michaux and Le Conte. 
the Devereaux; but the latter is claimed as a native. Another variety, the Delaware county, which is claimed to be identical with the Traminier, a European grape, is found to do well at Cincinnati; the identity of the two is however disputed. All the foreign grapes succeed well both north and south in cold graperies, i.e. under glass without fire-heat.

Vines, both native and foreign, attain great age; some of the latter are known to have lived three hundred years, and how long they were planted before the record began is not known. Vines, three feet in circunference, are not uncommon in Europe and America.

The grape is a cooling and refreshing fruit of the highest excellence; green, it is used for pies and tarts; when ripe, it is nutritious and medicinal. It is used in cases of dysentery, being diuretic and laxative, allaying thirst and reducing heat; it is also employed in pulmonary disorders. It is a most agreeable dessert fruit, and is likewise used for preserving, jellies, \&c. The dried fruit or raisins are employed extensively for the dessert, and in many prepations of cookery. The leaves are an elegant garnish to other table fruits; but the chief procuct of the grape is wine, which is superior to that made of any other fruit. That derived from the pure juice of the grape "is in all cases of langour and prostration of strength, and in the convalescence from protracted fever, the most grateful and efficacions cordial known." In a state of health, however, the highest medical authorities tell us that "it, at least, is useless, if not absolutely pernicious."

The wine of the grape is superior to that of any other fruit, because its acid, (the tartarie,) is insoluable in alcohol, hence as the must ferments and alcohol is formed, the acid suspended in the juice subsides, and combined with potash also in the juice, scttles in the lces. Thus the 
stronger the wine becomes by age and fermentation, the less acid it contains. Citric and malic acids, which exist in other fruits, are not thrown down in the lees by the formation of alcohol, and the wine from these is, therefore, inferior, and liable to acidity.

Large quantities of an excellent and wholesome wine are made near Cincinnati from the juice of the Catawba grape. The natural juice produces a specie of hock; but wines, resembling Champagne and Maderia, and beliered to be quite as good, are also produced. Wine in conler latitudes always has more aroma or boquet than in warm climates, but the wine of the latter has more strength. A good wine is said to be produced from the Scuppernong. grape. Excellent wine has been made from the Catawba, by $\mathrm{Mr}$. Axt,at Washington, in this State.

Position and soil. $-A$ hill side, on account of its superior drainage, is preferred for a vineyard. The soil should be a dry calcareous loam with a porous subsoil. If the soil does not abound in lime, it should manured with lime and ashes.

\section{ANALYSIS OF THE WILD GRAPE.}

\begin{tabular}{|c|c|c|c|c|}
\hline & & & & \\
\hline Potash, & . & 20.84 & 1.77 & 13.394 \\
\hline Soda, & • & 2.06 & 0.27 & 9.698 \\
\hline Chlorine & . & 0.02 & 0.40 & 0.741 \\
\hline Sulphuric Acid, & & 0.23 & trace & 2.062 \\
\hline Phosphate of Lime, & Tron & 15.40 & 5.04 & 32.950 \\
\hline Carbonic Acid, & . & $\begin{array}{r}1.20 \\
34.83\end{array}$ & $\begin{array}{r}0.04 \\
32.22\end{array}$ & 3.050 \\
\hline Lime, & . & 17.33 & 39.32 & 4.391 \\
\hline Magnesia, & . & 4.40 & 0.80 & 1.740 \\
\hline Silex, & . & 280 & 14.00 & 29.650 \\
\hline Soluble Silicia, $\}$ & . & & 0.30 & \\
\hline Coal and Organic matt & er, & 2.20 & 170 & \\
\hline Organic Acids, & & & & 2.250 \\
\hline & & .31 & 86 & 99.9 \\
\hline
\end{tabular}


Lime, potash and phosphates, are the mineral constituents mostly required. Potash, freely applied, is thought to improve the quality of the wine produced.

For vineyard culture of the Catawba grape, the ground should be subsoiled with a plow, or deeply trenched. A declivity should be thrown into terraces, with a slight inclination to the hill, that the water may be collected there, to be carried thence to the main drains. The Catawba grape* is planted by the wine-growers on level ground, in rows seven feet apart, and four feet in the row, but on hill sides three by five feet apart. The vineyard is laid off with a line and a stake put down where each vine is to grow; then a broad hole a foot deep is dug, in which are placed two cuttings, six or eight inches apart, at the brttom, in a slanting position, but with the top eyes only about an inch apart, and even with the surface-throw in a shovelful of well-decayed leaf mould, that the cuttings may strike freely. Corer with an inch of charenal dust or light mould, when the cuttings are planted. The cuttings should be short jointed and well ripened, each cutting containing about four joints. Cut them off close to the lower joint, and about an inch above the upper. The earth should be pressed closely around the cuttings. The best time for putting them out is the last of November or December. The finest vines are raised from euttings where they are to stand. Being undisturbed by removal, they are more thrifty and longlived. Remove all the cuttings but one, if more than one succeeds, and use them to replant where others have failed. During the summer keep the ground clean and light by repeated hoeings, and pull off superfluous shoots, leaving but one or two to grow at first, and one eventually. Next spring cut the vine down to two buds-one of which remove when the vine shoots,

* Soe Buchan on Grape Culture. 
and drive a stake seven feet long to each plant. Chestnut charred at the end is very good; but locust and cedar make the most permanent posts. Tie the young vine to the stake, remore all the suckers, and allow but one cane to grow. Keep free from weeds, and cultirate as.before. The next spring cut down the three buds, and the year after to five, and this year train two canes insteal of one. The pruning should take place from November to the last of February. The third or fourth year, according to the strength of the vine, cut down the weakest cane to a spur of two or three eyes, and select the best shoot of the preceding year, cut it down to six or eight joints, bend it over in the form of a hoop, and tie to the stake, or fasten it to the adjoining stake in a horizontal position.

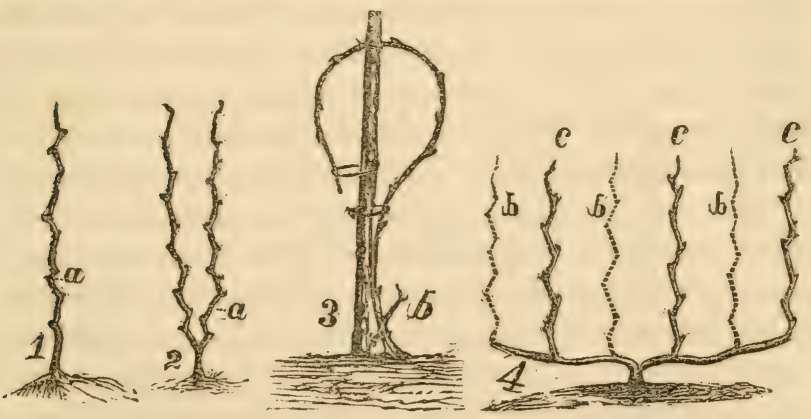

PRUNING THE VINE.

Fig. 1. Tine at the end of the second year, from a cutting, or the first after a Rooted vine is planted out.

Fig. 2. Vine at the end of the succeeding summer.

Fig. 3. Vine at the end of fourth from a cutting pruned in the bow form.

Fig. 4. Vine pruned after the renewal system.

$a$ Point where the shoots are to be cut of in pruning.

$b$ Places of removed shoots.

$\approx$ Bearing shoots.

The bow form is the best. Training the vine in this manner checks the flow of the sap, and causes the buds to break more evenly, retarding growth, and increasing pro- 
ductiveness. To do it, bend the shoot in a circular form, and fasten the top within three or four inches of the stake, having previously made a tie at the bottom and another at the centre of the bow. From this bow the fruit is to be producerl the current year, and the bearing wood of next year from the spur left for this purpose. The next winter this bow is to be cut away, and the bow for another crop is formed from the best branch of the new wood of last year. Keep the old stalk within eighteen inches of the ground. Tie the vines carefully, without breaking them, in damp weather, when the buds are swelling, the last of February or early in March. In the summer, remove suckers, and pinch off lateral shoots, leaving but two for the next year. Pinch ofi the ends of the bearing branches when they blossom, some three joints beyond the last blossom bunch. Remove no leaves from the bearing wood, but unnecessary lateral shonts may be pinched off when small. The object is to throw the strength of the vine into the fruit and the next year's bearing branches.

The vineyard should be heavily manured onee in two or three years. Wood-ashes and gypsum are good applications, and are thought to prevent the rot. The trimming's of the vines dug in, are found beneficial ; but leafmould well rotted, by the addition of lime and ashes, is the best application. Tines highly manured, and allowed to grow rampant, covering a large space, will produce a weak and worthless wine, and continue in bearing but two or three seasons.

Where grapes are liable to rot, it is best, for the more desirable kinds of table fruit, to train them to a trellis right or ten feet high, and protect them by a coping of boards, projecting over one foot on each side of the trellis. Ihis coping protects the plants from the heary dews and excess of moisture, and seems nearly as efficacious as a 
cold grapery. Set the vines six or eight feet apart, or raise them from cuttings at that distance, as before directed. Cut back the second year's growth of the cutting (the first if a vine is planted) to two buds the next winter. Allow these the ensuing season, to form two upright shoots (as in the bow method before described), which should be fastened to stakes. The next winter form the trellis by setting a post two feet deep, and firmly in the earth, between every two vines. To these attach the coping, and let the post at each end of the boards be of unequal length, varying an inch or so, that the water may run off. The bars may be made of laths, or No. 10 or 12 wire, fastened by staples. The first bar should be one foot from the earth, and the others should be that distance apart. Now bring down the two upright shonts, and fasten them each side to the lower bar of the trollis. Shorten them at two and a half to four feet from the main stem according to the distance between the vines. The next season, allow upright shoots to grow a foot apart, and stop them when they reach the top of the trellis. The trellis is now full of vines.

After the trellis is filled with upright shoots as above, in the renewal system of training, at the next pruning every other upright shoot is cut down within an inch of the main arm of the vine. The upright shoots that are left will bear, the coming summer, and from the stump of each upright cane removed, a young shoot is trained to take its place the succeeding year. At the next winter pruning, this is left to bear fruit, and the shoots which bore the preceding season are cut down in their turn to an inch of the main arm, from which young shoots are trained to prodnce fruit a year after. In this mode of pruning both native and foreign vines, the largest bunches and the best crops for a course of years are obtained.

The plan of protecting Grapes hy a coping to prevent 
rot, has been tested several years by Mr. Van Buren, and was very naturally suggested by the fact that grapes trained to a piazza or a house, when sheltered by the pro. jecting roof, are generally free from decay. Vines planted for experiment, with one half under a coping, and the other half exposed, have ripened perfectly where protected, and rotted badly where exposed. Vines are thought not so liable to rot when allowed to run high.

The Scuppernong Grape never rots, being protected by its thick skin; hence for our climate it is the most valuable of all grapes. It likes a good dry soil and plenty of room. The vines should be, at least, thirty fect apart. It bears better when trained over an arbor. It seems to need little pruning-the only care required, is to add to the scaffolding, year after year, as the vine extends. The vines should be trained evenly over the arbor, and not allowed to run together in a mass. Vines covering one or two thousand feet of scaffolding, and increasing in productiveness and extent, every year, are not uncommon, and the quantity of grapes such a vine has produced, has been nearly thirty bushels. This vine will not readily grow from cuttings, but is propagated solely by layers, which, put down in the winter or spring, may be taken up safely the ensuing winter. Stake them the first year and begin to make the arbor the second. Fruit will be borne the third year after planting.

Ashes, lime, rubbish, and its own leaves, are the best manure. The fruit of the Scuppernong is in fact almost too luscious, and hence is not as wholesome as the other cultivated varieties. All the culture this Grape requires is to keep soil free from weeds, until the vine begins to cover the arbor, when its shade and droppings will kill everything beneath it.

Wine.-The best wine produced in this comntry is that 
mule at Cincinnati from the Catawba grape. 'The grapes are not picked until dead ripe; all green or decayed berries are removed from the branches; they are then bruised in a mashing tub or passed through a small wooden mill, mashing the skins and pulp, but not the seeds. It is better to stem the grapes before pressing, which is done by running the mashed grapes through a wire screen with the meshes three-fourths of an inch apart. When shaken, the pulp and skins fall through, and the stems are thrown out. The pressing is now performed. A strong, tight box platform, six feet square, and six inches high at the sides, is made of two or three inch plank, and tightly wedged together in a heavy timber frame: a hole is made in the front to permit the juice to flow ont into a tub. On this platform a box, fire feet square made of one and a quarter inch hoards, ten inches high at the sides, and with holes at the lower edge, is placel to receive the mashed grapes; boards fitting loosely inside this box, are placed on the pile of mashed grapes, and pieces of scantling are laid across these to receive the pressure. This is applied by means of a lever and screw, until the juice is extracted. The outside of the cheese has to be cut off and thrown on top two or three times and repressed, to extract all the juice. The must should then be placed in clean casks, for fermentation. Everything used in wine-making must be surupulously clean, whether press, vessels, or casks, or the aroma and flaror of the wine will be lost.

At Cincinnati, with the Catawba grape, no sugar is added; but casks are filled with the juice within six inches of the bung, which is put in loosely, to allow the gas to escape without the wine running over; a cool dry cellar, is the best place for fermentation. In two or three weeks fermentation ceases, and the wine becomes clear, when the casks are filled and the bungs tightened. The wine is racked off the ensuing February, into clean casks, which 
are bunged tightly, and there left to improve by age. If racked more frequently, its acidity is increased; it will do to bottle when a year old; but if allowed to stand two years it will be better. A good wine is produced from Herbemont's Madeira, by the same process.

In this climate, as the grape ripens before the weather becomes cool, wine cannot be kept without the addition of sugar to the must, or brandy to the wine. Mr. Weller of Torth Carolina, adds three pounds of double refined sugar to each gallon of Scuppernong must. The cask must be well shaken. Mr. Herbemont used to add from two to two and a half pounds of sugar to the gallon of Herbemont Madeira juice. The same object is better obtained by the addition of good brandy to the wine as soon as properly fermented. Mr. Weller added to the must one-third pure brandy, shaking the cask well several times, the first week. Half of each of the above amounts of sugar and brandy may be added, instead of using either alone; but it seems almost incredible that so large an amount of sugar or spirit is required; yet the amount varies with the heat of the climate and the ripeness of the grapes.

In a cooi climate, two gallons of brandy to the barrel is sufficient, if the wine is kept in cellars, and racked off at at the bottom, when the crust at the top begins to break, into casks fumigated with sulphur. In a hot country, the amount of brandy must, as we see, be largely increased. The wine must be closely watched, and if disposed to further fermentation, more brandy must be added.

If wine is turbid, it can be fined with the white of eggs; one egg for erery six gallons. The whites are well beaten, then put into a tub, into which the wine is drawn, and while running, the whole is well churned and beaten briskly until the cask is drawn off; it is then returned to the cask which should not be quite full. The froth pro- 
duced should all go back into the cask, and the top of the wine should be stirred; the cask is then bunged up and left until the wine is clear; the froth produced aids in the process of fining.

A fine, sparkling, or Champagne wine, is produced by the addition of Rock Candy to each Alask, when the wine is bottled. The amount required is not divulged.

\section{FOREIGN VARIETIES.}

Delancare County. $-\Lambda$ small grape, color of Catawba; bunches small; skin thin, transparent; juice brisk and vinous; one of the best table grapes. Vine like the foreign grape - said to be the Traminier grape of Germany. Succeeds well in New Jersey and Ohio. Worthy of trial.

Devereanx.-The best foreign grape for open air culture. Branches about six inches long, shouldered; making them some three inches broad at the base; berries generally with one seed, medium, round, very compact or crowded on the bunch; skin thin, black and covered with blue bloom; flesh juicy, with a brisk, agreeable flavor, much better than the native grapes. A great bearer and free from rot. Ripens middle of August.

Sherry.-Bunches medium size, shouldered, compact; skin thin, black covered with blue bloom; berries round, medium size, with one stone; flesh very juicy, rich, highflavored and exceedingly sweet--much better than Blue Frontignan. Resembles Devereaux, and may be identical; but the bunches are not so large and the berries are more sugary and high-flavored; this may be an accident of aspect or soil. Does not rot. The best grape cultivated here.

The Black Cluster, Blue Frontignan, Early Chasselas, Black Hamburgh and Miller's Burgundy, if well cultivated and protected by a coping, succeed here. 


\section{NA'TIVE GRAPES.}

Bland, or Bland's Madeira.-Bunches long and loose; berries round, on long stalks, hanging thinly; skin thin, pale red when ripe; flesh slightly pulpy, of sprightly delicate flavor, a little astringent; foliage light green, smoother and more delicate than that of the Catawba; ripens last of Angust; cuttings do not readily strike; it often drops its leaves before the fruit ripens, which destroys the flavor.

Catruba.-Bunches of medium size, shouldered, somewhat loose; berries large, round; skin rather thick, pale rest in shade, but deep red in sun, with lilac bloom; flesh slightly pulpy, juicy, very sweet, with an aromatic, xich, musky flavor; ripens last of August. A hardier grape than the Isabella, and the best of all for wine.

Diana.-1 Cataw'ua scedling; resembles its parent in bunch and lerry, but with less color; berries round, juicy, rich, swert and musky. Ripens middle of August.

Isabella.-Bunches large, rather compact, shouldered; berries large, oval, purplish black, with blue bloom; skin thick; flesh tender, with little pulp, juicy, sweet, with slight musky aroma; liable to rot and requires a coping. A better grape to my taste than Bland or Catawba. Ripens August 15th.

Lenir.-Bunches large, compact, sometimes shouidered; berries small, black, free from pulp, sweet, and palatable.

Norton's Virginia.-Bunches long, sometimes shouldered; rather coinpact; herries small, round; skin thin, dark purple. Fot a very good grape for the dessert. Always bears, is free from rot, and is as hardy as a Scuppernong. Ripens middle of August. Said to make a tolerable wine. Ohio.-Bunches very large, shouldered; berries small, 
black, sweet, and free from pulp. Does well on an arbor. Requires long pruning.

Scuppernong (Titis Rotundifolia).-Bunches very small, with from two to four, and seldom over six berries, which are round and large; skin very thick, light green, marked with yellow dots; flesh pulpy, juicy, sweet, and of rich, luscious flaror. The best of all grapes for ordinary culture in this climate. Mrust be trained on arbors. Does not grow from cuttings readily.

Warren (Warrenton, or Herbemonl's ITadeira).-A native of this State, and long known as the Warrenton, whence obtained by Herbemont, who gave it his own name. Bunches of merlium size, long, sometimes shouldered; berries round, medium size, and rather closely set; skin thin, dark purple, with light bloom. Grapes on the same bunch do not color evenly, varying from a light to a dark purple; flesh tender, melting, fiee from pulp; flavor sweet and pleasant, when fully ripe. An enormous bearer. Probably it would ripen more uniformly, if the bunches were properly thinned. A fine dessert and wine grape, though somewhat subject to rot. The wine can scarcely be dis. tinguished fiom Spanish Manzanilla. Clermont, Marion, Zane, and Imitation Hamburgh, are new Ohio grapes, of good reputation, not yet tested at the south. Harris and Long are two good southern grapes, fully equal to the foregoing. Brinckle, Cassady, Clara, Concord, Emily, Graham, Raabe, and Thurmond are all new varieties, of excellent flavor, but of which the merits are hardly known yet. 'The latter is of best quality.

\section{Zizephus Sativax.-Jujube Plum.}

This fruit has been cultivated at Augusta, Ga., by Mr. Change and by Mr. Chisholm, of Beaufort, S. C. It is a small tree, or thorny shrub, from the south of France, 
bearing an oval, reddish plum, about the size of an olive, and enclosing an oblong stone pointed at both ends. It is of a sweet, clammy taste, from which the "Jujube paste" is made. It is served up at the table, in Italy and Spain, during winter, as a dry sweetmeat. 'The tree is grown in hedge-rows, about Genoa and Nice. Seeds have been sent out from the Patent-Office. They would probably require about the same culture as the pomegranate. 






\section{LIBRARY OF CONGRESS}

||||||||||||||||||||||||||||||||||||||||||||||||||||||||||||||||||||||||||||||||||||||||||||||||| 00009389003 